Wood Biology and Wood Products

Georg-August-University Göttingen

Germany

Wood Laboratory

Empa - Swiss Federal Laboratories

for Materials Science and Technology

Dübendorf

Switzerland
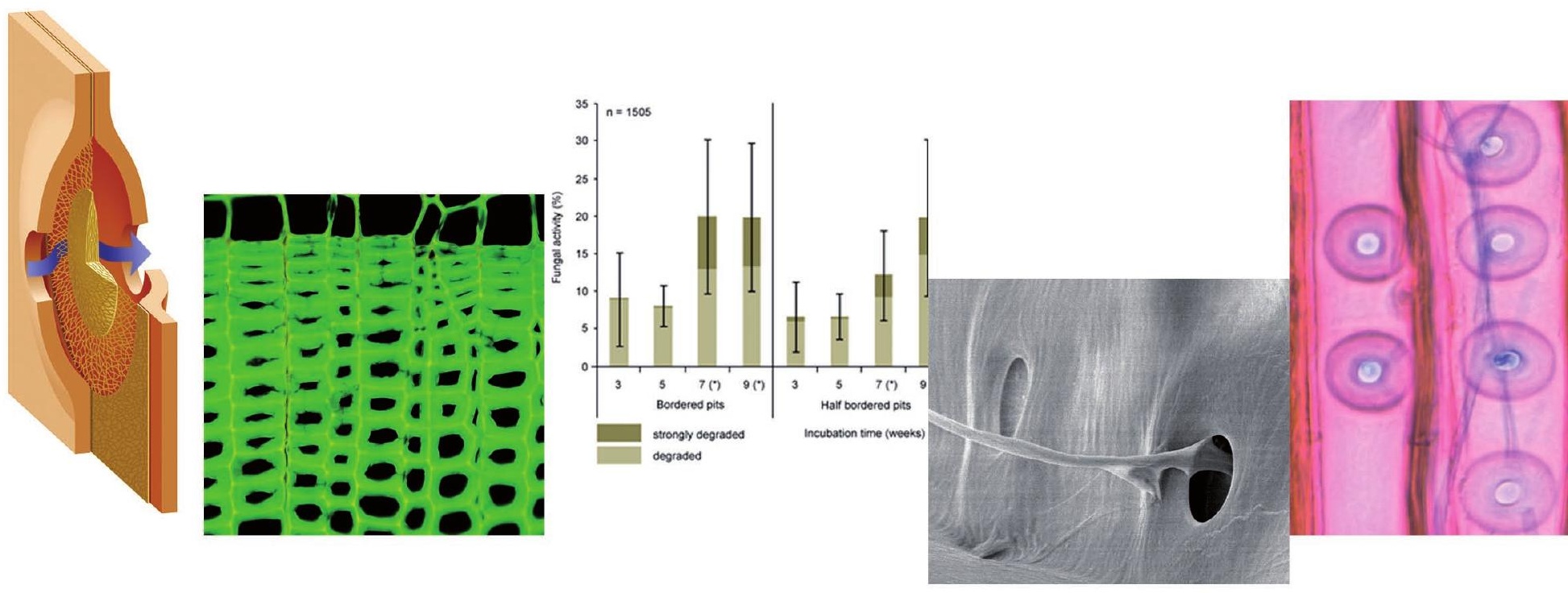

Christian Lehringer

Permeability improvement of Norway spruce wood with the white rot fungus Physisporinus vitreus 



\title{
Permeability improvement of Norway spruce wood with the white rot fungus Physisporinus vitreus
}

\author{
Dissertation \\ In Partial Fulfillment of the Requirements for the Doctoral Degree (Dr. rer. nat.) \\ of the Faculty of Forest Sciences and Forest Ecology \\ Georg-August-University Göttingen \\ Submitted \\ by Christian Lehringer
}

Göttingen 2011 
Referee 1: Prof. Dr. H. Militz

Referee 2: Dr. K. Richter

Referee 3. Prof. Dr. R. Wimmer

Supervisors:

Referee 4.: PD Dr. G. Koch

Prof. Dr. H. Militz

Referee 5.: Prof. Dr. U. Kües

Dr. K. Richter

Referee 6.: Prof. Dr. Dr. h. c. F. Hapla

Martin Arnold

Date of oral examination: 28. January 2011 
LIFE IS ORGANIC 



\section{ACKNOWLEDGEMENTS}

Three years of intense work on one topic. Three years of interesting discoveries and creativity. Three years of disappointing drawbacks and doubts. Three years of learning and understanding. Three years of fun! And luckily, I was not alone...

My three supervisors Prof. Dr. Holger Militz, Dr. Klaus Richter and Martin Arnold helped me greatly finding my way through these three years. Therefore, I cordially express my gratitude for their trust, support, encouragement, patience and expertise.

Furthermore, I acknowledge Prof. Dr. F.W.M.R Schwarze and Dr. Mark Schubert for the critical and informative discussions we had about the results of my research.

The Empa Wood Lab in Dübendorf receives a big 'thanks' for the collegial, openminded and always helpful atmosphere. Special thanks go to Anja, Tina, Esther, Markus, Dani, Michael and Walter for support in sample preparation, experiment setup and measurements; to my PhD-colleagues Jessie, Thao, Chrigu, Robert, Ahmad and Saeed for interesting and entertaining discussions not only during the coffee breaks; and to Walter, Bruno and Sam who were my constant fellows at Tuesday's running appointment.

Within the Empa/Eawag facilities, I particularly thank Stephanie, Maura and Wiebke from the library for patient and helpful support during literature research; and to Anton Koster, André Niederer, Martin Gutknecht and Astrid Künzler from the graphics and printing department for help in typesetting, graphical design and poster printing.

While the Empa Wood Lab was my centre for research activities, the working group Wood Biology \& Wood Products at the Georg-August-University in Göttingen provided the institutional framework for my PhD. During my periodic visits I was always welcomed warmly by the entire working group. Among them all, I express a special gratitude to Susanne, Carsten, Uli, André, Karl, Bernd und Mirko for professional technical support and great hospitality.

My research activities offered me the possibility to conduct some measurements away from Empa. I carried out chemical and UV-spectroscopic analysis of wood specimens at the Institute of Wood Technology and Wood Biology in Hamburg. PD. Dr. Gerald Koch, Prof. Dr. Bodo Saake and their working groups are acknowledged profoundly for their professional assistance. To Gerald, in specific, I express my deep gratitude for the long lasting idealistic support and the sincere cooperation with him during my $\mathrm{PhD}$ and in times before. 
Prof. Dr. Hrvoje Turkulin and Vjekoslav Živković enabled me to visit the Wood Technology Department at the University of Zagreb and conduct microtensile measurements. I truly appreciate their competent and helpful guidance mixed with hospitality and amicable welcome.

Apart from the professional support, I experienced a lot of private encouragement from friends and family that provided me with the required strength to bring this thesis to a successful end.

While I certainly did not discuss too many scientific details with Bandli, Marc, Nils and Örnie; Holger, Tilmann, Klaus and Mirko, our old friendships were a necessary balance for myself and many times offered me efficient distraction from mental blockades.

My former student mates Jan, Oli, Uli, Philip, Jan Peter and Hauke certainly must obtain a very personal acknowledgement at this place: it's just great to still have you around. Thanks for your mental support, for corrections and technical advises, and for honest discussions on future decisions we had! I cross my fingers that you get your projects finished successfully soon and we will keep our friendship going!

Being a German in Switzerland can sometimes be a little tricky. But, honestly, my family and I felt always comfortable and warmly welcome in this nice country. This was definitely carried by the nice friendships we made to Ruedi, Michi \& Angelika, Küde \& Franzi, Candid \& Ariane, Ingo \& Vaike, Danielle and to Beat.

Finally - and this is not just the 'must-say-at-the-end' - the biggest support was certainly given to me by my parents and sisters Annette and Katrin;

and by Karen and Janno! THANK YOU! 


\section{TABLE OF CONTENTS}

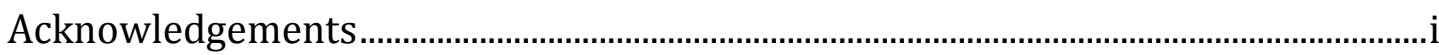

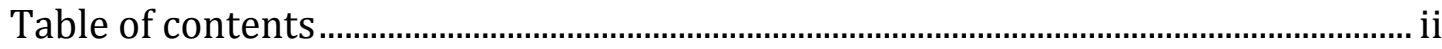

Abbreviations …..........................................................................................................ii

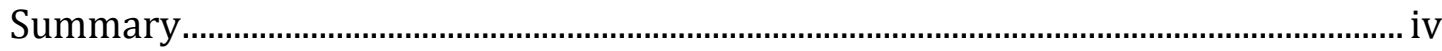

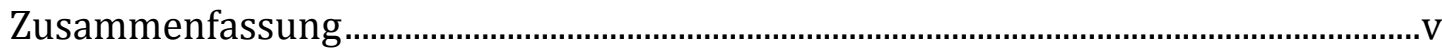

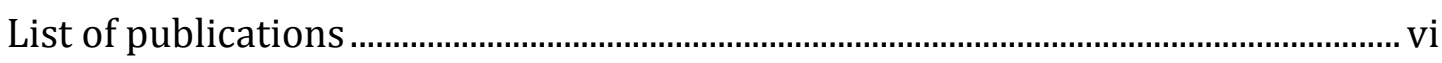

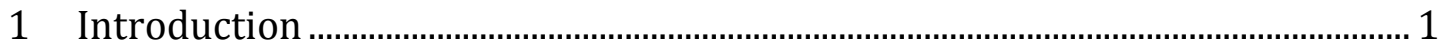

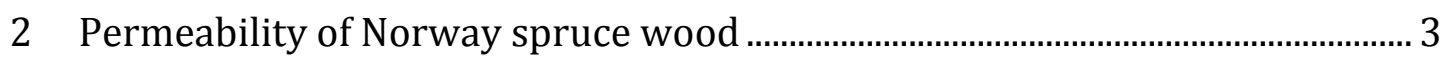

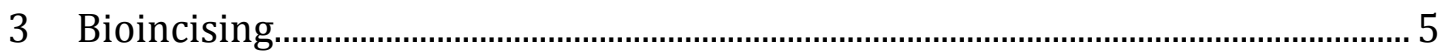

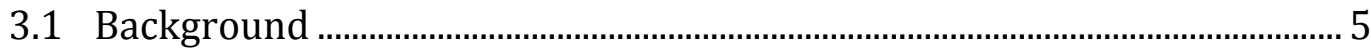

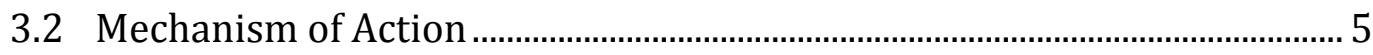

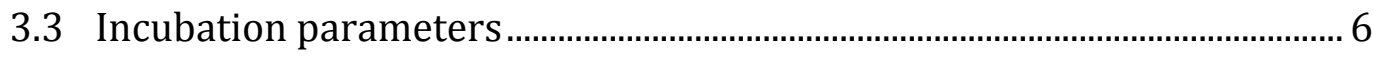

3.3.1 Water activity $\mathrm{a}_{\mathrm{w}}$ and oxygen supply ……...................................... 7

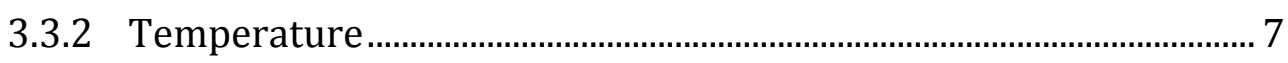

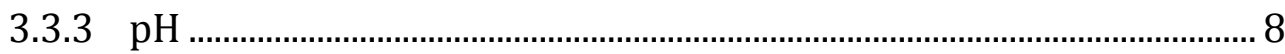

3.3.4 Nutrient supply and carbon/nitrogen ratio (C/N-ratio) ................. 8

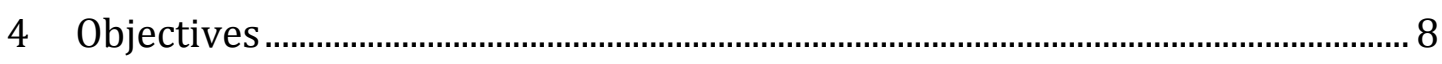

4.1 Material characterization of the bioincised wood.......................................... 9

4.2 Treatment with surface modification substances ....................................... 9

4.3 Wood properties after bioincising and surface modification .....................10

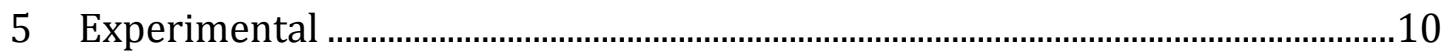

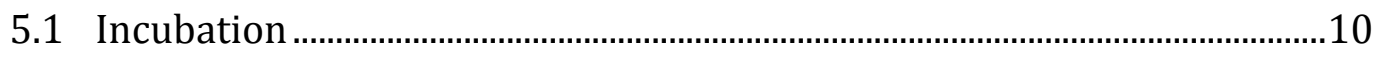

5.2 Laboratory experiments and analysis ...........................................................12

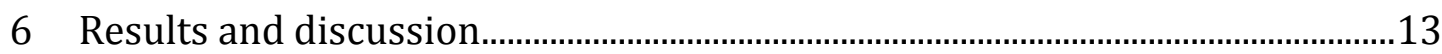

6.1 Material characterization of the bioincised wood.......................................13

6.2 Treatment with surface modification substances .......................................16

6.3 Wood properties after bioincising and surface modification....................20

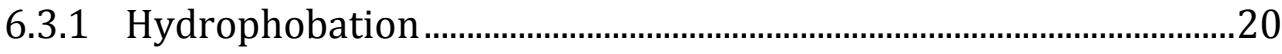

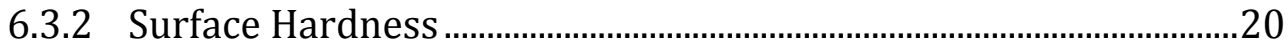

6.3.3 Fire resistance...............................................................................22 


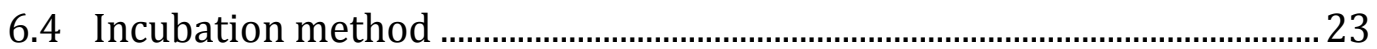

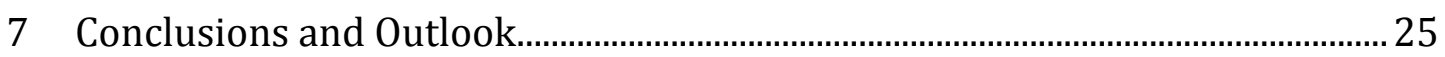

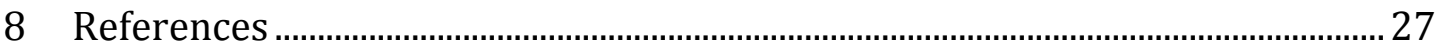

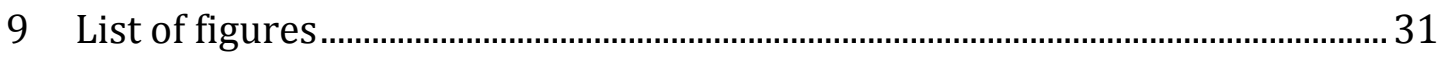

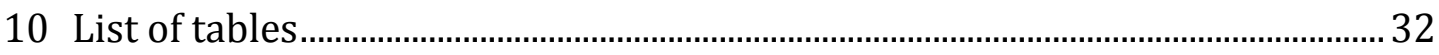

11 Annex 


\section{ABBREVIATIONS}

$\begin{array}{ll}\text { DMDHEU } & \text { 1.3-dimethylol-4.5-dihydroxyethyleneurea } \\ \text { HW } & \text { heartwood } \\ \text { kDa } & \text { kiloDalton (measure of weight for protein molecules) } \\ \text { LP } & \text { ligninperoxidase } \\ \text { L x R x T } & \text { longitudinal x radial x tangential } \\ \text { MEA } & \text { malt extract agar } \\ \text { MP } & \text { manganperoxidase } \\ \text { PG } & \text { polygalacturonase } \\ \text { RH } & \text { relative humidity } \\ \text { SW } & \text { sapwood } \\ \text { WMC } & \text { wood moisture content } \\ \text { WPG } & \text { weight percent gain }\end{array}$




\section{SUMMARY}

As solid wood, Norway spruce (Picea abies (L.) Karst.) is used in a wide range of applications for interior and exterior situations. Due to its low natural durability against wood decay fungi, a treatment with wood preservatives is necessary for certain applications. In addition, there is a growing interest for treatment with waterborne surface modification substances that specifically improve selected wood properties of Norway spruce such as UV-resistance, hydrophobicity, hardness and fire resistance. The impregnation with such substances requires often a wood permeability that allows a sufficiently deep and homogenous distribution of the substances in the wood in order to obtain an efficient wood property improvement.

However, Norway spruce wood is known to have a low permeability which is related mainly to the aspiration of bordered pits during wood drying. In the living tree, permeability is mainly determined by the bordered and half bordered pits that constitute the interconnecting voids between the tracheids and the xylem ray parenchyma. During wood drying, most of these pits get irreversibly closed due to the aspiration of the flexible pit membranes. The resulting low impregnability complicates treatment of Norway spruce with liquid preservatives or wood modification substances.

Short term incubation of Norway spruce wood with the white rot fungus Physisporinus vitreus is a biotechnological approach for improving the permeability of this refractory species. The process, called "bioincising", is based on the growth of the fungal hyphae through the tracheids and xylem ray parenchyma. As discussed by Schwarze and Landmesser (2000) and Schwarze et al. (2006), fungal activity induces the degradation of pit membranes after 6 weeks of incubation and thus significantly improves the uptake of liquid substances, causing only negligible losses of impact bending strength.

The scope of this thesis was to evaluate the effects of $P$. vitreus' activity on the properties of Norway spruce sapwood and heartwood during incubation times between 3 and 9 weeks. In the course the thesis, three major fields of research were defined: 1) description of fungal activity and of the resulting wood properties after bioincising; 2) uptake and penetration depth of modification substances into the bioincised wood was, and 3) combined effect of bioincising and treatment with modification substances on the wood properties.

It could be shown that fungal activity of $P$. vitreus induces both a selective delignification and a simultaneous degradation in the tracheid cell walls. Degradation of pit membranes and damages of the tracheid cell wall occurred simultaneously. Mass losses were comparably low and surface hardness was moderately re- 
duced, indicating that $P$. vitreus is a fungus with a comparably low lignolytic capacity. Substance uptake and penetration depth were significantly improved after 5 weeks of incubation in both sapwood and heartwood specimens. However, impregnation of the bioincised wood with modification substances for UVprotection, hydrophobation, hardness and fire resistance did not result in a pronounced property improvement.

The bioincising technique is still in the process of optimization. Parameters such as water activity $\mathrm{a}_{\mathrm{w}}$, temperature, $\mathrm{pH}$ and nutrient supply influence mycelia growth speed and homogeneity of fungal activity. These parameters must be adjusted for an optimal process control. The results of the presented research activities contribute to the improvement of this process control. A new pilot incubation system has recently been developed and promises further improvement of the bioincising process.

However, large scale industrial application is still far away. From the current state of development, products with smaller dimensions, lower quantities and higher value creation appear to be a feasible pathway for the near future of bioincising. 


\section{ZUSAMMENFASSUNG}

Als Massivholz wird Fichte (Picea abies (L.) Karst.) in einer Vielzahl von Anwendung im Innen-und Außenbereich verwendet. Auf Grund seiner geringen natürlichen Dauerhaftigkeit gegen holzzerstörende Pilze ist eine Behandlung mit Holzschutzmitteln für bestimmte Anwendungen erforderlich. Außerdem besteht ein wachsendes Interesse an der Behandlung von Fichtenholz mit wasserbasierten Modifizierungssubstanzen, die spezifische Eigenschaften der Holzoberfläche verbessern, wie z.B. UV-Stabilität, Hydrophobizität, Härte und Feuerwiderstandsfähigkeit. Die Imprägnierung mit solchen Substanzen erfordert oftmals eine Holzpermeabilität, welche eine ausreichend tiefe und homogene Verteilung der Wirksubstanzen im Holz erlaubt, um eine deutliche Eigenschaftsverbesserung zu erreichen.

Allerdings weist Fichtenholz eine geringe Permeabilität auf, die auf einen Tüpfelverschluss im Laufe der Holztrocknung zurückzuführen ist. Im lebenden Baum wird die Permeabilität hauptsächlich durch die behöften und halb-behöften Tüpfel bestimmt, die die Verbindungskanäle zwischen den Tracheiden und Holzstrahlzellen darstellen. Während der Holztrocknung werden die meisten dieser Tüpfel durch eine irreversible Anlagerung der flexiblen Tüpfelmembran an die Zellwand verschlossen. Die sich daraus ergebende verringerte Imprägnierbarkeit erschwert die Behandlung von Fichtenholz mit Holzschutzmitteln und Modifizierungssubstanzen.

Die Behandlung von Fichtenholz mit dem Weißfäulepilz Physisporinus vitreus über einen kurzen Zeitraum ist ein biotechnologischer Versuch, die Permeabilität von schwer imprägnierbaren Holzarten zu erhöhen. Das so genannte "Bioincising"-Verfahren basiert auf dem Wachstum von Pilzhyphen durch die Tracheiden und Holzstrahlzellen. Wie in den Arbeiten von Schwarze und Landmesser (2000) und Schwarze et al. (2006) diskutiert, bewirkt die Pilzaktivität einen Abbau der Tüpfelmembranen und erhöht somit nach 6 Wochen Inkubation signifikant die Flüssigkeitsaufnahme, ohne hierbei eine nennenswerte Reduktion der Bruchschlagfestigkeit zu verursachen.

Hauptaufgabe in der vorliegenden Doktorarbeit war eine Beurteilung der Effekte auf die Eigenschaften von Fichtensplint und -kernholz, die sich nach einer 3 bis 9-wöchigen Inkubation mit $P$. vitreus ergeben. Es wurden hierfür drei Bereiche für die wissenschaftliche Forschung definiert: 1) die Beschreibung der Pilzaktivität und die daraus resultierenden Eigenschaftsveränderungen des Fichtenholzes; 2) die Veränderung der Substanzaufnahme und der qualitativen Eindringtiefe und 3) die Beurteilung des Gesamteffektes, der sich aus der Kombination von Bioincising und der anschliessenden Behandlung mit Modifizierungssubstanzen auf ausgewählte Holzeigenschaften ergibt. 
Es konnte gezeigt werden, dass die Aktivität von P. vitreus eine selektive Delignifizierung und einen simultanen Abbau in den Tracheiden-Zellwänden hervorruft. Weiterhin wurde ein gleichzeitiger Abbau von Tüpfelmembranen und eine Schädigung der Tracheiden-Zellwände beobachtet. Hierbei waren die Masseverluste gering und die Oberflächenhärte wurde nur wenig reduziert, was auf eine vergleichsweise geringe holzzersetzende Aktivität von $P$. vitreus hinweist. Substanzaufnahme und Eindringtiefe waren nach 5-wöchiger Inkubation sowohl im Splint- als auch im Kernholz signifikant erhöht. Es konnten allerdings keine deutlichen Eigenschaftsverbesserungen nach einer Imprägnierung mit Substanzen für die UV-Stabilität, Hydrophobizität, Härte und Feuerwiderstandsfähigkeit gemessen werden.

Der Bioincising-Prozess ist derzeit noch in der Optimierungsphase. Verschiedene Parameter wie Wasseraktivität $\mathrm{a}_{\mathrm{w}}$, Temperatur, $\mathrm{pH}$-Wert und Nährstoffangebot beeinflussen die Geschwindigkeit und Homogeneität der Pilzbesiedlung und -aktivität und müssen für eine verbesserte Prozesskontrolle weiter optimiert werden. Die Ergebnisse dieser Arbeit tragen zu dieser Prozessoptimierung bei. Eine weiterentwickelte Pilotanlage wurde kürzlich in Betrieb genommen und verspricht einen verbesserten Inkubationsprozess.

Eine großtechnische Anwendung des Bioincising-Verfahrens liegt jedoch in ferner Zukunft. Auf Grundlage des aktuellen Kenntnisstandes ist eine Anwendung des Bioincising-Verfahren für hochwertige Produkte mit kleineren Dimensionen und in geringeren Stückzahlen wahrscheinlich. 


\section{LIST OF PUBLICATIONS}

\section{Paper I}

Bioincised wood as substrate for surface modifications.

Lehringer, C., Arnold, M., Richter, K., Schubert, M., Schwarze, F.W.M.R., Militz, H. In: Englund F, Hill CAS, Militz H, Segerholm BK (Hg.) The Fourth European Conference on Wood Modification. Stockholm, 2009: 197-200.

\section{Paper II}

A review on promising approaches for liquid permeability improvement in softwoods.

Lehringer, C., Richter, K., Schwarze, F.W.M.R., Militz, H.

Wood Fiber Science, 2009, 41: 373-385.

\section{Paper III}

Anatomy of bioincised Norway spruce wood.

Lehringer, C., Hillebrand, K., Richter, K., Arnold, M., Schwarze, F.W.M.R., Militz, H. International Biodeterioration and Biodegradation, 2010, 64: 346-355.

\section{Paper IV}

Resistance of bioincised wood treated with wood preservatives to bluestain and wood-decay fungi.

Schubert, M. Volkmer; T., Lehringer, C., Schwarze, F.W.M.R.

International Biodeterioration and Biodegradation, 2011, 65, 1: 108-115.

\section{Paper V}

Effect of Physisporinus vitreus on wood properties of Norway spruce. Part 1: Aspects of delignification and surface hardness.

Lehringer, C., Koch, G., Adusumalli, R.-B., Mook, W.M., Richter, K., Militz, H.

Holzforschung, 2011: accepted.

Paper VI

Effect of Physisporinus vitreus on wood properties of Norway spruce. Part 2: Aspects of microtensile strength and chemical changes.

Lehringer, C., Saake, B., Živković, V., Richter, K., Militz, H.

Holzforschung, 2011: submitted. 


\section{INTRODUCTION}

Wood is a desired material. The UNECE region consumes 1.2 billion cubic meters of wood annually for construction, paper, other wood products, and energy (UNECE/FAO 2010). Worldwide, the demand for wood as renewable source is increasing, since non-renewable materials are increasingly being replaced by wood products, especially in the energy sector. Today, the major source of renewable energy is from woody biomass (UNECE/FAO 2010). This development induces shortages of supply for the material use of wood and thus increasing raw material prices. The increasing competition for wood requires a more efficient material utilization. This includes not only recycling and material savings, but also the lifetime extension of wood products.

The life-time of wood products is mainly determined by the environmental conditions to which they are exposed and the specific wood properties. Microorganisms, moisture and temperature changes, light and UV-radiation, abrasion and mechanical forces represent stresses to the material that must be counterbalanced by the wood properties such as natural durability, density and dimensional stability (Bergman et al. 2010).

Wood has advantageous properties such as a good strength-to-weight ratio, a warm and aesthetic appearance and a natural degradability that makes it an environmentally sustainable material (Rowell 2005). But wood is also a hygroscopic material that reacts to changes of moisture content (Siau 1995) by swelling and shrinking. Under the influence of UV-radiation (e.g. from sunlight), lignin can be depolymerized, resulting in a yellow-brownish-black discoloration of the wood surface (Feist and Hon 1984). The flash point of wood is between $200^{\circ} \mathrm{C}$ and $470^{\circ} \mathrm{C}$, making it an easily combustible material (Bergman et al. 2010). And finally, because of its biodegradability wood is susceptible to decay by microorganisms under certain conditions, such as increased moisture content (Schmidt 2006).

While all processes of natural depolymerization of the lignocellulosic biopolymers are essential for ecosystem stability, they are mostly considered as a hindrance for technical wood applications and reduce the life-time of wood products. They can explicitly be avoided by wood modification that involves the application of biological (fungi, bacteria, enzymes), physical (heat) or chemical (chemicals) methods (Hill 2006). Especially the treatment with chemical substances requires a wood permeability that allows a sufficiently deep and homogenous distribution of the substances into the wood (Hill 2006).

Some wood species such as Norway spruce (Picea abies (L.) Karst.) are known to have a low permeability (Liese and Bauch 1967b; Flynn 1995). For these wood 
species, impregnation with wood preservatives or other wood modification substances is very complex and a penetration deeper than the surface layer (Figure 1, Paper II) is difficult to be achieved. Consequently, permeability improvement of the wood border zone is a feasible way to enhance the substance uptake.

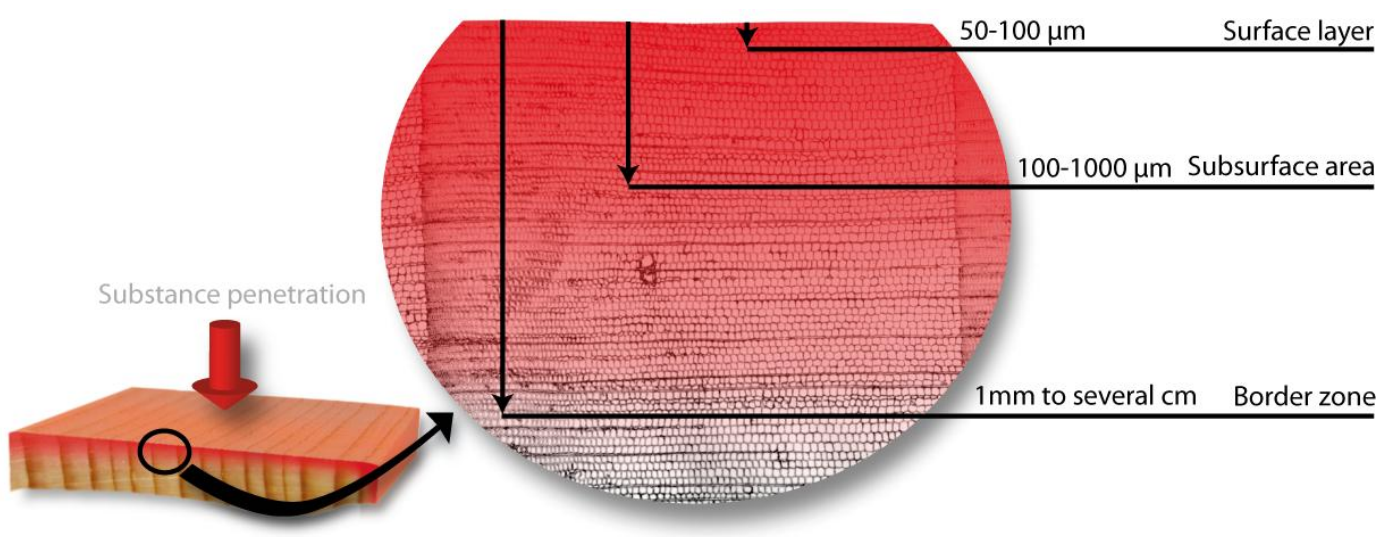

Figure 1 Schematic of different zones of the wood surface used to describe liquid penetration in radial and tangential directions (Paper II).

A variety of modification substances is applied in order to improve selected wood properties. According to their mode of function and to the property-to be improved, certain penetration depths have to be achieved 1) in order to ensure homogenous distribution of the modification substances and 2) to obtain an optimal effect and a maximum lifetime performance. For example, a treatment for wood preservation requires much deeper penetration into the wood than a treatment for UV-protection substances. Table 1 gives an overview of these modification approaches, including the targeted improvement and the required individual penetration depth in the tangential and radial orientations (more detailed in Paper II).

Table 1 Wood preservation and wood modification treatments according to the required penetration depth of the applied substance (extracted from Paper II).

\begin{tabular}{|l|l|l|l|l}
\hline Property improvement & $\begin{array}{l}\text { Desired penetration depth in tangential and radial } \\
\text { orientation }\end{array}$ \\
\hline $\begin{array}{l}\text { Resistance against biodegrada- } \\
\text { tion/ durability }\end{array}$ & $\begin{array}{l}\text { Complete penetration or at least border zone following certain } \\
\text { standards (e.g. EN 335-2; EN 351-1) }\end{array}$ \\
\hline UV-protection & Surface layer and subsurface area \\
\hline Hydrophobation - liquid water & Surface layer and subsurface area \\
\hline Hydrophobation - water vapor & Complete or at least border zone penetration \\
\hline $\begin{array}{l}\text { Fire resistance - foam forming } \\
\text { systems }\end{array}$ & Surface layer and subsurface area \\
\hline Fire resistance - salt solutions & Subsurface area to border zone \\
\hline Hardness & Subsurface area to border zone \\
\hline
\end{tabular}


The main goal of the present work was to investigate the permeability improvement of Norway spruce wood by means of a biotechnological approach, named "bioincising". I discussed short term incubation of Norway spruce sapwood and heartwood with the white rot fungus Physisporinus vitreus and the resulting effect on wood permeability. Furthermore, I conducted detailed material characterization of the bioincised wood. Finally, I evaluated if enhanced uptake of selected modification substances resulted in a property improvement such as UVresistance, hydrophobicity, hardness and fire resistance.

The following sections represent a synopsis of the major research activities and a discussion of the most important results. More detailed information can be found in the scientific papers as summarized in the Annex at the end of this work and indicated with cross references in the text.

\section{PERMEABILITY OF NORWAY SPRUCE WOOD}

With a share of $45 \%$ of the national timber volume, Norway spruce is the most important timber species in Switzerland (LFI 2010). As solid wood, Norway spruce is used in a wide range of applications, such as construction material for interior and exterior situations, for façade claddings or for wood floorings (Wagenführ 2007). But Norway spruce wood has a low natural durability against wood decay fungi, and is assigned to durability class 4 according to EN 350-2 (1994). This requires a chemical wood preservation when the wood is used in structural constructions of utility class 4 (EN 460 1994; EN 335-2 2006). In addition, there is a growing interest for a treatment with waterborne surface modification substances that specifically improve selected wood properties of Norway spruce such as UV-resistance, hydrophobicity, hardness and fire resistance.

Generally, vacuum-pressure impregnation is used on industrial scale to treat the wood with wood preservatives, e.g. with waterborne metal salts (Richardson 2001). Compared to other wood species, Norway spruce is difficult to be impregnated with wood preservatives and other modifications substances. The refractory behavior is due to the aspiration of the pit membranes in the tracheid cell walls (Figure 1). In the living tree, these bordered and half-bordered pits provide interconnecting voids between the adjacent tracheids and in the crossfields of tracheid and xylem ray parenchyma cells (Hacke et al. 2004). The pits substantially determine the permeability of a softwood species. During wood drying, water evaporates from the wood surface and causes a capillary suction in the tracheids (Salin 2006). Air enters the capillary system and causes different pressure levels in adjacent tracheids. In consequence, the elastic pit membrane is deflected and the thickened part of the membrane (torus) attaches to the opening in the cell wall (porus); this closure is called "aspiration". Aspiration is considered to be irreversible because of the formation of hydrogen bonds between the to- 
rus/margo and the pit opening (Liese and Bauch 1967b; a; Thomas and Kringstad 1971). Thus, a subsequent introduction of liquid substances is difficult, so that even with highly efficient vacuum-pressure impregnation techniques penetration depths of only a few millimeters are achieved (Flynn 1995).
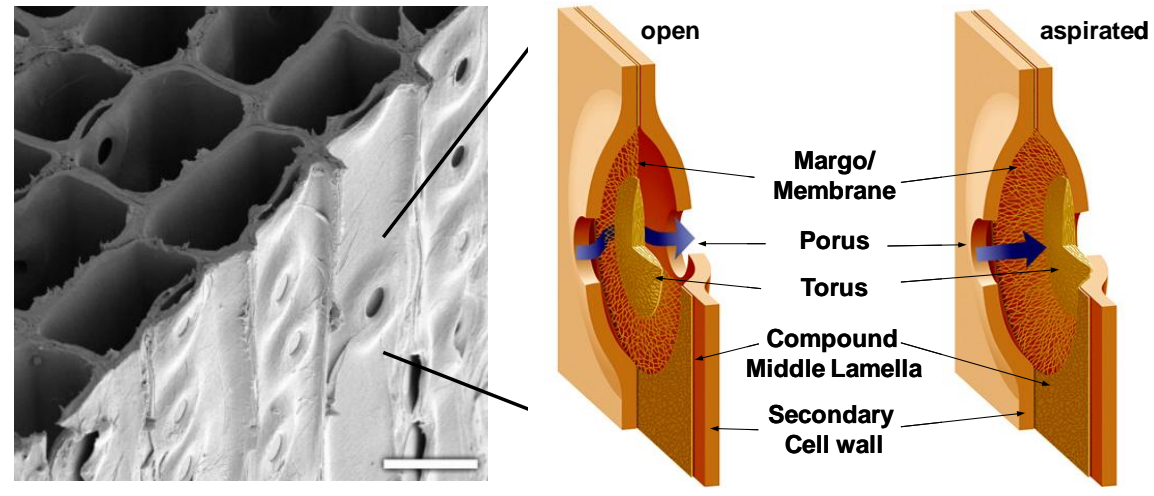

Figure 2 Bordered pits act as interconnecting voids between adjacent tracheids. After aspiration, the torus restricts the flow of fluids (Paper II). Scale bar $20 \mu \mathrm{m}$.

In the past, several mechanical systems were developed to achieve a deeper and homogenous distribution of liquid substances into refractory wood species (Perrin 1978; Keith and Chauret 1988; Richter 1989; Morris et al. 1994). On industrial scale, incising technologies like drilling and slit-perforation are well established for permeability improvement of the wood border zone. Hereby, small openings of down to $5 \mathrm{~cm}$ depth are driven into the wood surface. These openings act as pathways for subsequent intrusion of wood preservatives and modification substances. However, the physical damages reduce the mechanical strength and the visible marks on the wood surface limit the application of incised wood to areas where aesthetic aspects are of minor importance. In North America, mechanical incising technologies are widely used for the pretreatment of sawn wood, whereas in Europe, they are mostly limited to the air-soil zone treatment of poles.

As alternative to these mechanical approaches, different biotechnological concepts were developed to improve the wood permeability. Observations from water storage ("ponding") of wood over longer periods revealed that bacteria selectively degraded the pit membranes and thus induced a significant permeability improvement (Ünligil 1972; Kobayashi 1998). The systematic treatment of wood with these bacteria (Nijdam et al. 2001) or with isolated enzymes (Nicholas and Thomas 1968; Militz 1993) showed to improve the permeability under certain conditions, but none of the processes was brought to industrial application. Process control is complex and areas of improved permeability are always heterogeneously distributed in the wood substrate. Moreover, an efficient and homogenous introduction of bacteria and enzymes deeper into the wood is difficult due their own immobility and due to the impermeability of the aspirated pit membranes. 
The application of wood colonizing fungi for permeability improvement promised to overcome these problems. In contrast to isolated enzymes or bacteria, wood colonizing fungi show a higher mobility and spread their enzymes actively by mycelia penetration into the substrate. During the first period of substrate colonization, the excreted enzymes alter the chemical structure of the pit membranes and contribute to their selective degradation with almost no negative effect on the strength properties of the wood matrix (Messner et al. 2003).

\section{BIOINCISING}

\subsection{BACKGROUND}

When Schwarze and Landmesser (2000) investigated the basidiomycete Physisporinus vitreus on wood of Douglas fir (Pseudotsuga menziesii) and Norway spruce (Picea abies (L.) Karst.), they reported that the fungus had selectively degraded the membranes of bordered pits and half-bordered pits. P. vitreus was originally isolated from cooling towers where it was found to degrade the construction timber under very moist conditions (Schmidt et al. 1996). Subsequent laboratory studies (Schwarze et al. 2006) showed that $P$. vitreus caused a significant permeability improvement in Norway spruce and Silver fir (Abies alba Mill.) after six weeks of incubation inducing only negligible reduction of the impact bending strength. Hereby, the effect was not limited exclusively to the sapwood, but also in the normally more resistant heartwood a significant permeability improvement was recorded. In previous studies, Rosner et al. (1998) and Messner et al. (2003) used Trichoderma spp. to increase the permeability of Norway spruce logs prior to preservative treatment. The procedure resulted in a higher uptake of wood preservatives in the sapwood of spruce, but the heartwood remained unaffected.

Thus, the treatment with the white rot fungus Physisporinus vitreus is considered to be a promising approach for enhancing the uptake of preservatives and wood modification substances in the sapwood and heartwood of refractory wood species. The process was named "bioincising" and patented by Schwarze (2008). A thorough overview of the mechanism of action and the differences towards previous biotechnological approaches is given in Paper II. However, a brief summary of the most important aspects will be presented in the following sections.

\subsection{MECHANISM OF ACTION}

The permeability improvement occurs due to fungal growth from the radial and tangential wood surfaces into deeper areas of the wood block. The hyphae largely follow the nutrient-rich ray parenchyma cells and spread from there into the adjacent tracheids. According to Schwarze and Landmesser (2000) and Schwarze et al. (2006) this occurs primarily by selective degradation of membranes in the crossfield pits or bordered pits. 
This selectivity towards pit membrane degradation is one of the crucial aspects for a successful bioincising process. During the investigations for this thesis I revealed that $P$. vitreus did not selectively degrade the pit membranes, but also degraded the cell wall constituents simultaneously. The high selectivity towards pit membrane hydrolysis, as described by Schwarze and Landmesser (2000) and Schwarze et al. (2006), could not be confirmed. Moreover, I identified selective delignification and simultaneous degradation in close proximity to each other, comprising the decay patterns of a white rot fungus and a soft rot type I and II. One possibility for this non-selective degradation is that the incubation parameters were not optimized.

Obviously, the environmental growth conditions have a central influence on the mechanism of $P$. vitreus colonizing the wood of Norway spruce. The speed and homogeneity of substrate colonization and the selectivity of fungal activity towards pit membrane degradation is determined by the incubation parameters, as discussed below and in the Papers III, V, and VI.

\subsection{INCUBATION PARAMETERS}

Activity of wood decay fungi is subject to change over a period of time, as described by a sigmoid growth curve (Figure 3, Rypacek 1966; Zabel and Morrell 1992; Schmidt 2006). For an efficient bioincising process, a short lag phase and a high growth rate of $P$. vitreus are required. The lag phase is the period of time between the introduction of a wood decay fungus on a substrate and the time it begins to exponentially degrade the wood substance. The incubation procedure has to be interrupted at the end of the lag phase or the early log phase by steam sterilization (Schubert 2010; personal communication). At later stages the risk of major strength losses especially at the substrate surface starts to increase.

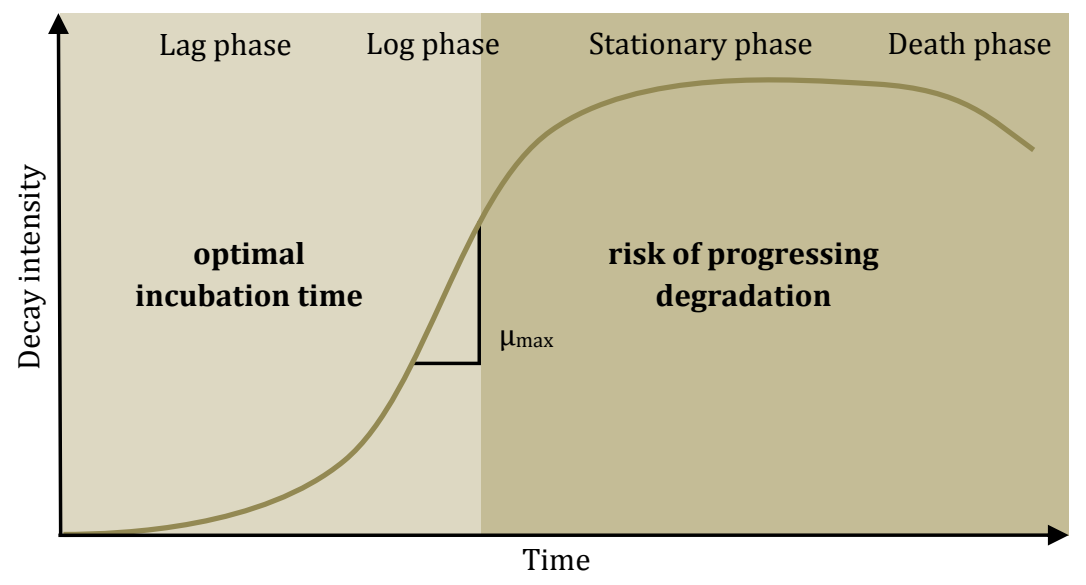

Figure 3 Representative growth curve of a wood decay fungus (after Rypacek 1966; Zabel and Morrell 1992; Schmidt 2006).

During the lag phase, wood degradation is low since the fungus adapts to the environmental conditions in the substrate, enzyme excretion is moderate and pre- 
ferably freely available carbohydrates are metabolized without causing major damages to the cell wall structure. The mycelium grows through the wood mostly following the ray parenchyma. Schwarze et al. (2006) mentioned that the hyphae of $P$. vitreus grow in the ray parenchyma and in the lumina of the tracheids, preferentially hydrolyzing the membranes of bordered pits and crossfield pits.

The log phase is characterized by an exponential increase of fungal activity. The fungus has established its mycelium, and hyphal growth proceeds quickly in the tracheids until decay intensity reaches a stationary phase. Here, the fungal activity remains on a stable level until limitation of nutrients reduces the hyphal growth and with it the decay intensity.

In the following, the most relevant parameter for incubation will be presented and briefly discussed.

\subsubsection{WATER ACTIVITY AW AND OXYGEN SUPPLY}

Water activity $\mathrm{a}_{\mathrm{w}}{ }^{1}$ is a highly significant parameter for $P$. vitreus growth, as shown by Schubert et al. (2009). The minimum for wood decay basidiomycetes on MEA is $\mathrm{a}_{\mathrm{w}}=0.97$ (Schmidt 2006). For P. vitreus, growth was fastest at $\mathrm{a}_{\mathrm{w}}=0.998$ and decreased drastically at $\mathrm{a}_{\mathrm{w}}=0.982$; at $\mathrm{a}_{\mathrm{w}}=0.955$, no growth was detected within the incubation period of 20 days (Schubert et al. 2009).

Schmidt et al. (1996; 1997) observed an extraordinarily strong dependence of P. vitreus on high moisture levels. They reported preferential colonization and degradation of water-saturated Norway spruce wood with low oxygen content (wood moisture content, WMC > 100\%). At WMC > 90\%, fungal growth within wood is normally impeded because of the lack of oxygen. This is not the case with $P$. vitreus and highlights the remarkable biological capacity of this fungus to degrade timber in the special habitat of extremely moist wood.

\subsubsection{TEMPERATURE}

Schubert et al. (2009), also found that the incubation was strongly dependent on temperature, especially in combination with water activity $\mathrm{a}_{\mathrm{w}}$. The optimum temperature for supporting growth was $20^{\circ} \mathrm{C}$ at $\mathrm{a}_{\mathrm{w}}=0.982$ and growth decreased with decreasing temperature. However, $P$. vitreus showed detectable growth at all temperatures tested.

\footnotetext{
1 Water actitivity $\mathrm{a}_{\mathrm{w}}$ : measure for free or unbound water available in wood for microbial growth. For microorganisms not the whole water content of the substrate is available, but only the part of the total water which is not hygroscopically bound (Schmidt 2006).
} 


\subsection{3 $P H$}

The $\mathrm{pH}$ has a significant influence, but according to Schubert et al. (2009) it plays a secondary role. It was considered to be optimal at pH 5 .

\subsubsection{NUTRIENT SUPPLY AND CARBON/NITROGEN RATIO (C/N-RATIO)}

The carbon/nitrogen-ratio (C/N-ratio) of the nutrient medium has an important influence on the selectivity of $P$. vitreus (Levi and Cowling 1969; Kirk et al. 1978; Reid 1983; Dill and Kraepelin 1986; Rios and Eyzaguirre 1992; Wang et al. 1997). Selective delignification is promoted by a low nitrogen concentration in the nutrient medium and it is well established that a narrow $\mathrm{C} / \mathrm{N}$-ratio usually facilitates the degradation of polysaccharides by wood decay fungi. Thus, a wide $\mathrm{C} / \mathrm{N}$-ratio might be favorable as will be discussed further below in chapter 6.4 and in Papers III and VI.

\section{OBJECTIVES}

The bioincising process is still in the procedure of optimization and an upscaling is currently being attempted. The activities are methodically subdivided into two major fields of activity (Figure 4).

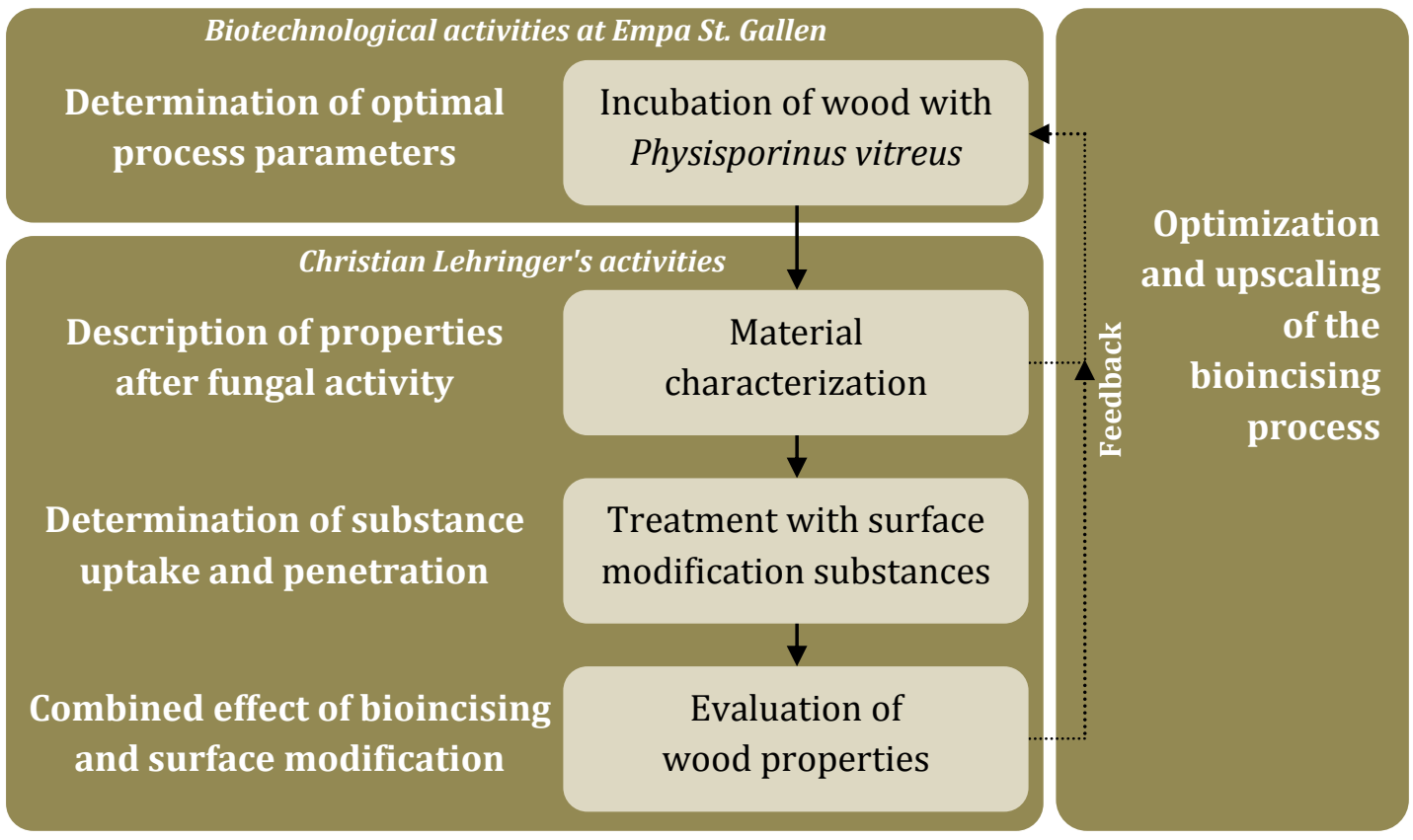

Figure 4 Major fields of research during optimization and upscaling of the bioincising process.

The first set of investigations covered the biotechnological process control and development that was basically undertaken by mycologists in the working group "Wood protection and Biotechnology" at Empa St. Gallen. Physical, chemical and biological growth parameters and their sensitive control during fungal incubation were investigated. 
Secondly, during my own investigations, the bioincised wood was subject of systematic quality control and material characterization that generated information for a feedback to process optimization. Knowledge about the wood-fungus interaction and possible adverse effects on the final wood properties allowed more specific corrections and improvements of the bioincising process. Within the scope of my work, I defined three major work packages that served as methodological frame for the outcome of this thesis.

\subsection{MATERIAL CHARACTERIZATION OF THE BIOINCISED WOOD}

The characterization of the bioincised wood included the description of the wood properties and anatomical characteristics that were influenced by fungal activity over a period of 9 weeks incubation. Hereby, special focus was set on the growth behavior of $P$. vitreus' hyphae through the wood. Four major aspects were addressed:

1. Homogeneity of the substrate colonization and the fungal activity of $P . v i^{-}$ treus.

2. Selectivity of pit membranes degradation during incipient period of substrate colonization.

3. Quantification of cell wall damages during incipient period of substrate colonization.

4. Evaluation of P. vitreus' decay pattern according to Schmidt (2006).

Furthermore, material characteristics were determined that could give evidence for mechanical and chemical alterations, such as mass loss, decrease of surface hardness, degree of delignification, changes of gas permeability, and $\mathrm{pH}$-values.

Among the three work packages, the majority of scientific activities was deployed within this field. The idea was to gain a thorough understanding of the bioincised wood properties before progressing to the application and evaluation of surface modification substances (see also Table 2 in chapter 5.2 ).

\subsection{TREATMENT WITH SURFACE MODIFICATION SUBSTANCES}

The main objective in this working package was to gather information about the penetration behavior of different wood modification substances in the bioincised wood. Three different application methods were used: brushing, dipping and vacuum impregnation (Paper I). Different commercial products for hydrophobation, UV-protection, fire resistance and surface hardness were applied and their efficiency was evaluated.

The determination of the quantitative substance uptake by weight measurements provided information about the overall permeability improvement in the 
wood samples. In addition, systematic microscopic analysis of cross sections revealed the qualitative penetration depth of the modifications substances into the wood (Paper II). These two measurements allowed the interpretation of the following aspects:

1. Quantity and quality of substance distribution in the bioincised wood.

2. Relation between application method and the penetration depth and quality.

3. Determination of (preferable) pathways of intrusion (radial or tangential, via ray parenchyma or tracheid lumina).

\subsection{WOOD PROPERTIES AFTER BIOINCISING AND SURFACE MODIFICATION}

Bioincising of the wood (surface) is expected to have several effects on the wood properties. First, a permeability improvement allows an increased substance uptake of the bioincised wood. Depending on the specific mode of modification, a better performance of this substance is then conceivable. Second, potentially adverse effects from bioincising are also possible, such as reduced mechanical properties, increased combustibility, altered chemical behavior of the substrate surface (e.g. pH-value), or raised susceptibility for microbial attack. These adverse effects can overshadow the enhanced performance of the applied modification substance to a level where in the end a negative overall result is recorded. Hence, two major objectives were defined:

1. Relation between enhanced uptake of the specific modification substance and the resulting wood properties.

2. Detection of adverse effects of bioincising for the overall performance of the surface modification procedure.

\section{EXPERIMENTAL}

\subsection{INCUBATION}

All experiments were conducted on laboratory scale with wood specimens from Norway spruce (Picea abies (L.) Karst.) that measured $20 \times 3 \times 3 \mathrm{~cm}$ (L x R x T). This sample size was bigger than that from previous laboratory studies (Schwarze and Landmesser 2000; Schwarze et al. 2006) and was chosen due for the intended process upscaling.

After infection with Physisporinus vitreus, the wood specimens were stored for 3 , 5,7 , and 9 weeks in sealed containers on $1 \%$ malt extract agar (MEA) at $22^{\circ} \mathrm{C}$ (detailed material and methods in Papers III, V and VI). The specimens were positioned with the tangential surface directly on the nutrient medium in order to promote hyphal growth via the xylem ray parenchyma. Even though it differs 
from the normal procedure, the direct contact to the nutrient medium allowed a faster colonization of the fungus into the wood. However, one major disadvantage of this incubation method is apparent from Figure 5. Substrate colonization occurred rather heterogeneously, possibly due to the unequal distribution of nutrients and moisture content. In the bottom area of the specimens, fungal activity was always the highest. Hence, a differentiation of the specimen surfaces was necessary. If in the following not indicated specifically, sample preparation for experimental work was done from the bottom of the specimens.
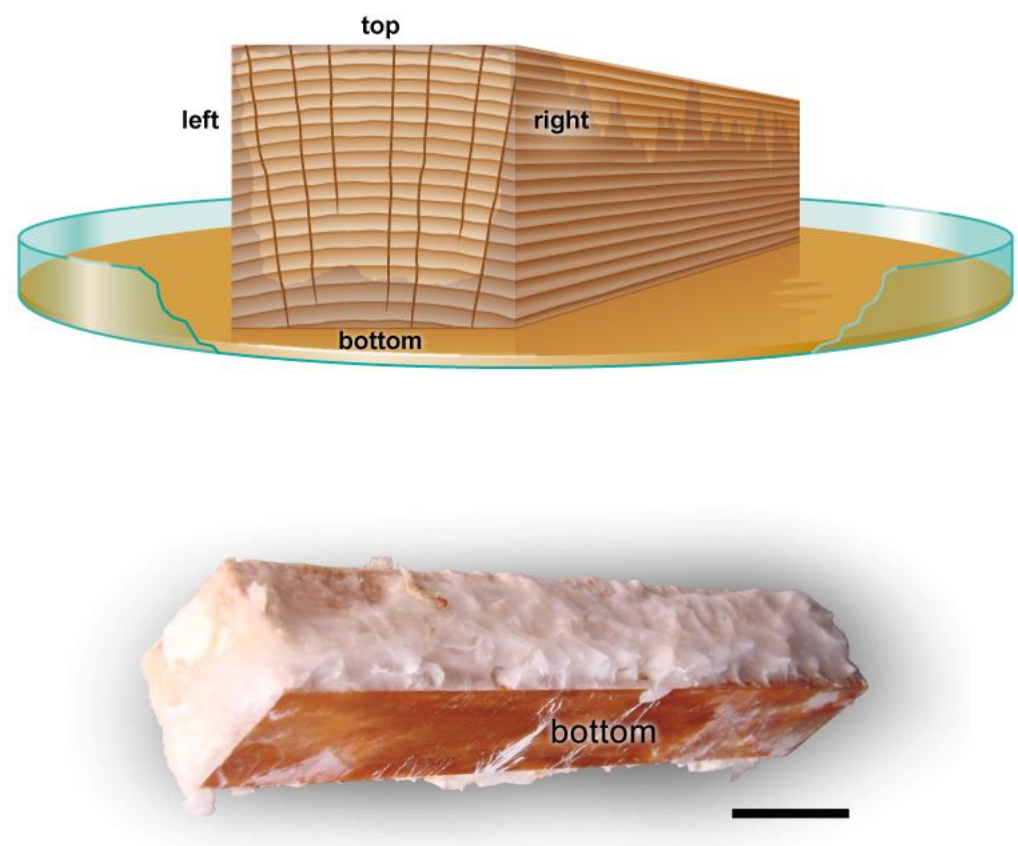

Figure 5 Above: Schematic illustration of incubation setup (Paper V). After infection with Physisporinus vitreus, the wood specimens were stored for 3, 5, 7, and 9 weeks in sealed containers on a 1\% malt extract agar (MEA) at $22^{\circ} \mathrm{C}$. After removal of the surface mycelium, slightly discolored areas indicated a heterogeneous colonization of the fungus into the wood. Below: Photograph of a specimen after removal from the nutrient medium. Scale bar $=3 \mathrm{~cm}$ 


\subsection{LABORATORY EXPERIMENTS AND ANALYSIS}

A broad range of experimental and analytical methods was applied within the three work packages shown in Table 2.

Table 2 Work packages and analytical methods that were applied (I to VI = results published in scientific Paper, *results evaluated but not published in a scientific journal).

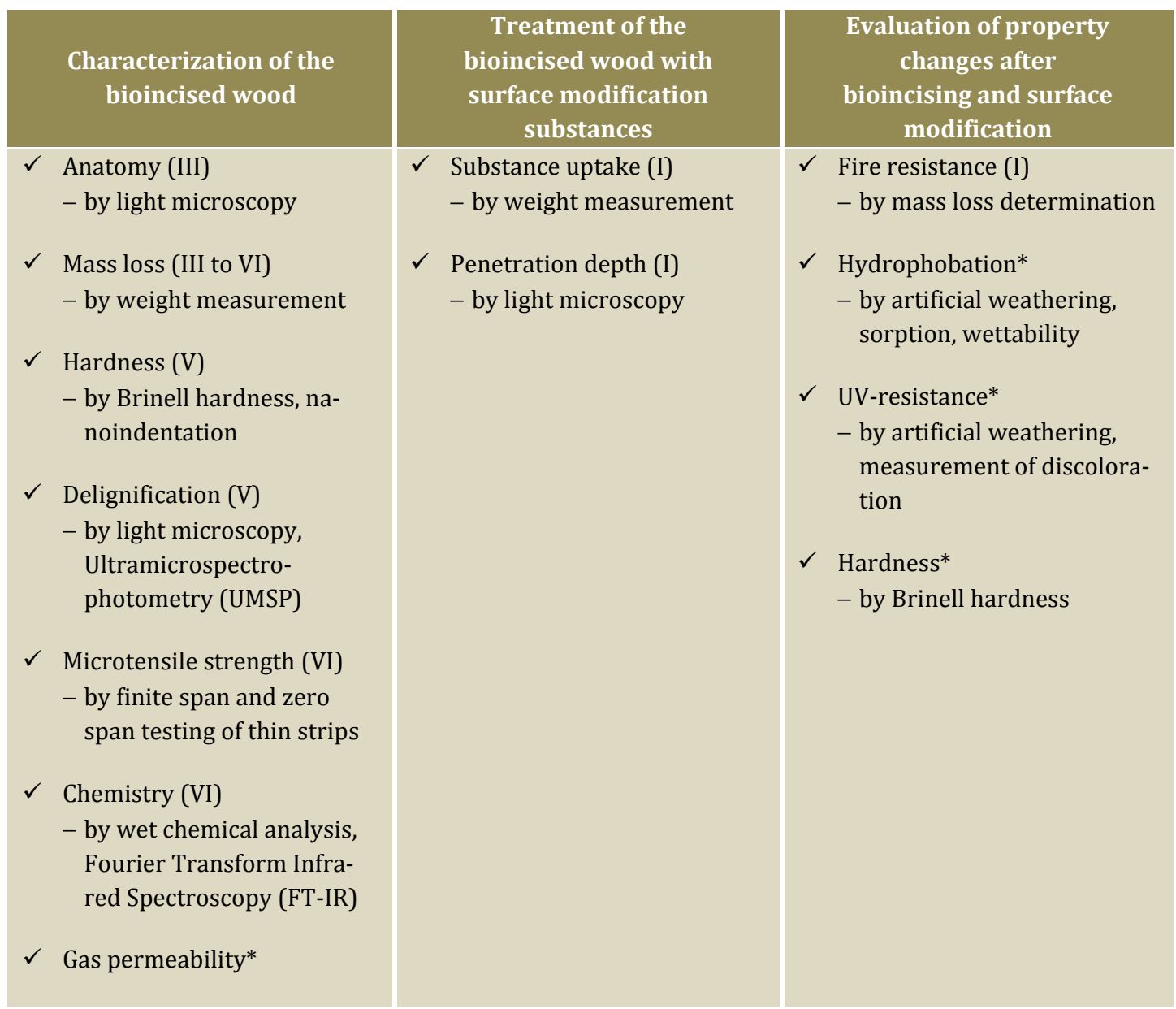

Most of the results of the experiments were published in scientific articles that are enclosed in the appendix. A synopsis of the essential published results will be given in the following sections, together with selected results that were not published so far. These results are included because they present valuable supplementary information to the laboratory experiments. 


\section{RESULTS AND DISCUSSION}

\subsection{MATERIAL CHARACTERIZATION OF THE BIOINCISED WOOD}

A detailed microscopic analysis of structural changes during bioincising is presented in Paper III. I found that $P$. vitreus caused both a selective delignification and a soft rot Type I and II in tracheid cell walls comprising a high heterogeneity during wood colonization (Figure 6).

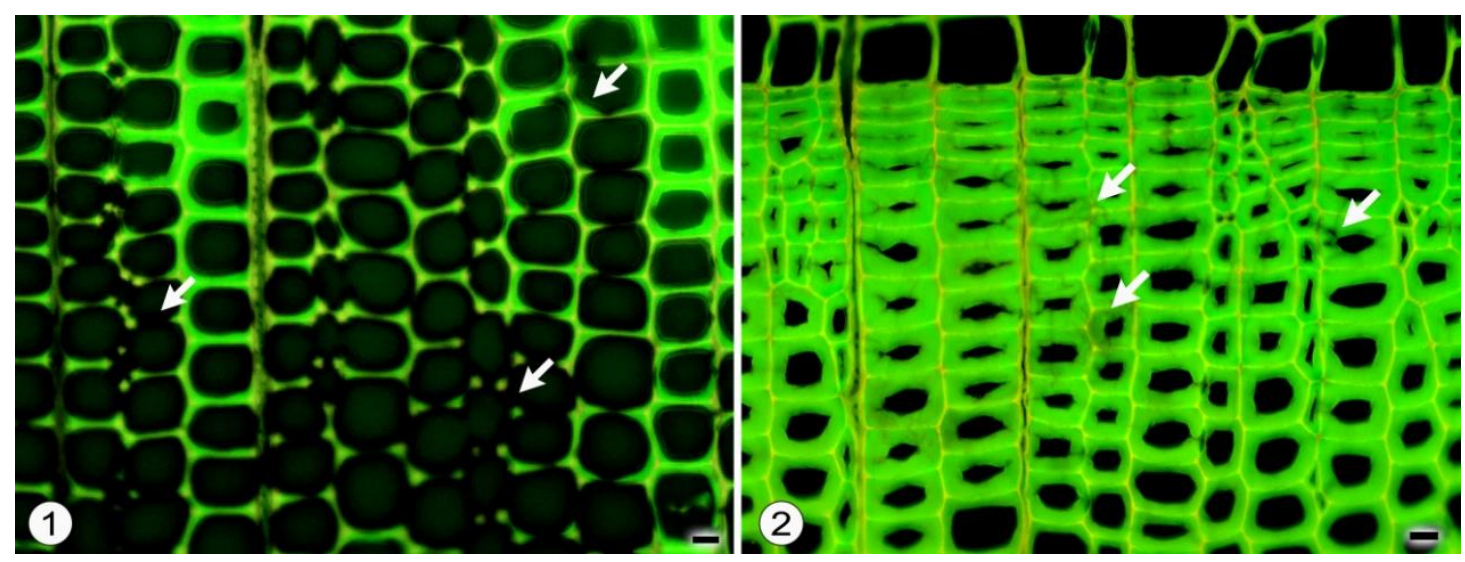

Figure 6 Transverse sections of Norway spruce wood after 9 weeks incubation with Physisporinus vitreus (Paper III). 1.: Selective delignification. 2.: Hyphal tunneling and soft rot in secondary walls of tracheids. Sections stained with acridine orange and viewed with UV-excitation. Scale bars $=10 \mu \mathrm{m}$.

After statistical evaluation it was apparent that the degradation of pit membranes occurred simultaneously with the formation of boreholes, cavities and notches in tracheid cell walls (Figure 7).

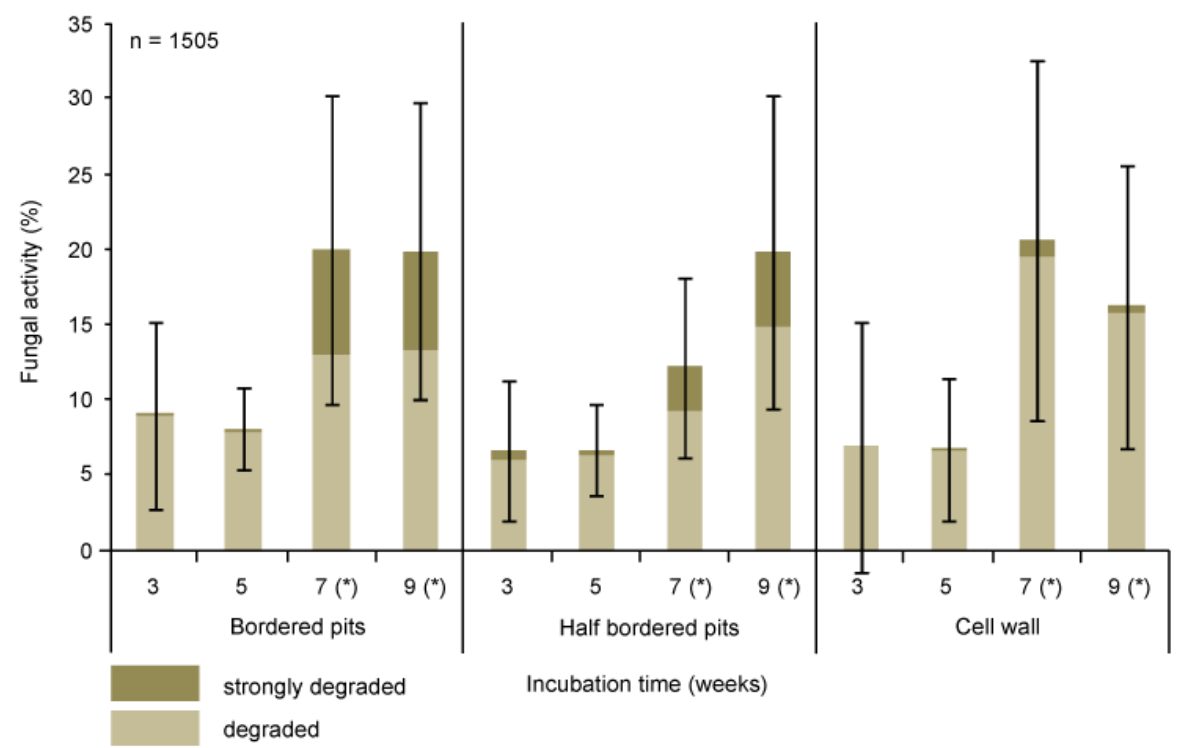

Figure 7 Intensity of Physisporinus vitreus activity on bordered pits, half bordered pits and tracheid cell wall after different incubation times (Paper III). The values of sapwood/heartwood and earlywood/latewood were combined for more explicit illustration. The error bars reflect the overall standard deviation. $\left({ }^{*}\right)=$ significant difference of the data from 7 and 9 weeks compared to the data of 3 and 5 weeks $(\mathrm{p}<0.05)$. 
The activity of $P$. vitreus was higher in the sapwood, but a notable effect was also recorded in the heartwood. The occurrence of selective delignification and simultaneous degradation of lignin, cellulose and hemicelluloses could furthermore be demonstrated by Ultramicrospectrophotometry (UMSP, Paper V), by Fourier Transform Infrared Spectroscopy (FT-IR) and by wet chemical analysis (both Paper VI).

Analysis of Brinell hardness revealed a significant hardness reduction in the subsurface area after 7 and 9 weeks incubation which was attributed to the partial delignification and mechanical disintegration of the tracheid cell walls (Paper V). Results from nanoindentation tests did not show a clear effect of fungal activity because of the material heterogeneity and the high spatial resolution of this technique (Paper V). However, nanoindentation was an interesting methodological approach to the investigation of mechanical changes at the subcellular level due to fungal degradation.

Microtensile tests were conducted on thin strips in order to better understand the chemical alterations of the wood constituents due to fungal activity and the corresponding changes of mechanical properties. In accordance with previous results, indications for the occurrence of selective delignification and simultaneous degradation were evident also with this method (Paper VI).

In all these experiments, the analytical methods were near the limit of detection, which was especially true for FT-IR and wet chemical analysis. This was mostly due to the low mass losses of below $10 \%$ (Paper III, V, VI). In accordance to other works (Schwarze and Landmesser 2000; Schwarze et al. 2006; Schwarze et al. 2008) P. vitreus showed a low degradative potential and induced relatively low mass losses compared to other white rot fungi such as Trametes versicolor.

Measurements of longitudinal gas permeability were conducted to document the effect of fungal activity on the wood. Dried and filtered air (step-wise increased from 0.5 to 2 bar) was used on cylindrical specimens of $20 \mathrm{~mm}$ diameter and 20 $\mathrm{mm}$ length with a longitudinal fiber orientation (Figure 8). 


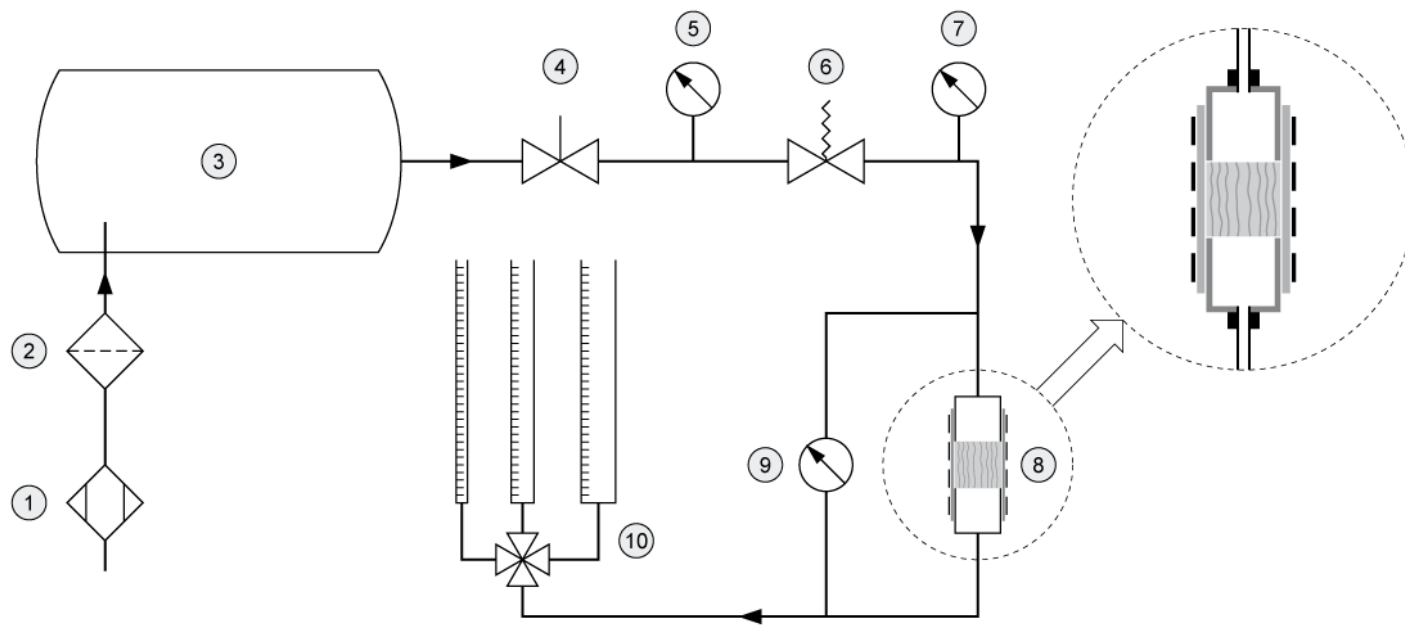
(1) Air dryer
(2) Air filter
(5) Control pressure measurement
(3) Pressure tank (Compressed air)
(6) Needle valve
(4) Modulating valve
(7) Pressure measurement in front of sample
(9) Differential pressure measurement
(10) Set of volume flow rate meters for different measurement ranges

Figure 8 Schematic illustration of the gas permeability measurement device used in the present study.

The measurements were performed on conditioned specimens under constant climate of $20^{\circ} \mathrm{C} / 65 \%$ relative humidity $(\mathrm{RH})$. The specimens were laterally sealed with a silicon sealant, then placed in an elastic rubber tube and fixed with hose clamps to ensure a gas tight fitting into the measurement device. Flow rate was determined at constant differential gas pressure. The coefficient for gas permeability was then calculated according to Equation 1 (Siau 1984; Thoemen and Klueppel 2008) and presented in Darcy (1 Darcy $\left.=9.8697^{*} 10^{-13} \mathrm{~m}^{2}\right)$.

$$
K=\frac{\mu \cdot Q \cdot L \cdot P_{1}}{A \cdot \Delta P \cdot \bar{P}}
$$

(Equation 1)

where $K=$ permeability $\left(\mathrm{m}^{2}\right), \mu=$ dynamic gas viscosity of air (Pa s), $Q=$ volumetric flow rate $\left(\mathrm{m}^{3} \mathrm{~s}^{-1}\right), L=$ specimen length in flow direction (m), $P_{1}=$ pressure behind specimen (bar), $A=$ specimen area perpendicular to flow direction $\left(\mathrm{m}^{2}\right), \Delta P=$ pressure difference in flow direction (bar) and $\bar{P}=$ average pressure measured before and behind the sample (bar)

Longitudinal gas permeability was slightly increased after 3 weeks incubation, compared to the control specimens (Figure 9). After 5 weeks incubation, permeability showed a significant increase and after 7 weeks incubation, gas permeability tripled to 0.16 Darcy. The highest increase was recorded after 9 weeks, where the gas permeability was almost two-fold (0.35 Darcy) compared with the values recorded after 7 weeks. 


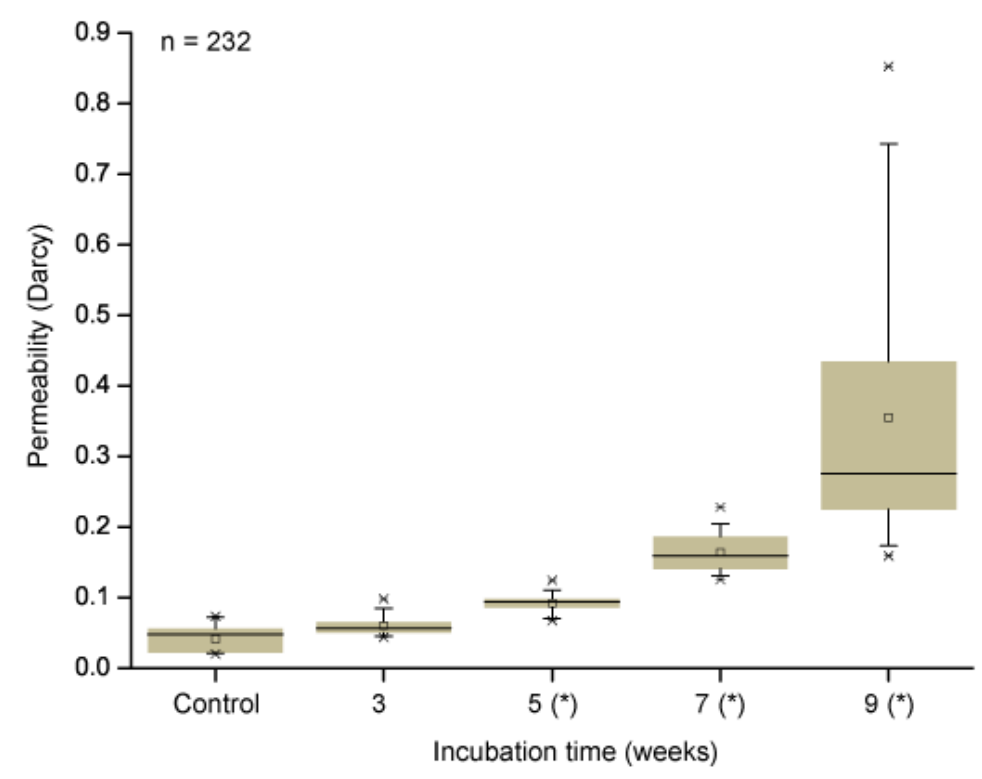

Figure 9 Gas permeability of Norway spruce heartwood after 3, 5, 7, and 9 weeks incubation with Physisporinus vitreus. $(*)=$ significant difference in comparison to control $(\mathrm{p}<0.05)$.

The method of direct gas permeability measurements revealed consistent results which recorded the fungus-wood-interaction over an incubation period of up to 9 weeks. Several studies discuss the gas permeability improvement induced by microorganisms (Johnson 1979; Kobayashi 1998; Nijdam et al. 2001; Bradic and Avramidis 2007; Reinprecht and Pánek 2008). It has been reported that positive effects of microorganisms could be observed in sapwood regions with enhanced gas permeability, which has been contributed to the degradation of bordered pits. But for heartwood, no or only negligible effects were described. Thus, $P$. vitreus appears to be a promising fungus for the permeability improvement even in the heartwood of Norway spruce.

As demonstrated in the gas permeability measurements, the variability of results was high, especially with longer incubation times. Fungal activity increased the material heterogeneity. The statistical relevance of some data is therefore limited. This reflects the difficulty to reliably analyze fungal activity in the wood substrate. Heterogeneous distribution of hyphae and localized areas of enzymatic activity in the wood require a vast amount of observations to obtain statistically valid results.

\subsection{TREATMENT WITH SURFACE MODIFICATION SUBSTANCES}

The bioincised wood was treated with substances for hydrophobation, UVprotection, surface hardness and fire resistance. The substances (except hot melting wax for surface hardness) were waterborne systems and were applied either by brushing, dipping (30 min) or vacuum impregnation (20 min, $7 \mathrm{mBar}$ ).

Considering that these wood modification systems require specific penetration depths for optimal performance, I discussed the capability of bioincising to en- 
hance permeability at the required penetration depths in Paper II. It is considered that UV-light radiation penetrates the wood surface down to depths of $75 \mu \mathrm{m}$ and visible light reaches depths of $200 \mu \mathrm{m}$ (Jirous-Rajkovic et al. 2004; Rowell 2005). If weathering effects such as humidity and temperature changes are considered, the maximum depth of photodegradation is approximately 750 to $900 \mu \mathrm{m}$. Therefore, the deposition of UV-protective substances into the surface layer (50 to $100 \mu \mathrm{m}$, see also Figure 1) and subsurface area (100 to $1000 \mu \mathrm{m}$ ) is supposed to be sufficient for an efficient protection against photodegradation. However, according to the Beer-Lambert law ${ }^{2}$, the best UVprotection of wood surfaces is achieved with film-forming coating systems.

\section{Hydrophobation substances}

Tests with hydrophobation substances, whose results for uptake and penetration depth are presented in Paper I, showed that a positive effect of bioincising for the substance uptake and penetration depth is only apparent for the vacuum impregnation. When application was conducted by brushing or dipping, substance uptake as well as penetration depth remained at a negligible level. Thus, the permeability improvement by bioincising is apparently not so efficient that impregnation could be replaced by less sophisticated methods, e.g. by dipping.

On the basis of these preliminary findings, the subsequent tests for substance uptake and penetration depth were conducted exclusively with vacuum impregnated samples. Figure 10 displays the results from a study where three commercial hydrophobation substances on basis of organofunctional silanes were impregnated into bioincised sapwood and heartwood samples of Norway spruce.

\footnotetext{
2 Beer-Lambert law: quantitative relationship between the absorbance of radiant energy, the concentration of the sample solution, and the length of the path through the sample (Atkins 2000).
} 


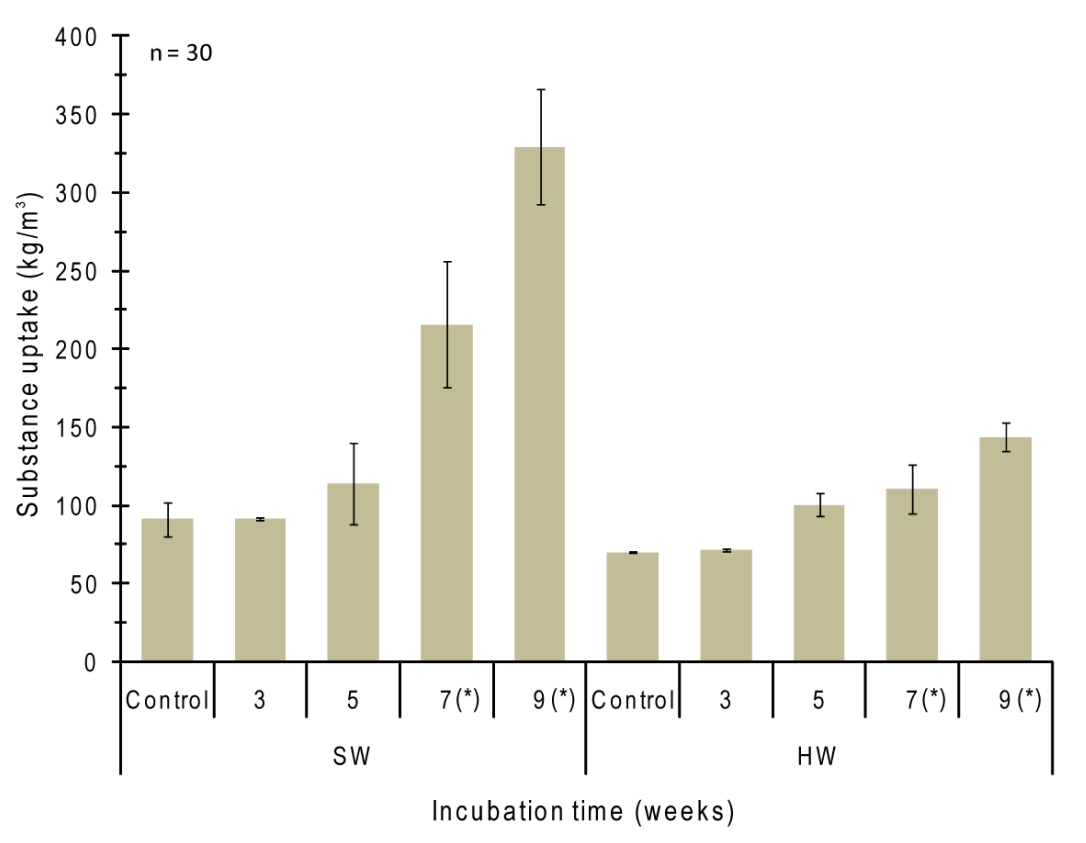

Figure 10 Hydrophobation substance uptake of Norway spruce sapwood (SW) and heartwood (HW) after 3, 5, 7, and 9 weeks incubation with Physisporinus vitreus. Application: vacuum impregnation (20 min, 7 mBar). $\left({ }^{*}\right)=$ significant difference to control $(\mathrm{p}<0.05)$.

The effect of bioincising is clearly discernable in both, sapwood and heartwood samples, where after 7 weeks incubation a significant uptake improvement was recorded compared to control specimens. After 9 weeks, penetration depth was increased from average $80 \mu \mathrm{m}$ (Control) to average $250 \mu \mathrm{m}$ (Figure 11). Variability was high for both uptake and penetration depths.

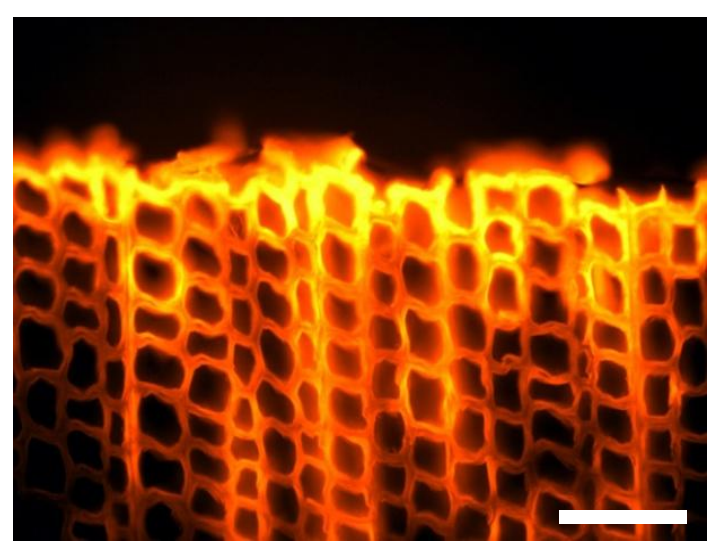

Control

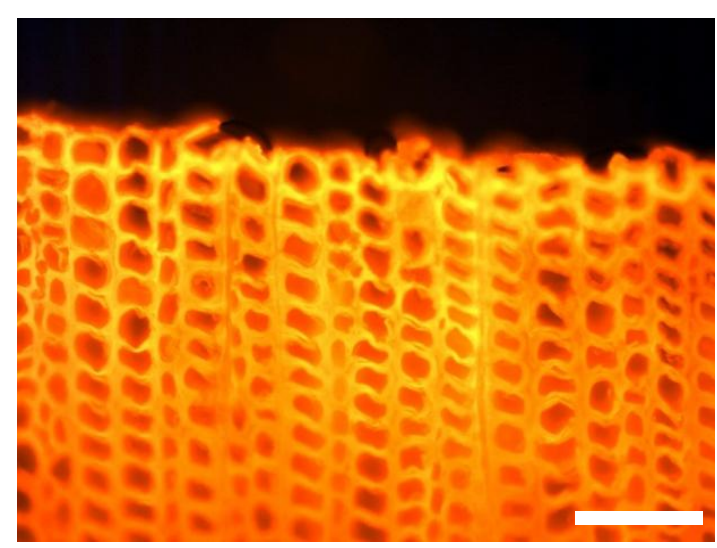

9 weeks

Figure 11 Transverse sections of Norway spruce heartwood after incubation with Physisporinus vitreus and subsequent impregnation with hydrophobation substances. The substances were stained with fluorescence dye Rhodamin prior to application. Scale bars $=60 \mu \mathrm{m}$. 


\section{Surface hardness substances}

The bioincised wood heartwood specimens of Norway spruce (incubation time 6 weeks) were impregnated with different substances for surface hardness improvement. Following substances were chosen due to their surface hardness improving effect:

\section{Methylated melamine-formaldehyde}

- $10 \%$ aqueous solution, $1 \%$ triethanoleamine (pH-stabilizer)

- Methylated melamine-formaldehyde can be impregnated in monomeric form into the cell wall structure to reduce hygroscopicity and to improve dimension stability. Besides, a positive effect on surface hardness is recorded (Miroy et al. 1995; Gindl and Gupta 2002; Deka et al. 2007)

\section{3-dimethylol-4.5-dihydroxyethyleneurea (DMDHEU)}

- 1.3 molar, $1.5 \% \mathrm{MgCl}_{2}$ as catalyst

- DMDHEU is a cyclic N-methylol compound, currently used in industrial chemical wood modification (Belmadur ${ }^{\circledR}$ ) to improve wood properties such a dimension stability and durability, but also with positive effects on surface hardness (Yasuda et al. 1994; Xie et al. 2007; Dieste et al. 2008).

\section{Hot melting wax}

- Montan wax: Licowax E Flakes ${ }^{\circledR}$ (Clariant, Basel, Switzerland)

- Hot melting waxes are esters of fatty acids with higher alcohols usually used as water repellents due to their hydrophobic properties, but also with effects on surface hardness (Scholz et al. 2010a)

The uptake (here presented in weight percent gain, WPG) of all three substances was significantly increased in comparison to the control specimens (Figure 12). According to microscopic studies, penetration depth in the bioincised specimens varied between $250 \mu \mathrm{m}$ and $1 \mathrm{~mm}$. Besides substance intrusion through the bordered pits of the tracheids, the wood rays played a significant role for substance distribution in the wood. The special role of wood rays during wood impregnation was also described and critically discussed by many authors (Liese and Bauch 1967b; Bailey and Preston 1969; Keith and Chauret 1988; Olsson et al. 2001) and is subject of review in Paper II. However, like in all other studies for uptake and penetration depths, a strong variability of measurement data was recorded due to the heterogeneous colonization of $P$. vitreus into the substrate. 


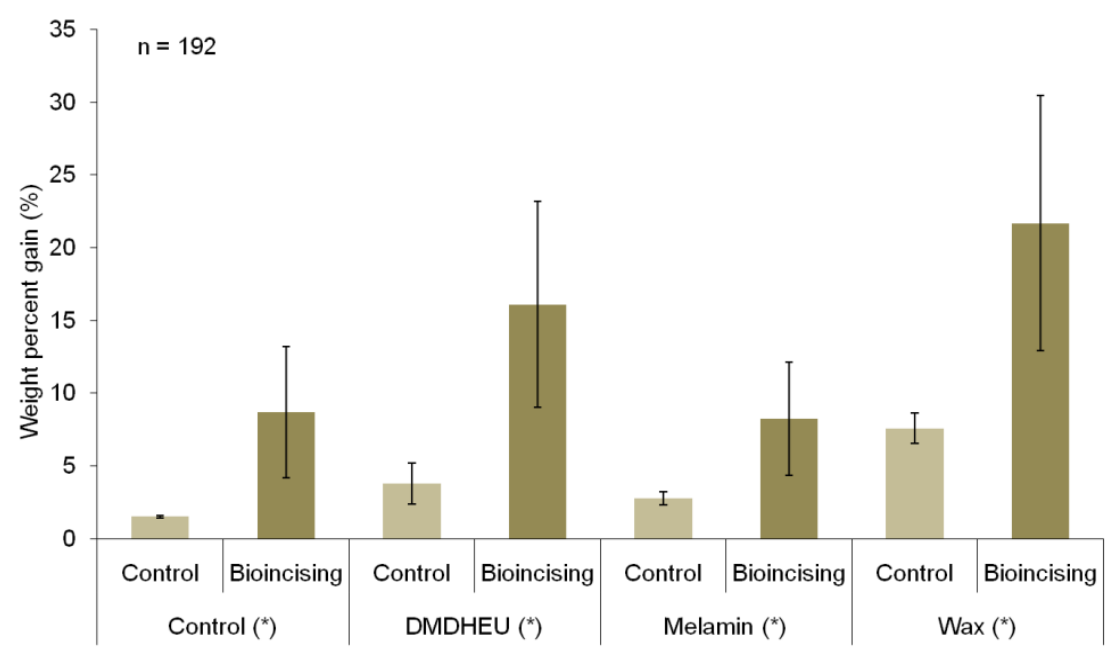

Figure 12 Weight percent gain (WPG) of different surface hardness modification substances into heartwood of Norway spruce after six weeks of bioincising and vacuum impregnation. $\left({ }^{*}\right)=$ significant difference between bioincised specimen and control $(\mathrm{p}<0.05)$.

\subsection{WOOD PROPERTIES AFTER BIOINCISING AND SURFACE MODIFICATION}

The combination of bioincising and subsequent modification is supposed to result in significantly improved material properties. Otherwise, the fungal pretreatment is useless and can be disregarded from an economic perspective.

\subsubsection{HYDROPHOBATION}

Even though the uptake of hydrophobation substances in the bioincised wood was increased, no effect could be recorded for hydrophobation. After 2 weeks of exposure to water saturated air, none of the applied hydrophobation substances reduced the water vapor uptake, independently from previous substance uptake. However, it is a well known fact that treatment with organofunctional silanes has no influence on the water vapor uptake into the wood as long as these substances do not covalently bond to the hydroxyl groups of the cell wall constituents (Donath et al. 2006; Mai et al. 2007).

Liquid water uptake was influenced negatively by bioincising. The increased uptake of hydrophobation substance did not show any positive effect. By contrast, an increased liquid water uptake was recorded already after 4 hours in submersion test. This is due to the enhanced permeability, induced by bioincising. Obviously, the hydrophobation effect of the substance was counteracted by a better susceptibility of the wood to liquid water. This could be expected, since the main goal of bioincising is the permeability improvement for waterborne substances.

\subsubsection{SURFACE HARDNESS}

Brinell hardness was reduced by bioincising (incubation time 6 weeks) as shown in Figure 13. A treatment with DMDHEU and methylated Melamineformaldehyde slightly compensated this reduction and is in accordance with results from previous works (Yasuda and Minato 1994; Gindl and Gupta 2002; Di- 
este et al. 2008). But still an overall reduction of surface hardness was measured. Solely, the impregnation with a hot melting wax significantly improved the Brinell hardness of bioincised wood as also described by Scholz et al. (2010a).

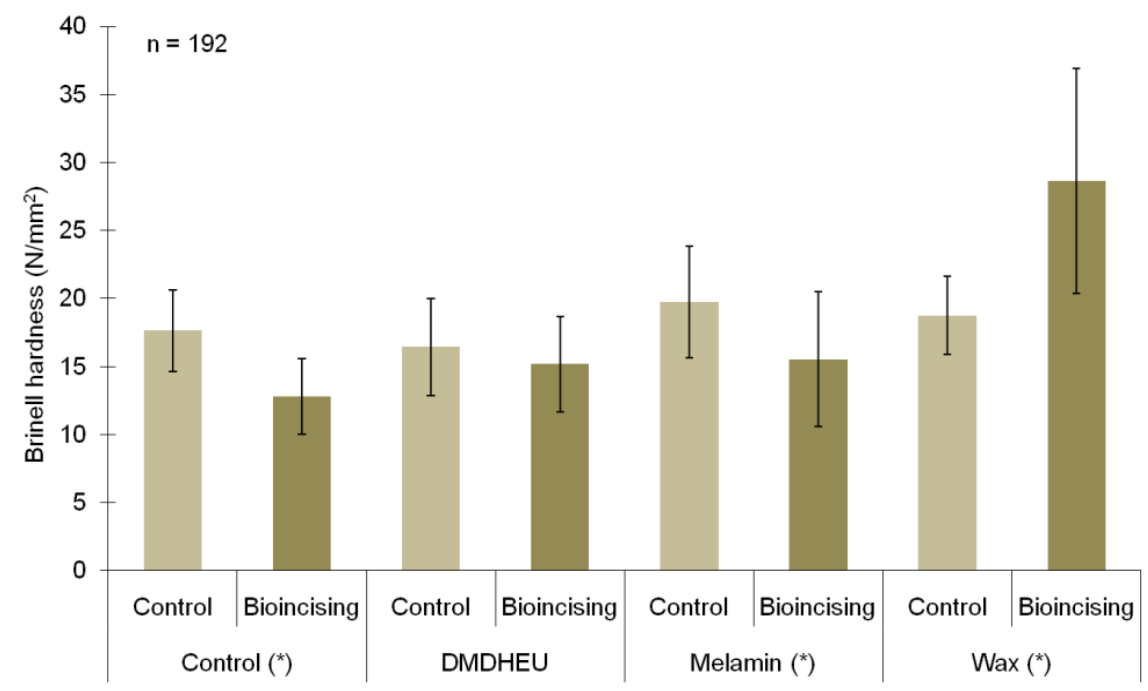

Figure 13 Brinell hardness of bioincised wood (six weeks of incubation) after impregnation with different substances for surface hardness improvement. $\left({ }^{*}\right)=$ significant difference between bioincised specimen and control $(\mathrm{p}<0.05)$.

These differences can be explained by the mode of function of the applied substances:

Modification by melamine-formaldehyde treatment is targeted to modify the cell wall structure itself. Rapp et al. (1999) proved that melamine-formaldehyde had diffused into all layers of the treated wood cell walls. Melamine-formaldehyde resins are characterized by a variety of advantageous properties, such as high hardness and stiffness, and are capable of forming hydrogen bonds (Hagstrand 1999). Hence, embedding in the cell wall layers and adherence/chemical reaction to cell wall components will result in hardness improvement (Deka et al. 2007).

The mode of action of DMDHEU is cross-linking with wood compounds and its self-polycondensation within the cell wall. Impregnation causes permanent bulking of the cell wall and thus reduces subsequent dimensional changes of the wood (Militz et al. 2010). Likewise to melamine-formaldehyde, the resulting hardness improvement is due to its activity within the cell wall.

In contrast to melamine-formaldehyde and DMDHEU, the mode of action for waxes is different. Scholz et al. (2010a) did not measure any swelling of the cell wall after wood impregnation with hot melting waxes. Wax molecules obviously do not infiltrate the wood cell wall during treatment. Moreover, there is no affinity between the hydrophobic wax and the hydrophilic hydroxyl groups of the cell wall constituents. Although the aliphatic chains in paraffin have a certain free- 
dom of movement, an infiltration within intermicellar void spaces in the cell wall is not possible (Scholz et al. 2010b) and the wax is exclusively deposited in the cell lumina (Figure 14).

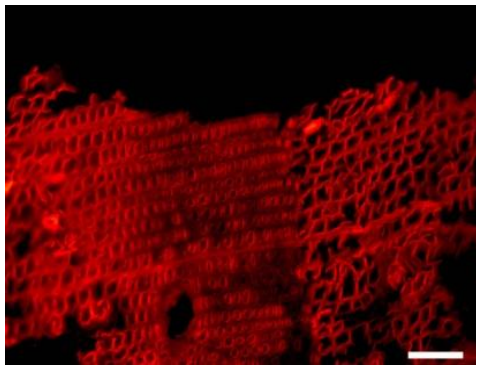

DMDHEU

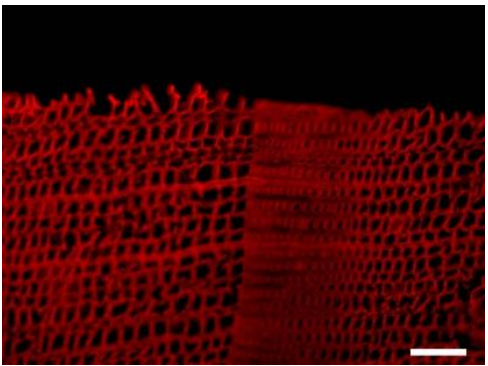

Melamine-formaldehyde

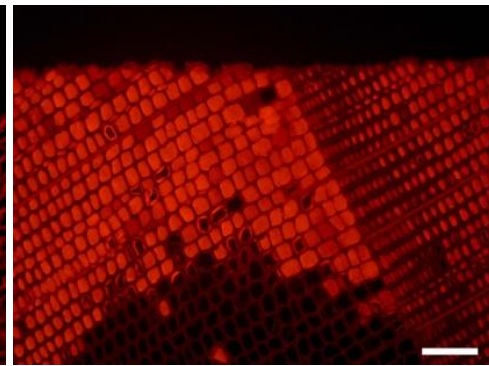

Hot melting wax

Figure 14 Cross sections of Norway spruce heartwood after six weeks incubation with Physisporinus vitreus and subsequent impregnation with surface hardness improving substances. The substances were stained with fluorescence dye Rhodamin prior to application. Scale bars $=100 \mu \mathrm{m}$.

The hardness enhancing effect of the wax is thus based on the higher uptake. A higher amount of lumina in the tracheids is filled out with wax and in consequence, Brinell hardness is increased. Mechanical forces are rather supported by the wax than by the cell wall structure. Hence, the reduced mechanical integrity of the cell wall does not significantly influence surface hardness anymore and is compensated by the wax infiltration.

In contrast, cell wall active substances like melamine-formaldehyde and DMDHEU cannot balance the cell wall degradation induced by $P$. vitreus activity and thus result in an overall lower Brinell hardness.

\subsubsection{FIRE RESISTANCE}

While surface fire retardant coatings lose their efficiency when the protection layer has been physically destroyed, deep impregnation systems continue to control charring rate and flame formation over an extended period of severe fire impact. Similarly to wood preservatives, their effect depends strongly on a deep and homogenous penetration of the fire retardants into the wood.

The results of a study on fire resistance are presented in Paper I. Fire-retardant salt solutions were applied by vacuum impregnation. Bioincising of Norway spruce wood for 6 weeks caused a significantly enhanced substance uptake. But likewise to above presented results, the bioincising process showed a negative overall effect for the improvement of fire resistance. The bioincised specimens showed higher mass losses after 3 minutes of flame exposition than the control samples. Obviously, fungal activity has not only degraded the bordered pits but also negatively affected the secondary cell wall of the tracheids (as also shown by microscopic analysis). The higher permeability possibly promoted a faster distribution of the hot combustion gases through the wood cells. 


\subsection{INCUBATION METHOD}

The presented results demonstrate the potential of bioincising for permeability improvement of refractory wood species. An improvement of substance uptake and a deeper substance penetration into the subsurface area and border zone is possible. However, the incubation process must further be improved to

1. obtain a more homogenous substrate colonization by P. vitreus,

2. reduce incubation times,

3. improve the selectivity of $P$. vitreus towards an exclusive degradation of pit membranes.

Schwarze and Landmesser (2000) and Schwarze et al. (2008) conducted the incubations of $P$. vitreus on vermiculite that provides a wide C/N-ratio of 400/1, similar to the $\mathrm{C} / \mathrm{N}$-ratio of Norway spruce. The incubation during our experiments was done on MEA in order to promote a rapid and homogenous colonization of the wood substrate by $P$. vitreus. This nutrient medium provides a narrow $\mathrm{C} / \mathrm{N}$-ratio of about 50/1, meaning that relatively more nitrogen is available than on vermiculite. Since nitrogen is commonly the limiting parameter for a fast fungal growth (Cowling and Merrill 1966; Levi and Cowling 1969; Kirk and Yang 1979), relatively high growth rates could be triggered on MEA. But the present studies provide evidence that incubation of wood specimens on MEA results in sub-optimal conditions for a selective delignification or a selective pit membrane degradation (see also Dill and Kraepelin (1988), Rios and Eyzaguirre (1992)).

During the incubation process used in this thesis, the one-sided exposition of the specimens to the nutrient medium caused a heterogeneous moisture distribution in the substrate. The WMC and with it the water activity, $\mathrm{a}_{\mathrm{w}}$, at the bottom side of the specimens were much higher than at the three other faces. Moreover, the moisture content in the whole system was probably too low. Schubert et al. $(2009 ; 2010)$ found that water activity $\mathrm{a}_{\mathrm{w}}$ and temperature have a highly significant influence on the growth rate (see also section 3.3.1). To get a short lag phase and high growth rate, the wood moisture content should be adjusted to at least the fiber saturation point and superficial drying of the wood should be avoided by setting low air flow around the wood. It is therefore recommended to develop a closed incubation system that allows a sensitive moisture control, e.g. by sequential water spraying.

Considering these aspects and combining them with the information from $\mathrm{C} / \mathrm{N}$ ratio, it can be assumed that $P$. vitreus was subjected to certain stresses during wood colonization in my experiments. In consequence $P$. vitreus deployed an enzymatic activity which resulted in the presence of several decay patterns and a reduced selectivity towards pit membrane degradation. 
The enzymatic processes behind this heterogeneous decay pattern have not yet been fully understood. Until now, no complete essay about the enzyme production of $P$. vitreus has been published. However, it appears that $P$. vitreus produces a particular laccase system. This laccase with a mass of about 53 kiloDalton $(\mathrm{kDa})$ is closer to a bacterial laccase (40 to $60 \mathrm{kDa}$ ) than to a fungal laccase $(60$ $80 \mathrm{kDa}$ ). Moreover, P. vitreus apparently excretes little or no amounts of manganperoxidase (MP), ligninperoxidase (LP) and polygalacturonase (PG) (Schubert 2010; personal communication). Supposedly because of this specific enzyme composition, $P$. vitreus is a relatively weak lignolytic fungus that

1. causes only small mass losses during incipient period of substrate colonization and

2. potentially shows a higher selectivity towards pit membrane degradation than other white rot fungi.

On basis of the presented findings, a new incubation system was recently developed (Schwarze 2010; personal communication). This pilot installation allows a more accurate control of the mentioned parameters and is currently been tested. Preliminary results show that substrate colonization occurs more rapidly and more homogenously. Further investigations will have to show whether fungal selectivity and the homogeneity of permeability improvement are also enhanced. 


\section{CONCLUSIONS AND OUTLOOK}

Bioincising is an interesting biotechnological approach for the surface pretreatment of refractory wood species. The white rot fungus $P$. vitreus can be used to significantly improve the permeability of sapwood and heartwood of Norway spruce. Mass loss and adverse effects on mechanical properties are relatively low in comparison to other wood decay fungi. The wood surface is more susceptible for subsequent impregnation with modification substances that are able to penetrate deeper in to the subsurface layers.

Even though the installation of a new pilot incubation system by the mycologists from Empa St. Gallen is a valuable step ahead in further optimization of the incubation process, the bioincising process itself is still far away from industrial application:

- For construction purposes, big volumes of cheap standard products are required. Suitable bioreactors with sufficient capacity, sensitive process control and sterile working conditions first must be developed in order to enable an economic and efficient incubation process.

- Processing time allows bioincising only of wood surfaces. Under optimal growth conditions for $P$. vitreus, incubation times between 2 and 4 weeks seem to be feasible. However, within this relatively short period a penetration of the fungus through larger wood profiles - as used in e.g. construction timber - is hardly possible. Thus, the effect of permeability improvement is rather limited to the subsurface area and border zone of the pretreated wood.

- Process control is difficult and requires detailed biotechnological knowledge. The larger the dimensions of the incubated specimens are, the more difficult is a homogenous colonization and permeability improvement. Moreover, the risk of contamination by antagonistic microorganisms increases in larger scaled process.

- Natural variability of water activity $a_{w}$ in the treated wood. In freshly sawn timber, WMC is lower in heartwood than in sapwood. This would probably require conditioning of the wood previous to incubation in order to provide optimal moisture conditions for fungal growth.

- Until now, no feasible large scale application has been identified. Higher uptake and deeper penetration was proven for a range of different modification substances. A specific property improvement, however, could exclusively be reported for a hot melting wax that was impregnated in order in increase the surface hardness. 
- Economic aspects of the bioincising process have not been regarded so far. The combination of bioincising and subsequent surface treatment must induce such a property improvement that the market is willing to pay the additional costs which are generated by the bioincising process (Figure 15).

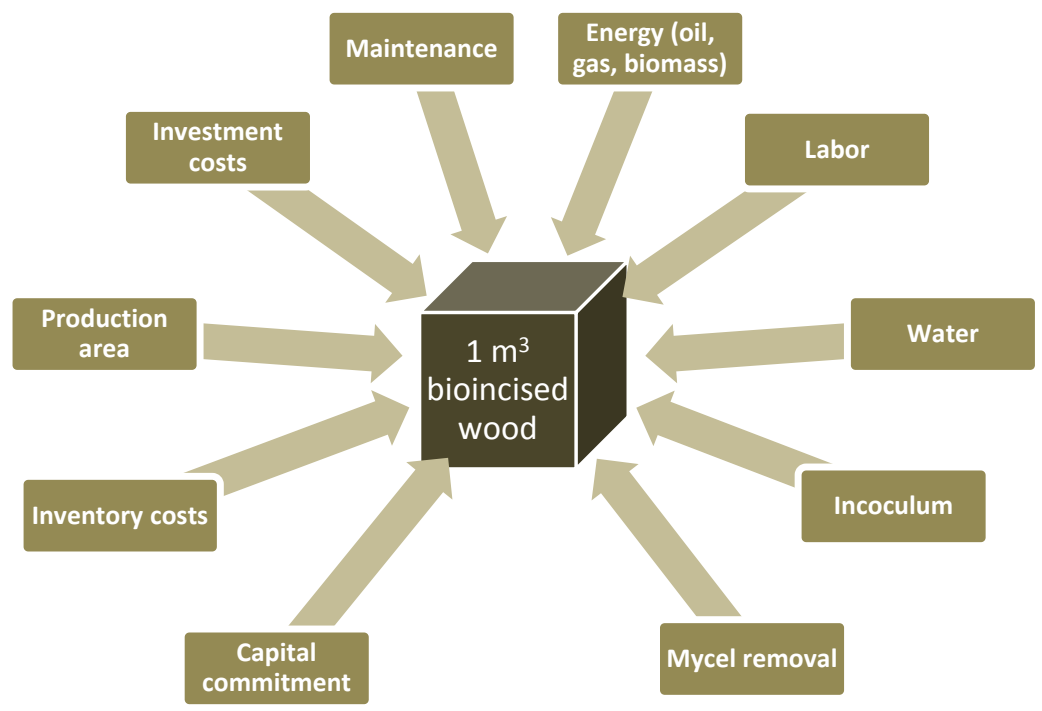

Figure 15 Possible matters of expense for the production of bioincised wood.

Thus, according to the current state of knowledge, an application of the bioincising process for specialized niche products is maybe the most probable approach. Products with smaller dimensions, lower quantities and higher value creation appear to be a feasible pathway for the closer future of bioincising. Currently, $P$. vitreus is already been successfully applied to Norway spruce wood to improve the acoustic properties of the tonewood used for music instruments such as violins (Schwarze et al. 2008; Spycher et al. 2008). 


\section{REFERENCES}

Atkins, W.P. (2000) Physikalische Chemie. Wiley-VCH, Weinheim: p. 1106.

Bailey, P.J., Preston, R.D. (1969) Some aspects of softwood permeability. Holzforschung 23: 113-120.

Bergman, R., Cai, Z., Carll, C.G., Clausen, C.A., Dietenberger, M.A., Falk, R.H., Frihart, C.R., Glass, S.V., Hunt, C.G., Ibach, R.E., Kretschmann, D.E., Rammer, D.R., Ross, R.J., Stark, N.M., Wacker, J.P., Wang, X., White, R.H., Wiedenhoeft, A.C., Wiemann, M.C., Zelinka, S.L. (2010) Wood Handbook, Wood as an Engineering Material. U.S. Department of Agriculture, Forest Service, Forest Products Laboratory, Madison, WI: p. 508.

Bradic, S., Avramidis, S. (2007) Longitudinal air permeability of pinewood with beetle transmitted blue-stain. Holz Roh-Werkst. 65: 183-185.

Cowling, E.B., Merrill, W. (1966) Nitrogen in wood and its role in wood deterioration. Canadian Journal of Botany 44: 1539-1554.

Deka, M., Gindl, W., Wimmer, R., Christian, H. (2007) Chemical modification of Norway spruce (Picea abies (L) Karst) wood with melamine formaldehyde resin. Indian J. Chem. Techn. 14: 134-138.

Dieste, A., Krause, A., Bollmus, S., Militz, H. (2008) Physical and mechanical properties of plywood produced with 1.3-dimethylol-4.5-dihydroxyethyleneurea (DMDHEU)modified veneers of Betula sp. and Fagus sylvatica. Holz Roh-Werkst. 66: 281287.

Dill, I., Kraepelin, G. (1986) Palo podrido: Model for extensive delignification of wood by Ganoderma applanatum. Appl. Environ. Microbiol. 52: 1305-1312.

Dill, I., Kraepelin, G. (1988) Degradation of Lignin/Cellulose by White-rot Fungi: Influence of Specific Ecological Factors [Der Abbau von Lignin/Cellulose durch Weiss-

-Pilze: Einfluss spezifischer ökologischer Faktoren]. Forum Mikrobiologie 11: 484-489.

Donath, S., Militz, H., Mai, C. (2006) Creating water-repellent effects on wood by treatment with silanes. Holzforschung 60: 40-46.

EN 335-2 (2006) Durability of wood and wood-based products - Definition of use classes - Part 2: Application to solid wood. CEN European Committee for Standardization.

EN 350-2 (1994) Durability of wood and wood-based products - Natural durability of solid wood - Part 2: Guide to natural durability and treatability of selected wood species of importance in Europe. CEN European Committee for Standardization.

EN 351-1 (2007) Durability of wood and wood-based products - Preservative-treated solid wood - Part 1: Classification of preservative penetration and retention. CEN European Committee for Standardization.

EN 460 (1994) Durability of wood and wood-based products - Natural durability of solid wood. Guide to the durability requirements for wood to be used in hazard classes. CEN European Committee for Standardization.

Feist, W.C., Hon, D.N.-S. 1984. Chemistry of weathering and protection. In: Rowell, R.M., ed. The Chemistry of Solid Wood, Advances in Chemistry Series No. 207. American Chemical Society, Washington, DC. Eds.: pp. 401-451.

Flynn, K.A. (1995) A review of the permeability, fluid flow, and anatomy of spruce (Picea spp.). Wood Fiber Sci. 27: 278-284.

Gindl, W., Gupta, H.S. (2002) Cell-wall hardness and Young's modulus of melaminemodified spruce wood by nano-indentation. Composites Part A: Applied Science and Manufacturing 33: 1141-1145. 
Hacke, U.G., Sperry, J.S., Pittermann, J. (2004) Analysis of circular bordered pit function II. Gymnosperm tracheids with torus-margo pit membranes. Am. J. Bot. 91: 386400.

Hagstrand, P.O. (1999) Mechanical analysis of melamine-formaldehyde composites. Ph.D. thesis, Chalmers University of Technology, Gothenburg, Sweden: $\mathrm{p} 44$.

Hill, C.A.S. (2006) Wood modification: chemical, thermal and other processes. John Wiley \& Sons Ltd, The Atrium, Southern Gate Chichester, UK: p. 260.

Jirous-Rajkovic, V., Turkulin, H., Miller, E.R. (2004) Depth profile of UV-induced wood surface degradation. Surf. Coating Int. B Coating. Trans. 87: 241-247.

Johnson, B.R. (1979) Permeability changes induced in three western conifers by selective bacterial inoculation. Wood and Fiber 11: 10-21.

Keith, C.T., Chauret, G. (1988) Anatomical studies of CCA penetration associated with conventional (tooth) and with micro (needle) incising. Wood Fiber Sci. 20: 197208.

Kirk, T.K., Schultz, E., Connors, W.J. (1978) Influence of culture parameters on lignin metabolism by Phanerochaete chrysosporium. Arch. Microbiol. 117: 277-285.

Kirk, T.K., Yang, H.H. (1979) Partial delignification of unbleached kraft pulp with ligninolytic fungi. Biotechnology Letters 1: 347-352.

Kobayashi, Y. (1998) Drying and anatomical characteristics of sugi wood attacked by bacteria during pond storage. J. Wood Sci. 44: 432-437.

Levi, M.P., Cowling, E.B. (1969) Role of nitrogen in wood deterioration. VII. Physiological adaptation of wood-destroying and other fungi to substrates deficient in nitrogen. Phytopathology 59: 460-468.

LFI (2010) National forest inventory, Switzerland. Landesforstinventar 3, Internet: www.lfi.ch, date of acquisition: 3.12.2010.

Liese, W., Bauch, J. (1967a) On the closure of bordered pits in conifers. Wood Sci. Technol. 1: 1-13.

Liese, W., Bauch, J. (1967b) On anatomical causes of refractory behaviour of spruce and Douglas fir. J. I. Wood Sci. 4: 3-14.

Mai, C., Nguyen, H.M., Donath, S., Weigenand, O., Militz, H. (2007) Neuartige Systeme zur Hydrophobierung von Holz in der Außenanwendung. 25. Holzschutz-Tagung der DGfH am 20. und 21. September 2007 in Biberach/Riß: 73-85.

Messner, K., Bruce, A., Bongers, H.P.M. (2003) Treatability of refractory wood species after fungal pre-treatment. In: Proceedings of the Second European Conference on Wood Modification 2003, Göttingen: 389-401.

Militz, H. (1993) Enzymatische Behandlungen von Fichtenrund- und Schnittholz zur Verbesserung der Tränkbarkeit. Holz Roh-Werkst. 51: 339-346.

Militz, H., Schaffert, S., Peters, B.C., Fitzgerald, C.J. (2010) Termite resistance of DMDHEU-treated wood. Wood Sci. Technol.: 1-11.

Miroy, F., Eymard, P., Pizzi, A. (1995) Wood hardening by methoxymethyl melamine. Holz Roh-Werkst. 53: 276.

Morris, P.I., Morrell, J.J., Ruddick, J.N.R. (1994) A Review of Incising as a Means of Improving Treatment of Sawnwood. Int. J. Res. Group Wood Preserv.: 1-24.

Nicholas, D.D., Thomas, R.J. (1968) The influence of enzymes on the structure and permeability of loblolly pine. Proceedings of the American Wood Preservers' Association 64: 1-7.

Nijdam, J.J., Lehmann, E., Keey, R.B. (2001) Bacterial treatment of Pinus radiata timber to improve permeability. Proceedings of the 2nd Inter-American Drying Conference, July 8-10, 2001, Veracruz, Mexico.: 1-11.

Olsson, T., Megnis, M., Varna, J., Lindberg, H. (2001) Study of the transverse liquid flow paths in pine and spruce using scanning electron microscopy. J. Wood Sci. 47: 282-288. 
Perrin, P.W. (1978) Review of incising and its effects on strength and preservative treatment of wood. Forest Prod. J. 28: 27-33.

Rapp, A.O., Bestgen, H., Adam, W., Peek, R.D. (1999) Electron energy loss spectroscopy (EELS) for quantification of cell-wall penetration of a melamine resin. Holzforschung 53: 111-117.

Reid, I.D. (1983) Effects of nitrogen supplements on degradation of aspen wood lignin and carbohydrate components by Phanerochaete chrysosporium. Appl. Environ. Microbiol. 45: 830-837.

Reinprecht, L., Pánek, M. (2008) Bio-treatment of spruce wood for improving of its permeability and soaking. Pt.1: Direct treatment with the bacterium Bacillus subtilis. Wood Res-Slovakia 53: 1-12.

Richardson, B.A. (2001) Wood preservation. 2nd edition, repr. Spon Press, London: p. 226.

Richter, K. (1989) Perforation and impregnation methods to improve weather resistance of structural timber. Empa Research and working report 115/19, Dübendorf, Switzerland: 1-44.

Rios, S., Eyzaguirre, J. (1992) Conditions for selective degradation of lignin by the fungus Ganoderma australis. Appl. Microbiol. Biotechnol. 37: 667-669.

Rosner, B., Messner, K., Tucker, E., Bruce, A. (1998) Improved preservative penetration of spruce after pretreatment with selected fungi. I. Fungal pretreatment of pole sections. Int. J. Res. Group Wood Preserv.: 1-14.

Rowell, R.M. (2005) Handbook of Wood Chemistry and Wood Composites. CRC Press, Florida, USA: p. 487

Rypacek, V. (1966) Biologie holzzerstörender Pilze. Gustav Fischer Verlag, Jena: p. 211.

Salin, J.G. (2006) Drying of sapwood analyzed as an invasion percolation process. Maderas: Ciencia y Tecnologia 8: 149-158.

Schmidt, O., Liese, W., Moreth, U. (1996) Decay of timber in a water cooling tower by the basidiomycete Physisporinus vitreus. Material und Organismen 30.

Schmidt, O., Schmitt, U., Moreth, U., Potsch, T. (1997) Wood decay by the white-rotting basidiomycete Physisporinus vitreus from a cooling tower. Holzforschung 51: 193-200.

Schmidt, O. (2006) Wood and tree fungi. Springer Verlag, Berlin, Heidelberg: p. 334.

Scholz, G., Krause, A., Militz, H. (2010a) Full impregnation of modified wood with wax (Volltränkung modifizierten Holzes mit Wachs). European Journal of Wood and Wood Products: Article in press.

Scholz, G., Van Den Bulcke, J., Boone, M., Zauer, M., BÃøucker, E., Van Acker, J., Militz, H. (2010b) Investigation on wax-impregnated wood. Part 1: Microscopic observations and 2D X-ray imaging of distinct wax types. Holzforschung 64: 581-585.

Schubert, M., Dengler, V., Mourad, S., Schwarze, F.W.M.R. (2009) Determination of optimal growth parameters for the bioincising fungus Physisporinus vitreus by means of response surface methodology. J. Appl. Microbiol. 106: 1734-1742.

Schubert, M., Mourad, S., Schwarze, F. (2010) Radial basis function neural networks for modeling growth rates of the basidiomycetes Physisporinus vitreus and Neolentinus lepideus. Appl. Microbiol. Biotechnol. 85: 703-712.

Schubert, M. (2010; personal communication) Empa - Swiss Federal Laboratories for Materials Science and Technology. Working group for wood protection and biotechnology: 12. November 2010.

Schwarze, F.W.M.R., Landmesser, H. (2000) Preferential degradation of pit membranes within tracheids by the basidiomycete Physisporinus vitreus. Holzforschung 54: 461-462. 
Schwarze, F.W.M.R., Landmesser, H., Zgraggen, B., Heeb, M. (2006) Permeability changes in heartwood of Picea abies and Abies alba induced by incubation with Physisporinus vitreus. Holzforschung 60: 450-454.

Schwarze, F.W.M.R. (2008) Procedure and composition for the improvement of the uptake and distribution of soaking compositions in woods. EP1681145, Empa Swiss Federal Laboratories for Materials Science and Technology, Überlandstrasse 129, 8600 Dübendorf, CH.

Schwarze, F.W.M.R., Spycher, M., Fink, S. (2008) Superior wood for violins - Wood decay fungi as a substitute for cold climate. New. Phytol. 179: 1095-1104.

Schwarze, F.W.M.R. (2010; personal communication) Empa - Swiss Federal Laboratories for Materials Science and Technology. Working group for wood protection and biotechnology: 1. November 2010.

Siau, J.F. (1984) Transport Processes in Wood. Springer Verlag, Heidelberg, Germany: p. 245.

Siau, J.F. (1995) Wood: Influence of moisture on physical properties. Dep. of Wood Science and Forest Products, Virgnia Polytechnic Institute and State University, USA: p. 227.

Spycher, M., Schwarze, F., Steiger, R. (2008) Assessment of resonance wood quality by comparing its physical and histological properties. Wood Sci. Technol. 42: 325342.

Thoemen, H., Klueppel, A. (2008) An investigation on the permeability of different wood furnish materials. Holzforschung 62: 215.

Thomas, R.J., Kringstad, K.P. (1971) The role of hydrogen bonding in pit aspiration. Holzforschung 25: 143-149.

UNECE/FAO (2010) Forest products annual market review 2009-2010. United Nations Economic Comission for Europe/ Food and Agriculture Organization of the United Nations Geneva timber and forest study paper 25: 188.

Ünligil, H.H. (1972) Penetrability and strength of white spruce after ponding. Forest Prod. J. 22: 92-100.

Wagenführ, R. (2007) Holzatlas. 6. Fachbuchverlag im Carl Hanser Verlag, Leipzig: p. 816.

Wang, Z., Leone, R., Breuil, C. (1997) Why fungal growth is less effective in aspen heartwood than in aspen sapwood. Material und Organismen 31: 145-155.

Xie, Y., Krause, A., Militz, H., Turkulin, H., Richter, K., Mai, C. (2007) Effect of treatments with 1,3-dimethylol-4,5-dihydroxy-ethyleneurea (DMDHEU) on the tensile properties of wood. Holzforschung 61: 43-50.

Yasuda, R., Minato, K. (1994) Chemical modification of wood by non-formaldehyde cross-linking reagents - Part 1 . Improvement of dimensional stability and acoustic properties. Wood Sci. Technol. 28: 101-110.

Yasuda, R., Minato, K., Norimoto, M. (1994) Chemical modification of wood by nonformaldehyde cross-linking reagents - Part 2. Moisture adsorption and creep properties. Wood Sci. Technol. 28: 209-218.

Zabel, R.A.Z., Morrell, J.J. (1992) Wood microbiology: decay and its prevention. Academic Press Inc., San Diego: p. 476. 


\section{LIST OF FIGURES}

Figure 1 Schematic of different zones of the wood surface used to describe liquid penetration in radial and tangential directions (Paper II). 2

Figure 2 Bordered pits act as interconnecting voids between adjacent tracheids. After aspiration, the torus restricts the flow of fluids (Paper II)......................................................... 4

Figure 3 Representative growth curve of a wood decay fungus ................................................ 6

Figure 4 Major fields of research during optimization and upscaling of the bioincising process.

Figure 5 Above: Schematic illustration of incubation setup (Paper V).

Figure 6 Transverse sections of Norway spruce wood after 9 weeks incubation with Physisporinus vitreus (Paper III).

Figure 7 Intensity of Physisporinus vitreus activity on bordered pits, half bordered pits and tracheid cell wall after different incubation times (Paper III).

Figure 8 Schematic illustration of the gas permeability measurement device used in the present study.

Figure 9 Gas permeability of Norway spruce heartwood after 3, 5, 7, and 9 weeks incubation with Physisporinus vitreus. 16

Figure 10 Hydrophobation substance uptake of Norway spruce sapwood (SW) and heartwood (HW) after 3, 5, 7, and 9 weeks incubation with Physisporinus vitreus. .......... 18

Figure 11 Transverse sections of Norway spruce heartwood after incubation with Physisporinus vitreus and subsequent impregnation with hydrophobation substances. 18

Figure 12 Weight percent gain (WPG) of different surface hardness modification substances into heartwood of Norway spruce after six weeks of bioincising and vacuum impregnation.

Figure 13 Brinell hardness of bioincised wood (six weeks of incubation) after impregnation with different substances for surface hardness improvement.

Figure 14 Cross sections of Norway spruce heartwood after six weeks incubation with Physisporinus vitreus and subsequent impregnation with surface hardness improving substances. 22

Figure 15 Possible matters of expense for the production of bioincised wood. 26 


\section{LIST OF TABLES}

Table 1 Wood preservation and wood modification treatments according to the required penetration depth of the applied substance (extracted from Paper II)................................... 2

Table 2 Work packages and analytical methods that were applied. . .12 
Annex

\section{ANNEX}

Paper I Bioincised wood as substrate for surface modifications.

Paper II A review on promising approaches for liquid permeability improvement in softwoods.

Paper III Anatomy of bioincised Norway spruce wood.

Paper IV Resistance of bioincised wood treated with wood preservatives to blue-stain and wood-decay fungi.

Paper V Effect of Physisporinus vitreus on wood properties of Norway spruce. Part 1: Aspects of delignification and surface hardness.

Paper VI Effect of Physisporinus vitreus on wood properties of Norway spruce. Part 2: Aspects of microtensile strength and chemical changes 




\title{
Bioincised wood as substrate for surface modifications
}

\author{
Christian Lehringer ${ }^{1}$, Martin Arnold ${ }^{1}$, Klaus Richter ${ }^{1}$, Mark Schubert ${ }^{1}$, \\ Francis W.M.R. Schwarze ${ }^{1}$, Holger Militz ${ }^{2}$ \\ ${ }^{1}$ Empa, Swiss Federal Laboratories for Materials Testing and Research, Wood Laboratory, \\ Dübendorf/St. Gallen, Switzerland [email: christian.lehringer@empa.ch] \\ ${ }^{2}$ Georg-August University Göttingen, Wood Biology and Wood Products, Germany \\ [email: hmilitz@gwdg.de]
}

Keywords: Bioincising, Norway spruce, Penetration depth, Permeability, Uptake

\begin{abstract}
The aspiration of bordered pits during drying of wood is the most important reason for a limited impregnability of Norway spruce (Picea abies (L.) Karst.). Incubation of this wood species with the white rot fungus Physisporinus vitreus for a period of 6 weeks (Bioincising) improves significantly the subsequent uptake of liquid modification substances. There is evidence that the enhanced permeability is caused by a selective degradation of bordered pit membranes during the initial period of substrate colonization. It is suggested that the bioincised material can be impregnated more efficiently with surface modification substances. For a successful upscaling to industrial application, a uniform colonization of the substrate and controlled fungal activity must be achieved to ensure a homogenous distribution of wood modification substances. The present paper identifies the influence of Bioincising on the uptake of liquid modification substances. As example, preliminary results from flame resistance tests are presented that showed a negative effect of Bioincising on the target property. A better understanding of fungus growth in wood and the optimization of the Bioincising process is needed to improve the treatability of Norway spruce with surface modification substances.
\end{abstract}

\section{INTRODUCTION}

The limited impregnability of Norway spruce (Picea abies (L.) Karst.) is mainly caused by the aspiration of bordered pits during wood drying. The bordered pits represent the interconnecting pathways for liquids between adjacent tracheids. To reopen the wood structure for a subsequent treatment with wood preservatives or wood modification substances, various incising techniques have been developed (Hansmann et al. 2002). Earlier work based on biotechnological concepts such as fungi pre-treatment (Messner et al. 2003) or technical enzymes (Militz 1990) showed a positive effect on impregnability of spruce sapwood. Despite first promising results, transfer to industrial application was not achieved. Moreover, the effect on spruce heartwood was comparably low.

In contrast, the inoculation of coniferous wood with the white rot fungus Physisporinus vitreus induces a selective degradation of bordered pits in sapwood and heartwood during early stages of colonization. As a consequence, incubation of Norway spruce heartwood with $P$. vitreus for a period of 6 weeks resulted in a significant enhanced uptake of water, while impact bending strength was reduced only negligibly (Schwarze et al. 2006). Hence, the so called Bioincising process could be a promising approach to 
improve the uptake of preservatives and wood modification substances into the heartwood of refractory species, such as Norway spruce.

\section{Biotechnological parameters}

Based on promising findings from previous laboratory investigations (Schwarze et al. 2006), an industry cooperation project was launched with the objective of scaling up the Bioincising process to industrial scale. For this purpose, detailed knowledge about the biotechnological parameters and their sensitive control during incubation determine the optimization of the inoculation with P. vitreus. In this context, Schubert et al. (2008) conducted a parameter analysis using the Response Surface Methodology (RSM) and found a strong influence of substrate humidity (water activity $\mathrm{a}_{\mathrm{w}}$ ) on the growth of $P$. vitreus. Moreover, the study showed that $P$. vitreus is highly susceptible to contaminations during the initial growth phase of substrate colonization. This has a negative influence on the homogeneity of colonization. To reduce the contamination rate the incubation of wood in bioreactors after sterilisation is currently being evaluated. Anyhow, for industrial applications a feasible and cost efficient technology has to be developed.

\section{Surface modification on bioincised wood}

In addition to the investigation of the biotechnological principles, the biologically modified wood is presently being characterized as a substrate and possible applications for surface modification on this new material are evaluated. Depending on the target property to be improved, certain penetration depths and a high uniformity of treatment have to be achieved.

In the present paper, the influence of Bioincising on subsequent substance uptake and average penetration depth is discussed. Additionally, on base of preliminary flame resistance tests the interaction between the bioincised wood and wood surface modification substances is presented.

\section{EVALUATION OF THE BIOINCISED MATERIAL}

\section{Material and methods}

Wood samples ( $30 \times 40 \times 15 \mathrm{~mm}$, length $\times$ width $\mathrm{x}$ height) of Norway spruce (Picea abies) were incubated for 6 weeks and then (as well as control samples) treated with a range of wood modification substances to improve hydrophobicity and fire resistance.

The aqueous substances were applied to the material by brushing, dipping (30 minutes) and vacuum impregnation (20 min, $7 \mathrm{mBar}$ ). Five hydrophobisation agents and three flame retardants were used, all of them commercial products. To avoid major capillary uptake, the endgrain surfaces were sealed with a polyurethane coating prior to treatment. All substances were stained with fluorescence dye Rhodamin for microscopic analysis.

The total substance uptake of the samples was measured gravimetrically directly after treatment. For a better comparability of the results, the uptake data were recalculated to $\mathrm{kg} / \mathrm{m}^{3}$. For the evaluation of the penetration depth, the samples were cut in transverse sections that then were planed with a microtome knife. Fluorescence photographs were taken at $2.5 \mathrm{x}$ magnification under a microscope.

Fire resistance was measured by exposing the treated samples horizontally to a propane flame for $3 \mathrm{~min}$. After removing the char, mass loss was determined gravimetrically. 


\section{Results for uptake and penetration of hydrophobisation substance}

After brushing and dipping no or little effect of Bioincising on the uptake was observed, whereas a significantly higher retention was apparent when the samples were impregnated in a vacuum chamber (Figure 1). The bioincised material revealed a much higher variance.

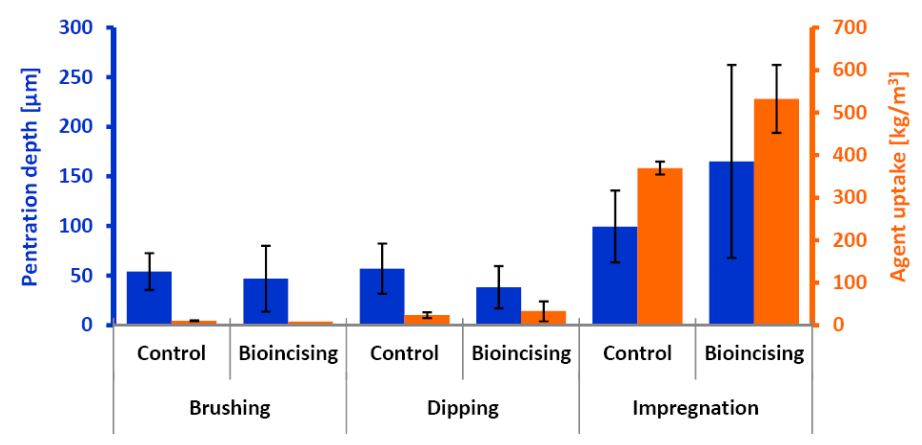

Figure 1: Liquid substance uptake and average penetration depth in bioincised material

Brushed and dipped samples showed a substance penetration into the sub-surface of only two or three cell rows $(40-60 \mu \mathrm{m})$. In contrast, impregnation resulted in a deeper penetration, which was even more pronounced in bioincised wood (Figure 2). Local distribution and penetration depth of the applied substances varied strongly for all application methods, especially for the bioincised samples.

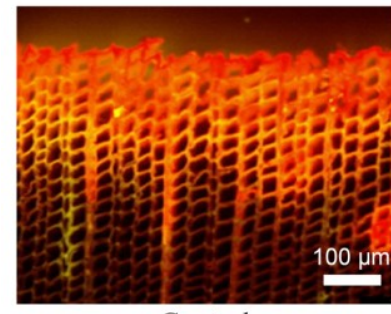

Control

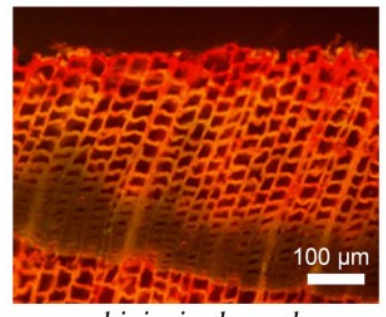

bioincised wood

Figure 2: Microscopic photographs of impregnated samples (commercial hydrophobisation substance)

\section{Results for flame resistance of bioincised and fire protected wood}

Preliminary tests for flame resistance revealed that a higher uptake of substances in bioincised wood did not automatically result in an improvement of wood surface properties (Figure 3).

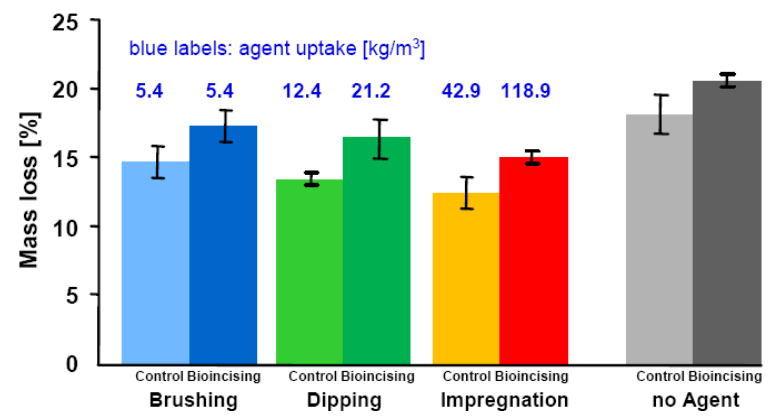

Figure 3: Mass loss during 3 min burning test of fire protected wood

The uptake of flame retardants by the bioincised material was significantly improved for dipping and impregnation. But despite of that fact, a significantly higher mass loss was measured for all treated, bioincised samples. Anyhow, comparison with the untreated controls showed significantly, that the flame retardant performed well. Most probably 
the Bioincising process affected the cell wall structure in a manner that promotes flammability. Possible reasons could be a change in the chemical composition of the cell wall by $P$. vitreus and hence a reduction of density and a delignification of the inner secondary wall. Another hypothesis is that the reopened bordered pits promote the faster distribution of hot gases within the cellular system. Further work is in progress to reveal the exact reasons.

\section{CONCLUSIONS}

Bioincising of Norway spruce wood for 6 weeks resulted in an enhanced uptake of liquid substances after vacuum impregnation. The selective degradation of bordered pits by Physisporinus vitreus activity is regarded as reason for this effect. Due to the heterogeneous colonization of the substrate, substance uptake and penetration depths varied strongly.

Preliminary tests on bioincised wood showed a negative effect for a subsequent modification of selected properties, such as flame resistance. Most probably, fungus activity has not only degraded the bordered pits but also delignified the inner secondary wall. These possible negative effects of fungal degradation on the cell wall will be subject of future work. Furthermore the ingress of the wood modification substances through cellular system is currently being elucidated.

The optimization of the Bioincising process is still in progress; therefore, the present results are indicative. A profound understanding of wood-fungus-interactions on wood permeability will help to optimize the treatment of the bioincised wood with surface modification substances.

\section{ACKNOWLEDGEMENTS}

The authors like to express their gratitude for the support by the partners of the research project "Bioincising of softwoods with Physisporinus vitreus". Financial support by the Swiss Confederation's innovation promotion agency (CTI) is gratefully acknowledged.

\section{REFERENCES}

Hansmann, C., Gindl, W., Wimmer, R. and Teischinger, A. (2002). Permeability of wood - A review. Drevarsky Vyskum/Wood Research 47(4): 1-16.

Messner, K., Bruce, A. and Bongers, H. P. M. (2003). Treatability of refractory wood species after fungal pre-treatment. Proceedings of the European Conference on Wood Modification 2003: 389-401.

Militz, H. (1990). Die Verbesserung der Imprägnierbarkeit von Fichtenholz mittels enzymatischer und chemischer Vorbehandlung. Dissertation, Landbouwuniversiteit Wageningen, Netherlands: 220.

Schubert M., Dengler V., Mourad S. and. Schwarze, F.W.M.R. (2009) Determination of optimal growth parameters for the bioincising fungus Physisporinus vitreus by means of response surface methodology. Journal of Applied Microbiology, In Press

Schwarze, F. W. M. R., Landmesser, H., Zgraggen, B. and Heeb, M. (2006). Permeability changes in heartwood of Picea abies and Abies alba induced by incubation with Physisporinus vitreus. Holzforschung 60(4): 450-454. 



\title{
A REVIEW ON PROMISING APPROACHES FOR LIQUID PERMEABILITY IMPROVEMENT IN SOFTWOODS
}

\author{
Christian Lehringer* \\ PhD Student \\ Klaus Richter $\dagger$ \\ Head of Wood Laboratory \\ Francis W. M. R. Schwarze \\ Senior Scientist \\ Empa, Swiss Federal Laboratories for Materials Testing and Research \\ Dübendorf/St. Gallen, Switzerland \\ Holger Militz \\ Head of Department \\ Institute for Wood Biology and Wood Products \\ Georg-August-University \\ Göttingen, Germany \\ (Received April 2009)
}

\begin{abstract}
The low liquid permeability of refractory wood species such as Norway spruce [Picea abies (L.) Karst.] and white Fir (Abies alba) is related mainly to the aspiration of bordered pits during wood drying. The resulting low permeability complicates treatments with liquid preservatives or wood modification substances. This article provides a literature review on various mechanical and biotechnological approaches that were developed for improving liquid permeability. In this context, we focus on the incubation of Norway spruce wood with a white rot fungus, Physisporinus vitreus (Pers.) P. Karst. The process is termed "bioincising" and results in a significant increase in wood permeability. This is most probably caused by the selective degradation of bordered pit membranes and simple pits of xylem ray parenchyma during the initial period of wood colonization. Subsequently, we discuss how bioincising could be a potential pretreatment method for wood preservation and selected wood modification substances. Considering that these wood modification systems require specific penetration depths for optimal performance, we discuss the capability of bioincising to enhance permeability at the required penetration depths. In this regard, we propose a terminology for better differentiation of penetration depths by liquid substances into the wood.
\end{abstract}

Keywords: Bioincising, impregnation, penetration depth, permeability improvement, wood modification.

\section{INTRODUCTION}

Permeability represents a material property that is of specific importance for different technical processes in the wood industry. Not only for preservative impregnation, but also for pulping and wood drying, the permeability of wood to gases and liquids influences the design of indus-

\footnotetext{
* Corresponding author: christian.lehringer@empa.ch $\uparrow$ SWST member
}

trial wood processing procedures. Furthermore, the application of substances to enhance selected wood properties such as hardness, UV stability, water and vapor repellency, dimensional stability, and fire resistance requires a movement of liquids into the wood to different depth levels.

Permeability determines the flow of liquid or gaseous phases through a solid medium. Siau (1984) defines permeability as a measure of the ease with which fluids are transported through a 
porous solid under the influence of a pressure gradient. The pore size and distribution, but even more so, the degree of pore interconnectivity (tortuosity), influences the material permeability.

In softwoods, bordered pits act as interconnecting pathways between adjacent tracheids. During wood drying, a large number of the bordered pits are aspirated. This occurs as a result of pressure differences between the tracheids. Hence, the liquid permeability of, for example, Norway spruce [Picea abies (L.) Karst.] is reduced to $1-5 \%$ of that of green wood (Messner et al 2003). Although this so-called pit aspiration is an efficient response of the living tree to counteract embolism in the water-conducting sapwood, it presents an undesirable obstacle for treatment of the wood with liquid substances. To overcome the problem, ample research on transport processes, pit aspiration mechanisms, and permeability improvement on Norway spruce has been conducted (Liese and Bauch 1967; Petty 1970; Palin and Petty 1981; Flynn 1995; Hansmann et al 2002). Besides numerous mechanical incising and drilling techniques for reopening the wood structure for subsequent impregnation, several biotechnological approaches have been developed on the basis of bacterial, enzymatic, or fungal activity (Militz 1993b; Nijdam et al 2001; Messner et al 2003; Reinprecht and Pánek 2008). One of the latest approaches is the incubation of Norway spruce with the white-rot fungus Physisporinus vitreus (Pers.) P. Karst over a period of approximately 6 wk (Schwarze et al 2006). During its initial period of colonization, this fungus apparently selectively degrades the pit membranes. The permeability is significantly improved without severe strength losses by "bioincising."

In this article, we give an overview of the mechanisms that lead to a reduction of permeability in softwoods. Fundamentals of flow in porous media like wood are briefly discussed before we present different techniques for the improvement of wood permeability. The bioincising process is then outlined as a potential technique to improve the permeability to specific depths of the wood substrate. Regarding this differentia- tion, we suggest that certain wood modification systems require specific penetration depths. For example, substances for UV and visible light protection have to penetrate only the subsurface area, whereas substances for dimension stability have to penetrate the wood at much deeper levels for positive effects. When adapted to these specific requirements, bioincising can be a potential technique to customize the depth of penetration for the target property, which can be improved by the subsequent treatment. Therefore, bioincising is discussed in the context of permeability improvement to specific levels of depth and selected wood modification techniques. To provide an understanding for discussion, we further suggest terminology for the precise differentiation of penetration depths in the wood.

\section{PERMEABILITY OF SOFTWOODS}

\section{Role of Pits for Fluid Transport in Wood}

In the xylem of living softwoods, fluid transport occurs primarily in the longitudinal direction through the axially oriented tracheid lumina that are interconnected with fields of bordered pits in their tapered end walls (Hacke et al 2004). During preservative treatment or drying of wood, the same pathways are used for fluid transport in longitudinal and transverse directions. In these directions, flow paths are controlled by the bordered pits, whereas the horizontally aligned rays constitute the main pathways for flow in the radial direction during impregnation (Wardrop and Davies 1961; Liese and Bauch 1967; Comstock and Coté 1968; Comstock 1970; Richter and Sell 1992; Matsumura 1999; Usta and Hale 2006). Flow in the tangential and radial directions is much less than in the longitudinal direction (Lihra et al 2000; Usta and Hale 2004; Tarmian and Perré 2009). The spreading of fluids from xylem ray elements to longitudinal tracheids (and vice versa) is still under discussion (Olsson et al 2001). Characteristics of the cross-field pits and the structure of ray tissue vary greatly among softwood species; hence, the transverse permeability depends on the number 
and size of ray parenchyma and ray tracheids. Simple pits between the ray parenchyma cells restrict fluid transport because the pit membranes can only be penetrated by diffusion or through plasmodesmata (Fujikawa and Ishida 1975). Moreover, deposited extractives are believed to reduce permeability of ray parenchyma cells (Olsson et al 2001). Some authors have shown that the transport in ray parenchyma is important (Wardrop and Davies 1961; Keith and Chauret 1988), whereas others state the contrary (Bailey and Preston 1969). The ray tracheids on the outermost position of the ray tissue have been found to act as important transport paths during impregnation (Liese and Bauch 1967; Olsson et al 2001). Similarly as between longitudinal tracheids, fluid transport in ray tracheids occurs through bordered pits.

The bordered pits of the longitudinal tracheids substantially determine the permeability of a softwood species. In reaction to different pressure levels in adjacent tracheids during the drying of wood, the pit is aspirated with the margo and torus attached to the inner wall of the pit opening (Fig 1). Aspiration is considered irreversible because of the formation of hydrogen bonds between the torus/margo and the pit opening. These forces are seldom overcome by high pressures during processing (Liese and Bauch 1967; Thomas and Kringstad 1971).

Permeability is reduced not only during drying process, but also during heartwood formation in the living tree. Inorganic constituents and ligno complex substances incrust the cell walls and the torus and margo of bordered pits. Consequently, MC in the heartwood of the living tree is reduced, resulting in some level of pit aspiration. Furthermore, depositions of hydrophobic organic wood extractives occlude the pit membranes (Comstock 1965; Bamber and Fukazawa 1985; Mantanis and Young 1997).

After drying wood, the latewood regions commonly have a higher permeability than the earlywood (Kininmonth 1971; Siau 1995). Pits in latewood have thicker strands, a tighter margo texture, smaller diameters, a higher degree of lignifications, and denser configuration of the pit chamber, resulting in a higher stiffness. Furthermore, because of the thicker cell walls in latewood, the torus must move a greater distance to aspirate. As a consequence, the necessary forces for deflection and adhesion need to be greater, and fewer pits in the latewood are aspirated during drying. Although dry latewood contains fewer and smaller pits, it is more permeable than seasoned earlywood in which the pits tend to aspirate faster during drying. In the green conditions, this relation is reversed, in which the larger pits in earlywood are not aspirated and permit a higher bulk flow (Liese and Bauch 1967; Erickson 1970; Flynn 1995; Hansmann et al 2002).

Resin canals and intercellular spaces also play a certain role in softwood impregnation, because fluids penetrate the void spaces and then enter the adjacent tracheids (Koran 1989). Although
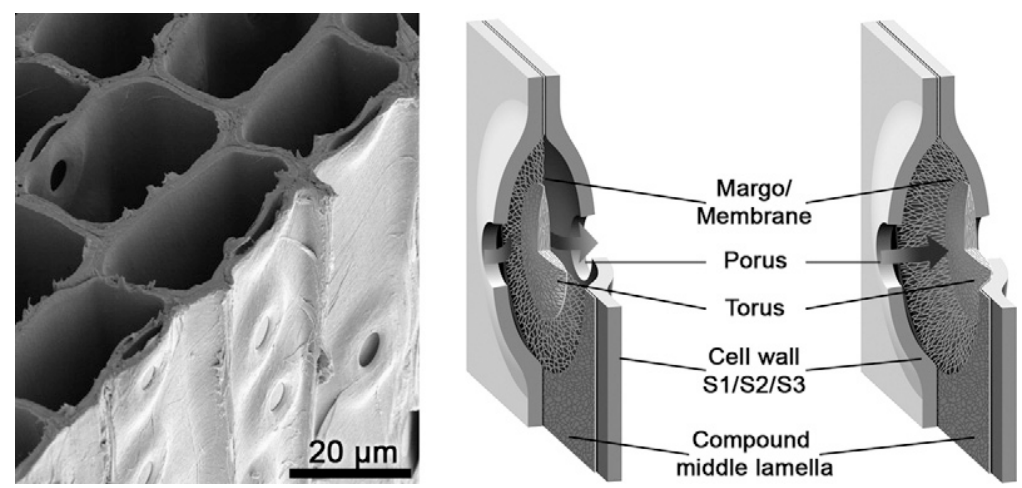

Figure 1. Bordered pits act as interconnecting voids between adjacent tracheids. After aspiration, the torus restricts fluid flow. 
pit interaction is not directly involved, we mention these pathways at this point to complete the description of fluid movement through softwoods.

\section{Flow Through Porous Media}

According to Siau (1984), the transport of fluids can be separated into bulk flow and diffusion. Although bulk flow through interconnected cell lumina is vital for impregnation of wood with liquid preservatives, the diffusion processes are more important for kiln drying of wood. Bulk flow is mainly determined by permeability, which itself is related to the porosity of a system and the size and quantity of openings that interconnect the single pores (tortuosity).

The description of viscous liquid transport through wood is commonly defined by Darcy's law, which states a direct dependency of the media to a pressure gradient:

$$
k=\frac{\text { Flux }}{\text { Gradient }}=\frac{Q / A}{\Delta P / L}=\frac{Q L}{A \Delta P}
$$

where $\mathrm{k}=$ permeability $\left(\mathrm{m}^{4} / \mathrm{N} \cdot \mathrm{s}\right), \mathrm{Q}=$ volumetric flow rate $\left(\mathrm{m}^{3} / \mathrm{s}\right), \mathrm{L}=$ length of specimen in the flow direction $(\mathrm{m}), \mathrm{A}=$ cross-sectional area of specimen perpendicular to the flow direction $\left(\mathrm{m}^{2}\right)$, and $\Delta \mathrm{P}=$ pressure differential $(\mathrm{Pa})$.

Wood anisotropy, interaction between fluid and substrate, pit aspiration, plugging of pits and pores with bubbles or particles, turbulent flow, occurrence of molecular slip effects, or fluid compressibility require an adaptation of $\mathrm{Eq} 1$ for a realistic determination of wood permeability. Several works present an overview on determining permeability of wood (Resch and Ecklund 1964; Banks 1981; Siau 1984; Hansmann et al 2002).

\section{TECHNIQUES FOR THE IMPROVEMENT OF LIQUID PERMEABILITY}

\section{Mechanical Opening of the Wood Structure}

Incising of refractory wood species such as Norway spruce is a well-established technique to mechanically open the wood structure for subsequent impregnation or drying (Keith and Chauret 1988; Richter 1989; Morris et al 1994). Different perforation systems using needles, drills, slit discs, lasers, and water jets have been reported (Richter 1989). However, visible marks on the wood surface and strength losses are considered to be disadvantageous for certain wood products. Microwave treatments have also been attempted (Terziev 2002; Li et al 2005; Merenda and Holan 2008). In this technique, the induced destruction of bordered pits facilitated the penetration of liquids, but the mechanical properties were presumably negatively altered. In North America, mechanical incising technologies are widely used for the pretreatment of sawn wood, whereas in Europe, they are mostly limited to the air-soil zone treatment of poles.

\section{Reversing Pit Aspiration}

The irreversibility of bordered pit aspiration is considered to be caused by strong forces induced by hydrogen bonding between the margo/torus and the adjacent cell wall (Thomas and Kringstad 1971). Fujii et al (1997) and Matsumura (1999) described the positive effect of steam treatment or hot water extraction on gas permeability, in which the hydrogen bonding in the aspirated pits may have been reduced. Exchanging the moisture in green wood with a less polar or nonpolar solvent before drying (solvent-exchange drying) reduces the degree of pit aspiration (Hayashi et al 1966; Siau 1984; Hansmann et al 2002). Bao et al (2001) showed that a low level of aspirated pits in the sapwood results when wood goes from green to a dry state by ethanol-exchange drying. In general, deaspiration is promoted when the solvent has lower swelling characteristics than water and/or when it lacks the ability to form hydrogen bonds. Fluids conducive to this process typically contain benzene or pentane.

\section{Biological Treatments}

The controlled use of microbial decomposition is a biotechnological method that can be used 
for wood modification [see Mai et al (2004) for a review]. Biological concepts that enhance the permeability of softwoods have been developed using enzymes, bacteria, and fungi.

Bacteria. Bacterial activity is considered to be the main cause of improvement in softwood permeability during ponding (storing logs in water over a long period) (Adolf et al 1972; Unligil 1972; Kobayashi 1998; Nijdam et al 2001). Wood exposed to bacterial degradation showed lower pectin contents, pit membranes were destroyed, and substances encrusting the cell lumina and pit chambers were partly removed. However, the necessity for prolonged treatment and inhomogeneous variations of permeability has ruled out further commercial use.

Enzymes. The improvement of softwood permeability by means of enzymes was investigated by Nicholas and Thomas (1968) and Militz (1993a, 1993b), among others. The activity of pectinases, cellulases, and hemicellulases resulted in the partial degradation of pit membranes. The permeability of Norway spruce heartwood and sapwood was improved with a mixture of different enzymes. However, similar to bacterial treatment, several weeks of incubation were required to obtain an enhanced permeability, and localized differences in enzyme activity led to inconsistent results. The introduction of bacteria and enzymes into dried wood is difficult because the aspirated pits counteract rapid and uniform ingress of microbial suspensions. Moreover, the processes are difficult to control and scaling up to industrial application has been unsuccessful.

Fungi. In contrast to isolated enzymes, hyphae of white rot fungi are able to transport their specific enzymes deep into the wood substrate during colonization. The hyphae largely follow the nutrient-rich parenchyma cells and rays and grow from there into the adjacent tracheids primarily through simple or bordered pits or even by creating bore holes in the cell walls. During the first period of substrate colonization, the excreted enzymes alter the chemical structure of the pit membranes and contribute to their selective degradation with almost no negative effect on the strength properties of the wood matrix (Messner et al 2003). Investigations on Norway spruce infected with strains of Trichoderma, Dichomitus, and Phanerochaete resulted in an enhanced permeability of the sapwood, whereas the effect on the heartwood remained negligible (Rosner et al 1998). In contrast, incubation of Norway spruce and white fir for $6 \mathrm{wk}$ with a white rot fungi (Physisporinus vitreus) revealed significant permeability improvement in both sapwood and heartwood (Schwarze et al 2006). At the same time, impact bending strength was reduced negligibly. The process was subsequently patented (Schwarze 2006) and termed "bioincising." In the following section, we focus on the bioincising process and discuss its potential for permeability improvement in refractory species.

\section{THE BIOINCISING PROCESS}

The studies of Schwarze et al (2006) revealed an enhanced liquid uptake of $200-400 \%$ for bioincised heartwood of Norway spruce and Fir. As illustrated in micrographs by the authors, membranes in bordered pits of the tracheids and in simple pits of the ray parenchyma cells were most likely selectively degraded by the enzymatic activity of $P$. vitreus during the first period of substrate colonization. Schwarze et al (2006) suggested the excretion of polygalacturonase and oxalic acid by $P$. vitreus during incipient wood decay as promoting factors for the hydrolysis of the pectin-rich bordered pit membranes.

$P$. vitreus is known to have high tolerance to very wet conditions and has been isolated from wood in cooling towers. Considering this aspect, the selective degradation of pit membranes during the first period of substrate colonization has been interpreted as a strategy of $P$. vitreus to indirectly influence the MC of the wood (Schmidt et al 1997; Schwarze and Landmesser 2000). The biodegradation of pit membranes results in an increase of wood MC and favors an efficient and rapid distribution of hyphae 
in the substrate. Once the pit membranes are removed and a high MC is established, the distribution of lignolytic enzymes is facilitated. In a second period, degradation of the cell wall matrix occurs and weight and strength losses have been recorded. Therefore, fungal activity during the bioincising process must be restricted to the first period of substrate colonization to avoid severe damage to the wood matrix and exclusively limit changes to those that increase the permeability for gases and preservatives.

Schwarze et al (2006) conducted their investigation on specimens of relatively small dimensions $[100 \times 10 \times 15 \mathrm{~mm}$ and $100 \times 25 \times 15 \mathrm{~mm}$ $(1 \times \mathrm{t} \times \mathrm{r})]$. When incubation with $P$. vitreus was repeated with larger specimens of Norway spruce, fungus activity turned out to be heterogeneous across the substrate (Fig 2). The samples $(500 \times 50 \times 50 \mathrm{~mm})$ were obtained from an entire trunk to provide a comprehensible visual impression of differences between sapwood and heartwood. Radial or tangential grain orientation could of course not always be maintained. Checking of the bioincised specimens occurred during drying at $105^{\circ} \mathrm{C}$.

Impregnation of the bioincised samples with stained water revealed that permeability was preferentially improved in sapwood. Also, fungal activity could be documented in heartwood, but the permeability improvement occurred in local regions and activity was rather heterogeneous.
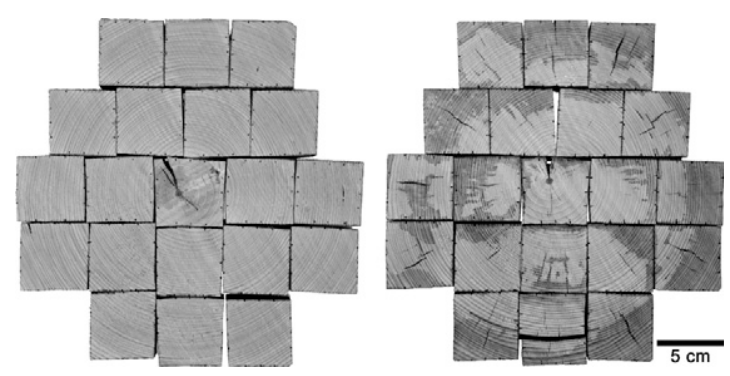

Figure 2. Liquid uptake of Norway spruce (left) and after 6 weeks of bioincising (right) demonstrated by vacuum impregnation (20 min, 0.7 mbar) with stained water. Note checking of the bioincised samples resulted from drying at $105^{\circ} \mathrm{C}$ (photographs from test series for Schwarze et al 2006).
Obviously, a range of biotechnological parameters still has to be optimized to enable homogenous and rapid colonization of the sapwood and heartwood with $P$. vitreus. Schubert et al (2009) showed in their study that the water activity and temperature have a strong influence for rapid mycelial growth during early stages of the bioincising process. Moreover, the studies showed that $P$. vitreus is susceptible to microbial contaminants, particularly for Trichoderma species during the lag phase. This also can have a negative impact on the homogeneity of colonization.

Currently, a number of investigations are underway to assess bioincising. First, we are evaluating material properties such as permeability, strength, and chemical composition of the bioincised wood. Second, we study the behavior of liquid substances during substrate penetration into the bioincised wood according to anatomical orientation. Finally, we try to estimate the effect of bioincising on the targeted properties for improvement after a subsequent application of wood modification substances. For this purpose, tests with respect to selected properties such as hydrophobicity, UV stability, surface hardness, or flame retardancy have been conducted. Because the results from the mentioned investigations will be the subject of further publications, only one example from preliminary tests will be presented in the following section.

\section{Preliminary Tests}

To evaluate the overall performance of the bioincised wood for subsequent treatment with property-improving substances, we conducted preliminary tests for flammability (Lehringer et al 2009). Wood samples $(30 \times 40 \times 15 \mathrm{~mm}$; $1 \times \mathrm{t} \times \mathrm{r}$ ) of Norway spruce were incubated with $P$. vitreus for $6 \mathrm{wk}$ and then treated with three commercial wood modification substances. The substances were applied to the material by brushing, dipping (30 min), and vacuum impregnation (20 min, $7 \mathrm{kPa}$ ). To avoid major capillary uptake, the endgrain surfaces were presealed with a polyurethane coating. The substance 
uptake of the wood modification agents was gravimetrically measured for the three application methods. Flammability was measured by exposing the treated samples horizontally to a propane flame for $3 \mathrm{~min}$. After removing the char, mass loss was determined gravimetrically.

For brushing and dipping, little or no effect of bioincising on the uptake was observed, whereas a clear improvement of penetrability was apparent when the agents were impregnated in a vacuum chamber. Despite an improved uptake of modification substances after impregnation, we found a negative effect of bioincising on the target properties (Lehringer et al 2009). The bioincised samples lost more mass than the control samples. Apparently, the cell wall structure was affected by the fungal activity that promoted the mass loss.

To reduce this type of side effect from $P$. vitreus and to bring the bioincising process in the area of technical application, future work must focus on optimizing the bioincising method.

In the past, wild-type strains of $P$. vitreus with dikaryotic mycelia have been used for the bioincising process. Each dikaryotic cell of $P$. vitreus, a tetrapolar heterokaryon, contains two nonidentical nuclei derived from the fusion of two different, sexually compatible primary mycelia, each bearing a single nucleus per cell. The dikaryotic mycelia of most $P$. vitreus isolates become pigmented in culture, producing brown exudates and darkening some softwoods during colonization. In addition, dikaryons in general have faster growth rates than monokaryons of the same species. These factors suggest that the use of a monokaryon of $P$. vitreus may be preferable to a dikaryon for the development of a biological bioincising system. Monokaryons show a reduced tendency to produce dark pigments in culture and cause less discoloration (Addleman and Archibald 1993). Additionally, because of the reduced growth rates, it may have reduced numbers of isozymes of secreted enzymes such as laccase and manganese peroxidase and consequently may have the potential to degrade bordered pit membranes more selec- tively. It is expected that monokaryons can enhance wood permeability more effectively than the dikaryons presently used. Moreover, they would provide a much simpler genetic and biochemical system for the elucidation of the bioincising mechanisms because they are more easily genetically modified.

\section{BIOINCISING AS POTENTIAL PRETREATMENT FOR WOOD MODIFICATION}

\section{Customized Permeability Improvement}

Although certain tasks are obviously still ahead, at this point, we would like to give an outlook of possible technical applications for bioincising. On the basis of the aspects presented, we consider bioincising to be a promising approach for controlled improvement of permeability to different depths of the wood substrate. Depending on the control of process parameters (temperature, nutrient and oxygen supply, substrate humidity, $\mathrm{pH}$, duration of incubation) and an improved selectivity of $P$. vitreus, wood permeability improvement could be customized for subsequent treatment with specific wood modification substances. For example, a treatment for dimension stability requires much deeper penetration into the wood than a treatment for UV protection substances (which are discussed in more detail). Thus, certain penetration depths have to be achieved to ensure 1) an efficient distribution of the modification substance and 2) reaching an optimal effect for the targeted property improvement.

\section{Definition of Penetration Depth}

Before we discuss the application of bioincising as pretreatment for subsequent wood modification, it is necessary to define the terminology concerning the penetration depth of liquid substances into the wood surface. Unfortunately, definitions in the literature are imprecise. They do not differentiate between the surface of the material and the zones beneath it. Because of the relatively rough and porous structure of the wood surface, its treatment with liquid 


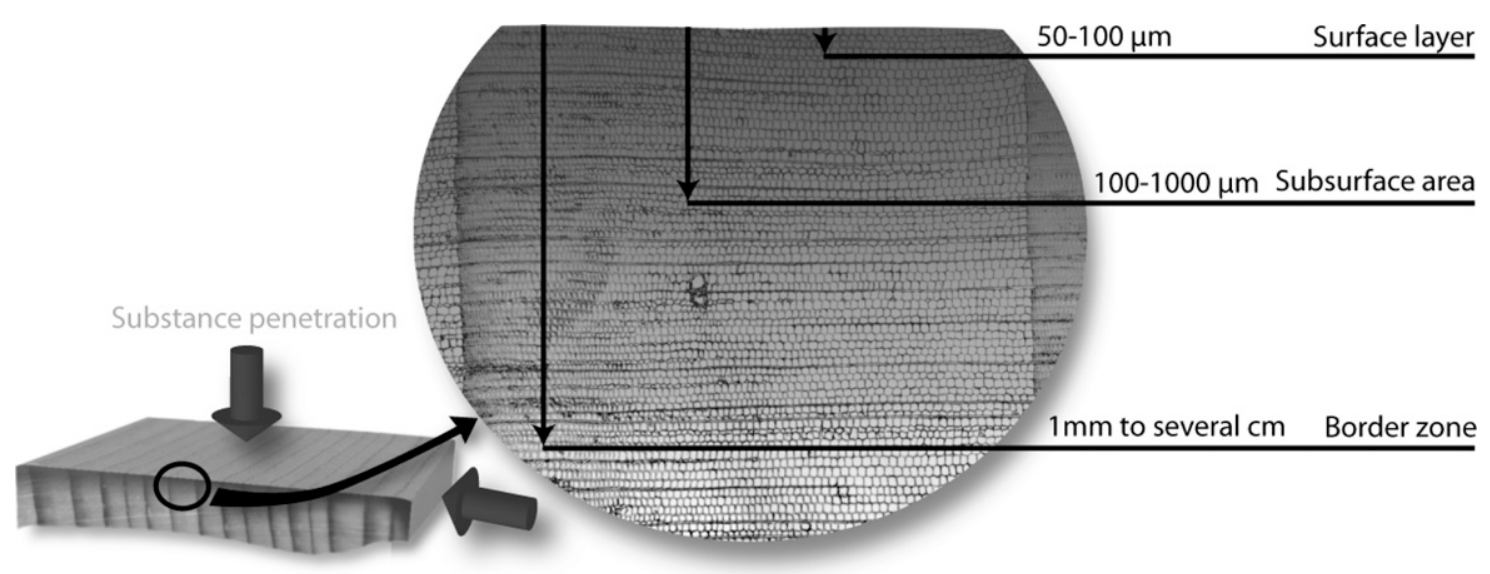

Figure 3. Schema for the differentiation of the wood surface into several zones to obtain a better distinction and description of liquid penetration in radial and tangential directions.

substances typically includes several cell rows in close proximity to the surface area because the substances fill the lumina of truncated cells.

As mentioned previously, penetration depth strongly depends on grain orientation. In practice, however, primarily tangential and/or radial surfaces are exposed to liquid substances. Normally, long pieces of wood are treated, in which those that are primarily transverse sections are comparably small and play a subordinate role for the penetration of liquids into the wood. Considering this aspect, we suggest three different depth zone terms for the radial and tangential orientations.

The term "surface layer" will refer to the zone that extends over approximately $3-4$ cell rows or a depth of approximately $50-100 \mu \mathrm{m}$. The zone beyond these first cell rows cannot be regarded as a direct surface and shall be termed "sub-surface area." During brushing or dipping, liquid substances often locally penetrate into this zone-for example, through the ray tracheids and ray parenchyma-which extend to a depth of approximately $100-900 \mu \mathrm{m}$. For impregnation treatment, higher penetration depths are desired. To define this zone, we propose a third "border zone," which describes the penetration of a wider region to a depth of several millimeters or more. The differentiation of these terms and penetration depths for radial and tangential orientation is illustrated in Fig 3.

\section{Potential Applications for Bioincising}

Regarding the proposed terms, in the following, we present selected target applications, in which bioincising could be considered as a pretreatment. Table 1 gives an overview of these applications, including the target of improvement and the required individual penetration depth in the tangential and radial orientations.

Preservative treatment. Treatment of wood with preservatives for protection against wooddestroying microorganisms is regulated or described by national standards (DIN 1990; CSA 1997; EN 2006; EN 2007; AWPA 2008). The standards define a minimum penetration depth for sapwood and/or heartwood depending on the natural durability of the species, its specific susceptibility to preservative treatment, and the conditions in which the wood will be used (use class). However, in practice, complete penetration cannot always be achieved either because of reduced uptake by refractory wood species or for reasons of economy. Commercial processes for effective preservative treatments have been developed. Most methods permit high penetration depths with homogenous distribution of the 
Table 1. Wood preservation and wood modification treatments according to the required penetration depth of the applied substance in tangential and radial orientation.

\begin{tabular}{|c|c|c|}
\hline Targeted effect & Desired penetration depth & Recommended application method \\
\hline Wood preservation & $\begin{array}{l}\text { Complete penetration or at least border zone } \\
\text { following certain standards (eg EN_335_1; } \\
\text { EN_351_2) }\end{array}$ & Impregnation \\
\hline Dimension stability & Complete penetration or at least border zone & Impregnation \\
\hline $\begin{array}{l}\text { Flame resistance with foam-forming } \\
\text { systems }\end{array}$ & Surface layer and subsurface area & Brushing, dipping \\
\hline Flame resistance salt solutions & Subsurface area to border zone & Dipping, Impregnation \\
\hline Hardness & Subsurface area to border zone & Dipping, Impregnation \\
\hline UV protection & Surface layer and subsurface area & Brushing, dipping \\
\hline Hydrophobation: liquid water & Surface layer and subsurface area & Brushing, dipping \\
\hline Hydrophobation: water vapor & Complete penetration or at least border zone & Impregnation \\
\hline
\end{tabular}

preservative but require expensive industrial facilities and high energy input.

Among these methods, vacuum and pressure impregnation techniques provide the best results. Nevertheless, mechanical drilling or incising is often required for refractory wood species. Hence, the pretreatment of wood with the bioincising technology could be an interesting alternative in this field to facilitate the impregnation process, to gain higher loading rates, and to obtain deeper penetration in refractory wood species.

Dimension stability. An improvement of thedimensional stability of wood is performed by blocking, reducing, or crosslinking of hydroxyl groups (Hill 2006). For this purpose, a wide range of substances and techniques has been developed, eg furfurylation, acetylation, dimethyloldihydroxyethyleneurea, (methylated) melamine-formaldehyde, and thermal modification. With the exception of thermal modification, the techniques use liquid substances that are impregnated. In untreated zones of the wood, the targeted effects are often irregularly realized, and local swelling and shrinking occur, resulting in internal strains and irregular deformation of the wood. Hence, the aim should be a complete and homogenous penetration of liquid modification substances in the required depth of the wood material.

Fire retardance. Fire protection for wood basically follows two principal systems. On the one hand, foam systems are mostly applied as coatings on the exposed wood surfaces. Under the influence of rising temperatures, these systems undergo a sequence of film softening, expansion, and setting of a rigid foam, which ideally traps inert gases and develops good adhesion to the surface. The temperature rise in wood is reduced and the time to ignition is prolonged as well as the depth of charring. For this type of treatment, no or only slight penetration of the substance into the wood surface is necessary. Consequently, these substances can be applied by brushing, dipping, or spraying.

On the other hand, fire-retardant salt solutions are applied by impregnation deeper into the wood. While surface coatings lose their efficiency when the protection layer has been physically destroyed, deep impregnation systems continue to control charring rate and flame formation over an extended period of severe fire impact. Similar to wood preservatives, the effect depends strongly on a deep and homogenous penetration of the flame retardants into the wood.

Although wood is a highly combustible material, the low thermal conductivity and insulating effect of the generated char provide the material with good properties for exposure to fire. The dimensional losses resulting from charring are taken into consideration for the design of wood elements in buildings to guarantee a certain time of service under the impact of fire. In 
contrast to wood protection or dimension stability, complete penetration of wooden construction units with fire retardants may not be required.

Hardness. For the improvement of surface hardness, full penetration is apparently not necessary. Gindl et al (2004) performed a melamine-formaldehyde (MF) resin treatment of Norway spruce wood and found that a penetration of $2-4 \mathrm{~mm}$ suffices for an optimal increase in surface hardness. However, satisfactory penetration was achieved only after a 3-da solvent-exchange immersion in liquid MF solution for diffusion of the substance into the wood cell walls. Vacuum treatment was not useful because of pit aspiration. Because a penetration of only a few millimeters is sufficient for a significant improvement of hardness, a full impregnation process does not appear to be necessary. However, species with a lower density will require a deeper penetration of hardness-improving substances than species with a higher density.

$\boldsymbol{U V}$ and visible light protection. The depth of light penetration into the wood surface and, with it, the region of possible photodegradation depends on the density of the specific wood species and on wavelength of the light. Denser wood is penetrated less by UV radiation. Moreover, light with shorter wavelengths penetrates wood less deeply. For UV light, penetration depths of $75 \mu \mathrm{m}$ have been reported, whereas visible light reaches depths of $200 \mu \mathrm{m}$ (Rowell 2005). If the impact of weathering effects such as humidity and temperature changes are considered, the maximum depth of photodegradation is approximately $750-900 \mu \mathrm{m}$. Therefore, the application of UV-protection substances by brushing or dipping into the surface layer and subsurface area might be sufficient for efficient protection against photodegradation.

Hydrophobation. The reduction of surface wettability is a central issue in weathering stabilization for wood in exterior uses. Hydrophobation of the surface can be performed by treatment of the wood surface with paraffins, waxes, oils, silane, siloxane, or silicone polymers. Capillarity is reduced by blocking penetration pathways such as tracheids, ray cells, and pits. Such treatments result in an increase in the contact angle for water (a change in surface tension), inducing a phenomenon also known as the Lotus effect (Donath et al 2006). Unfortunately, these surface treatments do not reduce the EMC, because no chemical modification of the cell wall is achieved (Mai et al 2007).

As in the case of UV and visible light protection, the improvement of permeability in the surface layer and subsurface area should be sufficient to improve the placement and distribution of hydrophobation substances for liquid water. The possible formation of cracks during weathering and the resulting opening of the protected wood surface to liquid water might indicate the need for deeper penetration.

Protection against water vapor and consequently long-term changes in EMC are much more difficult if film-forming finishes are not applied. As in the case of dimension stability, a full or at least a border zone penetration with hydrophobation substances would then be necessary.

\section{CONCLUSIONS AND OUTLOOK}

In the present article, we briefly summarize anatomical mechanisms responsible for the liquid flow in softwoods and review techniques for an improvement of permeability in refractory softwood species. A recent approach is aimed at a selective permeability improvement of Norway spruce by means of fungal pretreatment (bioincising). By applying bioincising under controlled conditions, liquid permeability of refractory wood species might be improved at defined depths. The examples given for current wood property improvement technologies showed different requirements of substance penetration into the wood at specific levels of depth.

Within the fields of application discussed, bioincising could be a method to promote the efficiency of the desired property improvement. 
The adaptation of the new process to these requirements would help to reduce the technological efforts for the subsequent treatment with modification substances. However, at present, the bioincising process is still in the process of optimization and not yet adapted to industrial applications. We are aware that an application of bioincising at the industrial scale will not be feasible until the biotechnological control of fungal activity permits a homogenous and controlled permeability improvement in the wood substrate. Especially for heartwood, fungal activity has to be intensified and more homogeneous. Undesired side effects of fungal growth must be minimized and a feasible way for the technical application developed.

The aspects presented demonstrate the potential of bioincising, but do not yet represent the latest state of development, because the optimization of the bioincising process is still in progress. Hence, additional work in this field must be carried out. A better understanding of wood-fungal interactions and of the resulting effects of bioincising on wood permeability will ultimately help improve the treatability of refractory wood species.

\section{REFERENCES}

Addleman K, Archibald F (1993) Kraft pulp bleaching and delignification by dikaryons and monokaryons of trametes versicolor. Appl Environ Microbiol 59(1):266 273.

Adolf FP, Gerstetter E, Liese W (1972) Untersuchungen über einige Eigenschaften von Fichtenholz nach dreijähriger Wasserlagerung. (Studies on selected properties of spruce wood after three years of ponding). Holzforschung 26:18 - 25 .

AWPA (2008) Book of standards. American Wood Protection Association. Birmingham, AL.

Bailey PJ, Preston RD (1969) Some aspects of softwood permeability. Holzforschung 23(2):113 - 120.

Bamber RK, Fukazawa K (1985) Sapwood and heartwood-A review. Forestry Abstr 46(9):567 - 580.

Banks W (1981) Addressing the problem of non-steady state liquid flow in wood. Wood Sci Technol 15(3):171177.

Bao F, Lu J, Zhao Y (2001) Effect of bordered pit torus position on permeability in Chinese yezo spruce. Wood Fiber Sci 33(2):193 - 199.
Comstock GL (1965) Longitudinal permeability of green eastern hemlock. Forest Prod J 15(10):441 - 449.

Comstock GL (1970) Directional permeability of softwoods. Wood Fiber Sci 1(4):283 - 289.

Comstock GL, Coté WA (1968) Factors affecting permeability and pit aspiration in coniferous sapwood. Wood Sci Technol 2(4):279 - 291.

CSA (1997) CSAO80. Canadian standards for wood preservation. CSA Technical Committee on Wood Preservation. Ottawa, Canada.

DIN (1990) DIN68800-3. Protection of timber; preventive chemical protection. DIN German Institute for Standardization. Berlin, Germany.

Donath S, Militz H, Mai C (2006) Creating water-repellent effects on wood by treatment with silanes. Holzforschung 60(1):40 - 46.

EN (2006) EN335_2. Durability of wood and wood-based products-Definition of use classes-Part 2: Application to solid wood. CEN European Committee for Standardization. Brussels, Belgium.

EN (2007) EN351_1 Durability of wood and wood-based products-Preservative- treated solid wood-Part 1: Classification of preservative penetration and retention. CEN European Committee for Standardization. Brussels, Belgium.

Erickson HD (1970) Permeability of southern pine woodA review. Wood Sci 2(3):149 - 158 .

Flynn KA (1995) A review of the permeability, fluid flow, and anatomy of spruce (Picea spp.). Wood Fiber Sci 27(3):278 - 284.

Fujii T, Suzuki Y, Kuroda N (1997) Bordered pit aspiration in the wood of Cryptomeria japonica in relation to air permeability. IAWA J 18(1):69 - 76.

Fujikawa S, Ishida S (1975) Ultrastructure of ray parenchyma cell walls of softwood. Mokuzai Gakkaishi 21:445 456.

Gindl W, Hansmann C, Gierlinger N, Schwanninger M, Hinterstoisser B, Jeronimidis G (2004) Using a watersoluble melamine-formaldehyde resin to improve the hardness of Norway spruce wood. J Appl Polym Sci 93(4):1900 - 1907.

Hacke UG, Sperry JS, Pittermann J (2004) Analysis of circular bordered pit function II. Gymnosperm tracheids with torus-margo pit membranes. Am J Bot 91(3):386 - 400 .

Hansmann C, Gindl W, Wimmer R, Teischinger A (2002) Permeability of wood-A review. Drev Vysk 47 (4): $1-16$.

Hayashi S, Nishimoto K, Kishima T (1966) Study on the liquid permeability of softwoods. Wood Res-Slovakia $38: 47-57$.

Hill CAS (2006) Wood modification: Chemical, thermal and other processes. John Wiley \& Sons Ltd, The Atrium Southern Gate Chichester, UK. 260 pp.

Keith CT, Chauret G (1988) Anatomical studies of CCA penetration associated with conventional (tooth) and with micro (needle) incising. Wood Fiber Sci 20(2): 197 - 208. 
Kininmonth JA (1971) Permeability and fine structure of wood to micro-filtered water. Holzforschung 25:127 - 133.

Kobayashi Y (1998) Drying and anatomical characteristics of sugi wood attacked by bacteria during pond storage. J Wood Sci 44(6):432 - 437.

Koran Z (1989) Anatomy and treatability of spruce wood. Pages 23 - 41 in Proc 1988 Forintek wood preservation seminar. 4 November 1988. Vancouver, Canada.

Lehringer C, Arnold M, Richter K, Schubert M, Schwarze FWMR, Militz H (2009) Bioincised wood as substrate for surface modifications. Pages 197 - 200 in F Englund, CAS Hill, H Militz, BK Segerholm, eds., Proc European Conference on Wood Modification, 27 - 29 May 2009, Stockholm.

Li X, Zhang B, Li W, Li Y (2005) Research on the effect of microwave pretreatment on moisture diffusion coefficient of wood. Wood Sci Technol 39(7):521 - 528.

Liese W, Bauch J (1967) On anatomical causes of refractory behaviour of spruce and Douglas fir. J I Wood Sci 4(19):3 - 14.

Lihra T, Cloutier A, Zhang SY (2000) Longitudinal and transverse permeability of balsam fir wetwood and normal heartwood. Wood Fiber Sci 32(2):164 - 178.

Mai C, Kües U, Militz H (2004) Biotechnology in the wood industry. Appl Microbiol Biotechnol 63(5):477 - 494.

Mai C, Nguyen HM, Donath S, Weigenand O, Militz H (2007) Neuartige Systeme zur Hydrophobierung von Holz in der Außenanwendung. (Innovative Systems for the hydrophobation of wood in exterior use). 25. Holzschutz-Tagung der DGfH, 20 - 21 September 2007; Biberach/Riß. Pages $73-85$.

Mantanis GI, Young RA (1997) Wetting of wood. Wood Sci Technol 31(5):339 - 353.

Matsumura J (1999) Impregnation of radiata pine wood by vacuum treatment II: Effect of pre-steaming on wood structure and resin content. J Wood Sci 45(6):456 - 462.

Merenda L, Holan J (2008) The permeability of microwave treated wood for distilled water. Acta U Agr Silvi Men Bru 56(1): 137 - 142 .

Messner K, Bruce A, Bongers HPM (2003) Treatability of refractory wood species after fungal pre-treatment. Pages 389 - 401 in Proc European Conference on Wood Modification. Göttingen.

Militz H (1993a) Der Einfluss enzymatischer Behandlung auf die Tränkbarkeit kleiner Fichtenproben. [The influence of pre-treatments with enzymes on the penetrability of small spruce wood specimens.] Holz Roh Werkst 51 (2): $135-142$.

Militz H (1993b) Enzymatische Behandlungen von Fichtenrund-und Schnittholz zur Verbesserung der Tränkbarkeit. [Enzymatic pre-treatment of spruce posts and sawn boards to improve their treatability with wood preservatives.] Holz Roh Werkst 51(5):339 - 346.

Morris PI, Morrell JJ, Ruddick JNR (1994) A review of incising as a means of improving treatment of sawnwood. International Research Group in Wood Preservation IRG/WP 94-40019. Pages 1 - 24.
Nicholas DD, Thomas RJ (1968) The influence of enzymes on the structure and permeability of loblolly pine. In Proc American Wood Preservers' Association, 22 - 24 April 1968. 64:1 - 7 .

Nijdam JJ, Lehmann E, Keey RB (2001) Bacterial treatment of Pinus radiata timber to improve permeability. Pages 1 - 11 in Proc of the 2nd Inter-American Drying Conference, July 8-10, 2001, Veracruz, Mexico.

Olsson T, Megnis M, Varna J, Lindberg H (2001) Study of the transverse liquid flow paths in pine and spruce using scanning electron microscopy. J Wood Sci 47(4):282 - 288.

Palin MA, Petty JA (1981) Permeability to water of the cell wall material of spruce heartwood. Wood Sci Technol 15(3): $161-169$.

Petty JA (1970) Permeability and structure of the wood of Sitka spruce. Proc R Soc Lond B Biol Sci 175:149 - 166.

Reinprecht L, Pánek M (2008) Bio-treatment of spruce wood for improving of its permeability and soaking. Pt. 1: Direct treatment with the bacterium Bacillus subtilis. Wood Res-Slovakia 53(2):1 - 12.

Resch H, Ecklund BA (1964) Permeability of wood. Exemplified by measurements on redwood. Forest Prod J 14:199 - 206 .

Richter K (1989) Perforation and impregnation methods to improve weather resistance of structural timber. Empa Research and working report 115/19 (Dept. 115, wood). Pages 1 - 44. Dübendorf, Switzerland.

Richter K, Sell J (1992) Untersuchung der kapillaren Transportwege im Weißtannenholz. [Investigation on the capillary transport system in wood of White Fir.] Holz Roh Werkst 50(9):329 - 336.

Rosner B, Messner K, Tucker E, Bruce A (1998) Improved preservative penetration of spruce after pretreatment with selected fungi. I. Fungal pretreatment of pole sections. Int $\mathrm{J}$ Res Group Wood Preserv IRG/WP 9840117:1 - 14 .

Rowell RM (2005). Handbook of wood chemistry and wood composites. CRC Press, Boca Raton, FL. 487 pp.

Schmidt O, Schmitt U, Moreth U, Potsch T (1997) Wood decay by the white-rotting basidiomycete Physisporinus vitreus from a cooling tower. Holzforschung 51(3):193 200.

Schubert M, Dengler V, Mourad S, Schwarze FWMR (2009) Determination of optimal growth parameters for the bioincising fungus Physisporinus vitreus by means of response surface methodology. J Appl Microbiol 106 (5):1734-1742.

Schwarze FWMR (2008) Procedure and composition for the improvement of the uptake and distribution of soaking compositions in woods. Patent EP1681145.

Schwarze FWMR, Landmesser H (2000) Preferential degradation of pit membranes within tracheids by the basidiomycete Physisporinus vitreus. Holzforschung 54(5):461 - 462.

Schwarze FWMR, Landmesser H, Zgraggen B, Heeb M (2006) Permeability changes in heartwood of Picea abies 
and Abies alba induced by incubation with Physisporinus vitreus. Holzforschung 60(4):450 - 454.

Siau JF (1984). Transport processes in wood. SpringerVerlag, Heidelberg, Germany. 245 pp.

Siau JF (1995). Wood: Influence of moisture on physical properties. Dept. of Wood Science and Forest Products Virgnia Polytechnic Instiute and State University. 227 pp.

Tarmian A, Perré P (2009) Air permeability in longitudinal and radial directions of compression wood of Picea abies L. and tension wood of Fagus sylvatica L. Holzforschung 63(3):352 - 356 .

Terziev N (2002) Effect of high temperature and microwave treatment on microstructure of softwoods. COST E15 Workshop: Methods for Improving Drying Quality of Wood 6.
Thomas RJ, Kringstad KP (1971) The role of hydrogen bonding in pit aspiration. Holzforschung 25(5):143 - 149.

Unligil HH (1972) Penetrability and strength of white spruce after ponding. Forest Prod J 22(9):92 - 100.

Usta I, Hale M (2006) Comparison of the bordered pits of two species of spruce (Pinaceae) in a green and kiln-dried condition and their effects on fluid flow in the stem wood in relation to wood preservation. Forestry 79(4):467 - 475 .

Usta I, Hale MD (2004) Radial permeability of Sitka spruce [Picea sitchensis (bong.) Carr.] as affected by aspects of ray cell tissue. J I Wood Sci 16(5):295 - 301

Wardrop AB, Davies GW (1961) Morphological factors relating to the penetration of liquids into wood. Holzforschung 15(5):129 - 141 . 




\title{
Anatomy of bioincised Norway spruce wood
}

\author{
Christian Lehringer ${ }^{\mathrm{a}, *}$, Konrad Hillebrand ${ }^{\mathrm{a}}$, Klaus Richter ${ }^{\mathrm{a}}$, Martin Arnold $^{\mathrm{a}}$, \\ Francis W.M.R. Schwarze ${ }^{\mathrm{a}}$, Holger Militz ${ }^{\mathrm{b}}$ \\ ${ }^{a}$ Empa - Swiss Federal Laboratories for Materials Testing and Research, Wood Laboratory, Überlandstrasse 129, Dübendorf CH-8600, Switzerland \\ ${ }^{\mathrm{b}}$ Wood Biology and Wood Products, Georg-August-University Göttingen, Büsgenweg 4, D-037077 Göttingen, Germany
}

\section{A R T I C L E I N F O}

\section{Article history:}

Received 1 February 2010

Received in revised form

11 March 2010

Accepted 17 March 2010

Available online 6 May 2010

\section{Keywords:}

Bioincising

Degradation

Delignification

Pit membrane

Tracheid cell wall

Wood permeability

\begin{abstract}
A B S T R A C T
Bioincising is a biotechnological method to enhance the permeability of refractory wood species such as Norway spruce (Picea abies (L.) Karst) by incubation with the white rot fungus Physisporinus vitreus. Increase in wood permeability is supposedly induced by the selective degradation of pit membranes in the bordered and half bordered pits, entailing only negligible changes in the tracheid cell wall. In order to analyze the fungal activity on pit elements and the cell wall structure, we incubated sap- and heartwood of Norway spruce for three, five, seven and nine weeks with P. vitreus. After incubation and wood sterilization we conducted a systematic microscopic study. We found that $P$. vitreus caused both a selective delignification and a soft rot Type I and II in tracheid cell walls comprising a high heterogeneity during wood colonization. Moreover it was apparent that the degradation of pit membranes occurred simultaneously with the formation of bore holes, cavities and notches in tracheid cell walls. The activity of $P$. vitreus was higher in the sapwood, but a notable effect was also recorded in the heartwood. The results indicate that the incubation conditions have to be further optimized to reduce the adverse effects of fungal activity on the tracheid cell walls and achieve a more homogenous wood colonization. The results of this study help to improve the bioincising process by understanding the growth characteristics of $P$. vitreus and the wood-fungus interaction during wood decay.
\end{abstract}

(c) 2010 Elsevier Ltd. All rights reserved.

\section{Introduction}

In softwoods such as Norway spruce (Picea abies (L.) Karst), bordered pits constitute the pathways for fluid transport between adjacent tracheids. The occlusion of these valve-like elements is called pit aspiration (Liese and Bauch, 1967). Pit aspiration occurs to a large extent during wood drying and results in a low permeability of the wood for fluids such as preservatives or modification substances. Generally it is desirable to achieve a deep and homogenous penetration of preservatives and modification substances into the wood in order to protect the wood against fungi and insects or to improve specific wood properties. Therefore, an increase in the permeability of refractory wood species is of interest in many fields of wood modification (Comstock, 1970; Erickson, 1970; Petty, 1970; Flynn, 1995; Hansmann et al., 2002; Lehringer et al., 2009b). In the past, permeability improvement has been attempted by the application of enzymes, bacteria and blue stain fungi, but industrial application was only reached seldom (Mai et al., 2004).

The biotechnological use of wood decay fungi for wood modification displays particular challenges for process control, but in

\footnotetext{
* Corresponding author. Tel.: +41 44823 4078; fax: +41 448234007

E-mail address: christian.lehringer@empa.ch (C. Lehringer).
}

some cases the use of white rot fungi has gained industrial application (Kirk and Yang, 1979; Mai et al., 2004). The so called bioincising process is a new biotechnological approach to improve the permeability by a fungal pre-treatment of wood with the basidiomycete Physisporinus vitreus (Lehringer et al., 2009b; Schwarze and Schubert, 2009). P. vitreus was initially isolated from wood in cooling towers, comprising very humid growth conditions that are rather atypical for basidiomycetes (Schmidt et al., 1996; van Acker and Stevens, 1996). But it showed to be a typical white rot fungus (Schmidt et al., 1997). Further studies with P. vitreus revealed tendencies to a selective delignification and a preferential degradation of pectin-rich pit membranes during initial stages of wood colonization (Schmidt et al., 1997; Schwarze and Landmesser, 2000). Schwarze et al. (2006) demonstrated that the incubation of refractory wood species such as Norway spruce and White fir (Abies alba Mill) with $P$. vitreus significantly improved the uptake and distribution of the synthetic organic textile dye Neolan Glaucin E-A causing only limited strength losses. Additional studies on bioincised wood by Lehringer et al. (2009a) indicated that chemical and structural alterations of the specimens due to fungal decay were apparent. Apparently, the fungal activity was not strictly related with the preferential degradation of the pit membrane but also with partial decomposition of the cell wall. In consequence 
it was hypothesized that $P$. vitreus like other basidiomycetes might switches from one decay pattern to another, causing also a soft rot in secondary walls of tracheids (Daniel et al., 1992; Schwarze et al., 1995; Schwarze, 2007).

According to Schmidt (2006) three types of fungal decay are described: white rot, brown rot and soft rot. White rot is further subdivided into selective delignification and simultaneous rot.

Selective delignification means that lignin and hemicelluloses are preferably metabolized, while the cellulose fraction of the cell wall is either degraded or persists even at an advanced stage. Hyphae grow on the S3 layer in the cell lumina of cells and secrete ectoenzymes that degrade lignin and hemicelluloses. This type of degradation gradually advances through the secondary wall towards the compound middle lamella. The thickness and the visible structure of the cell wall remain mostly unaltered, but the progressing delignification can be visualized by means of microscopic staining. At later stages, cellulose becomes hydrolyzed as well and the formation of cavities can occur (Schwarze and Engels, 1998).

Simultaneous rot is characterized by fungal ecto-enzymes which have the capacity to degrade cellulose, hemicelluloses and lignin at the same time. Hyphae grow in the cell lumina and penetrate the cell walls via bore holes. Erosion troughs (notches) are formed under the hyphae on the lumen side of the tracheid cell wall. In this way, cell wall thickness is gradually reduced. In addition, hyphae and enzymes can penetrate into the secondary wall and induce the formation of cavities, resembling the decay pattern of brown and soft rot.

This above mentioned strict classification of decay types has been discussed critically (Zabel and Morrell, 1992; Worrall et al., 1997; Eaton, 2000; Schwarze and Baum, 2000; Schmidt, 2006) and several works reported various decay patterns caused by one fungus in the same substrate (Blanchette, 1984, 1991; Schwarze et al., 1997; Anagnost, 1998; Ray et al., 2005).

In order to elucidate the wood-fungus interactions between Norway spruce and $P$. vitreus and to learn more about the specific fungal growth characteristics, we incubated sap- and heartwood with $P$. vitreus for three, five, seven and nine weeks. Subsequently we conducted a systematic anatomical study and statistically described the effects of fungal activity in the substrate. We compared the fungal impact on bordered pits and xylem ray parenchyma pits with the degradation of the cell wall structure. Furthermore, the aim of the study was to gain knowledge on fungal growth through the wood cells during early stages of colonization. Aspects of fungal selectivity and the different decay patterns were included into the investigations. Since the wood-fungus interaction is determined by various environmental parameters such as nutrient and oxygen supply, moisture content and carbon/nitrogenratio (Zabel and Morrell, 1992; Schmidt, 2006), the obtained results are discussed in the light of the specific incubation conditions.

\section{Materials and methods}

\subsection{Specimen material}

We used defect free and kiln dried wood from a Norway spruce ( $P$. abies) tree, grown in Switzerland. For sap- and heartwood, we prepared ten specimens respectively. Five specimens were taken in one longitudinal sequence from a board in order to minimize the influence of natural variability. Since five incubation times (control, three, five, seven and nine weeks) were tested, this axial pairing provided a good comparability between the different incubation times. Each specimen measured $200 \times 30 \times 30 \mathrm{~mm}$ (longitudinal $\times$ radial $\times$ tangential). Radial and tangential orientation of growth rings was always strictly maintained.

We sterilized the specimens with hot steam $\left(103^{\circ} \mathrm{C}\right.$ for $\left.2 \mathrm{~h}\right)$ and then inoculated them with the white rot fungus P. vitreus Empa 642.
Incubation was performed under sterile conditions by immersing the wood specimens in an emulsion of water, sawdust and fungal mycelia. The incubated specimens were then incubated on $1 \%$ malt agar and stored for three, five, seven and nine weeks at $22{ }^{\circ} \mathrm{C}$ and $70 \%$ relative air humidity $(\mathrm{RH})$. Each specimen was placed with one of its tangential surfaces on this nutrient medium in order promote the fungal growth in radial direction. After incubation, the mycelia were carefully removed from the surfaces and the specimens were steam sterilized as described above to stop further fungal activity. After drying for $48 \mathrm{~h}$ at $40{ }^{\circ} \mathrm{C}$., the specimens were reconditioned and stored at $20^{\circ} \mathrm{C}$ and $65 \% \mathrm{RH}$.

\subsection{Microscopy}

From the central part of the bottom side of each specimen - the face that was oriented towards the nutrient medium - we removed four blocks of $8 \times 8 \times 8 \mathrm{~mm}$ : two for light microscopy and two for field emission scanning electron microscopy (FE-SEM) (Fig. 1).

For light microscopy, transverse, radial and tangential sections of $15-20 \mu \mathrm{m}$ thickness were sectioned with a sliding microtome (Reichert, Austria). We subsequently stained the sections with astra blue $(0.5 \%)$ and safranine (1\%) for light microscopy investigations and with acridine orange $(0.01 \%)$ for fluorescence investigations under UV-light excitation (Aufsess et al., 1968; Gerlach, 1984; Srebotnik and Messner, 1994). Specimens incubated for seven and nine weeks had to be embedded with polyethylene glycol (PEG 1500) according to Bleicher (2008) in order to ensure high quality specimens during sectioning.

For FE-SEM, the moist blocks were trimmed with razor blades and then vacuum dried for $12 \mathrm{~h}$ at $40{ }^{\circ} \mathrm{C}$. After fixation on brass holders, the specimens were sputter coated with platinum with a thickness of $8 \mathrm{~nm}$ and a sputter current of $40 \mathrm{~mA}$ in an argon atmosphere $\left(5 \times 10^{-2}\right.$ mbar $)$ in a BAL-TEC Med 020 Sputter Coater (BAL-TEC AG, Liechtenstein).

Visible light and fluorescence microscopy investigations were made with an Axioplan 50 microscope (Carl Zeiss AG, Germany) at magnifications of $40 \times, 63 \times$ and $100 \times$. For the observations by transmitted light no filters were used whereas for fluorescence microscopy the excitation filter BP 365/12 and the band-elimination filter LP 397 were applied. Image capture was performed with the digital camera Leica DFC 420 (Leica Camera AG, Germany) and the computer software "Image Access ${ }^{\circledR}$ Version 7" (Imagic Bildverarbeitung AG, Switzerland) served for further processing of the micrographs.

FE-SEM observations were carried out with a Jeol cold FE-SEM 6300F (Jeol LTD., Japan) with an acceleration voltage of $5 \mathrm{kV}$ and a working distance of $25 \mathrm{~mm}$. Photographs were taken with the computer software "DIPS version 2.5" (Point electronic GmbH, Germany) and transferred to "Image Access ${ }^{\circledR}$ Version 7".

\subsection{Assessment of fungal activity}

Fungal activity in the wood specimens was assessed on the basis of more than 1500 micrographs obtained with light microscopy. About 100 FE-SEM images served as additional source of information. We collected information on hyphal distribution in tracheids and xylem ray cells, fungal degradation of bordered and half bordered pits, bore holes, erosion patterns and cavity formation in tracheid cell walls. For the systematic evaluation we defined three categories $^{1}$, according to the elements (1) bordered pits, (2) half bordered pits in crossfields and (3) tracheid cell walls. The level of fungal degradation in each of the three categories was classified

\footnotetext{
1 Throughout this article the term category will be linked to one of the three mentioned elements.
} 


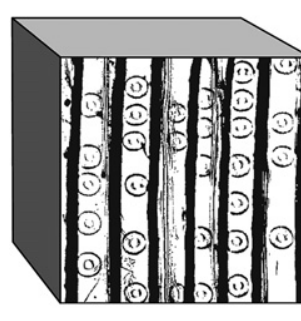

Wood block

$8 \times 8 \times 8 \mathrm{~mm}$

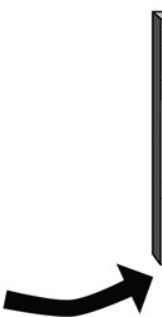

Radial section 15-20 $\mu \mathrm{m}$

$8 \times 8 \mathrm{~mm}$ for six photographs

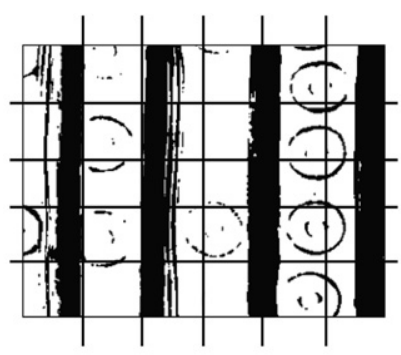

One of six photographs for evaluation with overlaid grid

Fig. 1. Schematic illustration of specimen preparation, micrograph assignment and systematic evaluation.

into intact, degraded and strongly degraded according to the following criteria catalogue (Tables $1-3$ ).

For category (1) and (2) we randomly selected twelve micrographs in each radial section, six in early and latewood respectively. Within these micrographs, we counted the overall amount of bordered pits or half bordered pits and classified them according to the intensity of fungal degradation.

For category (3) we overlaid a $5 \times 6$-field-grid on the images of radial sections. This was necessary, because the cell wall alterations were present throughout the whole micrograph area. Each field of the overlaid grid was classified and counted according to the intensity of fungal degradation on the tracheid cell wall in the specific area. Also here, earlywood and latewood were differentiated (Fig. 1).

Since the data for all three categories were always collected from one section of the same wood block, we derived the average values from the six micrographs. On this level we then calculated the percentage of degraded and strongly degraded features in relation to the total number of observed features.

The data were processed with the graph software Origin 6.1 (OriginLab Corporation, USA). After defining repeated measures for

Table 1

Classification of typical decay patterns in bordered pits of tracheids (radial longitudinal sections).

\begin{tabular}{|c|c|c|c|}
\hline $\begin{array}{l}\text { Intensity of } \\
\text { fungal activity }\end{array}$ & Description & Light microscopic observations & FE-SEM - observations \\
\hline Intact & $\begin{array}{l}\text {-Normal cell structure } \\
\text {-No fungal activity }\end{array}$ & Q. & \\
\hline Degraded & $\begin{array}{l}\text {-Hyphal activity on pit structure } \\
\text {-Hyphae growing through pits } \\
\text {-Bore holes in pits } \\
\text {-Circular coloration/staining of } \\
\text { the outer margo }\end{array}$ & & \\
\hline Strongly degraded & $\begin{array}{l}\text {-Torus/pit membrane dislocated/dissolved } \\
\text {-Porus/pit aperture clearly enlarged } \\
\text {-Pit aperture frayed/tattered }\end{array}$ & & \\
\hline
\end{tabular}


Table 2

Classification of typical decay patterns in half bordered pits in crossfields (radial longitudinal sections).

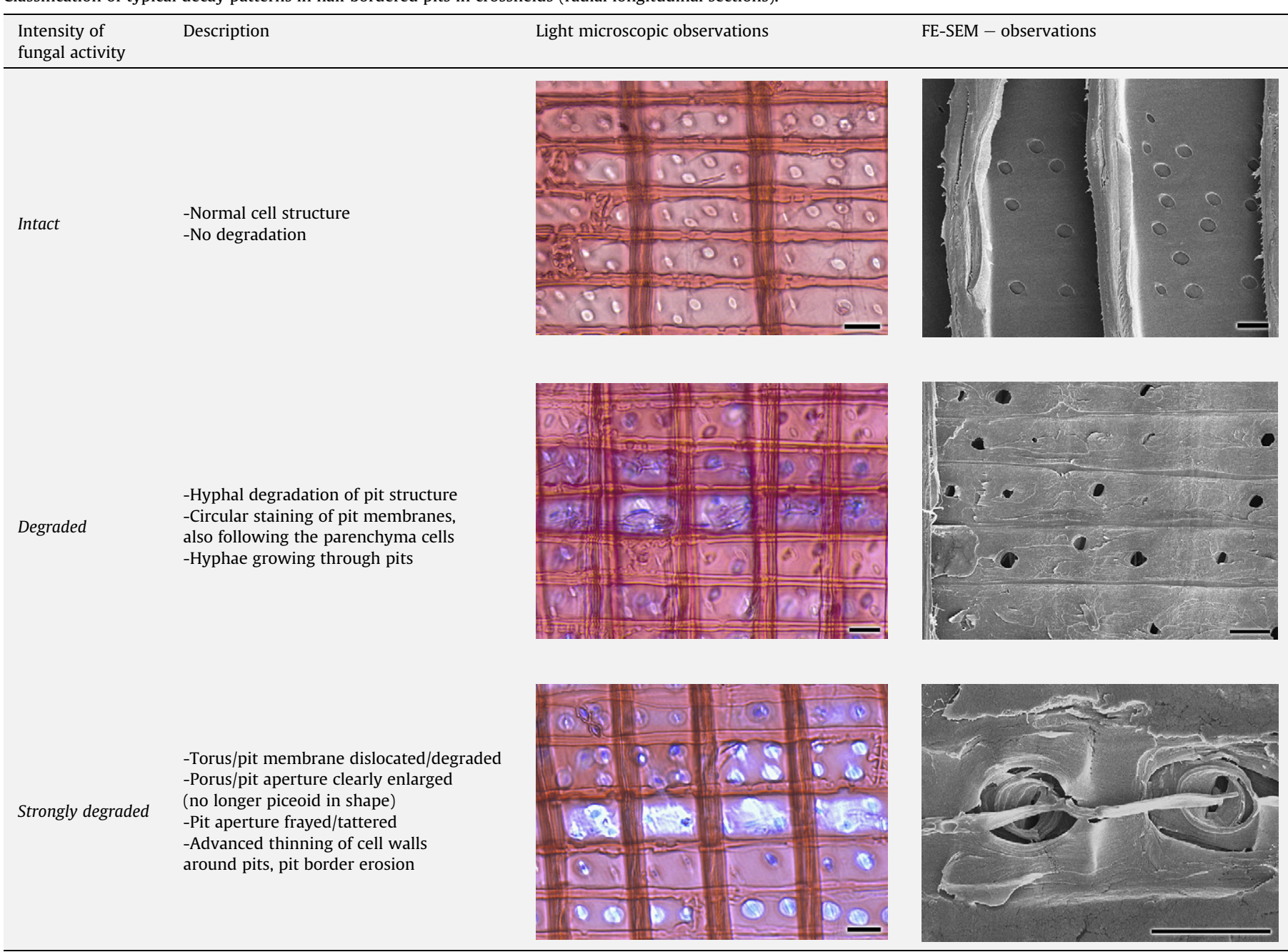

each radial section, one way Anova and Tukey honesty tests were conducted with the statistic software Systat12 (Systat Software Inc., USA). A probability value of $p<0.05$ was considered to print to significant differences. The data showed a strongly asymmetric structure, so that we transformed the data with Equation (1) in order to increase the power of the significance tests (Sachs, 1974). However, for an understandable visualization in the plots we referred to the original, non-transformed data.

$T=\arcsin \sqrt{\frac{\mathrm{x}}{100}}$

where $\mathrm{T}=$ transformed value, $\mathrm{x}=$ original value.

\subsection{Mass loss and moisture content}

Since the specimens were subjected to further investigations and were not altered by drying to $0 \%$ moisture content $(\mathrm{MC})$, we decided not to refer exactly to EN 113 for mass loss $(\Delta M)$ determination and to DIN-EN 13183-1 for MC determination. Instead, we measured the theoretical dry weight $(M t)$ of the conditioned specimens at $20{ }^{\circ} \mathrm{C} / 65 \% \mathrm{RH}$ before and after the incubation and verified the MC on the basis of exemplarily oven-dried specimens $(u=11.8 \% \pm 0.4)$. We applied Equation (2) and (3) according to Schmidt (2006).
$\Delta M=\frac{M_{0}-M_{1}}{M_{1}} * 100$

where $\Delta M=$ mass loss (\%), $M_{0}=$ dry mass before incubation $(\mathrm{kg})$, $M_{1}=$ dry mass after incubation $(\mathrm{kg})$.

$M_{0}=\frac{100 \cdot M t_{0}}{100+u}$ and $M_{1}=\frac{100 \cdot M t_{1}}{100+u}$

where $M t_{0}=$ conditioned mass before incubation, $M t_{1}=$ conditioned mass after incubation, $u=$ wood moisture content at $20{ }^{\circ} \mathrm{C} / 65 \% \mathrm{RH}$.

Anagnost and Smith (1997b) reported that for white rot fungi no changes in wood hygroscopicity must be expected and that consequently conditioned specimens can be used without severe over- or underestimation of moisture content. For each incubation period ten specimens were used to determine the average mass loss.

\section{Results and discussion}

\subsection{Intensity and distribution of fungal activity}

In the three categories, the intensity of $P$. vitreus activity was moderate during the first five weeks of incubation (Fig. 2). Only very few strongly degraded cells or pit structures were detected 
Table 3

Classification of typical decay patterns in tracheid cell walls (radial and tangential longitudinal sections).

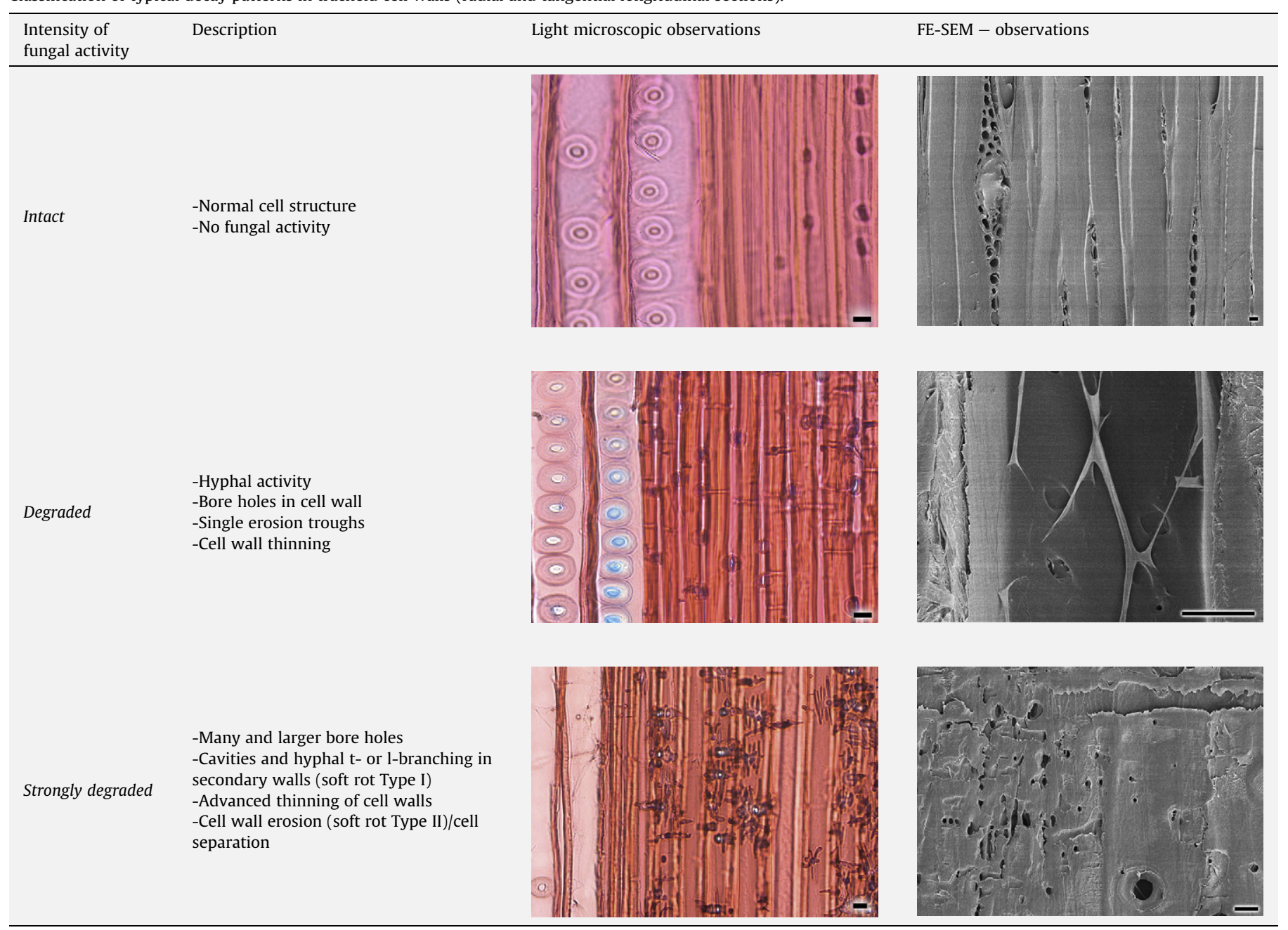

$(0-0.6 \%)$ and the values for degraded elements ranged in average between 6.9 and $9.0 \%$. The vast majority of counts was classified as intact (>90\%). After seven and nine weeks the rate of degraded elements increased significantly to values between 9.4 and $19.6 \%$ for all three categories. Correspondingly, the rate of strongly degraded elements in the categories bordered pits and half bordered pits increased to an average level between 2.8 and $6.9 \%$. But surprisingly, in the category cell wall the amount of strongly degraded cells remained at a low level (mean 0.4-1.1\%).

Compared to other white rot fungi, P. vitreus thus showed a reduced tendency to strongly degrade the tracheid cell walls at longer incubation periods (Schwarze et al., 1997). However, the fact that after seven and nine weeks the occurrence of strongly degraded elements was rather associated with the bordered and halfbordered pits indicates a possible advantage of this fungus for the bioincising process.

\subsubsection{Heart- and sapwood}

Bordered pits, half bordered pits and cell walls were degraded in both heart- and sapwood, but fungal activity was generally higher in the sapwood. Statistically, no significant differences were apparent from bordered pits and cell wall elements, but half bordered pits were degraded significantly more often in the sapwood (mean 13.9\%) than in the heartwood (mean 9.3\%). Commonly, fungal activity in Norway spruce wood can be expected to be higher in sapwood than in heartwood (Zabel and Morrell, 1992; Anagnost and Smith, 1997a; Wang et al., 1997). Our investigations clearly confirm this fact. But we could also show that $P$. vitreus is capable to develop a strong enzymatic activity in the heartwood tissue. This confirms the findings of Schwarze et al. (2006) who described a significant improvement of liquid uptake by $P$. vitreus in Norway spruce heartwood.

Under the aspect of permeability improvement it is of major interest to identify microorganisms that are able to develop their enzymatic activity in this durable tissue of the stem. Messner et al. (2003) and Reinprecht and Pánek (2008) described a permeability improvement of softwoods by means of several fungi, among others Trichoderma spp., which was however limited to the sapwood. Additionally, Rosner et al. (1998) tested the basidiomycetes Dichomitus squalens and Phanerochaete chrysosporium for the pre-treatment of Norway spruce wood, also showing that the use of certain basidiomycete-strains can result in an increase in permeability within the heartwood. The results of our work confirm that $P$. vitreus possess an affinity to colonize the heartwood even after relatively short incubation periods.

\subsubsection{Early- and latewood}

The bordered pits localized in the earlywood were slightly stronger degraded (mean 15.7\%) than the ones in latewood (mean $12.8 \%$ ). However, this tendency was not significant. Likewise, no 


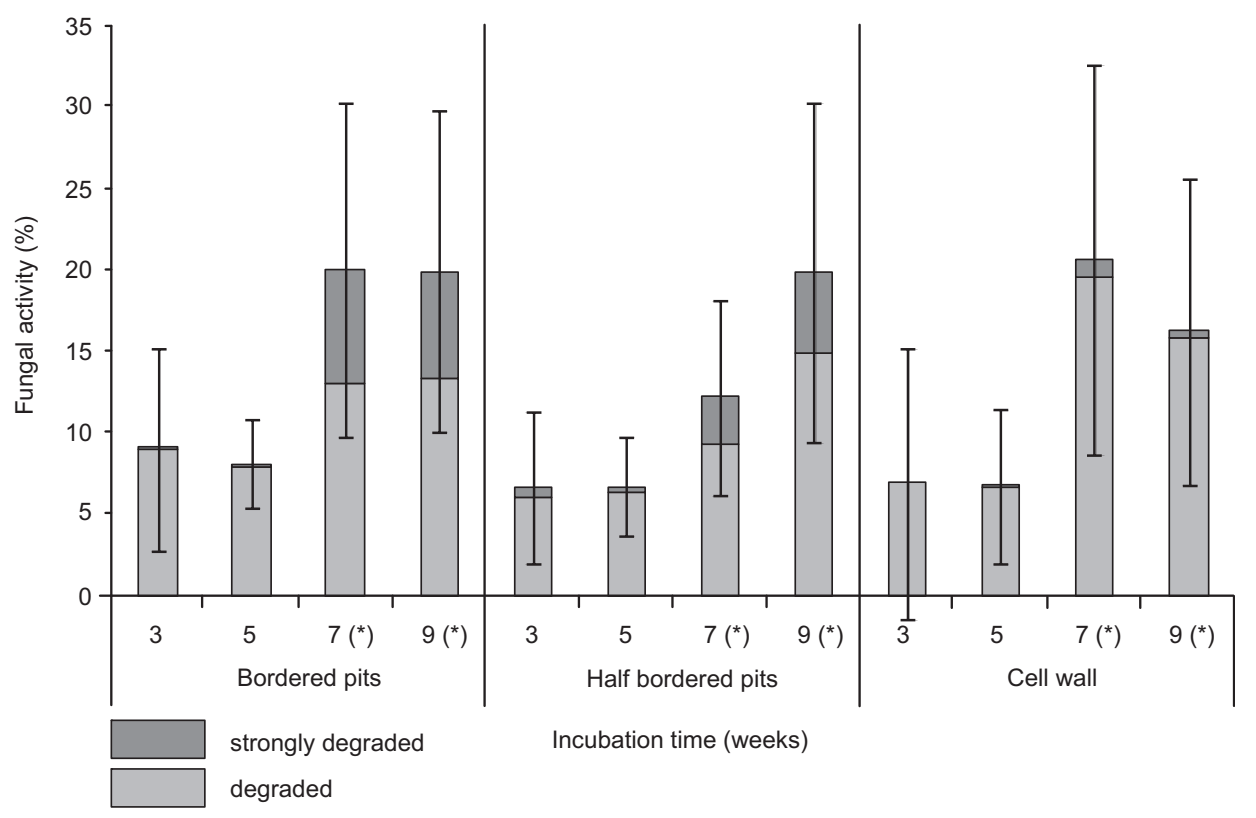

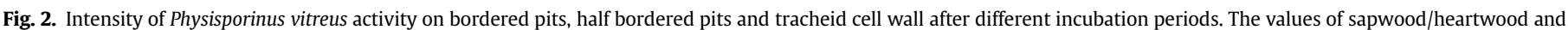

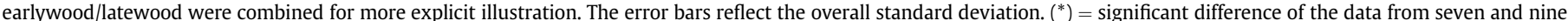
weeks compared to the data of three and five weeks $(n=1505)$.

significant differences were detected for fungal degradation of half bordered pits and cell wall elements, but the latewood was stronger affected than the earlywood regions.

Especially after seven to nine weeks of incubation, we found that $P$. vitreus formed cavities and notches mainly in latewood regions. The observed differences between early- and latewood may be explained by latewood being less accessible to hyphae due to the presence of fewer and smaller pits (Levin and Castro, 1998). This explanation is also true for Norway spruce wood where $P$. vitreus might be forced to create own voids by degrading the cell wall, since a higher density and only little availability of "natural" openings exists. Moreover, the absolute amount of degradable material is evidently higher in latewood due to its thicker cell walls. Skyba et al. (2009) showed on thermo-hygro-mechanically (THM) densified wood of Norway spruce that Trametes versicolor and T. pubescens circumvented the conditions that restricted hyphal growth by means of transverse bore holes through the tracheid cell walls. Liese (1970) suggested that the higher degree of lignification in early wood tracheids may have a protective function against white rot fungi. Thus, the latewood tracheids are decomposed faster and earlier than the earlywood tracheids.

\subsection{Degradation characteristics of Physisporinus vitreus}

The reduced fluorescence of acridine orange stained tissue revealed a selective delignification that was induced by $P$. vitreus in local areas of the wood. The characteristic delignification of the secondary cell wall (S2) by the white rot fungi commenced from the lumen towards the middle lamella (Fig. 3.1). But also a soft rot Type I and II occurred locally and was discernable by the formation of hyphal tunneling and cavities in the secondary walls (Fig. 3.2). We did not detect a homogenous distribution of decay but rather a clustered pattern of zones with lower and higher decay activity. Material heterogeneity increased with increasing incubation time, causing a higher data variability.

The presence of selective delignification and soft rot Type I and II caused by the same fungus has also been described for several

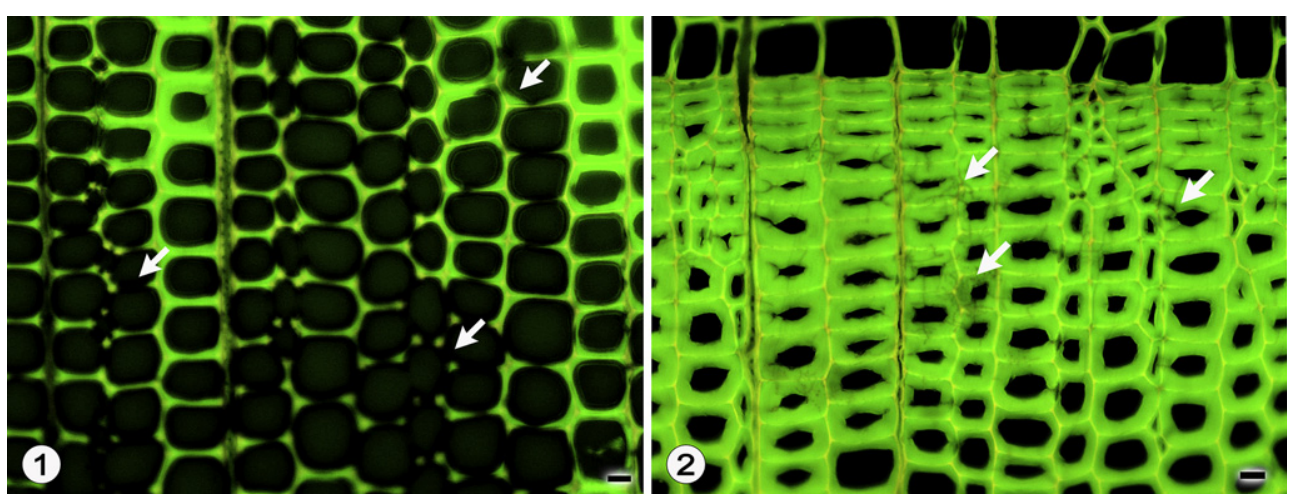

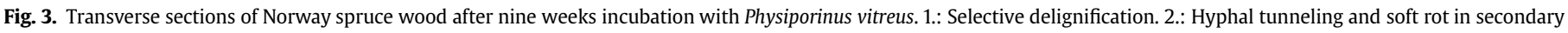
walls of tracheids. Incubation period: nine weeks. Sections stained with acridine orange and viewed with UV-excitation. - Scale bars $=10 \mu \mathrm{m}$. 
white rot fungi by various authors (Schwarze et al., 1997; Anagnost, 1998; Ray et al., 2005). The different decay types occurred in close proximity and in the same substrate. Hence, the fungi are capable of switching between decay types depending on the prevailing conditions in the wood (Zabel and Morrell, 1992; Schwarze and Baum, 2000; Deflorio, 2005). Eaton (2000) suggested that the classification of wood decay types mentioned in the introduction might be too rigid and does not reflect the true complexity of the natural situation.

The occurrence of cell wall alterations and the formation of branched cavities that we detected in latewood regions of seven and nine weeks incubated specimens is typical for soft rot Type I (as also illustrated by Schwarze (2007)). The local switching from white rot to soft rot-like decay patterns in the investigated material seems to be possible against this background (Schwarze and Engels, 1998). Selectivity of lignin degradation is also variable over the duration of the incubation. Thus, a fungus may be selective during early stages of colonization, but the selectivity turns into a nonselective decay with time, as observed with Ganoderma australe by Ferraz et al. (2000).

On average, heartwood specimens revealed a slightly lower mass loss after incubation with $P$. vitreus than sapwood specimens (Fig. 4). However, after three and five week's incubation mass loss ranged between 1.0 and $1.3 \%$, indicating a relatively low fungal activity. After seven weeks incubation sap- and heartwood showed a significant increase in mass loss to 2.4 and $2.1 \%$ respectively. After nine weeks, we recorded the largest mass losses but heartwood remained less affected than sapwood. Moreover after nine weeks mass losses exceeded $4 \%$ only in single wood specimens. Anyhow, at no incubation period significant differences between sapwood and heartwood mass loss were observed.

Commonly, tests with incubation periods of several months are conducted to determine the decomposition potential of wood decay fungi and mass losses of up to 60\% are reported (Blanchette et al., 1988; EN 113, 1996; Schmidt et al., 1996; Levin and Castro, 1998; Luna et al., 2004). In contrast, the mass losses recorded in our investigations were considerably lower, since the incubation periods were comparably short and exceeded the early decay stage of $P$. vitreus only by several days or weeks. The early decay stage is characterized (1) by fungal adaptation to the prevailing wood

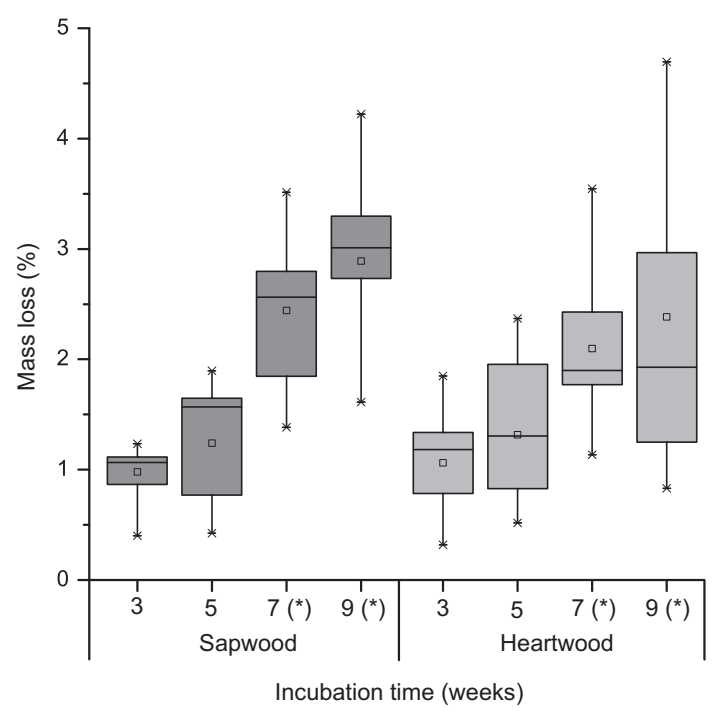

Fig. 4. Mass loss $\Delta M$ in sapwood and heartwood of Norway spruce after incubation with Physisporinus vitreus. $\left({ }^{*}\right)=$ significant increase of mass loss compared to three and five weeks $(n=100)$. conditions, (2) by hyphal growth mostly through xylem rays and axial parenchyma degrading easy accessible carbohydrates and (3) by a relatively low enzymatic activity which results in minor degradation of the cell wall structure (Zabel and Morrell, 1992; Schmidt, 2006). Hence, mass losses during the first five weeks were below $2 \%$. After seven weeks fungal activity steadily increased as apparently the initial period of substrate colonization had commenced and the wood matrix constituents were degraded to a significantly larger extent.

Schwarze et al. (2006) reported insignificant mass losses below $1 \%$ after six weeks incubation of $P$. vitreus on Norway spruce. In the same study, after twelve weeks the fungal activity had induced a significant $4 \%$ mass loss, confirming the tendency of our obtained data. In contrast to these findings, van Acker and Stevens (1996) observed much higher degradation rates of $P$. vitreus, where mass losses after 3 weeks of $5 \%$ or even $40 \%$ after 6 weeks were measured. Low mass losses occurring together with a significant permeability improvement are a positive aspect of the bioincising approach.

\subsection{Physisporinus vitreus selectivity towards pit membrane degradation}

Hyphae were found in the xylem ray parenchyma and the tracheid lumina growing to adjacent cells via pits. Hyphae grew through pit apertures eroding and dislocating the margo and torus and subsequently also enlarging the porus. In addition to pit openings we also observed the formation of bore holes in the tracheid cell walls with diameters of 1 and $5 \mu \mathrm{m}$ even after three weeks incubation (Fig. 5.1).

Advanced cell wall thinning and localized soft rot was apparent in strongly degraded tracheids and xylem ray cells after seven and nine week's incubation. Here, cavities (soft rot Type I), erosion notches (soft rot Type II) and hyphal tunneling developing in local clusters of high fungal activity were predominantly apparent within the latewood (Fig. 5.2 and 5.3). Hyphal tunneling was mostly t-branched, since the hyphae formed branches in the secondary walls growing perpendicular to the main growth direction.

In the observed material, bordered pits, half bordered pits and tracheid cell walls were equally degraded by $P$. vitreus. After incubation periods of three, five and nine weeks no significant differences were observed between the degradation of the pit structure and cell walls (Fig. 6).

After three and five week's incubation, fungal activity averaged between 6.3 and $9.1 \%$ for all three categories. Bordered pits appeared to be slightly stronger affected than half bordered pits and cell wall damages showed the lowest values at three weeks. After three and five weeks, on average up to $12 \%$ of the bordered and up to $8 \%$ of the half bordered pits were affected by fungal activity. After seven weeks incubation, half bordered pits were less degraded than the other two elements, resulting in significant differences between the categories in this case $(p<0.05)$ but most probably representing a random effect.

Between five and seven weeks fungal activity increased and resulted in an opening of bordered and half bordered pits at a mean range of 13.1 and $21.0 \%$ while $18.6 \%$ of the cell walls were affected, indicating a significant influence of the incubation time for all three categories. This significant and step wise increase of fungal activity could be observed in several data sets, as will be also shown further below. After nine weeks incubation no clear further increase of fungal activity was observed as the values only increased slightly (mean 19.0-21.6\%).

Schwarze and Landmesser (2000) described the preferential selective delignification of $P$. vitreus, which they observed on naturally infected wood from cooling towers. No simultaneous cell 

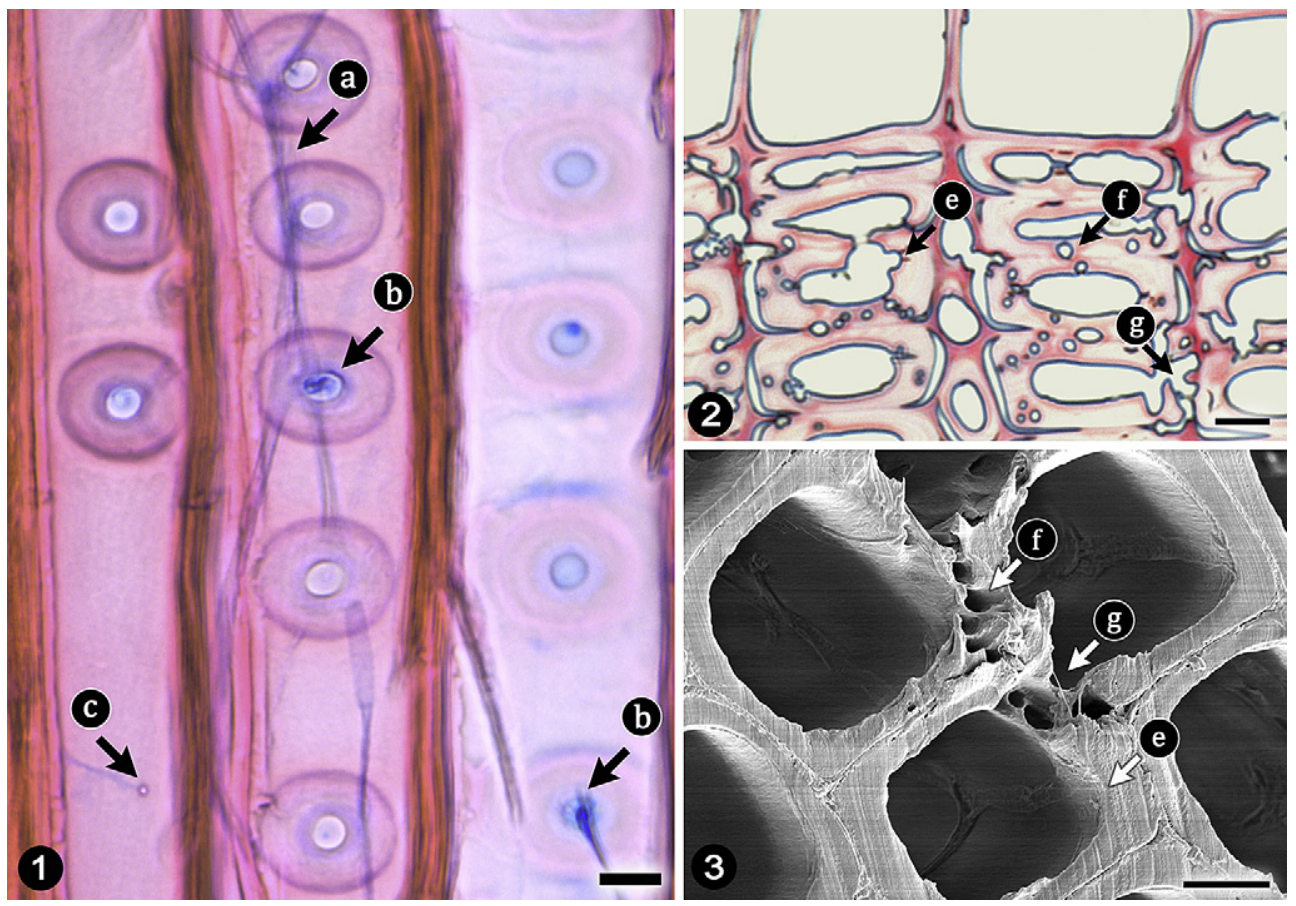

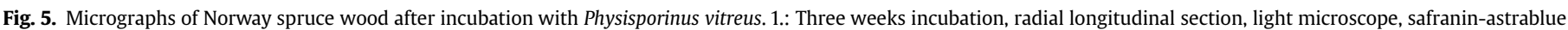

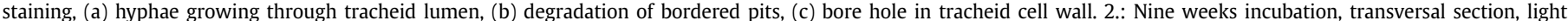

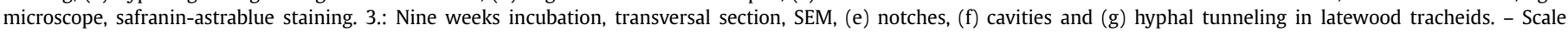
bars $=10 \mu \mathrm{m}$.

wall degradation but exclusively selective delignification was reported. Also Schwarze et al. (2006) emphasized a preferential degradation of pit membranes by $P$. vitreus at early stages of wood colonization. The fungus was attributed to significantly improve the permeability of refractory wood species by selectively opening the pit apertures in tracheids and ray parenchyma without causing major strength losses to the incubated material. No major cell wall

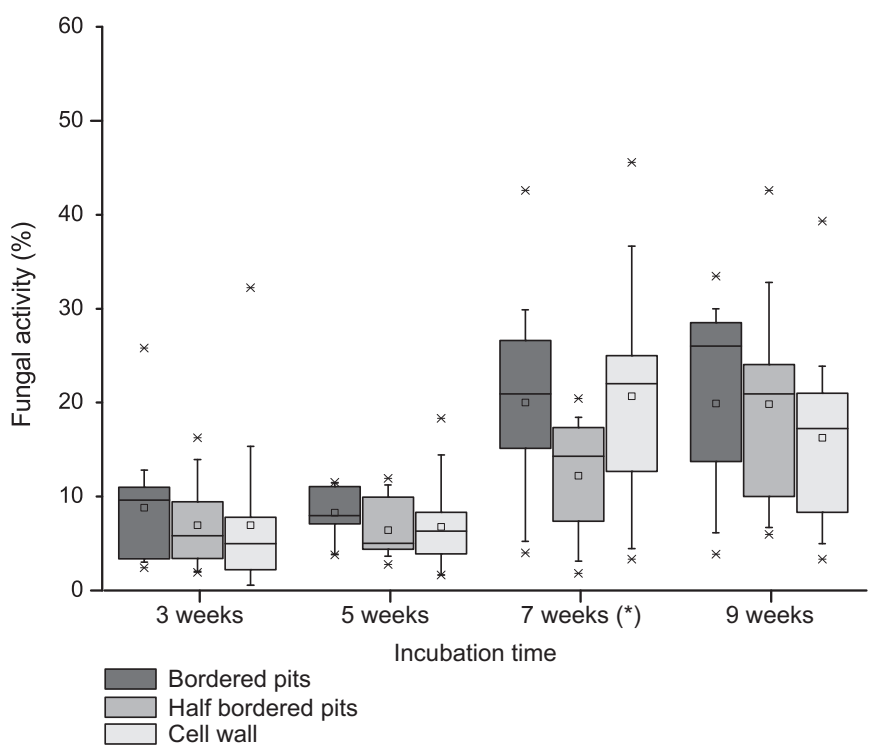

Fig. 6. Activity of Physisporinus vitreus on bordered pits, half bordered pits and tracheid cell wall after different incubation periods. The values of the levels degraded and strongly degraded were combined for more explicit illustration. $(*)=$ significant difference between half bordered pits and bordered pits/cell wall after seven weeks incubation $(n=1505)$. degradation was observed or described in these studies since extensive histological studies were not performed. But additional microscopic studies on the same material revealed localized regions with soft rot Type I and II, i.e. cavity formation and notches in the cell wall (data not shown). These observations matched well with our results since we could not confirm a high degree of selectivity of $P$. vitreus towards the pit membranes.

\subsection{Environmental conditions during incubation}

At this point it is necessary to discuss the environmental conditions during the incubation in order to better understand the factors that possibly influence the degradation characteristics of P. vitreus. Dill and Kraepelin (1988) formulated the hypothesis that selective delignification occurs best under conditions of high humidity, low nitrogen content and low oxygen tension. Interestingly, these are basically the growth conditions under which $P$. vitreus was isolated by Schmidt et al. (1996), namely from wet timber in water cooling towers.

Schubert et al. (2009) conducted detailed studies on influencing growth parameters for $P$. vitreus and found that besides nutrient and oxygen supply, water activity and the $\mathrm{pH}$ play a significant role for substrate colonization. Preliminary experiments in liquid conditions resulted in a homogenous and fast substrate colonization of $P$. vitreus in Norway spruce (Schubert, 2009, oral communication). The fungus was grown in a temperated liquid solution with sufficient oxygen and nutrient supply, with a narrow the carbon/nitrogen-ratio (C/N-ratio) - comparable to a malt agar nutrient medium - and the wood being immersed in the same container from the beginning of the experiment. But also here, $P$. vitreus did neither show an exclusive selective delignification pattern nor a selective pit membrane degradation.

The incubation process in the work of Schwarze et al. (2006) was conducted on a malt agar nutrient medium that had a narrow $\mathrm{C} / \mathrm{N}$ - 
ratio of $50 / 1$ and that was similar to the one we used for our incubation. These investigations suggest that the influence of nutrient supply and the $\mathrm{C} / \mathrm{N}$-ratio in the nutrient medium might play an important role for the decay type developed by $P$. vitreus during incubation.

Vermiculite instead, which was used in the incubation of Schwarze and Landmesser (2000) and Schwarze et al. (2008), had a wide $\mathrm{C} / \mathrm{N}$-ratio of $400 / 1$ so that in that case the limiting nitrogen supply probably triggered the fungus to predominantly cause a selective delignification. No apparent cell wall damages were reported. But it has to be mentioned that a low nitrogen concentration also limits the fast growth of fungal mycelia, as nitrogen is one crucial component for hyphal cell wall formation (Wang et al., 1997).

Kirk et al. (1978) found that a high nitrogen concentration $(24 \mathrm{mM})$ reduced the selective lignin degradation rate by $25-30 \%$ compared to a lower nitrogen concentration $(2.4 \mathrm{mM})$. At the same time, higher nitrogen concentrations and oxygen availability seemed to stimulate the polysaccharide breakdown, as shown by Dill and Kraepelin (1986) in their works on Ganoderma australis "palo podrido" and by Levi and Cowling (1969) and Reid (1983), working on P. chrysosporium. Also Rios and Eyzaguirre (1992) reported on $G$. australis that it showed best results in selective delignification at low nitrogen supply and low oxygen tension.

Considering the influencing factors such as nutrient supply, substrate moisture content and $\mathrm{C} / \mathrm{N}$-ratio we assume that $P$. vitreus was subjected to certain stresses during wood colonization in our experiments. In consequence $P$. vitreus deployed an enzymatic activity which resulted in the presence of several decay patterns in close proximity to another.

\subsection{Comments on the systematic analysis of wood-fungi interactions}

Light microscopy in combination with selected staining methods showed to be an efficient and reproducible method for the evaluation of a larger amount of anatomical features. A fast specimen preparation and a quick micrograph capture made the method to be first choice for the assessment during our investigations. In addition, FE-SEM provided valuable supplementary information on the three-dimensional wood fungus interactions, but did not allow a fast and efficient data capture.

The high standard deviations and the asymmetry of all measurement data reflect the difficulty to reliably analyze fungal activity in the wood substrate. Heterogeneous distribution of hyphae and localized enzymatic activity in the wood require a vast amount of microscopic observations to obtain statistically valid results.

One general problem for microscopic analysis is the individual subjectivity of the assessing person. Therefore we defined a detailed criteria catalogue in order to assure a high degree of objectivity and reproducibility. The criteria catalogue served as a classification guideline to estimate and classify the fungal activity on the individual anatomical elements. But a certain range of individual variability during data capture is naturally given by the assessing person and must be considered when analyzing the data. The presented data in this study are a result of a thorough evaluation process and serve to identify consistent trends.

\section{Conclusions}

The improvement of the incubation process for bioincising is still in progress. The decay patterns of $P$. vitreus and the influencing parameters that result in a selective degradation of the pit membranes are not yet fully understood and require supplementary research. Incubation conditions must be further optimized to stimulate a fast and homogenous colonization of wood and to reduce the negative side effects on the tracheid cell wall. Only a bioincising process with short incubation times, significant permeability improvements and negligible strength losses may provide a perspective for industrial application.

\section{Acknowledgements}

We like to thank Prof. Dr. Fritz Schweingruber and Prof. Dr. Olaf Schmidt for useful suggestions and comments during this study. Moreover, the authors gratefully acknowledge the helpful advises of Prof. emer. Dr. Hans-Rudolf Roth for the statistical analysis. The present study emerged from the research project CTI.8593.1 LSPPLS 'Bioincising of conifer wood with Physisporinus vitreus to improve its treatability for a range of wood preservation and modification methods'. The authors express their gratitude to the Swiss CTI (Innovation Promotion Agency) for its financial support.

\section{References}

Anagnost, S.E., 1998. Light microscopic diagnosis of wood decay. IAWA J. 19, 141-167. Anagnost, S.E., Smith, W.B., 1997a. Comparative decay of heartwood and sapwood of red maple. Wood Fiber Sci. 29, 189-194.

Anagnost, S.E., Smith, W.B., 1997b. Hygroscopicity of decayed wood: implications for weight loss determinations. Wood Fiber Sci. 29, 299-305.

Aufsess, H., Pechmann, H.V., Graessle, E., 1968. Fluoreszenzmikroskopische Beobachtungen an pilzbefallenem Holz. Holz Roh-Werkst 26, 50-61.

Blanchette, R.A., 1984. Selective delignification of wood by white-rot fungi. Appl. Biochem. Biotechnol. 9, 323-324.

Blanchette, R.A., 1991. Delignification by wood-decay fungi. Annu. Rev. Phytopathol. 29, 381-398.

Blanchette, R.A., Burnes, T.A., Leatham, G.F., Effland, M.J., 1988. Selection of whiterot fungi for biopulping. Biomass 15, 93-101.

Bleicher, N., 2008. An easy low-budget method to produce thin-sections of heavily decayed archaeological wood. Dendrochronologia 26, 9-11.

Comstock, G.L., 1970. Directional permeability of softwoods. Wood Fiber Sci. 1, 283-289.

Daniel, G., Volc, J., Nilsson, T., 1992. Soft-rot and multiple T-branching by the basidiomycete Oudemansiella mucida. Mycol. Res. 96, 49-54.

Deflorio, G., 2005. Wood Decay Dynamics in the Sapwood of Trees-In Vitro and In Vivo Studies on the Role of the Wood Substrate in Decay Development. AlbertLudwigs-Universität, Freiburg im Breisgau. 336.

Dill, I., Kraepelin, G., 1986. Palo podrido: model for extensive delignification of wood by Ganoderma applanatum. Appl. Environ. Microbiol. 52, 1305-1312.

Dill, I., Kraepelin, G., 1988. Degradation of lignin/cellulose by white-rot fungi: influence of specific ecological factors. (Der Abbau von Lignin/Cellulose durch Weissfäule-Pilze: Einfluss spezifischer ökologischer Faktoren). Forum Mikrobiologie 11, 484-489.

DIN-EN 13183-1, 2002. Feuchtegehalt eines Stückes Schnittholz: Bestimmung durch Darrverfahren. Deutsches Institut für Normung e.V.

Eaton, R., 2000. A breakthrough for wood decay fungi. New Phytol. 146, 3-4.

EN 113, 1996. Wood Preservatives - Test Method for Determining the Protective Effectiveness Against Wood Destroying Basidiomycetes - Determination of the Toxic Values. CEN Eur. Committee for Standardization.

Erickson, H.D., 1970. Permeability of southern pine wood - a review. Wood Sci. 2. 149-158.

Ferraz, A., Parra, C., Freer, J., Baeza, J., Rodriguez, J., 2000. Characterization of white zones produced on Pinus radiata wood chips by Ganoderma australe and Ceriporiopsis subvermispora. World J. Microbiol. Biotechnol. 16, 641-645.

Flynn, K.A., 1995. A review of the permeability, fluid flow, and anatomy of spruce (Picea spp.). Wood Fiber Sci. 27, 278-284.

Gerlach, D., 1984. Botanische Mikrotechnik - Eine Einführung. Georg Thieme Verlag, Stuttgart, New York.

Hansmann, C., Gindl, W., Wimmer, R., Teischinger, A., 2002. Permeability of wood a review. Drev Vysk 47, 1-16.

Kirk, T.K., Schultz, E., Connors, W.J., 1978. Influence of culture parameters on lignin metabolism by Phanerochaete chrysosporium. Arch. Microbiol. 117, 277-285.

Kirk, T.K., Yang, H.H., 1979. Partial delignification of unbleached kraft pulp with ligninolytic fungi. Biotechnol. Lett. 1, 347-352.

Lehringer, C., Arnold, M., Richter, K., Schubert, M., Schwarze, F.W.M.R., Militz, H. 2009a. Bioincised wood as substrate for surface modifications. In: Englund, F., Hill, C.A.S., Militz, H., Segerholm, B.K. (Eds.), The Fourth European Conference on Wood Modification, pp. 197-200. Stockholm.

Lehringer, C., Richter, K., Schwarze, F.W.M.R., Militz, H., 2009b. A review on promising approaches for liquid permeability improvement in softwoods. Wood Fiber Sci. 41, 373-385.

Levi, M.P., Cowling, E.B., 1969. Role of nitrogen in wood deterioration. VII. Physiological adaptation of wood-destroying and other fungi to substrates deficient in nitrogen. Phytopathology 59, 460-468. 
Levin, L., Castro, M.A., 1998. Anatomical study of the decay caused by the white-rot fungus Trametes trogii (Aphyllophorales) in wood of Salix and Populus. IAWA J. $19,169-180$

Liese, W., 1970. Ultrastructural aspects of woody tissue disintegration. Annu. Rev. Phytopathol. 8, 231-257.

Liese, W., Bauch, J., 1967. On anatomical causes of refractory behaviour of spruce and Douglas fir. J. Inst. Wood Sci. 4, 3-14.

Luna, M.L., Murace, M.A., Keil, G.D., Otaño, M.E., 2004. Patterns of decay caused by Pycnoporus sanguineus and Ganoderma lucidum (Aphyllophorales) in poplar wood. IAWA J. 25, 425-433.

Mai, C., Kües, U., Militz, H., 2004. Biotechnology in the wood industry. Appl Microbiol. Biotechnol. 63, 477-494.

Messner, K., Bruce, A., Bongers, H.P.M., 2003. Treatability of refractory wood species after fungal pre-treatment. In: Proceedings of the Second European Conference on Wood Modification 2003, Göttingen, pp. 389-401.

Petty, J.A., 1970. Permeability and structure of the wood of Sitka spruce. Proc. Roya Soc. London, Ser. B 175, 149-166.

Ray, M., Kleist, G., Murphy, R., 2005. Decay assessment in a hardwood handrail at the South Bank, London. J. Inst. Wood Sci. 17, 51-58.

Reid, I.D., 1983. Effects of nitrogen supplements on degradation of aspen wood lignin and carbohydrate components by Phanerochaete chrysosporium. Appl. Environ. Microbiol. 45, 830-837.

Reinprecht, L. Pánek, M.,2008. Bio-treatment of spruce wood for improving of its permeability and soaking. Pt. 2: direct treatment with the fungus Trichoderma viride. Wood Res-Slovakia 53,1-8.

Rios, S., Eyzaguirre, J., 1992. Conditions for selective degradation of lignin by the fungus Ganoderma australis. Appl. Microbiol. Biotechnol. 37, 667-669.

Rosner, B., Messner, K., Tucker, E., Bruce, A., 1998. Improved preservative penetration of spruce after pretreatment with selected fungi. I. Fungal pretreatment of pole sections. Int. J. Res. Group Wood Preserv.

Sachs, L., 1974. Applied Statistics (Angewandte Statistik: Planung und Auswertung Methoden und Modelle). Springer-Verlag, Berlin, Heidelberg, New York.

Schmidt, O., 2006. Wood and Tree Fungi. Springer Verlag, Berlin, Heidelberg.

Schmidt, O., Liese, W., Moreth, U., 1996. Decay of timber in a water cooling tower by the basidiomycete Physisporinus vitreus. Material und Organismen 30.

Schmidt, O., Schmitt, U., Moreth, U., Potsch, T., 1997. Wood decay by the whiterotting basidiomycete Physisporinus vitreus from a cooling tower. Holzforschung 51, 193-200.

Schubert, M., Dengler, V., Mourad, S., Schwarze, F.W.M.R., 2009. Determination of optimal growth parameters for the bioincising fungus Physisporinus vitreus by means of response surface methodology. J. Appl. Microbiol. 106, 1734-1742.
Schwarze, F.W., Lonsdale, D., Fink, S., 1995. Soft rot and multiple T-branching by the basidiomycete Inonotus hispidus in ash and London plane. Mycol. Res. 99, 813-820.

Schwarze, F.W.M.R., 2007. Wood decay under the microscope. Fungal Biol. Rev. 21, 133-170.

Schwarze, F.W.M.R., Baum, S., 2000. Mechanisms of reaction zone penetration by decay fungi in wood of beech (Fagus sylvatica). New Phytol. 146, 129-140.

Schwarze, F.W.M.R., Engels, J., 1998. Cavity formation and the exposure of peculiar structures in the secondary wall (S2) of tracheids and fibres by wood degrading basidiomycetes. Holzforschung 52, 117-132.

Schwarze, F.W.M.R., Landmesser, H., 2000. Preferential degradation of pit membranes within tracheids by the basidiomycete Physisporinus vitreus. Holzforschung 54, 461-462.

Schwarze, F.W.M.R., Landmesser, H., Zgraggen, B., Heeb, M., 2006. Permeability changes in heartwood of Picea abies and Abies alba induced by incubation with Physisporinus vitreus. Holzforschung 60, 450-454.

Schwarze, F.W.M.R., Lonsdale, D., Fink, S., 1997. An overview of wood degradation patterns and their implications for tree hazard assessment. Arboricultural J. 21, $1-32$.

Schwarze, F.W.M.R., Schubert, M., 2009. Enhanced uptake of wood modification agents in "bioincised" wood. Int. Res. Group Wood Prot. Paper prepared for 40th Annu. Meet. Beijing, China 24-28 May 2009, 1-8.

Schwarze, F.W.M.R., Spycher, M., Fink, S., 2008. Superior wood for violins - wood decay fungi as a substitute for cold climate. New Phytol. 179, 10951104.

Skyba, O., Niemz, P., Schwarze, F.W.M.R., 2009. Resistance of thermo-hygromechanically (THM) densified wood to degradation by white rot fungi. Holzforschung 63, 639-646.

Srebotnik, E., Messner, K., 1994. A simple method that uses differential staining and light microscopy to assess the selectivity of wood delignification by white rot fungi. Appl. Environ. Microbiol. 60, 1383-1386.

van Acker, J., Stevens, M., 1996. Laboratory culturing and decay testing with Physisporinus vitreus and Donkioporia expansa originating from identical cooling tower environments show major differences. Int. Res. Group Wood Pres, 8. IRG/ $\mathrm{WP} / 10184$

Wang, Z., Leone, R., Breuil, C., 1997. Why fungal growth is less effective in aspen heartwood than in aspen sapwood. Material und Organismen 31.

Worrall, J.J., Anagnost, S.E., Zabel, R.A., 1997. Comparison of wood decay among diverse lignicolous fungi. Mycologia 89, 199-219.

Zabel, R.A.Z., Morrell, J.J., 1992. Wood Microbiology: Decay and Its Prevention. Academic Press Inc., San Diego. 



\title{
Resistance of bioincised wood treated with wood preservatives to blue-stain and wood-decay fungi
}

\author{
M. Schubert ${ }^{\mathrm{a}, *}$, T. Volkmer $^{\mathrm{b}}$, C. Lehringer $^{\mathrm{c}}$, F.W.M.R. Schwarze ${ }^{\mathrm{a}}$ \\ ${ }^{a}$ Empa, Swiss Federal Laboratories for Materials Science and Technology, Wood Laboratory, Group of Wood Protection and Biotechnology, Lerchenfeldstrasse 5, \\ CH-9014 St. Gallen, Switzerland \\ ${ }^{\mathrm{b}}$ Berner Fachhochschule, Architektur, Holz und Bau, Solothurnstrasse 102, CH-2504 Biel, Switzerland \\ ${ }^{\mathrm{c}}$ Empa, Swiss Federal Laboratories for Materials Science and Technology, Wood Laboratory, Group of Wood and Surface Technology, Ueberlandstrasse 129, \\ CH-8600 Dübendorf, Switzerland
}

\section{A R T I C L E I N F O}

\section{Article history:}

Received 25 August 2010

Received in revised form

5 October 2010

Accepted 5 October 2010

Available online 27 October 2010

\section{Keywords:}

Bioincising

Blue-stain fungi

Physisporinus vitreus

Wood-decay

\begin{abstract}
A B S T R A C T
Bioincising is a biotechnological process that aims at the improvement of wood preservative uptake in wood species with a low permeability, such as Norway spruce (Picea abies (L.) Karst). The process is based on a short-term pre-treatment with white-rot fungus Physisporinus vitreus. During incubation the membranes of bordered and half bordered pits are supposed to be degraded by fungal activity resulting in a better treatability of the wood structure for wood preservatives. In the present study, first of all the resistance of bioincised Norway spruce heartwood and untreated controls against blue-stain and wooddecay fungi (white- and brown-rot) was determined. Then, bioincised and untreated specimens were dipped or vacuum impregnated with six wood preservatives and substance uptake was assessed gravimetrically. Additionally, the penetration of 3-iodo-2-propynyl butylcarbamate (IPBC) into the wood was analyzed by high-pressure liquid chromatography (HPLC). Finally, wood resistance was assessed according to the European standards EN 152 and EN 113. Results showed no difference between bioincised wood without preservatives and the untreated wood against blue-stain discolouration. However, a significant $(P<0.05)$ increase in susceptibility against wood decay was recorded. In the bioincised wood samples a significantly higher uptake of all the different preservatives was determined and the HPLC-method revealed that IPBC penetrated deeper into bioincised wood than into control samples. The improved uptake of preservatives into bioincised wood resulted in a significantly higher resistance against white- and brown-rot fungi. However, only a slight protection against wood discolouration by blue-stain fungi was recorded. The results of this study show for the first time that the biotechnological process with $P$. vitreus can be used to improve wood durability by increasing the uptake and penetration of wood preservatives.
\end{abstract}

(c) 2010 Elsevier Ltd. All rights reserved.

\section{Introduction}

In coniferous heartwood nearly all the pit membranes (torus) are aspirated into the bordered pits of tracheids after drying and, additionally, the surface of the pit membranes in heartwood are frequently covered with extractives (adcrustation) (Liese and Bauch, 1967; Watanabe et al., 1998). Aspiration of the bordered pits results in greatly reduced permeability of the wood and therefore treatment with wood preservatives or modifying agents that enhance the durability, fire-resistance, UV-protection, hydrophobicity or hardness is impeded (Lehringer et al., 2009b). In the

\footnotetext{
* Corresponding author. Tel.: +4171274 7624

E-mail address: mark.schubert@empa.ch (M. Schubert).
}

past, improving the wood permeability has been attempted by the application of enzymes, bacteria and several blue-stain and brownrot fungi (Green et al., 1995; Mai et al., 2004). The bioincising process is a new biotechnological approach to improve the permeability of Norway spruce (Picea abies (L.) Karst) heartwood via pre-treatment with the white-rot fungus $P$. vitreus (Pers.: Fr.) P. Karst. (Lehringer et al., 2009b; Schwarze and Schubert, 2009). Based on findings from previous laboratory investigations (Schwarze and Landmesser, 2000; Schwarze et al., 2006), an industry collaboration project was launched with the objective of scaling up this process to an industrial scale (CTI No. 8593.1 LSPP). For this purpose, a set of investigations was performed to identify and detect important physical, chemical and biological parameters that affect wood colonization by P. vitreus (Schubert et al., 2009, 2010b; Schubert and Schwarze, in press). In addition, the 
wood-fungus interaction between $P$. vitreus and Norway spruce sapwood and heartwood was recently investigated in detail (Lehringer et al., 2010).

Further aspects in the scaling up of bioincising is characterizing the resistance of biologically modified wood, as well as evaluating bioincised wood as an improved substrate for wood-modification substances. Therefore, the objective of this study was to characterize the resistance against blue-stain and wood-decay fungi of bioincised Norway spruce heartwood and control samples that were not treated with preservatives. Furthermore, the influence of bioincising on the uptake and average penetration depth of wood preservatives (WP), as well as the interaction between the bioincised wood and these substances, was analyzed.

\section{Materials and methods}

\subsection{Fungal strains}

The origins of the fungi used in the present study are provided in Table 1. The cultures are maintained in the collections of Empa, Swiss Federal Laboratories for Materials Science and Technology, Switzerland. For the present experiments, the initial inoculum was taken from cultures growing on $2 \%$ malt extract agar medium (Oxoid, Darmstadt, Germany) in Petri dishes stored at $4{ }^{\circ} \mathrm{C}$ for no longer than 6 months. All fungi were identified microscopically and the ITS1-5.8S-ITS2 region of the rDNA was amplified and sequenced for $P$. vitreus (EMBL, accession no. FM202494).

\subsection{Bioincising of Norway spruce wood with P. vitreus}

Heartwood specimens $(110 \times 40 \times 15 \mathrm{~mm}$, length $\times$ width $\times$ height), free of defects, were extracted longitudinally from boards of Norway spruce trees grown in Switzerland, in order to minimize the influence of natural variability. All specimens were conditioned at $20{ }^{\circ} \mathrm{C}$ and $65 \%$ relative humidity $(\mathrm{RH})$ until they reached an equilibrium moisture content of approximately 12\%. Prior to fungal inoculation the wood specimens were sterilized by ethylene oxide at 0.65 bar and $55{ }^{\circ} \mathrm{C}$ for $1 \mathrm{~h}$ and desorbed at $55^{\circ} \mathrm{C}$ for $24 \mathrm{~h}$. Subsequently, the wood specimens were inserted aseptically into Kolle flasks, according to EN 113 (CEN 1997), fully covered by P. vitreus and incubated in the dark for 6 weeks at $22 \pm 1{ }^{\circ} \mathrm{C}$ and $75 \pm 5 \% \mathrm{RH}$. After incubation, the mycelium was removed from the surface of the wood specimens, which were dried at room temperature before a defined part of each end-grain was sectioned to final dimensions of $65 \times 40 \times 15 \mathrm{~mm}$. All specimens were subsequently conditioned in a climate chamber $\left(20^{\circ} \mathrm{C}\right.$ and $\left.65 \% \mathrm{RH}\right)$. The control wood specimens were incubated in Kolle flasks, but without fungal inoculum.

Table 1

Origin of the fungi used in the study of bioincising.

\begin{tabular}{lll}
\hline Fungi & Origin & Test \\
\hline Physisporinus vitreus (Pers.: Fr.) P. Karst. & EMPA-642 $^{\mathrm{a}}$ & Bioincising \\
Coniophora puteana (Schum.: Fr.) Karst. & DSM-3085 $^{\mathrm{b}}$ & EN 113 \\
Gloeophyllum trabeum (Pers.:Fr.) Murrill & DSM-3087 $^{\mathrm{b}}$ & EN 113 \\
Oligoporus placenta (Fr.) Cooke & EMPA-45 $^{\mathrm{a}}$ & EN 113 \\
Trametes versicolor (L.: Fr.) Pilát & DSM-3086 $^{\mathrm{b}}$ & EN 113 \\
Aureobasidium pullulans (de Bary) Arnaud & DSM-2404 $^{\mathrm{b}}$ & EN 152 \\
Ceratocystis picea (Münch) H. \& P. Sydow & DSM-4842 $^{\mathrm{b}}$ & EN 152 \\
Cladosporium herbarum (Pers.: Fr.) Link & DSM-63422 $^{\mathrm{b}}$ & EN 152 \\
Discula pinicola (Naum.) Petr. & DSM-4948 $^{\mathrm{b}}$ & EN 152 \\
Sclerophoma pityophila (Corda) Höhn. & EMPA-315 $^{\mathrm{a}}$ & EN 152 \\
\hline
\end{tabular}

${ }^{a}$ Isolate from Empa, Swiss Federal Laboratories for Materials Science and Technology, Switzerland.

b Isolate from Deutsche Sammlung von Mikroorganismen und Zellkulturen GmbH, Germany.

\subsection{Treatment with wood preservatives}

Six WPs (ISP International Speciality Products AG, Germany) were tested on bioincised and untreated Norway spruce heartwood (Table 2).

The WPs were dissolved in water and adjusted to a final concentration of $50 \%$ (WP1-5) or 5\% (WP6). Prior to chemical treatment, the wood specimens were dried at $103{ }^{\circ} \mathrm{C}$ for $24 \mathrm{~h}$, cooled in a desiccator and then weighed. In addition, the end-grain of each specimen was sealed with soft silicone grease and firmly fixed between metal mounts to prevent the intrusion of WPs through eventually occurring cracks and shakes. The WPs were applied by dipping (30 min) or by vacuum impregnation at reduced pressure (40 mbar) for $20 \mathrm{~min}$ in a vacuum desiccator. The vessels were then brought back to atmospheric pressure and the specimens were left for further $120 \mathrm{~min}$ in the solution (European Standard EN 113, 1997). The total substance uptake via tangential and radial surfaces was then determined gravimetrically directly after treatment and recalculated to $\mathrm{kg} \mathrm{m}^{-3}$ according to EN 113.

\subsection{Determination of IPBC concentration in wood}

The uptake and penetration into the specimen surface of 3-iodo2-propynyl butylcarbamate (IPBC) were analyzed by high-pressure liquid chromatography (HPLC) according to the method of Volkmer et al. (2010). Chemical analysis was undertaken by HPLC reversed phase mode and the gradient method, using a C18 column (highdensified nucleosil). The eluent was a mixture of acetonitril and water (60:40 vol. \%), the injection volume was $20 \mu \mathrm{L}$ and the flow was $0.9 \mathrm{~mL} \mathrm{~min}^{-1}$. The retention time for IPBC under these conditions was $8.4 \mathrm{~min}$. Detection was performed with a diode array detector at $190 \mathrm{~nm}$ and a bandwidth of $8 \mathrm{~nm}$. Calibration was performed according to an industrial standard from ISP Germany. To determine the penetration of IPBC, small blocks $(25 \times 30 \mathrm{~mm})$ were sectioned in transversal orientation with a microtome to $50 \mu \mathrm{m}$ slices and combined into zones corresponding to $0-500 \mu \mathrm{m}$, 500-1000 $\mu \mathrm{m}, 1000-3000 \mu \mathrm{m}$, and 3000-5000 $\mu \mathrm{m}$.

\subsection{Biological tests}

Susceptibility against blue-stain and wood-decay fungi (Table 1) was determined for the untreated, bioincised heartwood according to EN 152-2 (CEN 1988) and EN 113 (CEN 1997) and compared with that of the untreated controls.

The interaction of the bioincised wood with the WPs and their efficacy in protecting the wood was tested in the same way, but with slight modification: A defined amount $(N=144)$ of each wood specimen that had been treated with a WP was sectioned from the middle of each sample to intensify the biological tests by exposing the inner area (cross-section) of the wood block to the blue-stain and wood-decay fungi. All wood specimens were sterilized with

Table 2

Characteristics of the wood preservatives used in the study of bioincising.

\begin{tabular}{lllll}
\hline \multicolumn{2}{l}{ Wood preservative } & Active substance & & Tests \\
\hline WP 1 & Biodocarb L20 TEX Bulk & IPBC $^{\mathrm{a}}$ & $\sim 20 \%$ & EN 152 \\
WP 2 & Biodocarb L15 BDG Bulk & IPBC & $\sim 15 \%$ & EN 152 \\
WP 3 & Biodocarb L30 BDG Bulk & IPBC & $\sim 30 \%$ & EN 152 \\
WP 4 & Fungitrol F-10 Bulk & IPBC & $10 \%$ & EN 152 \\
WP 5 & Fungitrol 920 & IPBC & $20 \%$ & EN 152 \\
WP 6 & VP7/260a & IPBC & $10 \%$ & EN 113 \\
& & Propiconazole $^{\mathrm{b}}$ & $10 \%$ & \\
\hline
\end{tabular}

\footnotetext{
a IPBC = 3-iodo-2-propynyl butylcarbamate

b Propiconazole = 1-[ [2-(2,4-dichlorophenyl)-4-propyl-1,3-dioxolan-2-yl]
} methyl]-1,2,4-triazole. 
ethylene oxide as described. All tests included additional virulence controls per treatment of untreated Norway spruce sapwood, placed into separate vessels (European Standard EN 113, 1997; European Standard EN 152-2, 1988). A total of 488 wood specimens were used in the biological tests, with the following modifications:

Bioincised: Norway spruce heartwood $(N=50)$ pretreated with P. vitreus.

Control: Norway spruce heartwood $(N=50)$ not treated with P. vitreus.

Virulence: Norway spruce sapwood $(N=100)$ not treated with $P$. vitreus and untreated with WP.

WPX-Imp: Control $(N=36)$ and bioincised $(N=36)$ wood impregnated with WP.

WPx/s-Imp: Control $(N=36)$ and bioincised $(N=36)$ wood impregnated with WP and sectioned before applying the biotests.

WPX-Dip: Control $(N=36)$ and bioincised $(N=36)$ wood dipped in WP.

WPx/s-Dip: Control $(N=36)$ and bioincised $(N=36)$ wood dipped in WP and sectioned before applying the biotests.

After 6 weeks incubation, the percentage of blue-stain discolouration of the wood specimens was evaluated by an automated image processing method using Matlab ${ }^{\circledR}$ (Version 7.4 R2007a, MathWorks, Natick, MA, USA) according to Schubert et al. (2010a). The ability of the wood-decay fungi to degrade the wood was determined gravimetrically after 16 weeks incubation and expressed as mass loss (\%) according to EN 113 (CEN 1997).

\subsection{Statistical analysis}

Analysis of variance (ANOVA) was used to assess the effect of different wood treatments; means were separated using $t$-tests or Duncan's multiple range test at a significance level $P<0.05$. Data expressed as percentages, such as blue-stain discolouration and mass loss, were arcsine-transformed prior to analysis and backtransformed to numerical values for visualization. The statistical package used for all analyses was SPSS ${ }^{\circledR}$ (Version 17.0, SPSS Inc., Chicago, IL, USA).

\section{Results and discussion}

\subsection{Susceptibility of bioincised wood against blue-stain and wood-decay fungi}

The susceptibility of Norway spruce sapwood (virulence controls) and the bioincised and control heartwood without treatment with WPs against blue-stain discolouration was compared. The blue-staining of the surface and inner area (crosssection) of the wood specimens after 6 weeks incubation was determined by the automated image processing method described by Schubert et al. (2010a). Quantification of the blue-stained area using this procedure is generally adequate, but to ensure accuracy some points had to be considered. The processing method was not able to distinguish other dark areas similar to blue-staining (e.g. dark spots). It also underestimated the blue-staining if the surface was nearly completely stained with high variation in colour intensity, by grading the lighter blue-stained areas as sound wood. However, overall the method allowed a rapid and objective determination of blue-staining of bioincised and untreated Norway spruce sap- and heartwood with and without WPs.

The Norway spruce sapwood (virulence controls) showed the highest rate of discolouration compared with the bioincised and control wood (Fig. 1). The lower resistance of Norway spruce sapwood compared with heartwood was also reported by Frühwald et al. (2007) and Sandberg (2008).
A comparison of the bioincised heartwood and the control specimens revealed no significant $(P \geq 0.05)$ difference for discolouration of the surface and inner areas (Fig. 1). Volkmer and Schwarze (2008), however, observed on Norway spruce sapwood, and particularly on Scots pine wood, which had been treated with a top-coat preservative (IPBC) an increased blue-stain intensity on the samples pretreated with $P$. vitreus. The wood specimens were exposed to weathering ( 6 months) and tested according to 152-2 (CEN 1988). The authors suggested that pre-treatment with $P$. vitreus enhanced the uptake of water and the subsequent increase in wood moisture may promote colonization by blue-stain fungi. Furthermore, the cell wall modifications by P. vitreus (e.g. selective delignification) may facilitate the decomposition of cellulose by blue-stain fungi (Volkmer et al., 2010). Noteworthy is that, in the present work, no enhancement of susceptibility against blue-stain fungi could be detected in Norway spruce heartwood after pretreament with $P$. vitreus.

In contrast the bioincised wood showed a higher susceptibility to wood-decay fungi (Fig. 2).

All the wood-decay fungi used in the present study, with the exception of Oligoporus placenta, caused significantly higher mass loss in the bioincised wood than in the untreated control (Fig. 2). Schwarze et al. $(2006,2008)$ showed in histological studies of Norway spruce wood that in combination with degradation of pit membranes, $P$. vitreus causes selective delignification of secondary cell walls without affecting the middle lamellae. Recently, Lehringer et al. (2010) also described a localized degradation by $P$. vitreus resembling soft-rot types I and II. The cell wall modifications by $P$. vitreus may facilitate the decomposition of cellulose by the wood-decay fungi. The degradation of cellulose and hemicellulose by brown-rot fungi takes place in different stages. It is assumed that cellulose-degrading enzymes are too large to penetrate the much smaller cell-wall capillaries without previous modification, so in the pre-cellulotic phase hydrogen peroxide is probably formed and with iron ions the lignocellulose matrix is lost (Koenigs, 1974a,b). As a result of slight delignification of the cell wall (particularly of the S2 layer) during the bioincising process, the cellulose-degrading enzymes of the brown-rot fungi may have easier access to the cellulose and hemicellulose in bioincised wood. The same could be valid for Trametes versicolor, a white-rot fungus that simultaneously degrades all wood polymers (lignin, hemicellulose and cellulose). The significantly higher mass loss in bioincised wood by $T$. versicolor is probably also related to the increased presence of readily accessible carbohydrates (i.e.

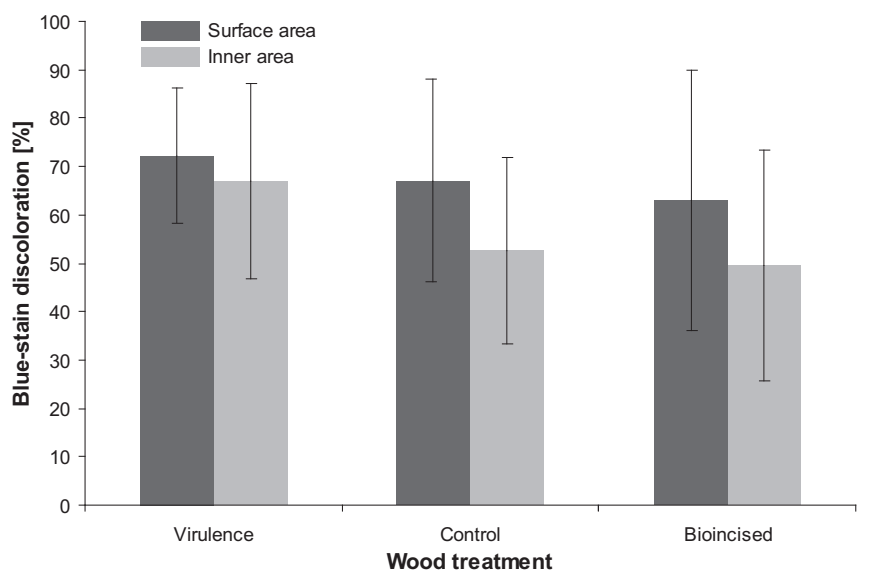

Fig. 1. Blue-stain discolouration [\%] of Norway spruce sapwood (virulence) and heartwood (control and bioincised wood) on the samples' surface and inner area (cross-section) without treatment by wood preservatives. 
a

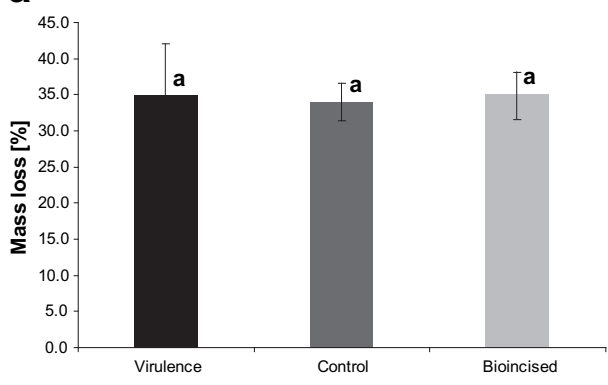

C

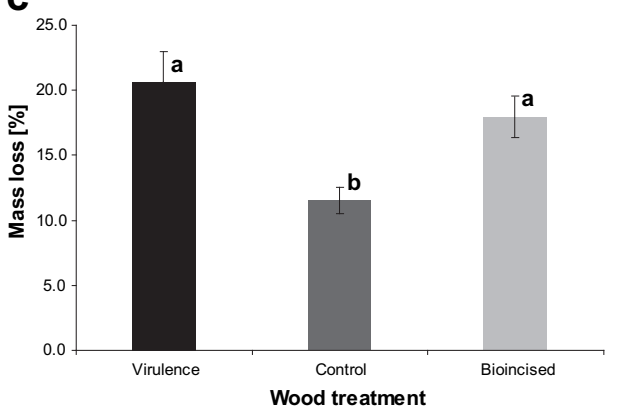

b

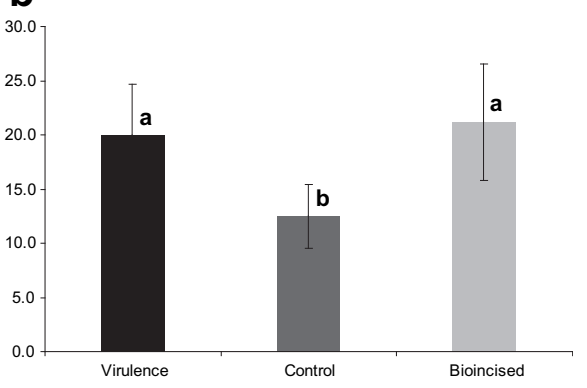

d

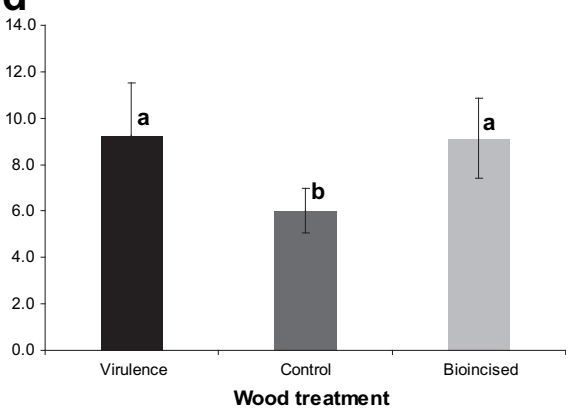

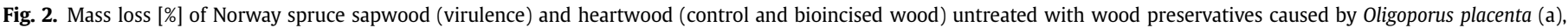

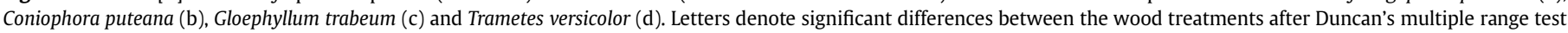
$(P<0.05)$.

hemicellulose and cellulose) (Fig. 2d). In addition to higher wood moisture, the particular cell wall modifications by $P$. vitreus could explain the enhanced susceptibility of bioincised wood to wooddecay fungi.

According to EN 350-2 (CEN 1994), the heartwood of Norway spruce is classified as weakly durable (durability class four). It is more resistant to wood-decay fungi than the sapwood, which is classified as non-durable (durability class five). In the present study, untreated heartwood showed a significantly higher resistance to wood-decay fungi than sapwood, whereas after bioincising the susceptibility for wood-decay fungi in heartwood specimen was similar to the virulent sapwood specimen (Fig. 2). It is evident that the 6-week incubation with $P$. vitreus negatively influenced the resistance of the wood to decay, as indicated by the significant differences between the bioincised and the control specimens (Fig. 2). Thus, the 6-week bioincised heartwood should probably be ranked as durability class five (European Standard EN 350-2, 1994).

\subsection{Wood preservative uptake in bioincised wood}

The uptake of all WPs was significantly increased in the bioincised wood, with the exception of Fungitrol 920 after dipping (Fig. 3a, b). In addition, the uptake of the WPs was much higher after pressure treatment than after dipping. These results are in good agreement with previous studies by Schwarze et al. (2006) and Lehringer et al. (2009a).

The results from HPLC confirm the abovementioned observations (Fig. 4). The mean IPBC content at different penetration depths in the bioincised wood and control specimens was much higher after impregnation than after dipping. In addition, the mean IPBC concentration at all analyzed penetration depths of bioincised wood was higher than in the control specimens, independent of the application method (Fig. 4). Furthermore, the uptake of preservatives was dependent on the WP used, as shown in Figs. 3 and 4.

Furthermore it can be shown by this method that the permeability improvement after six weeks incubation is mostly limited to the subsurface areas (as defined in Lehringer et al., 2009b). The highest concentrations were always measured between zero and $1000 \mu \mathrm{m}$, whereas below $1000 \mu \mathrm{m}$ in only two cases the concentration of $10000 \mu \mathrm{g} / \mathrm{g}$ was reached.
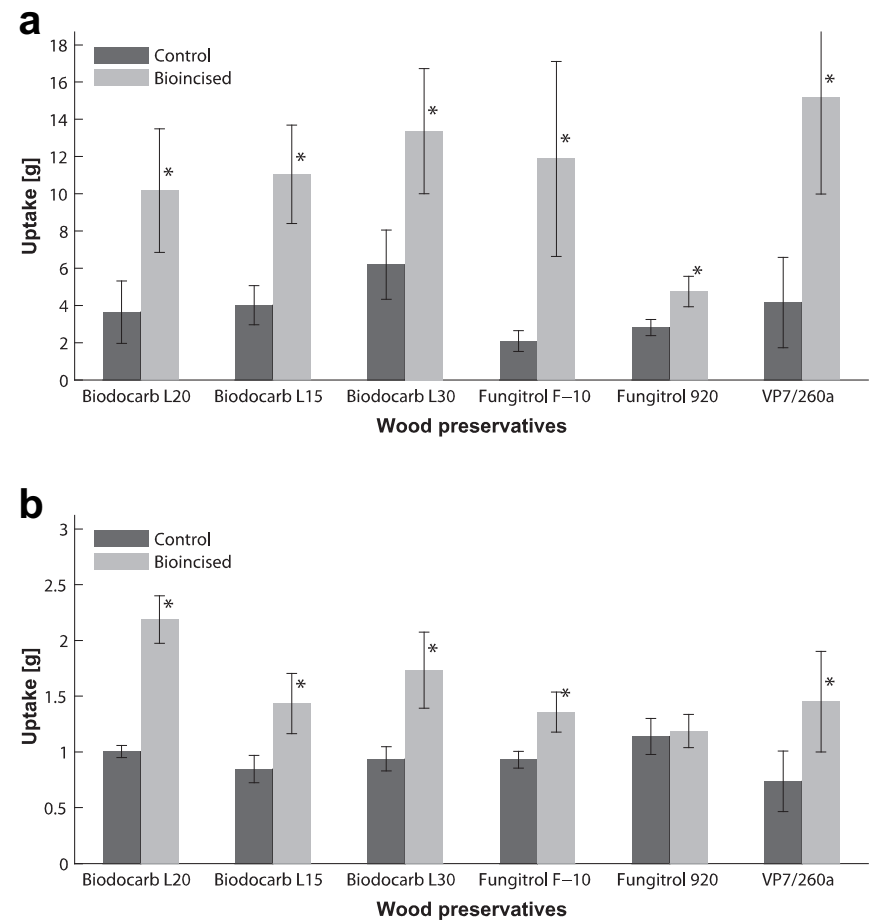

Fig. 3. Uptake of wood preservatives in heartwood specimens of Picea abies after 6 weeks incubation with Physisporinus vitreus and subsequent impregnation (a) and dipping (b). *Significantly increased uptake of wood preservatives compared with control $(t$-test, $P<0.05)$ 

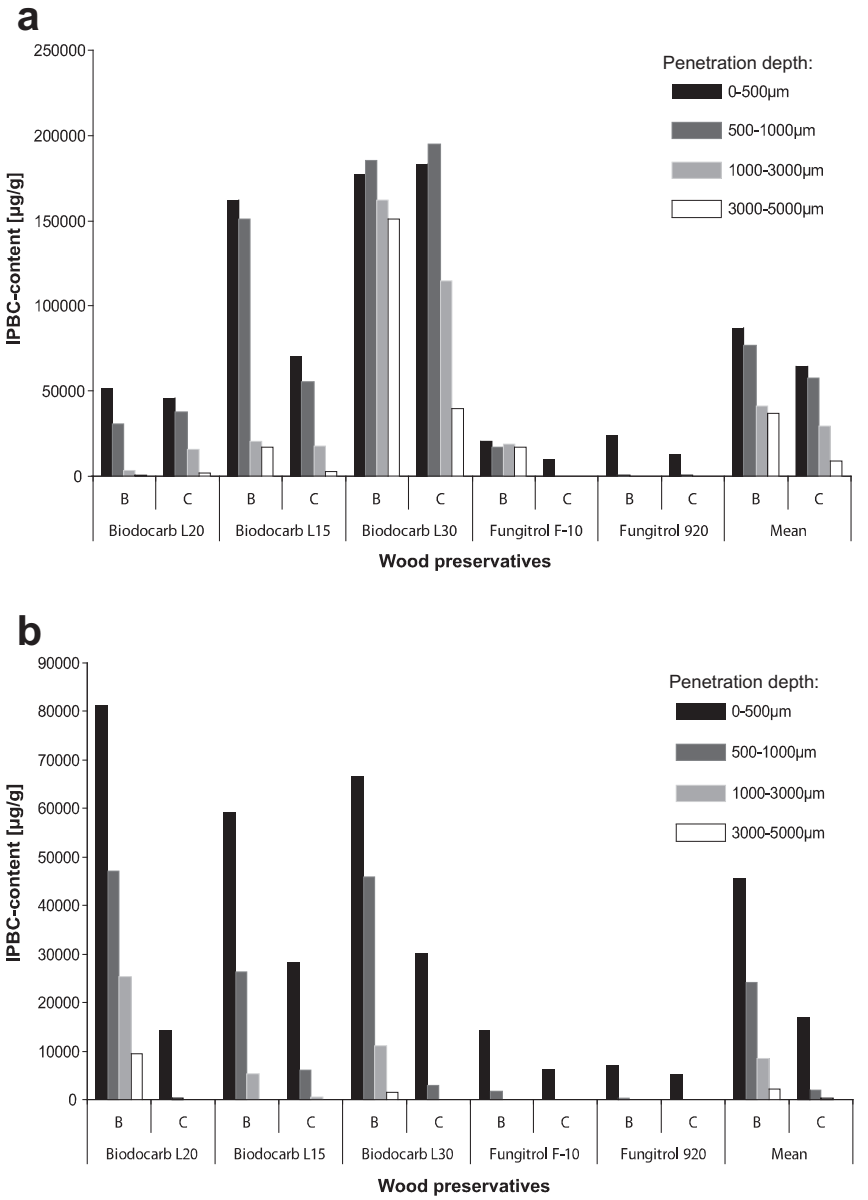

Fig. 4. IPBC (3-iodo-2-propynyl butylcarbamate) content $[\mu \mathrm{g} / \mathrm{g}]$ in bioincised (B) and control (C) wood treated with wood preservatives by vacuum impregnation (a) or dipping (b).

Volkmer et al. (2010) analyzed top-coated Norway spruce sapwood and recorded the highest IBPC concentrations in not bioincised wood. Our results of HPLC using coated Norway spruce heartwood specimens without weathering revealed higher concentrations of IPBC, at least in the outer layer of wood. One explanation for this discrepancy is that, because of the increased permeability of the bioincised wood, leaching of the active substance in the preservative is increased during weathering. Therefore, for better analysis of the interaction between bioincised wood and WPs no weathering of the analyzed specimens was performed in the present study.

\subsection{Interaction between bioincised wood and wood preservatives}

Analysis showed that the modification, as described above, of the biotests was appropriate and gave good results, particularly because all the WPs used in the present study showed high effectiveness and no significant difference in effect on unsectioned bioincised and control specimens could be detected. Therefore, the following results focus generally on the sectioned wood specimens.

As shown in Table 3, and for the two representative WPs (Fungitrol F-10 and Fungitrol 920) in Fig. 5, the mean amount of bluestain discolouration in bioincised wood was reduced in comparison to control specimens for both application methods. However, no significant difference could be detected for one of the WPs.

Blue-stain discolouration was on average greater in the dipped wood than in the vacuum impregnated wood (Table 3 and Fig. 5) and the data generally correlated with the results for the mean penetration of IPBC, where the penetration was deeper in the impregnated wood than in the dipped wood (Fig. 4). Furthermore, the generally good correlation between penetration and performance was expressed by WP 5, which showed the lowest uptake and penetration of IPBC, regardless of the application method, and the highest discolouration rate, as shown in Fig. 4. In addition, WPs 2 and 3 showed a high correlation between high penetration of IPBC and highest performance for the impregnation application method, whereas the correlation was less pronounced for the dipped wood samples (Fig. 4). For WP 1, no correlation between penetration and outcome could be detected, which indicates that the effectiveness of wood-modification substances is not only dependent on their uptake and penetration, but also on their formulation.

In the unsectioned wood specimens treated with WP 6, there was no or only a slight mass loss and no difference could be determined between the performance of WP 6 in bioincised and control wood against all the wood-decay fungi. These results also demonstrate the high effectiveness of this product against wooddecay fungi. In the sectioned wood specimens, however, considerable differences between the outcome for WP 6 in the bioincised and control wood was observed (Fig. 6). The interior of the control wood specimens showed macroscopic signs of degradation after 16 weeks incubation. Only the outer layers of the control wood were widely intact. In the sectioned bioincised wood, however, no or only slight wood degradation could be detected (Fig. 6).

Analysis revealed that the mass loss caused by all the wooddecay fungi was significantly reduced in bioincised wood compared with control wood, regardless of the application method (Fig. 6). This effect was more prevalent in the impregnated than in the dipped wood, which correlates with the uptake of WP 6 (Figs. 3 and 7). Overall, however, the increased retention of WP 6 in bioincised wood by either the vacuum impregnation or dipping

Table 3

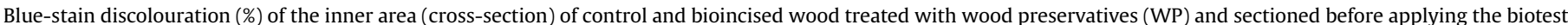
EN 152-2.

\begin{tabular}{|c|c|c|c|c|c|c|}
\hline & WP 1 & WP 2 & WP 3 & WP 4 & WP 5 & Mean \\
\hline \multicolumn{7}{|c|}{ Impregnation } \\
\hline Bioincised & $8.00 \pm 9.27$ & $0.00 \pm 0.00$ & $0.00 \pm 0.00$ & $2.75 \pm 5.50$ & $11.50 \pm 5.92$ & $4.45 \pm 4.14$ \\
\hline Control & $16.33 \pm 16.40$ & $0.00 \pm 0.00$ & $0.00 \pm 0.00$ & $12.50 \pm 14.46$ & $14.60 \pm 8.20$ & $8.69 \pm 7.81$ \\
\hline \multicolumn{7}{|l|}{ Dipping } \\
\hline Bioincised & $4.50 \pm 5.20$ & $0.00 \pm 0.00$ & $0.00 \pm 0.00$ & $15.56 \pm 10.56$ & $21.75 \pm 18.01$ & $8.36 \pm 6.75$ \\
\hline Control & $15.17 \pm 7.78$ & $0.00 \pm 0.00$ & $0.00 \pm 0.00$ & $19.25 \pm 5.44$ & $31.50 \pm 24.23$ & $13.18 \pm 7.49$ \\
\hline
\end{tabular}

WP 1 = Biodocarb L20 TEX Bulk.

WP 2 = Biodocarb L15 BDG Bulk.

WP 3 = Biodocarb L30 BDG Bulk.

WP 4 = Fungitrol F-10 Bulk

WP 5 = Fungitrol 920 . 
a

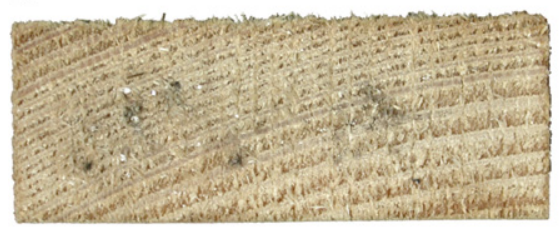

C

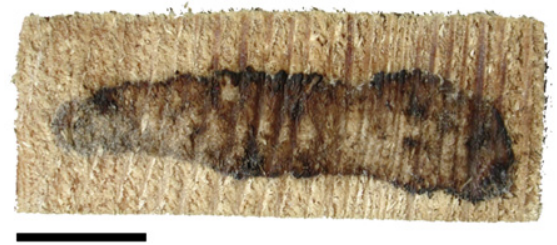

b

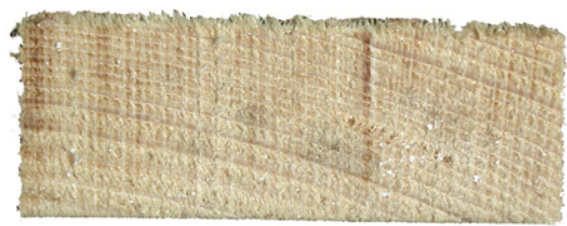

d

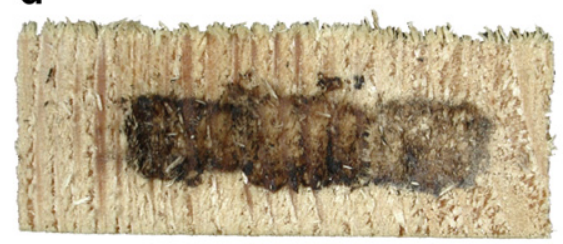

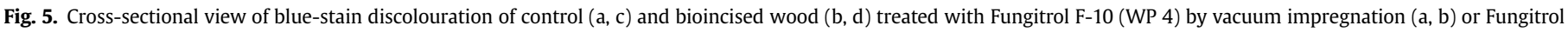
920 by dipping (c, d), then sectioned before applying the biotest, EN 152 . Scale bar $=1 \mathrm{~cm}$.

compared with the control wood led to an improved effectiveness of WP 6 against wood-decay fungi, expressed by the significant reduction in mass loss in bioincised Norway spruce heartwood.

For effective wood preservation, complete or at least border zone penetration is required (European Standard EN 335-2, 2006; European Standard EN 351-1, 2007; Lehringer et al., 2009b). However, in practice, complete penetration cannot be achieved in refractory wood species (e.g. Norway spruce heartwood), because of reduced permeability. To overcome this problem, mechanical drilling or an incising technique is often used (Perrin, 1978). But as our results show, the biotechnological process with $P$. vitreus is a promising method of achieving higher uptake rates and deeper penetration of WPs, thereby improving the effectiveness of the WPs used in the present study.

Lehringer et al. (2009a) conducted preliminary tests of the flammability of bioincised Norway spruce heartwood. The pre- treatment with $P$. vitreus was similar to the method described in the present work. Despite the higher uptake of wood-modification agents after brushing, dipping and particularly after impregnation, the authors found a negative effect of bioincising on the target properties of the agents, regardless of the application method (Lehringer et al., 2009a). Lehringer et al. (2010) showed that under incubation conditions using a malt agar nutrient medium (narrow $\mathrm{C} / \mathrm{N}$-ratio of approximately 50/1) the colonization of the wood was very inhomogenous and degradation of bordered pits was accompanied by cell-wall degradation (selective delignification and hotspots of soft-rot types I and II). The latter alterations in the cell wall structure, particularly both types of soft-rot, may be responsible for the enhanced flammability of bioincised wood. As Lehringer discussed in detail, a high nitrogen concentration (e.g. malt agar) seems to reduce the selective lignin degradation rate (Kirk et al., 1978) and additionally stimulates polysaccharide breakdown (Dill

b

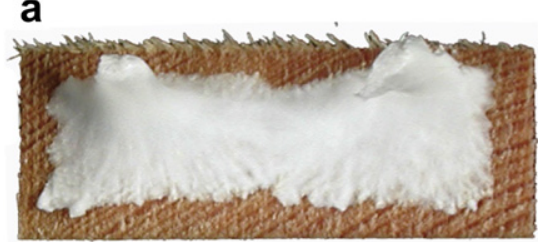

C

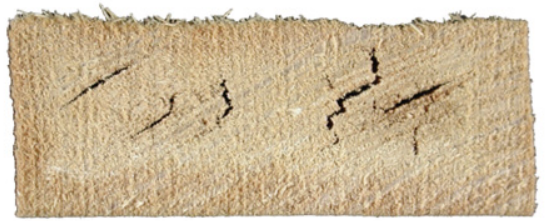

e

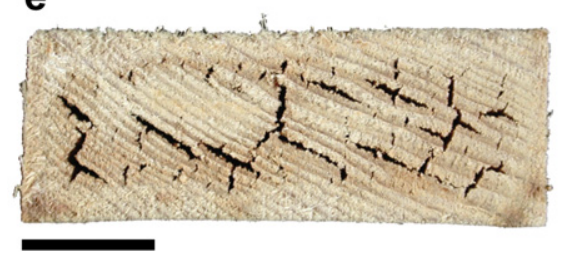

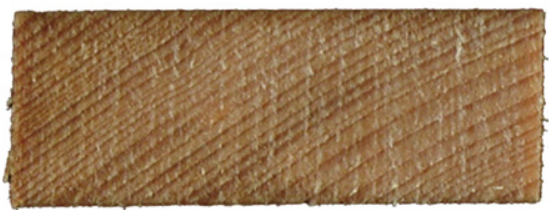

d

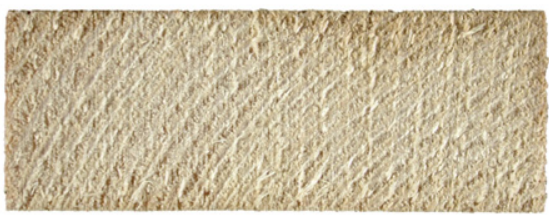

f

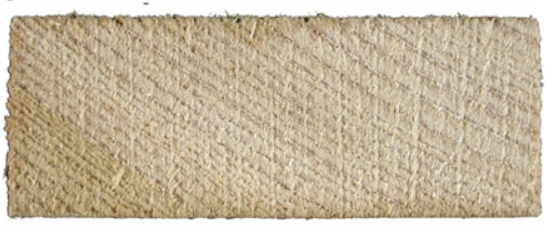

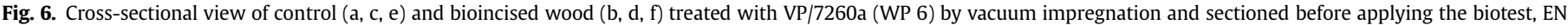

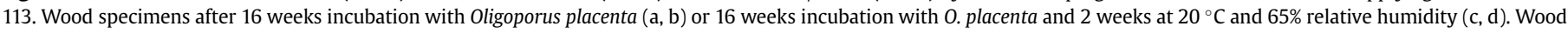
specimens after 16 weeks incubation with Gloephyllum trabeum and 2 weeks at $20{ }^{\circ} \mathrm{C}$ and $65 \%$ relative humidity (e, f). Scale bar $=1 \mathrm{~cm}$. 

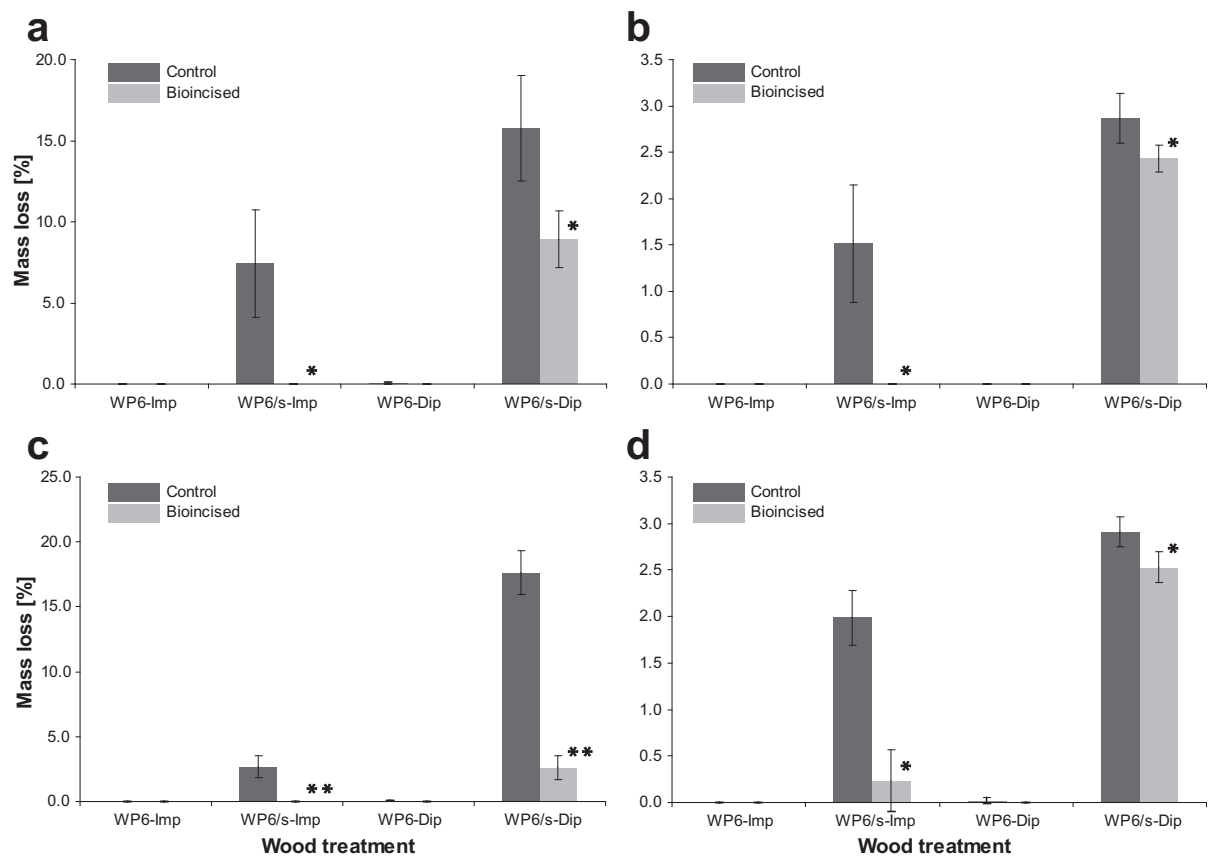

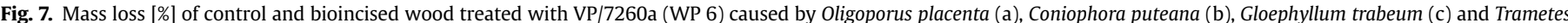

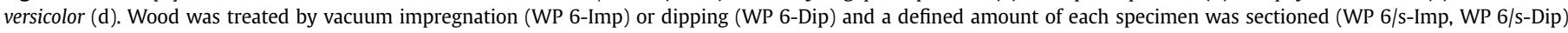
before applying the biotest, EN 113. *Significant difference between control and bioincised wood $\left(t\right.$-test, $\left.{ }^{*} P<0.05,{ }^{* *} P<0.0001\right)$.

and Kraepelin, 1986; Levi and Cowling, 1969; Reid, 1983). Schwarze and Landmesser (2000) and Schwarze et al. (2008) used vermiculite (wide C/N-ratio of approximately 400/1) in their studies and observed that the degradation of pit membranes only coincided with selective delignification of the tracheids without further cell wall damage. To upgrade the bioincising process for other woodmodification substances the negative side-effects must be reduced by adapting the incubation time ( $<6$ weeks) and by optimizing the incubation conditions.

\section{Conclusion}

In the present study, bioincised wood showed a significantly higher susceptibility to wood-decay fungi, whereas against bluestain fungi the bioincised wood was comparable with control wood. Gravimetric measurements showed that the uptake of WPs was significantly higher in bioincised wood and HPLC analysis revealed deeper penetration of IPBC in bioincised wood. An increased uptake of WPs resulted in a reduction in blue-stain discolouration and in an increase in efficacy against wood-decay fungi, as expressed by a significant reduction in mass loss in bioincised Norway spruce heartwood. The results show that the biotechnological process with $P$. vitreus is a promising method of improving wood durability by increasing the uptake and penetration of the WPs used in the present study.

\section{Acknowledgments}

The authors express their gratitude to the Swiss CTI (Innovation Promotion Agency, No. 8593.1 LSPP) for its financial support.

\section{References}

Dill, I., Kraepelin, G., 1986. Palo podrido: model for extensive delignification of wood by Ganoderma applanatum. Applied and Environmental Microbiology 52, 1305-1312.
European Standard EN 113, 1997. Wood preservatives. Test method for determining the protective effectiveness against wood destroying basidiomycetes - Determination of the toxic values. European Committee for Standardization (CEN), Brussels, Belgium.

European Standard EN 152-2, 1988. Test methods for wood preservative - Laboratory method for determining the preventive effectiveness treatment against blue stain in service - Part 2: Other methods. European Committee for Standardisation (CEN), Brussels, Belgium.

European Standard EN 335-2, 2006. Durability of wood and wood-based products Definition of use classes - Part 2: Application to solid wood. European Committee for Standardization (CEN), Brussels, Belgium.

European Standard EN 350-2,1994. Durability of wood and wood-based products Natural durability of solid wood - Part 2: Guide to natural durability and treatability of selected wood species of importance in Europe. European Committee for Standardization (CEN), Brussels, Belgium.

European Standard EN 351-1, 2007. Durability of wood and wood-based products Preservative treated solid wood - Part 1: Classification of preservative penetration and retention. European Committee for Standardization (CEN), Brussels, Belgium.

Frühwald, E., Li, Y., Wadsö, L., 2007. Mould growth on high-temperature dried and heat-treated Norway spruce. In: Nordic Workshop on Wood Engineering. Wood Tech, Sweden Skellefteå February 21. http://epubl.ltu.se/1402-1528/2007/06/ LTU-FR-0706-SE.pdf.

Green, F., Tschernitz, J.L., Kuster, T.A., Highley, T.L., 1995. Hydrolysis of bordered pits during colonization of conifers by brown-rot decay. In: Proceedings of the International Research Group on Wood Preservation, IRG/WP 95-10103, Helsinger, Denmark.

Kirk, T.K., Schultz, E., Connors, W.J., Lorenz, L.F., Zeikus, J.G., 1978. Influence of culture parameters on lignin metabolism by Phanerochaete chrysosporium. Archives of Microbiology 117, 277-285.

Koenigs, J.W., 1974a. Hydrogen peroxide and iron: a proposed system for decomposition of wood by brown rot basidiomycetes. Wood and Fibre Science 6, 66-79.

Koenigs, J.W., 1974b. Production of hydrogen peroxide by wood-rotting fungi in wood and its correlation with weight loss, depolymerization, and $\mathrm{pH}$ changes. Archives of Microbiology 99, 129-145.

Lehringer, C., Arnold, M., Richter, K., Schubert, M., Schwarze, F.W.M.R., Militz, H. 2009a. Bioincised wood as substrate for surface modifications, In: Englund, F. Hill, C.A.S., Militz, H., Segerholm, B.K. (Eds.), Proceedings of the European Conference on Wood Modification Stockholm, pp. 197-200.

Lehringer, C., Richter, K., Schwarze, F.W.M.R., Militz, H., 2009b. A review on promising approaches for liquid permeability improvement in softwoods. Wood and Fiber Science 41, 373-385.

Lehringer, C., Hillebrand, K., Richter, K., Arnold, M., Schwarze, F.M.W.R., Militz, H. 2010. Anatomy of bioincised Norway spruce wood. International Biodeterioration and Biodegradation 64, 346-355.

Levi, M.P., Cowling, E.B., 1969. Role of nitrogen in wood deterioration. VII. Physiological adaptation of wood-destroying and other fungi to substrates deficient in nitrogen. Phytopathology 59, 460-468. 
Liese, W., Bauch, J., 1967. On the closure of bodered pits in conifers. Wood Science and Technology 1,1-13.

Mai, C., Kües, U., Militz, H., 2004. Biotechnology in the wood industry. Applied Microbiology and Biotechnology 63, 477-494.

Perrin, P.W., 1978. Review of incising and its effects on strength and preservative treatment of wood. Forest Products Journal 28, 27-33.

Reid, I.D., 1983. Effects of nitrogen supplements on degradation of aspen wood lignin and carbohydrate components by Phanerochaete chrysosporium. Applied and Environmental Microbiology 45, 830-837.

Sandberg, K., 2008. Degradation of Norway spruce (Picea abies) heartwood and sapwood during 5.5 years' above-ground exposure. Wood Material Science \& Engineering 3, 83-93.

Schubert, M., Schwarze, F.M.W.R, Evaluation of the interspecific competitive ability of the bioincising fungus Physisporinus vitreus. Journal of Basic Microbiology, in press., doi:10.1002/jobm.201000176

Schubert, M. Dengler, V., Mourad, S., Schwarze, F.W.M.R., 2009. Determination of optimal growth parameters for the bioincising fungus Physisporinus vitreus by means of response surface methodology. Journal of Applied Microbiology 106, 1734-1742.

Schubert, M., Mourad, S., Schwarze, F.W.M.R., 2010a. Automated image processing for quantification of blue-stain discoloration of Norway spruce wood. Wood Science and Technology. doi:10.1007/s00226-010-0328-4.
Schubert, M., Mourad, S., Schwarze, F.W.M.R., 2010b. Radial basis function neural networks for modeling growth rates of the basidiomycetes Physisporinus vitreus and Neolentinus lepideus. Applied Microbiology and Biotechnology 85, 703-712.

Schwarze, F.W.M.R., Landmesser, H., 2000. Preferential degradation of pit membranes within tracheids by the basidiomycete Physisporinus vitreus. Holzforschung 54, 461-462.

Schwarze, F.W.M.R., Schubert, M., 2009. Enhanced uptake of wood modification agents in 'bioincised' wood. In: Proceedings of the International Research Group on Wood Preservation, IRG/WP 09-40445, Beijing, China.

Schwarze, F.W.M.R., Landmesser, H., Zgraggen, B., Heeb, M., 2006. Permeability changes in heartwood of Picea abies and Abies alba induced by incubation with Physisporinus vitreus. Holzforschung 60, 450-454.

Schwarze, F.W.M.R., Spycher, M., Fink, S., 2008. Superior wood for violins - wood decay fungi as a substitute for cold climate. The New Phytologist 179, 1095-1104. Volkmer, T., Schwarze, F.M.R., 2008. Diffusion behavior of IPBC in water based coatings on wooden facades. Holz als Roh und Werkstoff 66, 181-189.

Volkmer, T., Landmesser, H., Genoud, A., Schwarze, F.W.M.R., 2010. Penetration of 3-iodo-2propynyl butylcarbamat (IPBC) in coniferous wood pre-treated with Physisporinus vitreus. Journal of Coatings Technology and Research. doi:10.1007/ s11998-010-9259-0.

Watanabe, U., Imamura, Y., Iida, I., 1998. Liquid penetration of precompressed wood VI: anatomical characterization of pit fractures. Journal of Wood Science 44, 158-162. 



\section{Effect of Physisporinus vitreus on wood properties of Norway spruce. Part 1: Aspects of delignification and surface hardness}

\author{
Christian Lehringer ${ }^{1, *}$, Gerald Koch $^{2}$, \\ Ramesh-Babu Adusumalli³, William M. Mook ${ }^{3}$, \\ Klaus Richter ${ }^{1}$ and Holger Militz ${ }^{4}$ \\ ${ }^{1}$ Empa - Swiss Federal Laboratories for Materials Science \\ and Technology, Wood Laboratory, Dübendorf, \\ Switzerland \\ ${ }^{2}$ Institute of Wood Technology and Wood Biology, Federal \\ Research Institute for Rural Areas, Forestry and Fisheries, \\ Hamburg, Germany \\ ${ }^{3}$ Empa - Swiss Federal Laboratories for Materials Science \\ and Technology, Mechanics of Materials and \\ Nanostructures, Thun, Switzerland \\ ${ }^{4}$ Wood Biology and Wood Products, Burckhardt-Institute, \\ Georg-August-University, Göttingen, Germany \\ * Corresponding author. \\ Empa - Swiss Federal Laboratories for Materials Science \\ and Technology, Wood Laboratory, \\ Dübendorf, Switzerland \\ E-mail: christian.lehringer@empa.ch
}

\begin{abstract}
The white rot fungus Physisporinus vitreus is currently tested for several biotechnological applications such as permeability improvement of refractory wood species or the optimization of the acoustic properties of wood for violins. The enzymatic activity of $P$. vitreus results in the degradation of pit membranes and simultaneous alterations of the tracheid cell wall structure in wood of Norway spruce [Picea abies (L.) Karst]. By this means, selective delignification and simultaneous degradation occur in the latewood tracheids at short incubation times. To study the delignification of individual cell wall layers in latewood tracheids, cellular UVmicrospectrophotometry was applied to wood of Norway spruce that had been incubated for between 3 and 9 weeks. By means of this technique, the progressing delignification was demonstrated in the latewood tracheid secondary walls. Moreover, local delignification in close proximity to hyphal tunneling, cavities, and notches was evident. Additionally, the mechanical changes were measured (a) at the macroscopic level by Brinell hardness test and (b) at the cellular level by nanoindentation. Brinell hardness was significantly reduced with increasing incubation time which was attributed to the partial delignification. Unlike Brinell tests, results from nanoindentation tests did not show a clear effect of fungal activity because of the material heterogeneity and the high spatial resolution of this technique. The present study provides methodological approaches for the investigation of wood-fungus interactions and contributes to a better under-
\end{abstract}

standing of the characteristics of wood decay at the subcellular level caused by the white rot fungus $P$. vitreus. Moreover, it establishes the basis for a subsequent chemical analysis, for which the results will be the topic of a second paper in this series.

Keywords: Brinell hardness; delignification; nanoindentation; UV-microspectrophotometry (UMSP); wood decay.

\section{Introduction}

Wood decay fungi in biotechnological applications have been studied for more than 30 years. In the pulp and paper industry, white rot fungi are successfully applied in bio-pulping or bio-bleaching of Kraft pulp (Mai et al. 2004). In the context of wood technological tasks, fungi are able to modify specific properties of wood. During the early 1960s, the use of "Myco-wood" for pencil production was industrially conducted in the German Democratic Republic (Unbehaun et al. 2000). More recently, the white rot fungus Physisporinus vitreus was tested for improvement of acoustic properties of wood for violins (Schwarze et al. 2008) or permeability improvement ("bioincising") of Norway spruce (Schwarze et al. 2006; Lehringer et al. 2009). In these cases, homogeneous and rapid wood colonization and a controlled activity of the wood decay fungus are required to ensure a high and reproducible product quality within economically acceptable periods of time. Moreover, the surface of the treated wood must have an aesthetic appearance and its mechanical properties should not be weakened.

Schwarze et al. (2006) investigated the wood properties of Norway spruce heartwood that had been incubated with $P$. vitreus for 6 weeks. They found no significant reduction in impact bending strength. However, microscopic studies revealed morphological changes due to fungal activity, and simultaneous degradation of pit membranes and tracheid cell walls were observed even at early stages of substrate colonization (Lehringer et al. 2010). In the same study, selective delignification and simultaneous degradation of lignin and polysaccharides were observed corresponding to the characteristics of white rot and soft rot type I and type II. The term selective delignification means a successive decomposition of the cell wall components: the degradation of lignin and hemicelluloses occur preferably at the beginning of fungal colonization, whereas the cellulose fraction is degraded later (Liese 1970). Simultaneous rot is characterized by fungal ecto-enzymes which have the capacity to degrade cellulose, hemicelluloses, and lignin at the same time (Schmidt 2006). 
In these processes, at least two different enzymatic mechanisms are involved. White rot is based on a lignolytic system that brings about preferential lignin and hemicelluloses depolymerization at larger distances from fungal hyphae (Blanchette et al. 1985). Soft rot is characterized by the formation of narrow erosion cavities and hyphal tunneling that implies the presence of enzymes with a very low diffusibility (Blanchette et al. 1985). Kleist and Schmitt (2001) also found that the lignolytic activity was restricted to a very close vicinity of the areas of hyphal tunneling in the case if decay was caused by brown rot and soft rot in wood of Sapeli (Entandrophragma cylindricum Sprague).

Owing to the fungal activity occurring close to the surface, the surface hardness can decrease whereas the overall strength properties are not significantly affected. The mechanical integrity of the surface plays a key role, if high quality wood is required (e.g., violin wood, flooring). Hence, the effects of these alterations have to be investigated in detail.

The impact of wood decay fungi on mechanical properties of wood has been described in many studies (Morrell and Zabel 1985; Kim et al. 2005; Schmidt 2006). The surface hardness is strongly associated with cell wall density and with the lignin content of the cell wall matrix. Accordingly, cellular UV-microspectrophotometry (UMSP) was applied to characterize the delignification process of $P$. vitreus on Norway spruce after incubation times of up to 9 weeks. The UMSP technique is well suitable for detecting the topochemical distribution of lignin at a subcellular level (Koch and Kleist 2001; Irbe et al. 2006; Kim et al. 2008; Lehringer et al. 2008; Prislan et al. 2009). Bauch et al. (1976) applied UMSP successfully to investigate topochemical delignification caused by fungal decay in woody tissue. Kleist and Seehann (1997) described effects of fungal activity in latewood regions of Norway spruce wood after 8 weeks incubation with white rot fungus Stereum sanguinolentum. Lower lignin contents caused by fungal delignification result in lower absorbances at $280 \mathrm{~nm}$. Moreover, the local delignification around hyphal tunneling, cavities, and notches in the tracheid cell walls can be visualized by field imaging.

Surface hardness measurements according to the Brinell test method were performed, as this method is a sensitive indicator for chemical and morphological changes caused by wood decaying fungi (Rypacek 1966). Lignin modification (Hakala et al. 2005), lignin removal and the reduction of cell wall thickness due to hyphal tunneling, cavities, and notches result in hardness reduction (Whetten and Sederoff 1995).

Finally, nanoindentation tests were performed. The recorded load-displacement curve and the indentation depth deliver the basis to calculate hardness and the reduced elastic modulus at very high spatial resolution (Oliver and Pharr 2004). Previously, this method has been applied to investigate specific structural and mechanical properties of different wood tissues at the cell wall level (Gindl et al. 2004; Wang et al. 2006; Lee et al. 2007; Konnerth et al. 2009, 2010; Adusumalli et al. 2010; Stöckel et al. 2010).

The principle objective of the present study is to better understand the effect of delignification on the mechanical properties of wood incubated with $P$. vitreus. Topochemical alterations on the tracheid cell walls will be recorded and a correlation to the Brinell hardness will be observed. Moreover, the applicability of the nanoindentation technique on decayed wood should be assessed during short-term incubation times. An in-depth chemical analysis of changes in chemical composition due to fungal activity will follow in a second article of this series (Lehringer et al. 2011).

\section{Material and methods}

\section{Specimen material}

One board of defect-free and klin-dried wood from a Norway spruce tree [Picea abies (L.) Karst] was investigated. For sapwood and heartwood, three specimen collectives were prepared. In each collective, five specimens were always taken in one longitudinal sequence to minimize the influence of natural property variation within the single tree. As the samples were subjected to four different incubation periods and one control, this axial pairing provided a good comparability of the results. Each specimen measured $200 \times 30 \times 30 \mathrm{~mm}^{3}(\mathrm{~L} \times \mathrm{R} \times \mathrm{T})$. Sterilization was done with hot steam at $103^{\circ} \mathrm{C}$ for $2 \mathrm{~h}$; inoculation was done with the white rot fungus $P$. vitreus (microbial strain Empa 642).

The microbial strain of $P$. vitreus was grown on $4 \%$ malt extract agar (MEA) medium (Oxoid, Darmstadt, Germany) in each Petri dish stored at $22^{\circ} \mathrm{C}$ and $70 \%$ relative humidity ( $\left.\mathrm{RH}\right)$. Once a uniform mycelium had formed, $2 \mathrm{~g}$ of steam sterilized Norway spruce sawdust (grain size $4 \mathrm{~mm}$ ) was added to the Petri dishes and the system was left for another 4 weeks at $22^{\circ} \mathrm{C}$ and $70 \%$ RH. Finally, the infected sawdust was collected and brought into a suspension with sterilized water; solid to liquid ratio was $10 \mathrm{~g} \mathrm{l}^{-1}$.

Incubation was performed under sterile conditions by immersing the specimens in this water suspension including sawdust and fungal mycelia. The incubated specimens were then incubated on 1\% MEA and stored for 3, 5, 7, and 9 weeks at $22^{\circ} \mathrm{C}$ and $70 \%$ RH. Each specimen was placed with the tangential surface facing the pith on the nutrient medium (Figure 1). It is not the usual procedure, but the specimens were placed directly on the MEA aiming at rapid initial fungal colonization. After incubation, the mycelium was carefully removed from the surfaces and the specimens were steamsterilized as described above. After drying for $48 \mathrm{~h}$ at $40^{\circ} \mathrm{C}$, the specimens were reconditioned and stored at $20^{\circ} \mathrm{C}$ and $65 \% \mathrm{RH}$. Mass losses were calculated as described by Lehringer et al. (2010).

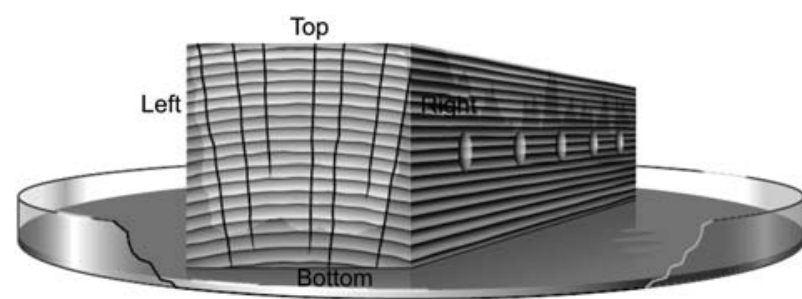

Figure 1 Schematic illustration of incubation of specimens with Physisporinus vitreus in a Petri dish and designation of the surfaces. The darker areas on the wood surfaces indicate zones of higher fungal activity. On the right-hand side is positioning of the Brinell hardness measurements. 


\section{Cellular UV-microspectrophotometry (UMSP)}

For cellular UMSP analyses, small blocks were extracted - of $5 \times 2 \times 2 \mathrm{~mm}^{3}(\mathrm{~L} \times \mathrm{R} \times \mathrm{T})$ from the bottom side of the incubated heartwood specimens - where fungal activity was the strongest. For each incubation time and the control samples, two replicates were made. The specimens were prepared with epoxy resin as embedding medium (Spurr 1969) as described by Kleist and Schmitt (1999). After trimming the embedded specimens, $1 \mu \mathrm{m}$ thin cross-sections were cut on an ultramicrotome Ultracut E (Reichert-Jung, Wetzlar, Germany) equipped with a diamond knife. The sections were transferred to quartz glass slides, thermally fixed at $70^{\circ} \mathrm{C}$ and embedded in glycerine. In these sections, two to three areas of high fungal activity in the latewood tracheids were selected under the light microscope for measuring.

The topochemical analysis was carried out with a UMSP 80 microspectrophotometer (Zeiss, Jena, Germany) equipped with a scanning stage enabling the examination of image profiles at $\lambda=280 \mathrm{~nm}$ that represents the absorbance maximum of softwood lignin (Koch and Kleist 2001). For the field scans, areas of approximately $40 \times 40 \mu \mathrm{m}^{2}$ were scanned line by line using Apamos ${ }^{\circledR}$ software (Zeiss, Jena, Germany). The scan program captures rectangular fields with a local geometric resolution of $0.25 \mu \mathrm{m} \times 0.25 \mu \mathrm{m}$ and yields a photometric resolution of 4096 grayscale levels, which are converted into 14 basic colors to visualize the absorbance intensities. The high resolution enables a differentiation of the UV absorbance within individual cell wall layers, including a histogram of the UV absorbance values. The average absorbance data were extracted for the secondary cell wall regions by setting appropriate filters with Apamos ${ }^{\circledR}$ software. For each specimen, five to seven average spectra were included into the statistical evaluation (resulting in $n=26$ ).

\section{Brinell hardness}

The Brinell hardness was determined five times for each specimen on each radial and tangential surface in a distance of $1.5 \mathrm{~cm}$ from the specimen edges (distance of the measurements: $3.5 \mathrm{~cm}$, Figure 1). Depending on the positioning of the specimen during incubation, the surfaces were designated as top, bottom, left, and right (Figure 1).

Altogether, 600 measurements were performed under standard laboratory climate conditions $\left(20^{\circ} \mathrm{C} / 65 \% \mathrm{RH}\right)$ (Table 1$)$.

A universal Brinell type testing machine (Zwick, Ulm, Germany) with $10 \mathrm{kN}$ load cell and $10 \mathrm{~mm}$ steel indenting ball was applied. The peak load of $500 \mathrm{~N}$ was reached after $15 \mathrm{~s}$, followed by a $30 \mathrm{~s}$ holding time and $15 \mathrm{~s}$ unloading. According to EN 1534 (2000), Brinell hardness is calculated as follows:

$H_{B}=\frac{2 F}{D^{*} \pi^{*}\left(D-\sqrt{D^{2}-d^{2}}\right)}$

where $H_{B}=$ Brinell hardness $\left(\mathrm{N} / \mathrm{mm}^{2}\right), F=\max$. force $(\mathrm{N}), D=$ diameter of steel ball $(\mathrm{mm}), d=$ diameter of intent $(\mathrm{mm})$.

Sonderegger and Niemz (2001) proposed a calculation as differential measurement of indentation depth between wood surface and lowest point of steel ball circumference, i.e., the depth of indentation $h:$

$h=\frac{\left(D-\sqrt{D^{2}-d^{2}}\right)}{2}$.

Brinell hardness was calculated in the present study according to the adapted Eq. (3).
Table 1 Experimental plan for Brinell hardness tests on sapwood (SW) and heartwood (HW).

\begin{tabular}{llc}
\hline \multicolumn{1}{c}{ Description } & \multicolumn{1}{c}{ Variable } & Factor \\
\hline Wood type & $\begin{array}{l}\text { Sapwood (SW), } \\
\text { Heartwood (HW) }\end{array}$ & 2 \\
Collective & A, B, C & 3 \\
Incubation time & $\begin{array}{l}\text { Control, 3, 5, } \\
\text { 7, 9 weeks }\end{array}$ & 5 \\
Side on specimen & $\begin{array}{l}\text { Top, bottom, } \\
\text { right, left } \\
\text { points per side }\end{array}$ & 4 \\
Measurement & Result from factor multiplication: $n=600$ \\
\hline
\end{tabular}

$H_{B}=\frac{F}{D^{*} \pi^{*} \mathrm{~h}}$.

\section{Nanoindentation}

The nanoindentation measurements (Hysitron Ubi nanoindenter, Hysitron Inc., Minneapolis, MN, USA, at ambient room climate) were carried out on the same blocks on which the UMSP measurements were performed. The sample preparation for nanoindentation was performed according to Konnerth et al. (2008). Latewood (LW) tracheids with decayed cell walls were located by light microscopy and the optical microscope of the nanoindenter. On average, 20 indents per sample were placed by visual positioning in the degraded LW tracheid cell walls. Earlywood cell walls were not indented, because cell walls were too thin.

A Berkovich indenter tip, edge length $<150 \mathrm{~nm}$, with three-sided pyramid geometry was used, which was pressed with a determined force into the cell wall cross-section. A maximum load of $250 \mu \mathrm{N}$ was selected for nanoindentation. Loading and unloading speed was $100 \mu \mathrm{N} \mathrm{s}^{-1}$ and the holding time at peak load was $15 \mathrm{~s}$ to monitor the visco-plastic creep. The selected surface regions $\left(40 \times 40 \mu \mathrm{m}^{2}\right)$ were then scanned with normal forces of approximately $200 \mathrm{nN}$ using the indentation tip.

The load-displacement curves obtained from all experiments were evaluated according to the method of Oliver and Pharr (1992). Peak load $\left(P_{\max }\right)$, contact area $(A)$, and initial slope of the unloading curve $(S)$ are the parameters for calculations of the hardness $(H)$ and the reduced modulus of elasticity $\left(E_{r}\right)$ (hereinafter referred as MOE) as shown in Eqs. (4) and (5):

$H=\frac{P_{\max }}{A}$

$E_{r}=\frac{1}{2} \sqrt{\pi} \frac{\mathrm{S}}{\sqrt{\mathrm{A}}}$

The contact area $A$ at $P_{\max }$ was determined from the known shape of the indenter, calibrated by indenting a material with known properties (in this case fused quartz).

\section{Statistical evaluation}

For all collected data, a one-way analysis of variance and a Tukey honesty test were conducted with the statistic software Systat $12^{\circledR}$ (Systat Software Inc., Chicago, IL, USA). A P-value of $<0.05$ was considered statistically significant. 


\section{Results and discussion}

\section{UMSP}

Delignification of individual cell wall layers and in localized regions caused by $P$. vitreus was detected at $280 \mathrm{~nm}$, at which softwood lignins have an absorbance maximum (Figure 2). The color pixels indicate different intensities of the UV absorbance at the respective $\lambda_{\max }$ values. As expected, the UV image profiles of sound spruce tracheids (Figure 2a) are characterized by high absorbance values in the cell corners and in the compound middle lamella $\left(A b s_{280 \mathrm{~nm}}=0.48-0.87\right)$. The absorbance in the secondary cell wall (S2) ranged between $A b s_{280 \mathrm{~nm}}=0.29$ and $A b s_{280 \mathrm{~nm}}=0.48$ and corresponded well to findings of Fergus et al. (1969) who described the average lignin content in the compound middle lamella (CML) being twice as high as that in the adjacent secondary tracheid walls.

Hyphal tunneling within the S2 of LW tracheids, which is commonly considered to be a characteristic of a soft rot type I (Schwarze 2007) is demonstrated in Figure 2c. The presence of hyphal tunneling - characterized by spots with significant lower absorbances - confirms the results from light microscopy investigations (Lehringer et al. 2010). There, selective delignification and simultaneous degradation were found in close proximity to each other. Delignification is limited to a very narrow region around the zone of hyphal growth as indicated clearly by low absorbances around these structures $\left(A b s_{280 \mathrm{~nm}}=0.09-0.22\right)$. The reason for this observation is clear: the lignolytic enzymes do not diffuse deeply into the secondary wall but rather act in close proximity to the hyphae, as also described by Kleist and Schmitt (2001) for brown rot fungi.

Effects of selective delignification are displayed in Figure 2c-e. Additional to the hyphal tunneling, reduced $A b s_{280 \mathrm{~nm}}$ (0.16 and 0.29) are discernable in larger areas of the secondary tracheid cell walls. In this case, $P$. vitreus depolymerizes lignin and hemicelluloses in the tracheid cell walls from the lumen towards the CML by means of extracellular enzymes and probably also by other coexisting lignolytic systems (Blanchette et al. 1985). By this means, the cell wall shape remains mostly unaltered and the same is true for

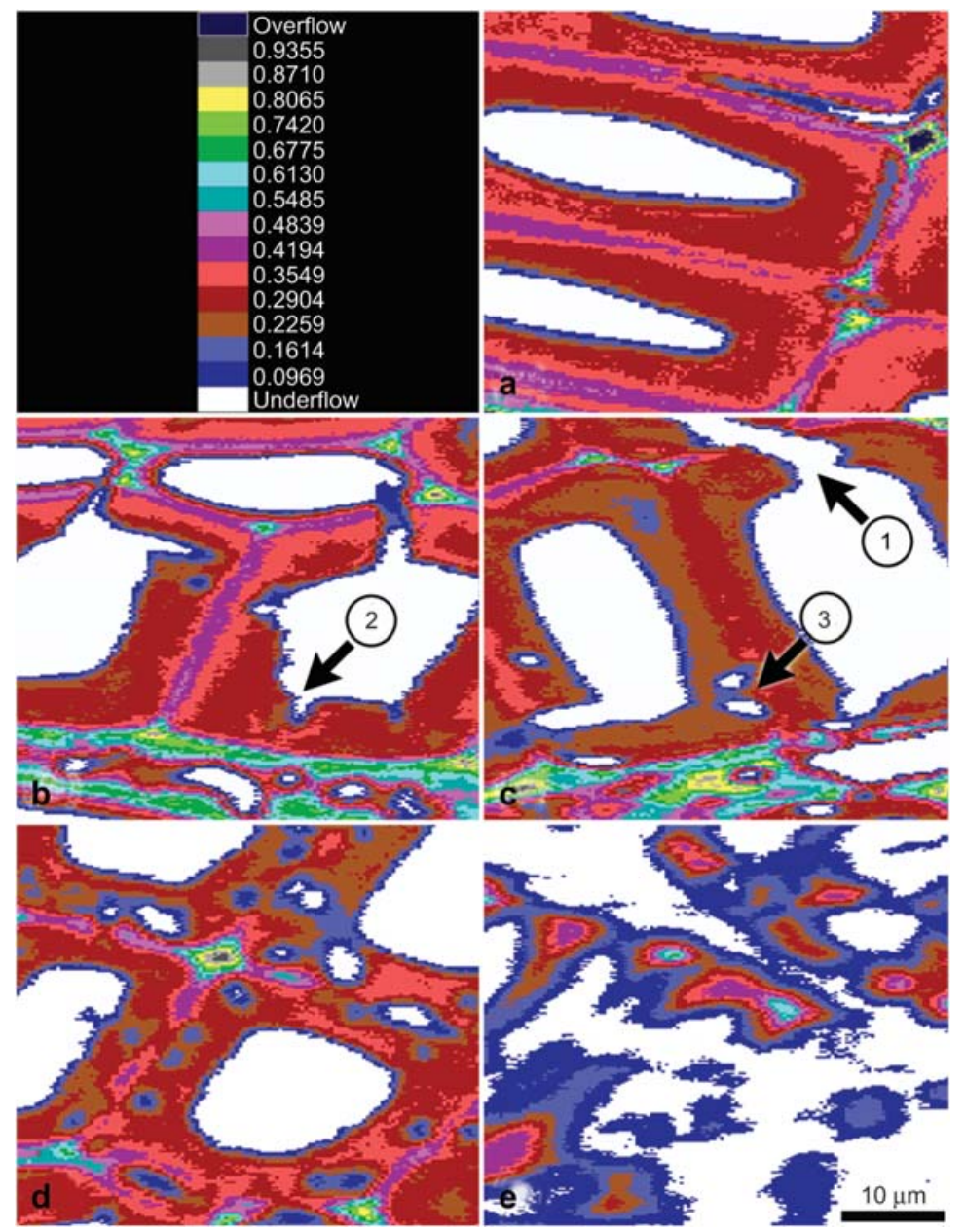

Figure 2 Representative UV microscopic scanning profiles of Norway spruce latewood tracheids after zero (a), 7 (b), 9 (c), 12 (d), and 32 (e) weeks of incubation with Physisporinus vitreus. The color pixels represent different UV absorbances of the cell wall layers at $\lambda=280 \mathrm{~nm}$. Hyphal tunneling (1), notches (2), and cavities (3) can be observed as proof for simultaneous degradation. The progress of selective delignification is visible by lowered absorbances in areas of the secondary cell wall layers. 
the cellulose within the cell wall. However, the CML showed discreet signs of delignification after 7 and 9 weeks incubation.

As an additional source of information, the status after 12 and 32 weeks of incubation is illustrated in Figure 2d,e. Here, the material was incubated with the same method. But the specimens originated from another wood board. This is the reason why the data were only taken for sporadic validation. Nevertheless, the images confirm the observed trend and exemplarily demonstrate the effects of fungal activity at advanced stages of degradation.

The mean UV absorbances showed a decreasing trend as a function of incubation time (Figure 3). Even though the changes are statistically not always significant compared to the control specimen, the trend depicts the expected tendency of increasing delignification with longer incubation times. After 3 and 5 weeks incubation, the decrease of average UV absorbances ranged at $-1.3 \%$ and $-1.9 \%$, respectively. After 7 and 9 weeks incubation time, the values decreased stepwise to $-6 \%$ and $-8.9 \%$, respectively.

The method of UMSP permits to plot discreet changes of mean lignin content even after short-time incubation with the white rot fungi $P$. vitreus. However, the statistical relevance of the data is limited because of the natural variability and increased heterogeneity due to fungal activity.

\section{Brinell hardness}

Heartwood and sapwood The Brinell hardness of the control samples in heartwood and sapwood was $18.1 \mathrm{~N} \mathrm{~mm}^{-2}$ and $18.9 \mathrm{~N} \mathrm{~mm}^{-2}$, respectively (Figure 4, box plots). As differences in Brinell hardness for radial and tangential measurement orientation were negligible, the average values were calculated. Generally, the values for the sapwood specimen were slightly higher than the heartwood specimen. This is due to the fact that the initial density of the sapwood specimens was $3.2 \%$ higher than the heartwood specimens.
The initial density of the sapwood samples was $0.47 \mathrm{~g} \mathrm{~cm}^{-3} \pm$ $4.4 \%$ and of the heartwood samples $0.45 \mathrm{~g} \mathrm{~cm}^{-3} \pm 6.8 \%$.

The first 5 weeks of colonization with $P$. vitreus resulted in a moderate effect on Brinell hardness. The changes of Brinell hardness were not statistically significant neither in sapwood nor in heartwood compared to the control. But after 7 and 9 weeks, the average Brinell hardness was reduced significantly to values between 13.4 and $16.5 \mathrm{~N} \mathrm{~mm}^{-2}$, which indicate a strong increase in fungal activity. Hence, the average decrease of Brinell hardness amounted to $-15.2 \%$ and $-29.9 \%$ for sapwood and $-14.5 \%$ and $-24.1 \%$ for heartwood after 7 and 9 weeks incubation, respectively (Figure 4, line plots).

Lehringer et al. (2010) found similar patterns by light microscopy on the same material. A significantly higher activity of $P$. vitreus was observed after 7 and 9 weeks incubation causing notably more effects on LW tracheid cell walls and pit structures than after 3 or 5 weeks. However, in comparison to other white rot fungi, degradation of the wood matrix remains at a low level even after 9 weeks incubation (see also van Acker and Stevens 1996; Reinprecht et al. 2007). The low mass losses of $2.4 \%$ for heartwood and $2.9 \%$ for sapwood samples validate the relative weak degradation potential of $P$. vitreus during short incubation times.

According to Rypacek (1966), Whetten and Sederoff (1995) and Adusumalli et al. (2010), the removal of lignin results in hardness reduction because lignin as a crosslinking agent is responsible for carrying compression forces within the cell wall and the tissue. Hence, the loss of Brinell hardness can safely be attributed to slight delignification, as shown above by UMSP, and the morphological changes of the tracheid cell walls, as demonstrated by Lehringer et al. (2010).

Spatial heterogeneity The asymmetric supply of nutrients, storage of carbohydrates, water, and oxygen induced a

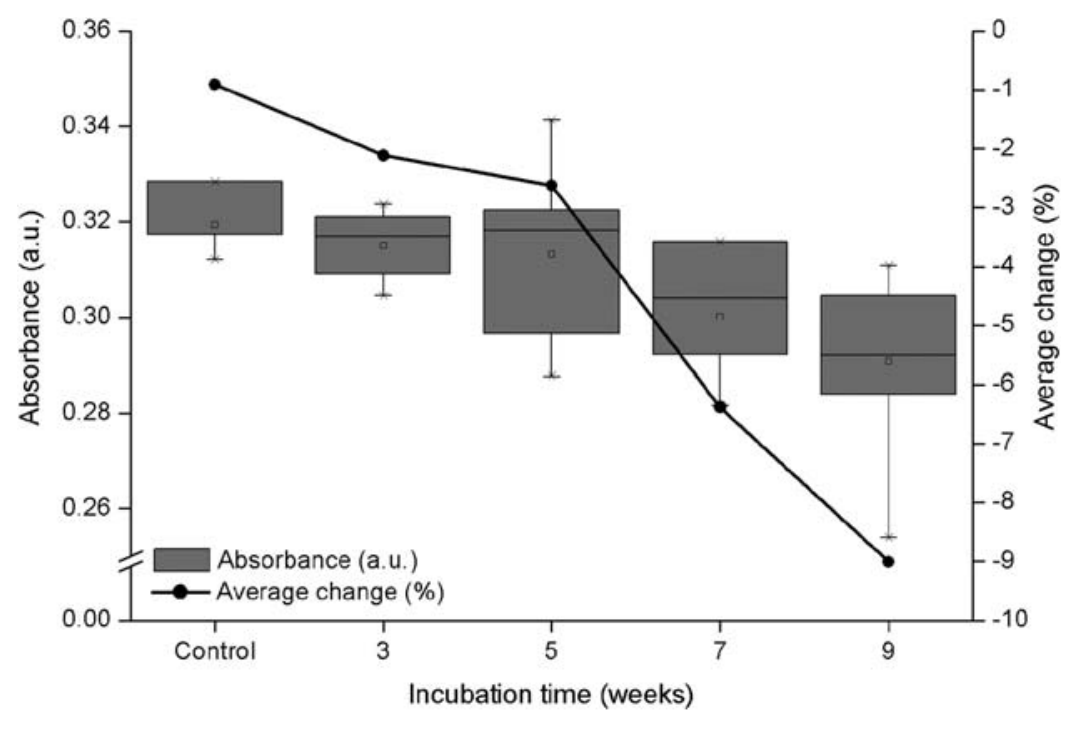

Figure 3 Decreasing UV absorbance at $\lambda=280 \mathrm{~nm}$ in latewood tracheids of Norway spruce after different incubation periods with white rot fungus Physisporinus vitreus. 


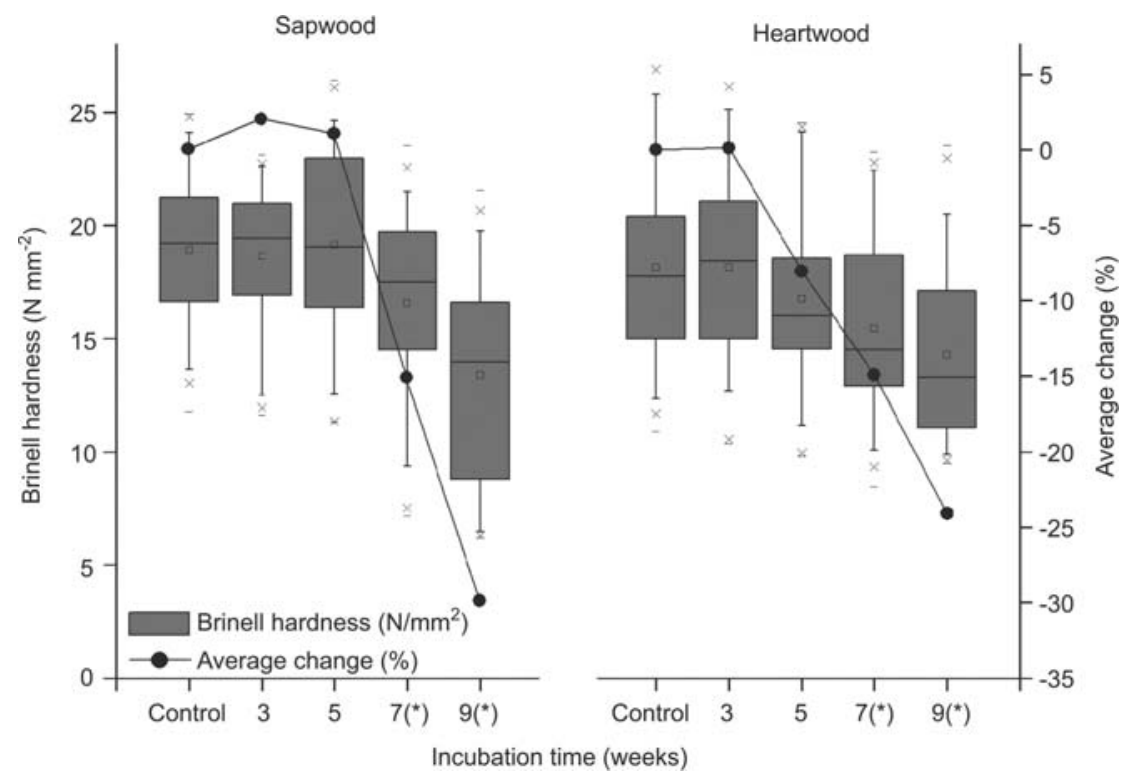

Figure 4 Change of Brinell hardness in Norway spruce after different incubation periods with white rot fungus Physisporinus vitreus. All data from top, bottom, left, and right specimen side are included. *Significant difference compared to control.

heterogeneous colonization of $P$. vitreus in the substrate. Consequently, the bottom areas of the specimen were significantly more affected than the top surfaces (Figures 1 and 5). The greatest reduction in Brinell hardness values was recorded after 9 weeks at the bottom of the sapwood specimen $(-45.2 \%)$.

Minor increases in Brinell hardness can be explained as normal oscillation of the measurement data that results from natural material heterogeneity and the earlywood/latewood distribution at the measurement spot.

\section{Nanoindentation}

Indentations were selectively performed in areas of visible fungal activity. The indenter tip was placed close to hyphal tunneling, cavities, and notches to record the effect of enzymatic degradation in the proximity of hyphal growth (Figure 6).

No clear influence of fungal activity on the nanoindentation data was found over a period of 9 weeks of incubation with $P$. vitreus (Figure 7). The average MOE and hardness for the heartwood control samples was measured to be

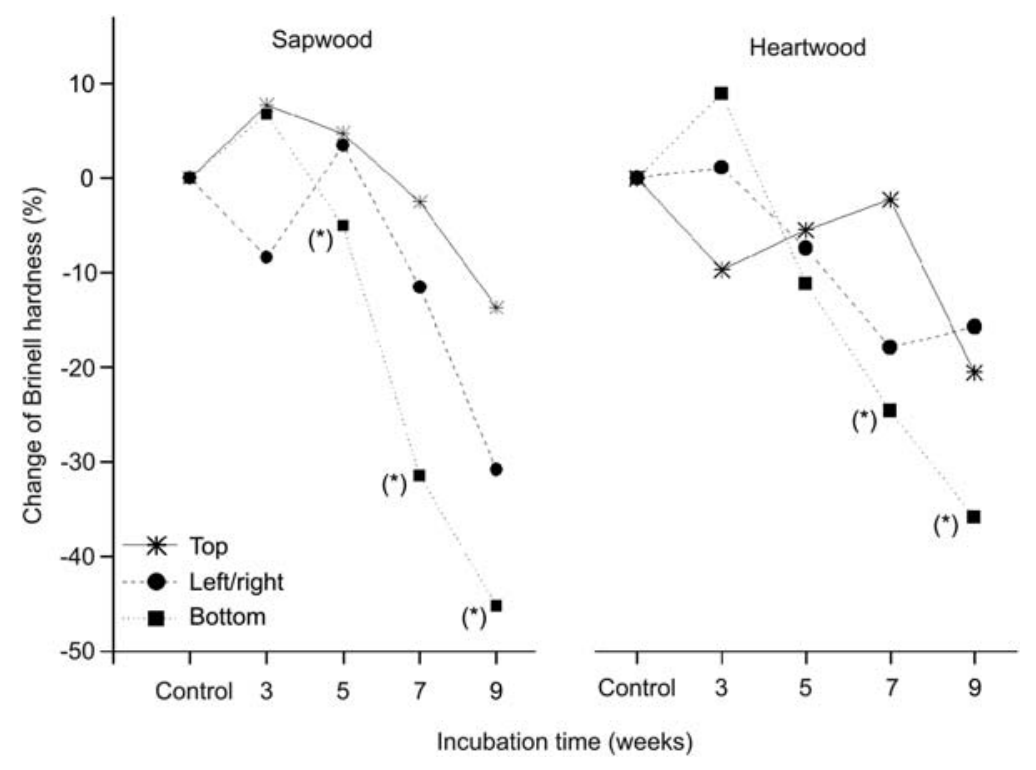

Figure 5 Percentage changes of Brinell hardness according to surface orientation during incubation. *Significant difference between top and bottom specimens. 


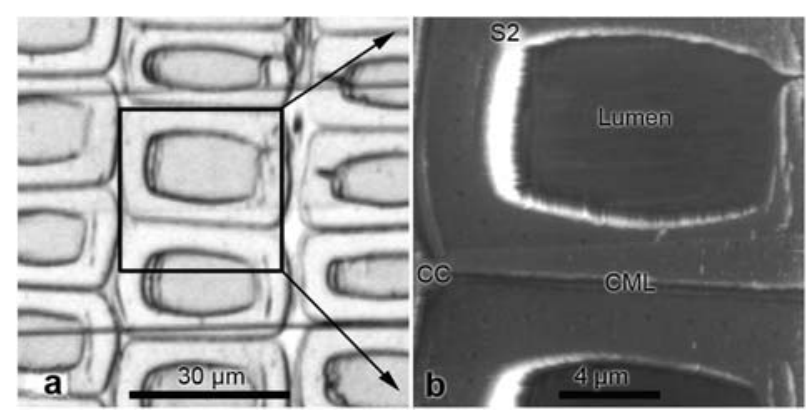

Figure 6 (a) Reflected light microscope micrograph of a polished cross-section of epoxy-resin embedded specimen. (b) Hysitron scanning image of wood cell wall after indentation testing. Note the indentation marks in the secondary cell walls. CC, cell corner; CML, compound middle lamella; S2, secondary cell wall. Both micrographs are from cuts after 5 weeks incubation.

$19.2 \pm 9.6 \%$ and $0.48 \pm 6.1 \% \mathrm{GPa}$, respectively. These values are somewhat comparable with data obtained by Wimmer et al. (1997) and Gindl et al. (2002). Between 3 and 9 weeks incubation, MOE and hardness oscillated between 19.420.3 GPa and 0.47-0.53 GPa, respectively.

As explained above, hardness is strongly influenced by the lignin content of the cell wall. Consequently, it can be expected that local delignification reduces the hardness within the cell wall. But apparently, the absolute changes in lignin content were too low for detection with nanoindentation measurements.

Nanoindentation evaluates only a very limited area within the tracheid cell wall, and hence large coefficients of variation $(\mathrm{CV})$ can be expected. However, the $\mathrm{CV}$ increased with longer incubation times to $10 \%$. This can be interpreted as an increasing heterogeneity of the cell wall matrix with increasing incubation times.

The MOE determined with nanoindentation corresponds to an MOE in compression. Therefore, one could assume that the MOE should clearly decrease in areas with a certain amount of delignification. But according to Bergander and Salmén (2002), delignification plays a subordinate role in this case, because lignin MOE is very low $(2.0 \mathrm{GPa})$ in com-
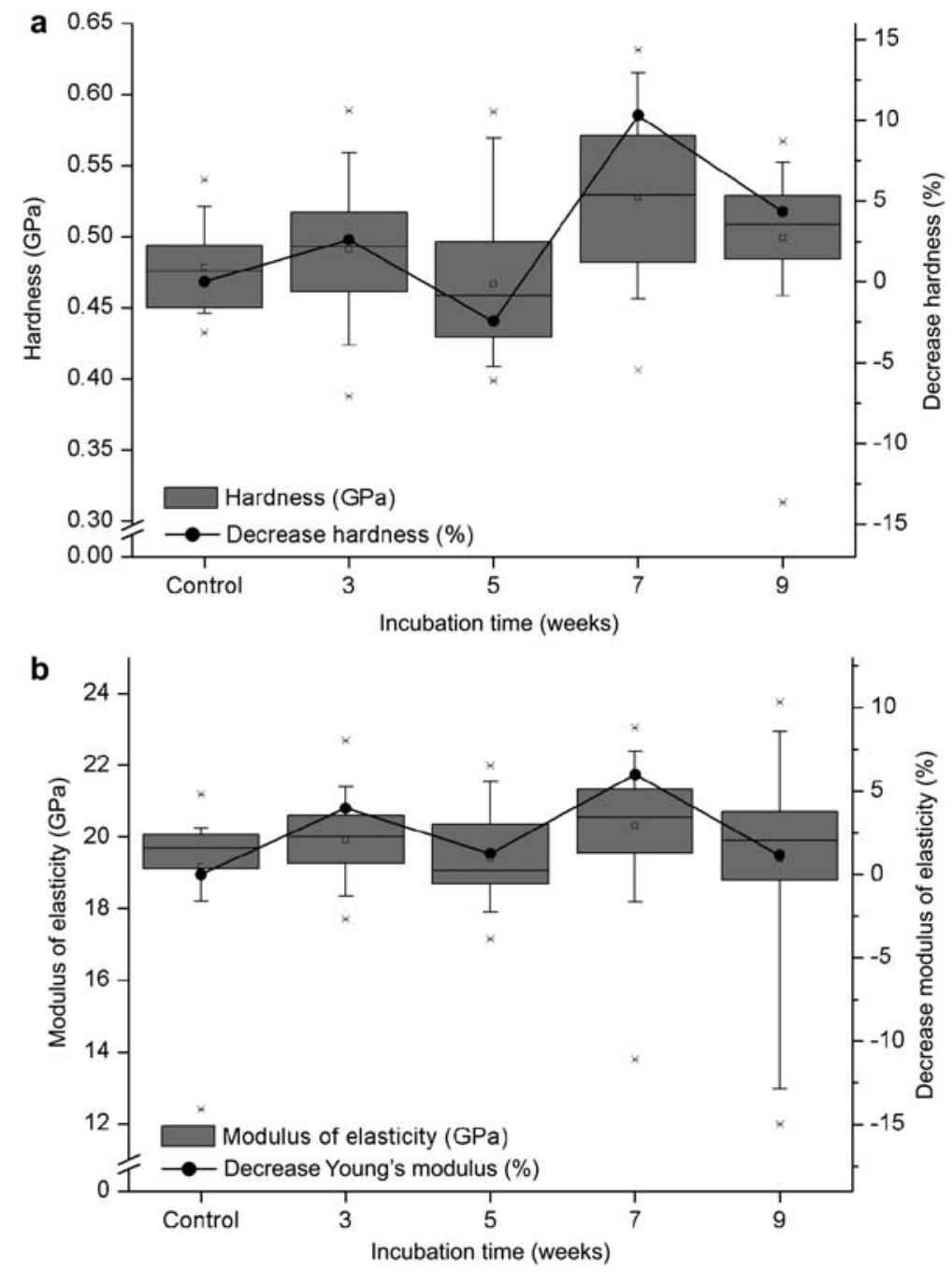

Figure 7 (a, b) Nanoindentation hardness and reduced modulus of elasticity (MOE) in secondary walls of latewood tracheids in Norway spruce wood incubated with Physisporinus vitreus. 
parison to hemicelluloses $(7.0 \mathrm{GPa})$ and cellulose $(167.5$ $\mathrm{GPa}$ ). Instead, the MOE is directly proportional to the microfibril angle (MFA) as suggested by Gindl and Schöberl (2004) and Wu et al. (2009). However, MFA measurements were not conducted in the present study because all specimens originated from a longitudinal sequence in the same board.

\section{Conclusions}

Cellular UMSP measurements showed that the white rot fungus Physisporinus vitreus induces selective delignification and simultaneous degradation in latewood tracheids of Norway spruce wood. The method allows detecting discreet changes of lignin content, caused by a white rot fungus. The effect is time-dependent and clearly visible after incubation times between 7 and 9 weeks. The coexistence of two lignolytic systems of $P$. vitreus can be confirmed by UMSP. The reduction of the Brinell hardness was only significant after 7 and 9 weeks of incubation. A good correlation between Brinell hardness and the progress of delignification was found. The results of nanoindentation were not as consistent as the results of Brinell hardness. The reproducibility of this method proved to be low due to the heterogeneity of the cell wall, which is changing during degradation. An in-depth analysis of chemical alterations induced by the enzymatic activity of $P$. vitreus will be the subject of the second article of this series (Lehringer et al. 2011).

\section{Acknowledgements}

We would like to thank Dr. J. Michler, Jessica Parsons, and Kombaiah Boopathy for their great support during nanoindentation measurements at Empa Thun. Moreover, we would like to express our gratitude to Markus Heeb (Empa St. Gallen) for his valuable assistance during laboratory work. We also gratefully acknowledge the professional contribution of Prof. F.W.M.R. Schwarze during intensive discussions and proofreading. The present study emerged from the research project CTI.8593.1 LSPP-LS 'Bioincising of conifer wood with Physisporinus vitreus to improve its treatability for a range of wood preservation and modification methods'. The authors express their gratitude to the Swiss CTI (Innovation Promotion Agency) for financial support.

\section{References}

Adusumalli, R.B., Mook, W.M., Passas, R., Schwaller, P., Michler, J. (2010) Nanoindentation of single pulp fibre cell walls. J. Mater. Sci. 45:2558-2563.

Bauch, J., Seehann, G., Fitzner, H. (1976) Microspectrophotometrical investigations on lignin of decayed wood. Mat. Org. Beiheft 3:141-152.

Bergander, A., Salmén, L. (2002) Cell wall properties and their effects on the mechanical properties of fibers. J. Mater. Sci. 37:151-156.

Blanchette, R.A., Otjen, L., Effland, M.J., Eslyn, W.E. (1985) Changes in structural and chemical components of wood delignified by fungi. Wood Sci. Technol. 19:35-46.
EN 1534 (2000). Wood and parquet flooring - Determination of resistance to indentation (Brinell) - Test method. CEN European Committee for Standardization.

Fergus, B.J., Procter, A.R., Scott, J.A.N., Goring, D.A.I. (1969) The distribution of lignin in sprucewood as determined by ultraviolet microscopy. Wood Sci. Technol. 3:117-138.

Gindl, W., Schöberl, T. (2004) The significance of the elastic modulus of wood cell walls obtained from nanoindentation measurements. Compos. A Appl. Sci. Manuf. 5:1345-1349.

Gindl, W., Gupta, H.S., Grünwald, C. (2002) Lignification of spruce tracheid secondary cell walls related to longitudinal hardness and modulus of elasticity using nano-indentation. Can. J. Bot. 80: 1029-1033.

Gindl, W., Gupta, H.S., Schöberl, T., Lichtenegger, H.C., Fratzl, P. (2004) Mechanical properties of spruce wood cell walls by nanoindentation. Appl. Phys. A Mater. Sci. Process. 79: 2069-2073.

Hakala, T.K., Lundell, T., Galkin, S., Maijala, P., Kalkkinen, N., Hatakka, A. (2005) Manganese peroxidases, laccases and oxalic acid from the selective white-rot fungus Physisporinus rivulosus grown on spruce wood chips. Enzyme Microb. Technol. 36: 461-468.

Irbe, I., Noldt, G., Koch, G., Andersone, I., Andersons, B. (2006) Application of scanning UV microspectrophotometry for the topochemical detection of lignin within individual cell walls of brown-rotted Scots pine (Pinus sylvestris L.) sapwood. Holzforschung 60:601-607.

Kim, G.H., Son, D.S., Kim, J.J. (2005) Fungi colonizing Douglasfir in cooling towers: identification and their decay capabilities. Wood Fiber Sci. 37:638-642.

Kim, J.S., Lee, K.H., Cho, C.H., Koch, G., Kim, Y.S. (2008) Micromorphological characteristics and lignin distribution in bamboo (Phyllostachys pubescens) degraded by the white rot fungus Lentinus edodes. Holzforschung 62:481-487.

Kleist, G., Seehann, G. (1997) Colonization patterns and topochemical aspects of sap streak caused by Stereum sanguinolentum in Norway spruce. Eur. J. Forest Pathol. 27:351-361.

Kleist, G., Schmitt, U. (1999) Evidence of accessory components in vessel walls of Sapelli heartwood (Entandophragma cylindricum) obtained by transmission electron microscopy. Holz Roh Werkst. 57:93-95.

Kleist, G., Schmitt, U. (2001) Characterisation of a soft rot-like decay pattern caused by Coniophora puteana (Schum.) Karst. in Sapelli wood (Entandrophragma cylindricum Sprague). Holzforschung 55:573-578.

Koch, G., Kleist, G. (2001) Application of scanning UV microspectrophotometry to localise lignins and phenolic extractives in plant cell walls. Holzforschung 55:563-567.

Konnerth, J., Harper, D., Lee, S.H., Rials, T.G., Gindl, W. (2008) Adhesive penetration of wood cell walls investigated by scanning thermal microscopy (SThM). Holzforschung 62:91-98.

Konnerth, J., Gierlinger, N., Keckes, J., Gindl, W. (2009) Actual versus apparent within cell wall variability of nanoindentation results from wood cell walls related to cellulose microfibril angle. J. Mater. Sci. 44:4399-4406.

Konnerth, J., Eiser, M., Jäger, A., Bader, T.K., Hofstetter, K., Follrich, J., Ters, T., Hansmann, C., Wimmer, R. (2010) Macro- and micro-mechanical properties of red oak wood (Quercus rubra L.) treated with hemicellulases. Holzforschung 64:447-453.

Lee, S.H., Wang, S., Pharr, G.M., Kant, M., Penumadu, D. (2007) Mechanical properties and creep behavior of lyocell fibers by nanoindentation and nano-tensile testing. Holzforschung 61: 254-260. 
Lehringer, C., Gierlinger, N., Koch, G. (2008) Topochemical investigation on tension wood fibres of Acer spp., Fagus sylvatica L. and Quercus robur L. Holzforschung 62:255-263.

Lehringer, C., Richter, K., Schwarze, F.W.M.R., Militz, H. (2009) A review on promising approaches for liquid permeability improvement in softwoods. Wood Fiber Sci. 41:373-385.

Lehringer, C., Hillebrand, K., Richter, K., Arnold, M., Schwarze, F.W.M.R., Militz, H. (2010) Anatomy of bioincised Norway spruce wood. Int. Biodeter. Biodegrad. 64:346-355.

Lehringer, C., Saake, B., Živković, V., Richter, K., Militz, H. (2011) Effect of Physisporinus vitreus on wood properties of Norway spruce. Part 2: aspects of microtensile strength and chemical changes. Holzforschung (submitted).

Liese, W. (1970) Ultrastructural aspects of woody tissue disintegration. Annu. Rev. Phytopathol. 8:231-257.

Mai, C., Kües, U., Militz, H. (2004) Biotechnology in the wood industry. Appl. Microbiol. Biotechnol. 63:477-494.

Morrell, J.J., Zabel, R.A. (1985) Wood strength and weight losses caused by soft-rot fungi isolated from treated southern pine utility poles. Wood Fiber Sci. 17:132-143.

Oliver, W.C., Pharr, G.M. (1992) Improved technique for determining hardness and elastic modulus using load and displacement sensing indentation experiments. J. Mater. Res. 7:1564-1580.

Oliver, W.C., Pharr, G.M. (2004) Measurement of hardness and elastic modulus by instrumented indentation: advances in understanding and refinements to methodology. J. Mater. Res. 19:320.

Prislan, P., Koch, G., Cufar, K., Gričar, J., Schmitt, U. (2009) Topochemical investigations of cell walls in developing xylem of beech (Fagus sylvatica L.). Holzforschung 63:482-490.

Reinprecht, L., Novotná, H., Stefka, V. (2007) Density profiles of spruce wood changed by brown-rot and white-rot fungi. Wood Res. Slovakia 52:17-28.

Rypacek, V. Biologie holzzerstörender Pilze. Gustav Fischer Verlag, Jena, 1966.

Schmidt, O. Wood and Tree Fungi. Springer Verlag, Berlin/Heidelberg, 2006.

Schwarze, F.W.M.R. (2007) Wood decay under the microscope. Fungal Biol. Rev. 21:133-170.

Schwarze, F.W.M.R., Landmesser, H., Zgraggen, B., Heeb, M. (2006) Permeability changes in heartwood of Picea abies and
Abies alba induced by incubation with Physisporinus vitreus. Holzforschung 60:450-454.

Schwarze, F.W.M.R., Spycher, M., Fink, S. (2008) Superior wood for violins - wood decay fungi as a substitute for cold climate. New Phytol. 179:1095-1104.

Sonderegger, W. and P. Niemz (2001). Determination of Brinell hardness on MDF and HDF panel boards by differential measurement of indentation depth (Untersuchungen zur Bestimmung der Brinellhärte an MDF- und HDF-Platten mittels Wegmessung) Int. report ETHZ/HW-HP-LZfP Nr. 3:1-10.

Spurr, A.R. (1969) A low-viscosity epoxy resin embedding medium for electron microscopy. J. Ultrastruct. Res. 26:31-43.

Stöckel, F., Konnerth, J., Kantner, W., Moser, J., Gindl, W. (2010) Tensile shear strength of UF- and MUF-bonded veneer related to data of adhesives and cell walls measured by nanoindentation. Holzforschung 64:337-342.

Unbehaun, H., Dittler, B., Kühne, G., Wagenführ, A. (2000) Investigation into the biotechnological modification of wood and its application in the wood-based material industry. Acta Biotechnol. 20:305-312.

van Acker, J., Stevens, M. (1996) Laboratory culturing and decay testing with Physisporinus vitreus and Donkioporia expansa originating from identical cooling tower environments show major differences. Int. Res. Group Wood Pres. IRG/WP/10184:8.

Wang, S., Lee, S.H., Tze, W.T.Y., Rials, T., Pharr, G.M. (2006) Nanoindentation as a tool for understanding nano-mechanical properties of wood cell wall and biocomposites. In: TAPPI International Conference on Nanotechnology, Atlanta, GA, USA. pp. $152-158$.

Whetten, R., Sederoff, R. (1995) Lignin biosynthesis. Plant Cell 7:1001-1013.

Wimmer, R., Lucas, B.H., Tsui, T.Y., Oliver, W.C. (1997) Longitudinal hardness and Young's modulus of spruce tracheid secondary walls using nanoindentation technique. Wood Sci. Technol. 31:131-141.

Wu, Y., Wang, S., Zhou, D., Xing, C., Zhang, Y. (2009) Use of nanoindentation and silviscan to determine the mechanical properties of 10 hardwood species. Wood Fiber Sci. 41:64-73.

Received July 16, 2010. Accepted September 28, 2010. 


1 Effect of Physisporinus vitreus on wood properties of Norway spruce. Part 2: As-

3 Christian Lehringer ${ }^{1^{*}}$, Bodo Saake $^{2}$, Vjekoslav Živković $^{3}$, Klaus Richter $^{1}$, Holger Militz $^{4}$

$4{ }^{1}$ Empa - Swiss Federal Laboratories for Materials Science and Technology, Wood Labor5 atory, Dübendorf, Switzerland, *corresponding author: christian.lehringer@empa.ch

$6{ }^{2}$ University of Hamburg, Department of Wood Science, Chemical Wood Technology, 7 Hamburg, Germany

$8{ }^{3}$ University of Zagreb, Faculty of Forestry, Wood Technology Department, Zagreb, Croatia

94 Wood Biology and Wood Products, Burckhardt-Institute, Georg-August-University, 10 Göttingen, Germany

121 Abstract

13 The biotechnological application of the white rot fungus Physisporinus vitreus named "bio-

14 incising" is being currently investigated for permeability improvement of Norway spruce

15 (Picea abies (L.) Karst.) wood. During short term (< 9 weeks) incubation, fungal activity induces degradation of pit membranes and a simultaneous alteration of the tracheid cell wall structure. In part 1 of this article series, the occurrence of selective delignification and simultaneous degradation was shown by UV-microspectrophotometry (UMSP). Moreover, significant reduction of Brinell hardness was recorded after 7 and 9 weeks incubation. In order to better understand the chemical alterations of the wood constituents due to fungal activity and the corresponding changes of mechanical properties we applied microtensile tests on thin strips that were prepared from incubated Norway spruce wood. Clear indications for the occurrence of selective delignification and simultaneous degradation were 
evident. Determination of lignin content and carbohydrate analysis by borate anion exchange chromatography confirmed the results. Finally, Fourier transform infrared spectroscopy (FT-IR) was applied as methodological complementation. The interpretation of the spectra proved to be difficult since mass losses ranged at a low level $(<9 \%)$. Furthermore, lignin and carbohydrates were simultaneously degraded and no consistent reference peaks could be identified. However, the present study verifies the findings from part 1 of this article series and from previously conducted microscopic investigations. The results will help to better understand the degradation characteristics of $P$. vitreus and contribute to an enhancement of the bioincising process.

Keywords: chemical analysis; finite span; FT-IR; selective delignification; simultaneous degradation; zero span

\section{Introduction}

Permeability improvement of Norway spruce (Picea abies (L.) Karst.) wood by means of a biotechnological method called "bioincising" has been investigated intensively during the past years (Schwarze and Landmesser 2000; Schwarze et al. 2006; Schubert et al. 2009; Schwarze and Schubert 2009; Lehringer et al. 2010a; 2010b). Hereby, the white rot fungus Physisporinus vitreus is supposed to selectively degrade the membranes of the bordered and half-bordered pits during short term incubation times. The bioincised material showed significant improvement of liquid uptakes (Schwarze et al. 2006) but also anatomical changes of the cell wall structure due to fungal activity were reported by Lehringer et al. (2010a). Not only pit membranes are degraded selectively but also cell wall detoriation oc- 
curs, induced by a selective delignification and a simultaneous degradation of lignin and polysaccharides. The term selective delignification is applied to a successive decomposition of the cell wall components. Preferably the degradation of lignin and hemicelluloses occur at the beginning of fungal colonization, while the mainly the crystalline region of cel-

51 lulose fraction is degraded rather at later stages (Liese 1970). Simultaneous rot is charac-

52 terized by fungal ecto-enzymes which have the capacity to degrade cellulose, hemicelluloses and lignin at the same time (Schmidt 2006).

Analysis of Brinell hardness revealed a significant hardness reduction in the subsurface area after 7 and 9 weeks incubation (first paper of this article series, Lehringer et al. 2010b). In the same work, the application of cellular UV-microspectrophotometry (UMSP) indicated chemical alterations of the main wood components in close vicinity of fungal hyphae.

An improved knowledge of these chemical alterations is critical for further development of the process. For successful upscaling of the bioincising process, the incubation periodmust be short ( $<4$ weeks) and wood colonization homogeneous, to reduce adverse side effects e.g. structural alterations. Currently, the incubation conditions are being identified and optimized. For this purpose, a detailed knowledge of the degradation pattern of $P$. vitreus and of the resulting chemical alterations is crucial. Factors during incubation such as temperature, water activity, nutrient and oxygen supply have an influence on the homogeneity, the speed of substrate colonization and finally on the selectivity of fungal activity

67 towards different cell wall components. Especially the carbon/nitrogen-ratio (C/N-ratio) has recently been discussed to affect the degradation characteristics of $P$. vitreus (Lehringer et al. 2010a) during incubation. The specimens used in the present study were incubated on malt extract agar (MEA) that has a narrow $\mathrm{C} / \mathrm{N}$-ratio (50/1). It is well established that a nar- 
71 row $\mathrm{C} / \mathrm{N}$-ratio usually facilitates the degradation of polysaccharides by wood decay fungi.

72 In order to investigate these aspects of chemical changes and the resulting micromechanic

73 effects, the microtensile testing method appears to be a suitable approach.

74 Microtensile tests of microtomed (approx. $80 \mu \mathrm{m}$ thick) wood strips have been conducted in the past by various authors (Kennedy and Ifju 1962; Grozdits and Ifju 1969; Derbyshire et al. 1995; Turkulin and Sell 2002). Usually two measurement setups are applied. At the zero span method the jaws holding the thin strip are initially in contact. All microfibrils in the cross section are bridging the infinitesimal gap between the jaws and the test is principally a measure of microfibril strength. Since the microfibrils are the cell wall elements responsible for the longitudinal tensile strength of the wood structure, the zero span tensile strength is generally greater than any value of tensile strength determined in a finite span test. For the finite span method, the thin strips are mounted between the jaws with a free distance of $10 \mathrm{~mm}$. This approach provides further information about the bonding properties between the fibers, because the middle lamella (where the highest lignin content is found) will additionally react sensitively on the tensile stresses.

We applied microtensile tests on thin strips in order to investigate the mechanical changes of the tracheid cell (wall) matrix during incubation times between 0 and 9 weeks. We envisaged a predominant occurrence of selective delignification to be detected by a decreasing finite span strength (f-strength), whereas the zero span strength (z-strength) should decrease if the decay pattern is governed by simultaneous degradation of lignin and polysaccharides. Microtensile tests were used for material characterization in various contexts

92 (Derbyshire et al. 1995; Jirous-Rajkovic et al. 2004; Gierlinger and Burgert 2006; Keunecke and Niemz 2008; Eder et al. 2009; Xiao et al. 2010; Xie et al. 2010). However, to 
94 our knowledge this method has been previously applied for the characterization of decayed wood exclusively by Wilcox and Garcia (1968).

96 Subsequently, we carried out a wet chemical analysis in order to provide further informa-

97 tion about the degradative activity of $P$. vitreus. The wet chemical analysis for the investi98 gation on wood decaying fungi is a well established approach and has previously been 99 applied by e.g. Crawford et al. (1982), Rabinovich et al. (2004), Istek et al. (2005) and 100 Schmutzer et al. (2008).

101 Finally, Fourier transform infrared spectroscopy (FT-IR) was applied. The aim was to trace 102 the discreet changes in chemical properties with this method that requires - contrary to 103 wet chemical analysis - only small sample sizes and short analysis time. The method is 104 well accepted as a fast and efficient technique for analyzing and monitoring structural 105 wood changes during biological, chemical or physical modification (Owen and Thomas 106 1989; Faix et al. 1991; Moore and Owen 2001; Pandey and Pitman 2003).

107 The main objective of the present study is to elucidate the mechanical and chemical 108 changes that are induced by $P$. vitreus at the subsurface area during short term incubation 109 of spruce wood on MEA. Findings are expected to clarify whether the enzymatic activity of $110 P$. vitreus predominately results in a selective delignification or if a simultaneous degrada111 tion occurs in a first phase of substrate colonization. Finally, the results will contribute to 112 the further improvement of the bioincising incubation process. 


\section{$3 \quad$ Material and Methods}

\section{$114 \quad 3.1 \quad$ Specimen material}

115 One board of defect-free and kiln-dried wood from a Norway spruce tree (Picea abies (L.)

116 Karst.) was investigated. For sapwood and heartwood, three specimen collectives were 117 prepared. In each collective, five specimens were always taken in one longitudinal se118 quence in order to minimize the influence of natural property variation within the single 119 tree. As the samples were subjected to four different incubation periods and one control, 120 this axial pairing provided a good comparability of the results. Each specimen measured $121200 \times 30 \times 30 \mathrm{~mm}^{3}(\mathrm{~L} \times \mathrm{R} \times \mathrm{T})$. After sterilization, the specimens were incubated with the 122 white rot fungus $P$. vitreus for $3,5,7$, and 9 weeks at $22^{\circ} \mathrm{C}$ and $70 \% \mathrm{RH}$. For a detailed 123 description of material selection and specimen preparation see Lehringer et al. (2010b).

124 Density and mass loss were calculated as described in Lehringer et al. (2010a).

125 Chemical analysis and the FT-IR spectroscopy was conducted on smaller wood speci126 mens of Norway spruce sap-and heartwood $\left(L \times R \times T: 100 \times 15 \times 10 \mathrm{~mm}^{3}\right)$ that were incubated separately, but exactly following the same incubation routine as used for the larger specimens in Lehringer et al. (2010b). Three replicates for each incubation time were prepared. In contrast to the larger wood specimens, mass losses were determined after drying to a moisture content of $0 \%$ to provide a definite basis for further calculations.

\subsection{Microtensile testing}

132 Softwood and heartwood specimens from all three collectives were taken for thin strip preparation (Table 1). Blocks of $L \times R \times T 80 \times 10 \times 30 \mathrm{~mm}^{3}$ were prepared from the bottom surface of the incubated specimens where fungal activity was most pronounced (see also Lehringer et al., 2010b). 
Table 1 Experimental plan for microtensile strip preparation

\begin{tabular}{llc}
\hline Description & Variable & Factor \\
\hline Wood type & Sapwood (SW ), heartwood (HW) & 2 \\
Collective & A, B, C & 3 \\
Incubation time & control, 3, 5, 7, 9 weeks & 5 \\
Side on specimen & bottom & 1 \\
Replicates & Number of prepared strips & 20 \\
\hline
\end{tabular}

Result from factor multiplication: $n=600$

137 The blocks were vacuum impregnated with distilled water at ambient temperature until fully

138 saturated. Sequential microtoming of $80 \mu \mathrm{m}$ thin strips $(n=20$ per block $)$ in the longitudin-

139 al-radial plane was conducted with slight inclination of the specimens at an angle of $\sim 5^{\circ}$ to

140 the radial plane in order to avoid disturbing influences by the wood rays.

141 A thorough thickness control of each single strip was conducted. Thickness measurements

142 (average of 5 points on each strip) were made using an electronic thickness gauge (Mitu-

143 toyo, Kanagawa, Japan, accuracy $\pm 0.1 \mu \mathrm{m})$. All strips passing the target thickness by \pm

$1445 \%$ were rejected, resulting in 12 to 19 strips per block, thus the total number of tested

145 strips was $n=528$. Each strip was then cut in the tangential-radial plane into two parts,

146 which then were measured separately at finite span and zero span.

147 For microtensile testing a paper tester (Pulmac International Inc., Montpelier, VT, USA)

148 was used at standard laboratory conditions of $20^{\circ} \mathrm{C}, 65 \% \mathrm{RH}$. The ultimate breaking load

149 was recorded in pounds per square inch (Psi) and recalculated to Newton (N). The clamp-

150 ing pressure was set to $0.55 \mathrm{MPa}$ for finite span and $0.62 \mathrm{MPa}$ for zero span and the load-

151 ing rate was set to $70 \mathrm{kPa} \mathrm{s}^{-1}$ for all measurements. 
152 The trends of decreasing tensile strength against increasing incubation times were dis-

153 played by means of linear regression plots. Hereby, the slope of the regression lines was

154 taken as comparative measure for the intensity of fungal activity on the cell wall compo155 nents.

\section{$156 \quad 3.3 \quad$ Chemical analysis}

\section{$157 \quad$ 3.3.1 Two step hydrolysis and lignin determination}

158 All incubated specimens were ground in a vibration mill (Herzog, Osnabrück, Germany)

159 prior to hydrolysis. The milled powder was then conditioned at $20^{\circ} \mathrm{C}$ and $65 \% \mathrm{RH}$ and moisture content was determined for further calculations. A two step-hydrolysis with $72 \%$ $\mathrm{H}_{2} \mathrm{SO}_{4}$ for 1 hour at $30^{\circ} \mathrm{C}$ and $2.6 \% \mathrm{H}_{2} \mathrm{SO}_{4}$ for 40 minutes at $120^{\circ} \mathrm{C}$ was conducted. After filtration, $1 \mathrm{ml}$ of the hydrolyzate was removed for analysis in the Borate anion exchange chromatography. Lignin content was determined as hydrolysis residue (Willför et al. 2009) and acid-soluble lignin was measured by UV-spectroscopy $(\lambda=205 \mathrm{~nm})$ according to Tappi 250 (2005).

\subsubsection{Borate anion exchange chromatography for carbohydrate analysis}

The stationary phase consisted of the anion exchange MCI Gel CA08F (Mitsubishi Chemical Corporation, Tokyo, Japan) packed in Omnifit ${ }^{\circledR}$ (Bio-Chem Valve, Boonton, USA) empty columns of $7 \times 11.5 \mathrm{~mm}$. The mobile phase consisted of (A) $0.3 \mathrm{M}$ potassium tetraborate and (B) $0.9 \mathrm{M}$ potassium tetraborate at $0.7 \mathrm{ml} \mathrm{min}^{-1}$ gradient elution. The gradient elution was conducted as follows: 0min: $90 \%$ A, 10\% B; 35min: $10 \%$ A, 90\% B; 47 min: end. Postcolumn derivatization was obtained by the addition of cubicinchoniate $\left(0.35 \mathrm{ml} \mathrm{min}{ }^{-1}\right)$ and subsequent heating to $105^{\circ} \mathrm{C}$ in a $0.3 \mathrm{~mm}$ Teflon coil. Detection at $560 \mathrm{~nm}$ was performed with a UV-VIS-detector (Sinner et al. 1975; Sinner and Puls 1978; Willför et al. 2009). 
175 The amounts of detected monosaccharides were corrected for water addition during hy-

176 drolysis. The percentage losses for cellulose, xylan and mannan (Table 3, columns 12-15)

177 were determined corresponding to the constitution of their monosaccharides, respectively

178 the arabinoglucuronoxylans and galactoglucomannas of softwoods. According to (Timell

179 1967) and Janzon et al.(2008) the carbohydrates were calculated with Equations (1), (2)

180 and (3) where the mannose/glucose-ratio is defined with 3:1.

$$
\begin{aligned}
& \text { xylan }=\text { xylose }+4-O-\text { methylglucuronic acid }+ \text { arabinose } \\
& \text { mannan }=\text { mannose }+ \text { galactose }+\left(\frac{\text { mannose }}{3}\right) \\
& \text { cellulose }=\text { glucose }-\left(\frac{\text { mannose }}{3}\right)
\end{aligned}
$$

\section{$181 \quad$ 3.3.3 Fourier transform infrared spectroscopy (FT-IR)}

182 A spectrophotometer FTS-6000 with golden gate single reflection diamond ATR P/N

18310500 Series (Portsman Instruments AG, Biel-Benken, Switzerland) was used for collect-

184 ing the FT-IR spectra. The size of the measuring area was $0.36 \mathrm{~mm}^{2}$ and the resolution of 185 the equipment was set to $8 \mathrm{~cm}^{-1}$ with 32 average scans. Contact pressure was set to 100 $186 \mathrm{cN}$. Ten spectra were taken on the bottom side of each sample on the longitudinal-radial surface orientation - following one annual ring - and averaged for further evaluation.

188 The peak heights were determined using the software Resolutions Pro ${ }^{\circledR}$ (Digilab, Holliston, 189 USA). Subsequently, the peak heights for lignin associated bands were related against 190 carbohydrate reference peaks in order to display relative changes in the composition of the 191 wood constituents (Faix et al. 1991; Pandey and Pitman 2003). 


\subsection{Data analysis}

193 For all collected data, a one way ANOVA and a Tukey honesty test were conducted with 194 the statistic software Systat $12^{\circledR}$ (Systat Software Inc., Chicago, USA). A probability value 195 of $p<0.05$ was considered to print to significant differences.

\section{Results and discussion}

\section{$197 \quad 4.1 \quad$ Mictrotensile}

198 As shown in Table 2, the finite span strength (f-strength) was always at least one third 199 lower than the zero span strength (z-strength). This was to be expected, since the mode of 200 failure in zero span and in finite span tests is the same, but the bigger influence of plastic 201 deformations and inter-tracheid bonding in the CML generally causes lower strength val202 ues in finite span testing (Derbyshire et al. 1995; Turkulin and Sell 2002).

203 Table 2 Absolute values for microtensile strength after incubation of Norway spruce wood with $P$. 204 vitreus

\begin{tabular}{|c|c|c|c|c|c|}
\hline $\begin{array}{l}\text { Sapwood/ } \\
\text { Heartwood }\end{array}$ & $\begin{array}{l}\text { Incubation time } \\
\text { (weeks) }\end{array}$ & Mass loss $(\%)$ & Zero span (N) & Finite span (N) & $\begin{array}{l}\text { Index finite span } \\
\text { to zero span }\end{array}$ \\
\hline \multirow{5}{*}{ SW } & Control & - & $96.8 \pm 4.4$ & $66.6 \pm 6.2$ & 0.7 \\
\hline & 3 & $0.1 \pm 0.2$ & $96.8 \pm 6.8$ & $55.1 \pm 7.1$ & 0.6 \\
\hline & 5 & $1.2 \pm 0.5$ & $79.9 \pm 8$ & $50.2 \pm 7.9$ & 0.6 \\
\hline & 7 & $2.4 \pm 0.7$ & $69.4 \pm 9.6$ & $30.9 \pm 4.5$ & 0.4 \\
\hline & 9 & $2.9 \pm 0.8$ & $49.5 \pm 5$ & $23 \pm 6.2$ & 0.5 \\
\hline \multirow{5}{*}{ HW } & Control & - & $91 \pm 9.6$ & $60.4 \pm 10.5$ & 0.7 \\
\hline & 3 & $1.1 \pm 0.5$ & $89.3 \pm 9.5$ & $64.8 \pm 10.2$ & 0.7 \\
\hline & 5 & $1.3 \pm 0.6$ & $98.9 \pm 8.1$ & $68 \pm 9.3$ & 0.7 \\
\hline & 7 & $2.1 \pm 0.8$ & $69.6 \pm 8.7$ & $44.7 \pm 8.2$ & 0.6 \\
\hline & 9 & $2.4 \pm 1.4$ & $60.2 \pm 14.7$ & $41.5 \pm 5.3$ & 0.7 \\
\hline
\end{tabular}

205 In heartwood, the ratio $\mathrm{f} / \mathrm{z}$-strength ranged for all incubation times between 0.6 and 0.7 , 206 while for sapwood a larger span was recorded with ratios down to 0.4 and 0.5 after 7 and 9 weeks incubation, respectively. Turkulin and Sell (2002) conducted microtensile tests on 
208 photodegraded thin strips and reported similar ratios of $\mathrm{f}$ - and z-strength. The reduced val209 ues for sapwood samples with longer incubation time are due to relatively stronger de-

210 crease of $\mathrm{f}$-strength than z-strength. Increased delignification along with higher degrada-

211 tion rates of cellulose obviously induce a stronger effect on f-strength.

212 The sapwood specimens showed a significant loss of z-strength after 5 weeks incubation 213 (Figure 1). After 9 weeks, z-strength retention was recorded to $51.1 \pm 10 \%$ and the slope 214 of the regression line plotted to $-11.3^{*} x$. In comparison, f-strength for the softwood speci215 mens decreased significantly after 3 weeks incubation and resulted in a minimum strength 216 retention of $34.6 \pm 26.9 \%$ after 9 weeks. The regression line plotted to $-16.6^{*} x$.

217 The effect of $P$. vitreus on the heartwood specimens was less pronounced. A significant 218 drop of both z- and f-strength was recorded after 7 weeks and the strength retention after 2199 weeks was $66.1 \pm 24.4 \%$ for $z$-strength and $68.7 \pm 12.9 \%$ for f-strength. The regression 220 slopes for $z-$ and f-strength were $-5.7^{*} x$ and $-10.3^{*} x$, respectively.

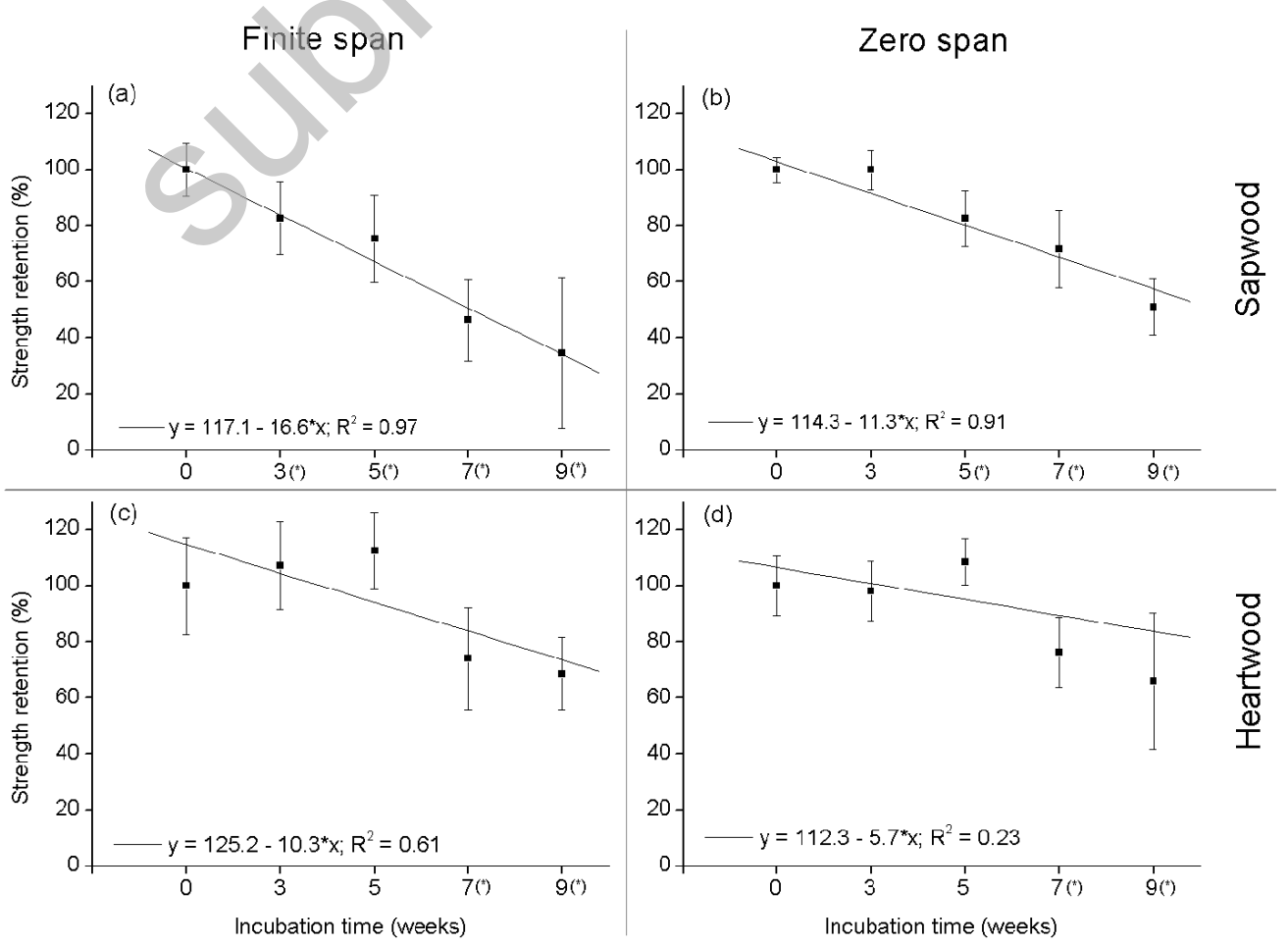


222 Figure 1 Effect of incubation with Physisporinus vitreus on microtensile strength of Norway spruce 223 sapwood $(a, b)$ and heartwood $(c, d) .\left(^{*}\right)=$ significant changes compared to control (zero weeks)

224 The slopes of the regression line serve as indicator for the degradation rates of $P$. vitreus 225 on lignin and cellulose. Firstly, the slopes for the sapwood specimens were always higher 226 than for the heartwood specimens. This suggests a higher degradation rate in sapwood 227 than in heartwood. Due to a lower degree of extractives and a general better accessibility 228 of nutrients and carbohydrates the degradative activity of wood decay fungi is commonly 229 higher in sapwood than in heartwood (Rypacek 1966; Schmidt 2006).

230 Secondly, the slopes of the linear regression and accordingly the strength losses in finite 231 span measurements were always higher than in zero span tests. It is a well accepted fact, 232 that the z-strength mainly reflects a testing of cellulose microfibrils in the tracheid cell walls 233 (Law et al. 1977; Derbyshire et al. 1996; Turkulin and Sell 2002). In contrast f-strength is a 234 measure for the inter-tracheid-bonding strength that is determined by the lignin content of 235 the compound middle lamella $(\mathrm{CML})$ and the cellulose microfibrils. According to this, the 236 higher losses in f-strength can be explained by delignification processes and the resulting 237 inter-fiber slippage effects. The degradation of cellulose additionally contributes to a loss of 238 f-strength. The microscopic and topochemical investigations on bioincised wood by Le239 hringer et al. (2010a; 2010b) revealed local regions of a selective delignification of the 240 tracheid cell walls by $P$. vitreus that is commencing from the lumen through the secondary 241 cell wall towards the CML. Even though the cell wall structure remains mostly intact during 242 the first 9 weeks of incubation, it is probable that the progressing delignification also wea243 kens the bonding properties of the CML.

244 The progressing weakening of the tracheid cell wall due to hyphal tunneling, cavities and 245 notches (as reported by Lehringer et al. 2010a,b) is mainly reflected by the decreasing z- 
246 strength. Chain length reduction of the microfibrils (degree of polymerization, DP) and lig-

247 nin depolymerization result in a pronounced reduction of tensile strength.

248 The microtensile strengths showed a stepwise decrease after 7 and 9 weeks (Figure

249 1a,c,d). Congruently, studies on morphological changes, Brinell hardness and delignifica-

250 tion determined by UMSP also displayed stronger effects of $P$. vitreus after 7 to 9 weeks

251 incubation (Lehringer et al. 2010a; 2010b). Hence, incubation times should be kept signifi-

252 cantly below 7 weeks to avoid major adverse effect on the mechanical wood properties.

253 For the heartwood specimens, partly increasing values of f-strength ( 3 and 5 weeks) and 254 of z-strength (5 weeks) were recorded (Figure 1). To our knowledge, in the existing litera255 ture it has not been described that increasing tensile strength occurred neither during 256 white, brown nor soft rot degradation. This effect could only be seriously explained by 257 chemical reactions (such as polymerization or cross-linking) that occur on the cellulose 258 and/or lignin polymers during fungal degradation. But instead, enzymatic depolymerization, 259 hydrolysis and oxidative reactions occur that commonly reduce the mechanical integrity of 260 the wood. Turkulin and Sell (2002) discussed the initial increase of z-strength that they ob261 served during photodegradation of softwoods by ultraviolet radiation. They proposed an in262 itial 'radiation induced cross-linking' between cellulose microfibrils that was later followed 263 by high strength losses. However, this hypothesis is not applicable in our case since we 264 worked with a wood decay fungus. Thus, the minor increases of microtensile strength must 265 rather be explained with a normal distortion of the measurement data. 


\subsection{Chemical analysis}

268 Weight losses of the specimen from chemical analysis ranged between $0.1 \pm 0.1 \%$ and 8.2 $269 \pm 0.6 \%$ in sapwood and $0.1 \pm 0.05 \%$ and $6 \pm 1.6 \%$ for heartwood (Table 3 ). These values 270 are higher than the recorded mass losses of the specimens used for microtensile testing 271 (see Table 2). This is due to the fact that the specimens incubated for chemical analysis 272 and FT-IR spectroscopy provided a smaller volume and thus the absolute losses by fungal 273 degradation resulted in virtually higher mass losses. But still, $P$. vitreus shows to be a 274 wood decay fungus with comparable low degradation rates, as also discussed by Lehring275 er et al. (2010b).

276 The percentage alterations of the main wood components are illustrated in Figure 2.

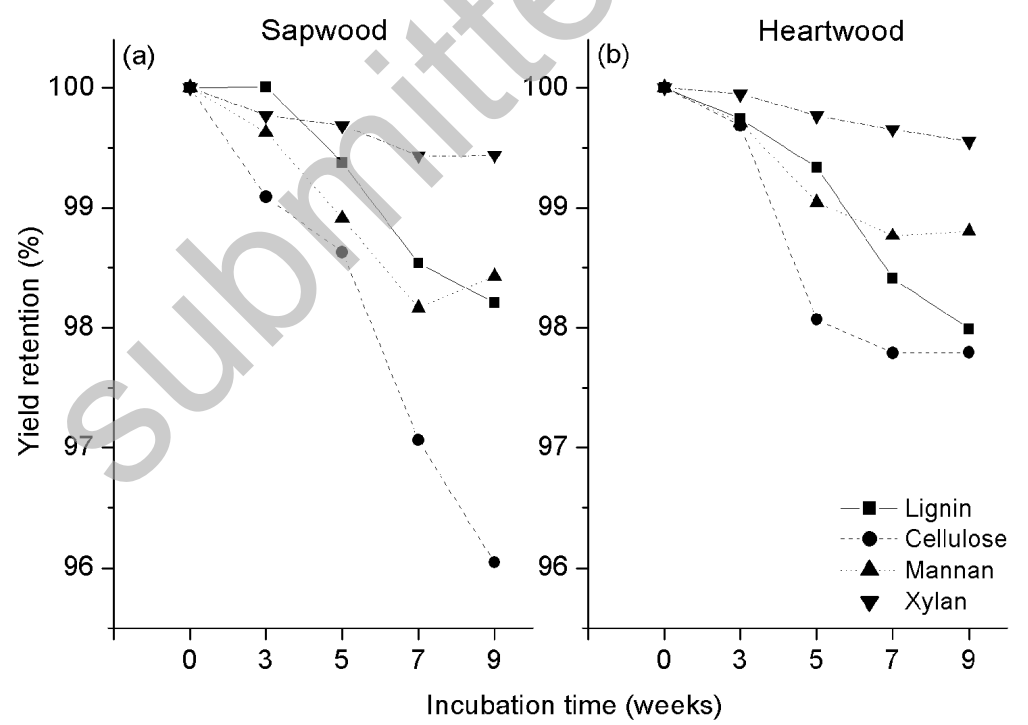

278 Figure 2 Effect of incubation with Physisporinus vitreus on chemical composition of Norway spruce 279 sapwood (a) and heartwood (b).

280 In sapwood and heartwood the lignin degradation commences at almost equal rates and 281 shows absolute losses of $-1.8 \%$ and $-2 \%$ after 9 weeks incubation respectively. The xylan 282 reduction after 9 weeks was slightly lower in heartwood specimens $(-0.6 \%$ SW $>-0.4 \%$ 
$283 \mathrm{HW})$ as well as the mannan loss $(-1.6 \% \mathrm{SW}>-1.2 \% \mathrm{HW})$. A difference was recorded for cellulose degradation: in sapwood, the cellulose degradation proceeded very rapidly after 3 weeks incubation and showed a continuously strong reduction rate of $-4 \%$ after 9 weeks incubation. In contrast, the heartwood specimens showed a strong decrease after 3 and 5 weeks but then the degradation level remained stable with $-2.2 \%$ after 7 and 9 weeks incubation.

The relatively high reduction of cellulose in softwood appear to suggest a soft rot type I and II in the latewood tracheids cell walls as shown by Lehringer et al. (2010a; 2010b).

291 However, results from microtensile tests (z-strength) did not reflect this stepwise reduction 292 (see Figure 1b).

293 The selectivity for lignin degradation can be expressed by the ratio of lignin loss/ cellulose 294 loss (Table 3, column 16). The ratio ranged around 0.5 for sapwood and between 0.3 and 295 0.9 for heartwood which indicates a rather low selectivity for lignin degradation. When Hakala et al. (2004) conducted a study with 86 isolates of white rot fungi on Norway spruce at 29710 weeks incubation, they found 17 strains that showed a selectivity ratio $>1.0$, among 298 others also Physisporinus rivulosus T241i, showed a high selectivity for lignin degradation 299 (ratio 3.3). In the latter study wood specimens were incubated on vermiculite that is known 300 to posess a wide $\mathrm{C} / \mathrm{N}$-ratio and stimulates a range of white rot fungi (probably also $P$. vitreus) to cause a selective delignification (Lehringer et al. (2010a). The present study pro-

302 vides additional evidence that incubation of wood specimens on MEA (i.e with a narrow $303 \mathrm{C} / \mathrm{N}-$ ratio) - as used in this work - results in sub-optimal incubation conditions for a selec304 tive delignification or a selective pit membrane degradation (see also Dill and Kraepelin 305 (1988), Rios and Eyzaguirre (1992)) 


\section{EMPA}

306 Table 3 Contents of lignin, composition of monomeric sugars in hydrolyzates and percent losses of wood constituents after incubation of 307 Norway spruce with Physisporinus vitreus.

\begin{tabular}{|c|c|c|c|c|c|c|c|c|c|c|c|c|c|c|c|}
\hline \multirow{2}{*}{$\begin{array}{l}\text { Sapwood/ } \\
\text { Heartwood }\end{array}$} & \multirow{2}{*}{$\begin{array}{l}\text { Incuba- } \\
\text { tion } \\
\text { time } \\
\text { (weeks) }\end{array}$} & \multirow{2}{*}{$\begin{array}{l}\text { Mass loss } \\
(\%)\end{array}$} & \multicolumn{8}{|c|}{ Extraction yield (abs.\%) } & \multicolumn{5}{|c|}{ Resulting losses (\%) } \\
\hline & & & Lignin* $^{*}$ & Gluc & Xyl & Man & Ara & Gal & Ram & $\begin{array}{l}\text { 4-O-Me- } \\
\text { GluA }\end{array}$ & & & Xylan & Mannan & $\begin{array}{c}\text { Selectivity } \\
\text { (\%lignin loss / } \\
\% \text { cellulose loss) }\end{array}$ \\
\hline \multirow{5}{*}{ SW } & Control & - & 26.5 & 50.1 & 5.6 & 12.8 & 1.1 & 1.1 & 0.1 & 0.6 & - & - & - & - & - \\
\hline & 3 & $0.1 \pm 0.1$ & 26.5 & 49.0 & 5.4 & 12.6 & 1.1 & 1.1 & 0.1 & 0.6 & -0.01 & -0.9 & -0.2 & -0.4 & 0.01 \\
\hline & 5 & $1.8 \pm 0.2$ & 25.9 & 48.3 & 5.2 & 12.0 & 1.2 & 1.0 & 0.1 & 0.7 & -0.6 & -1.4 & -0.3 & -1.1 & 0.46 \\
\hline & 7 & $5.5 \pm 0.3$ & 25.0 & 46.3 & 4.9 & 11.4 & 1.1 & 0.9 & 0.1 & 0.6 & -1.5 & -2.9 & -0.6 & -1.8 & 0.5 \\
\hline & 9 & $8.2 \pm 0.6$ & 24.7 & 45.2 & 4.9 & 11.7 & 1.1 & 0.9 & 0.1 & 0.6 & -1.8 & -4.0 & -0.6 & -1.6 & 0.45 \\
\hline \multirow{5}{*}{ HW } & Control & - & 27.7 & 50.1 & 4.6 & 12.6 & 1.1 & 0.9 & 0.1 & 0.6 & - & - & - & - & - \\
\hline & 3 & $0.1 \pm 0.05$ & 27.4 & 49.7 & 4.5 & 12.5 & 1.1 & 0.8 & 0.1 & 0.5 & -0.3 & -0.3 & -0.1 & -0.3 & 0.8 \\
\hline & 5 & $2.4 \pm 0.7$ & 27.0 & 47.7 & 4.3 & 12.0 & 1.1 & 0.8 & 0.1 & 0.5 & -0.7 & -1.9 & -0.2 & -1.0 & 0.35 \\
\hline & 7 & $3.9 \pm 0.8$ & 26.1 & 47.3 & 4.3 & 11.7 & 1.0 & 0.8 & 0.1 & 0.5 & -1.6 & -2.2 & -0.3 & -1.2 & 0.72 \\
\hline & 9 & $6 \pm 1.6$ & 25.7 & 47.3 & 4.3 & 11.7 & 0.9 & 0.9 & 0.1 & 0.4 & -2.0 & -2.2 & -0.4 & -1.2 & 0.91 \\
\hline
\end{tabular}




\subsection{FT-IR}

312 The spectra normalized at bands corresponding to carbohydrates $1157,1367,1733 \mathrm{~cm}^{-1}$

313 (Faix et al., (1991), Pandey and Pitman (2003; 2004)) did not show a clear trend for selec-

314 tive lignin degradation. Only discreet differences between the spectra from different incu-

315 bation times are discernable (Figure 3 ).
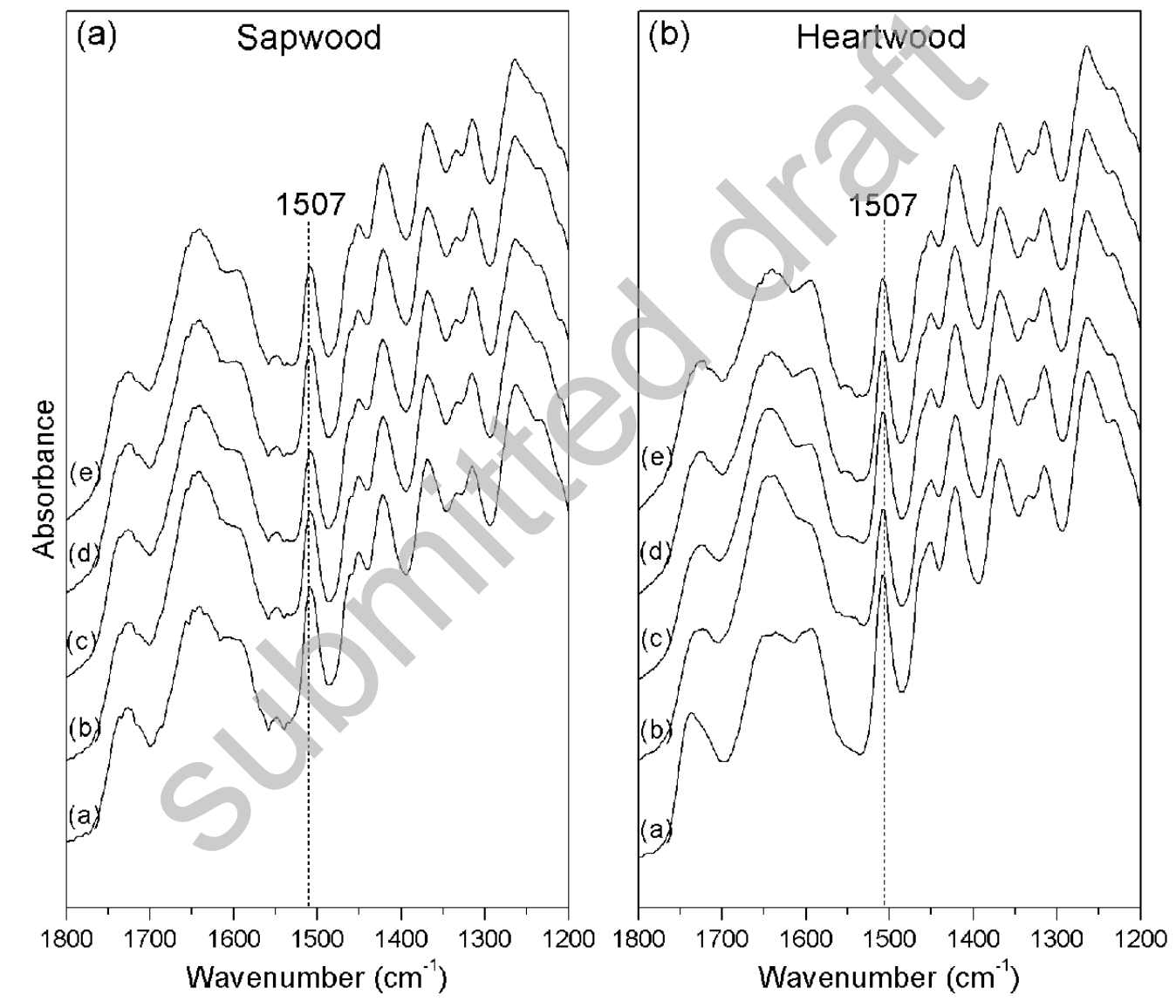

317 Figure 3 FT-IR spectra normalized at $1367 \mathrm{~cm}^{-1}$ of Norway spruce sapwood $(A)$ and heartwood (B) 318 after incubation with Physisporinus vitreus: (a) Control, (b) 3 weeks, (c) 5 weeks, (d) 7 weeks, (e) 9 319 weeks

320 The quantification of changes in the chemical structure did not provide consistent results.

321 The peak heights at 1507, 1596 and $1638 \mathrm{~cm}^{-1}$ (representing modification of lignin) did not reveal a constant reduction with increasing incubation periods. Moreover, the cellulose and 
323 hemicelluloses bands associated at wavenumber 1367 and $1733 \mathrm{~cm}^{-1}$ did not remain at a

324 constant level but displayed sporadic decreases and increases. In order to obtain informa-

325 tion about the selectivity of wood decay, we calculated ratios with the main band intensities

326 (Table 4). Following Faix et al. (1991) the ratios of $1507 / 1638$ and $1596 / 1638 \mathrm{~cm}^{-1}$

327 (representing the modification of lignin) should show an inverse trend to the mass loss

328 when considerable changes in the lignin fraction would be detected. This is not the case.

329 Table 4 Mass loss and ratios of intensities associated with carbohydrates bands after incubation of

330 Norway spruce with Physisporinus vitreus.

\begin{tabular}{|c|c|c|c|c|c|}
\hline \multirow{2}{*}{$\begin{array}{l}\text { Sapwood/ } \\
\text { Heartwood }\end{array}$} & \multirow{2}{*}{$\begin{array}{l}\text { Incubation time } \\
\quad \text { (weeks) }\end{array}$} & \multirow{2}{*}{$\begin{array}{c}\text { Mass loss } \\
(\%)\end{array}$} & \multicolumn{3}{|c|}{$\begin{array}{l}\text { Relative intensities of aromatic skeletal vibra- } \\
\text { tion against bands for carbohydrates and lig- } \\
\text { nin modification }\end{array}$} \\
\hline & & & $\begin{array}{c}\text { Average ratio } \\
1507 / 1367\end{array}$ & $\begin{array}{c}\text { Average ratio } \\
1507 / 1638\end{array}$ & $\begin{array}{c}\text { Average ratio } \\
1596 / 1638\end{array}$ \\
\hline \multirow{5}{*}{ SW } & Control & - & 1.43 & 0.95 & 0.72 \\
\hline & 3 & $0.1 \pm 0.1$ & 1.21 & 0.65 & 0.62 \\
\hline & 5 & $1.8 \pm 0.2$ & 0.99 & 0.60 & 0.66 \\
\hline & 7 & $5.5 \pm 0.3$ & 1.23 & 0.74 & 0.69 \\
\hline & 9 & $8.2 \pm 0.6$ & 1.16 & 0.66 & 0.68 \\
\hline \multirow{5}{*}{ HW } & & - & 1.67 & 1.21 & 1.03 \\
\hline & & $0.1 \pm 0.05$ & 1.25 & 0.70 & 0.66 \\
\hline & & $2.4 \pm 0.7$ & 1.45 & 0.87 & 0.73 \\
\hline & & $3.9 \pm 0.8$ & 1.31 & 0.92 & 0.91 \\
\hline & 9 & $6 \pm 1.6$ & 1.17 & 0.89 & 0.97 \\
\hline
\end{tabular}


331 The calculated retention for the ratio of $1507 / 1367 \mathrm{~cm}^{-1}$ (lignin against carbohydrates) re-

332 vealed a slight trend of preferential delignification. But mass losses induced by $P$. vitreus

333 remained explicitly below $10 \%$. In such case, the sensitivity of solid state FT-IR spectros-

334 copy is too low for a consistent and reproducible analysis. Results from comparable FT-IR

335 investigations (Faix et al. 1991; Pandey and Pitman 2003) showed mass losses between

33623 and $56 \%$ and hence delivered clearly interpretable spectra.

337 Furthermore, lignin, hemicelluloses and cellulose were degraded simultaneously by $P$. vi338 treus (see Figure 2). Consequently, the cellulose assigned reference peaks are not stable enough as reference for semiquantitative determination in this case.
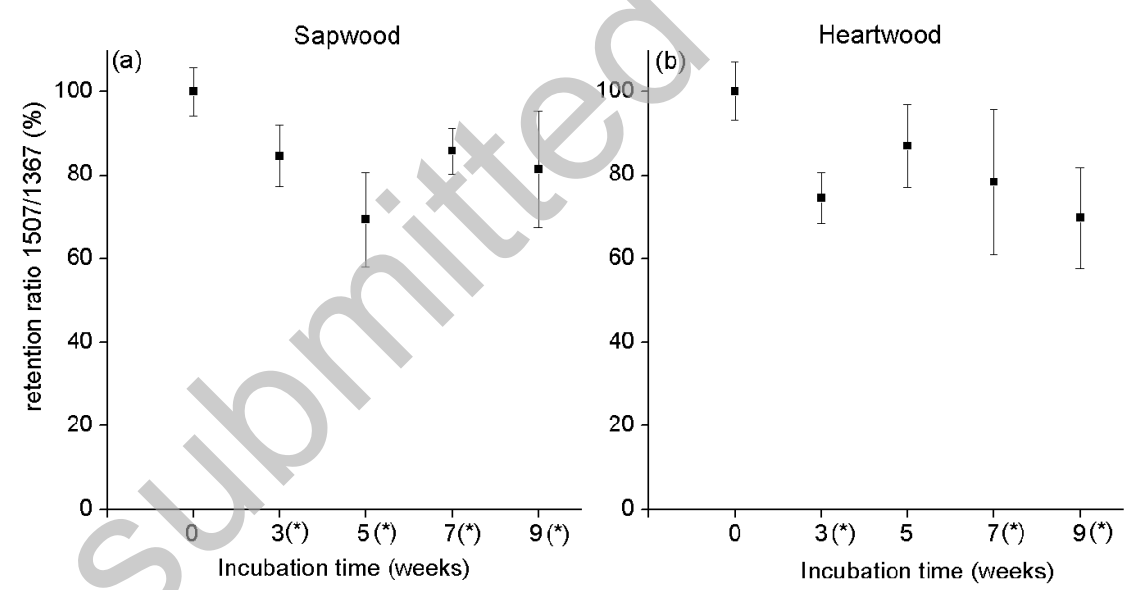

341 Figure 4 Retention of wavenumber ratio $1507 / 1367 \mathrm{~cm}^{-1}$ after incubation of Norway spruce with

342 Physisporinus vitreus. $\left({ }^{*}\right)=$ significant changes compared to control (zero weeks)

343 Hence, even though ANOVA plotted to significant differences (Figure 4), a consistent in-

344 terpretation of the data is questionable. A serious interpretation of FT-IR data was not 345 possible on the basis of the investigated material and no reliable confirmation of the results 346 from chemical analysis could be provided with this approach. 


\section{$3475 \quad$ Conclusions}

348 Results from microtensile testing confirm the findings of previous studies (2010a; Lehring349 er et al. 2010b). Indications for a selective delignification and a simultaneous degradation 350 of lignin and carbohydrates can be drawn from zero span and finite span testing results. 351 Accordingly, chemical analysis displays the degradation of lignin, hemicelluloses and 352 even to a higher extent - of cellulose. Hence, $P$. vitreus is a wood decay fungus that is 353 able to show different degradation patterns in the same substrate. However, it appears to 354 be a wood decay fungus with moderate degradation rates.

355 Incubation on MEA obviously triggered $P$. vitreus to induce both a selective delignification 356 and a simultaneous degradation, reflecting the degradation patterns of a white rot fungus 357 and soft rot type I and II. Thus, incubation with a wide $\mathrm{C} / \mathrm{N}$-ratio nutrient medium might be 358 favorable to increase selective delignification and pit membrane degradation. These find359 ings will be implemented in the future optimization of the incubation process for the bioin360 cising technology.

\section{$3616 \quad$ Acknowledgements}

362 We thank for the highly productive discussions with Dr. K. Pandey concerning the evalua363 tion of the FT-IR-measurements. Moreover we express our gratitude to Markus Heeb

364 (Empa St. Gallen) for his skillful assistance during laboratory work. We also gratefully ac365 knowledge the professional contribution of Prof. Dr. F.W.M.R Schwarze during intensive 366 discussions and proofreading.

367 The present study emerged from the research project CTI.8593.1 LSPP-LS 'Bioincising of conifer wood with Physisporinus vitreus to improve its treatability for a range of wood pre- 
servation and modification methods'. The authors express their gratitude to the Swiss CTI

370 (Innovation Promotion Agency) for its financial support.

\section{$\begin{array}{lll}371 & 7 & \text { References }\end{array}$}

Crawford, D.L., Barder, M.J., Pometto lii, A.L., Crawford, R.L. (1982) Chemistry of softwood lignin degradation by Streptomyces viridosporus. Arch. Microbiol. 131:140145.

Derbyshire, H., Miller, E.R., Turkulin, H. (1995) Investigations into the photodegradation of wood using microtensile testing - Part 1: The application of microtensile testing to measurement of photodegradation rates. Holz Roh-Werkst. 53:339-345.

--- (1996) Investigations into the photodegradation of wood using microtensile testing: Part 2: An investigation of the changes in tensile strength of different softwood species during natural weathering. Holz Roh-Werkst. 54:1-6.

Dill, I., Kraepelin, G. (1988) Degradation of Lignin/Cellulose by White-rot Fungi: Influence of Specific Ecological Factors [Der Abbau von Lignin/Cellulose durch WeissfaulePilze: Einfluss spezifischer ökologischer Faktoren]. Forum Mikrobiologie 11:484489.

Eder, M., Jungnikl, K., Burgert, I. (2009) A close-up view of wood structure and properties across a growth ring of Norway spruce (Picea abies [L] Karst.). Trees - Struct. Funct. 23:79-84.

Faix, O., Bremer, J., Schmidt, O., Tatjana, S.J. (1991) Monitoring of chemical changes in white-rot degraded beech wood by pyrolysis-gas chromatography and Fouriertransform infrared spectroscopy. J. Anal. Appl. Pyrolysis 21:147-162.

Gierlinger, N., Burgert, I. (2006) Secondary cell wall polymers studied by confocal raman microscopy: Spatial distribution, orientation, and molecular deformation. New Zeal. J. Forest Sci. 36:60-71.

Grozdits, G.A., Ifju, G. (1969) Development of tensile strength and related properties in differentiating coniferous xylem. Wood Sci. 1:137-147.

Hakala, T.K., Maijala, P., Konn, J., Hatakka, A. (2004) Evaluation of novel wood-rotting polypores and corticioid fungi for the decay and biopulping of Norway spruce (Picea abies) wood. Enzyme Microb. Technol. 34:255-263.

Istek, A., Sivrikaya, H., Eroglu, H., Gulsoy, S.K. (2005) Biodegradation of Abies bornmülleriana (Mattf.) and Fagus orientalis (L.) by the white rot fungus Phanerochaete chrysosporium. Int. Biodeter. Biodegr. 55:63-67.

Janzon, R., Saake, B., Puls, J. (2008) Upgrading of paper-grade pulps to dissolving pulps by nitren extraction: Properties of nitren extracted xylans in comparison to $\mathrm{NaOH}$ and $\mathrm{KOH}$ extracted xylans. Cellulose 15:161-175.

Jirous-Rajkovic, V., Turkulin, H., Miller, E.R. (2004) Depth profile of UV-induced wood surface degradation. Surf. Coating Int. B Coating. Trans. 87:241-247. 
Kennedy, R.W., Ifju, G. (1962) Applications of microtensile testing to thin wood sections. Tappi 45:725-733.

Keunecke, D., Niemz, P. (2008) Axial stiffness and selected structural properties of yew and spruce microtensile specimens. Wood Res-Slovakia 53:1-14.

Law, K.N., Garceau, J.J., Koran, Z. (1977) Measurement of intra-increment tensile strength by using a zero-span technique. Wood Sci. 10:42-48.

Lehringer, C., Hillebrand, K., Richter, K., Arnold, M., Schwarze, F.W.M.R., Militz, H. (2010a) Anatomy of bioincised Norway spruce wood. Int. Biodeter. Biodegr. 64:346355.

Lehringer, C., Koch, G., Adusumalli, R.-B., Mook, W.M., Richter, K., Militz, H. (2010b) Effect of Physisporinus vitreus on wood properties of Norway spruce. Part 1: Aspects of delignification and surface hardness. Holzforschung:accepted.

Liese, W. (1970) Ultrastructural aspects of woody tissue disintegration. Annu. Rev. Phytopathol. 8:231-257.

Moore, A.K., Owen, N.L. (2001) Infrared spectroscopic studies of solid wood. Appl. Spectrosc. Rev. 36:65-86.

Owen, N.L., Thomas, D.W. (1989) Infrared studies of 'hard' and 'soft' woods. Appl. Spectrosc. 43:451-455.

Pandey, K.K., Pitman, A.J. (2003) FTIR studies of the changes in wood chemistry following decay by brown-rot and white-rot fungi. Int. Biodeter. Biodegr. 52:151-160.

--- (2004) Examination of the lignin content in a softwood and a hardwood decayed by a brown-rot fungus with the acetyl bromide method and fourier transform infrared spectroscopy. J. Polym. Sci. Pol. Chem. 42:2340-2346.

Rabinovich, M.L., Bolobova, A.V., Vasil'chenko, L.G. (2004) Fungal decomposition of natural aromatic structures and xenobiotics: A review. Appl. Biochem. Microbiol. 40:117.

Rios, S., Eyzaguirre, J. (1992) Conditions for selective degradation of lignin by the fungus Ganoderma australis. Appl. Microbiol. Biotechnol. 37:667-669.

Rypacek, V. Biologie holzzerstörender Pilze. Gustav Fischer Verlag, Jena, 1966.

Schmidt, O. Wood and tree fungi. Springer Verlag, Berlin, Heidelberg, 2006.

Schmutzer, M., Schwanninger, M., Fackler, K., Messner, K., Gradinger, C. (2008) Comparison of methods to evaluate the potential of fungal growth on decay of spruce wood after short-time treatment. Int. Biodeter. Biodegr. 61:319-324.

Schubert, M., Dengler, V., Mourad, S., Schwarze, F.W.M.R. (2009) Determination of optimal growth parameters for the bioincising fungus Physisporinus vitreus by means of response surface methodology. J. Appl. Microbiol. 106:1734-1742.

Schwarze, F.W.M.R., Landmesser, H. (2000) Preferential degradation of pit membranes within tracheids by the basidiomycete Physisporinus vitreus. Holzforschung 54:461462. 
Schwarze, F.W.M.R., Landmesser, H., Zgraggen, B., Heeb, M. (2006) Permeability changes in heartwood of Picea abies and Abies alba induced by incubation with Physisporinus vitreus. Holzforschung 60:450-454.

Schwarze, F.W.M.R., Schubert, M. (2009) Enhanced uptake of wood modification agents in "bioincised" wood. International Research Group on Wood Protection Paper prepared for the 40th Annual Meeting Beijing, China 24-28 May 2009:1-8.

Sinner, M., Simatupang, M.H., Dietrichs, H.H. (1975) Automated quantitative analysis of wood carbohydrates by borate complex ion exchange chromatography. Wood Sci. Technol. 9:307-322.

Sinner, M., Puls, J. (1978) Non-Corrosive dye reagent for detection of reducing sugars in borate complex ion-exchange chromatography. J. Chromatogr., A 156:197-204.

Tappi 250 (2005) Acid-soluble lignin in wood and pulp. Tappi Usefull Methods 250.

Timell, T.E. (1967) Recent progress in the chemistry of wood hemicelluloses. Wood Sci. Technol. 1:45-70.

Turkulin, H., Sell, J. (2002) Investigations into the photodegradation of wood using microtensile testing. Part 4: Tensile properties and fractography of weathered wood. Holz Roh-Werkst. 60:96-105.

Wilcox, W.W., Garcia, B.J. (1968) Changes in wood properties at the boundary of polyporus amarus decay pockets. Wood Sci. Technol. 2:115-127.

Willför, S., Pranovich, A., Tamminen, T., Puls, J., Laine, C., Suurnäkki, A., Saake, B., Uotila, K., Simolin, H., Hemming, J., Holmbom, B. (2009) Carbohydrate analysis of plant materials with uronic acid-containing polysaccharides-A comparison between different hydrolysis and subsequent chromatographic analytical techniques. Ind. Crops. Prod. 29:571-580.

Xiao, Z., Xie, Y., Militz, H., Mai, C. (2010) Effects of modification with glutaraldehyde on the mechanical properties of wood. Holzforschung 64:475-482.

Xie, Y., Xiao, Z., Goodell, B., Jellison, J., Militz, H., Mai, C. (2010) Degradation of wood veneers by Fenton's reagents: Effects of wood constituents and low molecular weight phenolic compounds on hydrogen peroxide decomposition and wood tensile strength loss. Holzforschung 64:375-383. 



\title{
Christianger
}

\section{The author}

\author{
Dipl.-Holzwirt Christian Lehringer \\ christianlehringer(at)gmx.ch \\ * $15^{\text {th }}$ December 1976
}

\section{Professional History}

08/2007 - 02/2011 PhD-Student at Empa, Swiss Federal Laboratories for Materials Science and Technology, Dübendorf, Switzerland with degree 'Dr. rer. nat.' (magna cum laude) at Georg-August-University of Göttingen, Germany

10/2008 Leo-Schörghuber-Award for Diploma thesis, Munich, Germany

04/2007-07/2007 Scientific employee at the Institute of Wood Technology and Wood Biology (vTI), Hamburg, Germany

- Research in Juvenile Wood and structural characterization of wood

- Study about wood as bio-energy source

08/2000 - 02/2007 Studies of wood science and technology with degree as Diplom-Holzwirt, University of Hamburg, Germany

- Diploma thesis „Ultrastructural and topochemical investigations in the tension wood of Acer (Acer spp.), Beech (Fagus sylvatica) and Oak (Quercus robur)“

08/1997 - 09/2000 Education for Cabinet maker, Rendsburg, Germany

\section{Publications}

Lehringer, C., Gierlinger, N., Koch, G. (2008) Topochemical investigations on tension wood fibres of Acer spp., Fagus sylvatica L. and Quercus robur L. Holzforschung 62: 255-263.

Lehringer, C., Daniel, G., Schmitt, U. (2009) TEM/FE-SEM studies on tension wood fibres of Acer spp., Fagus sylvatica L. and Quercus robur L. Wood Sci. Technol. 43: 691-702.

Lehringer, C., Arnold, M., Richter, K., Schubert, M., Schwarze, F.W.M.R., Militz, H. (2009) Bioincised wood as substrate for surface modifications. 4th European Conference on Wood Modification, Stockholm: 197-200.

Lehringer, C., Richter, K., Schwarze, F.W.M.R., Militz, H. (2009) A review on promising approaches for liquid permeability improvement in softwoods. Wood Fiber Sci. 41: 373-385.

Lehringer, C., Hillebrand, K., Richter, K., Arnold, M., Schwarze, F.W.M.R., Militz, H. (2010) Anatomy of bioincised Norway spruce wood. Int. Biodeter. Biodegr. 64: 346-355.

Lehringer, C., Schwarze, F.W.M.R., Schubert, M., Arnold, M., Richter, K. (2010) Bioincising - Verbesserte Permeabilität des Holzes durch Pilzbehandlung. Bulletin Holzforschung Schweiz, Schweizerische Arbeitsgemeinschaft für Holzforschung SAH 18:5-7.

Schubert, M., Volkmer T., Lehringer, C., Schwarze, F.W.M.R. (2011) Resistance of bioincised wood treated with wood preservatives to blue-stain and wood-decay fungi. Int. Biodeter. Biodegr. 65: 108-115.

Lehringer, C., Koch, G., Adusumalli, R.-B., Mook, W.M., Richter, K., Militz, H. (2011) Effect of Physisporinus vitreus on wood properties of Norway spruce. Part 1: Aspects of delignification and surface hardness. Holzforschung 65: in print.

Lehringer, C., Saake, B., Živković, V., Richter, K., Militz, H. (2011) Effect of Physisporinus vitreus on wood properties of Norway spruce. Part 2: Aspects of microtensile strength and chemical changes. Holzforschung: submitted. 



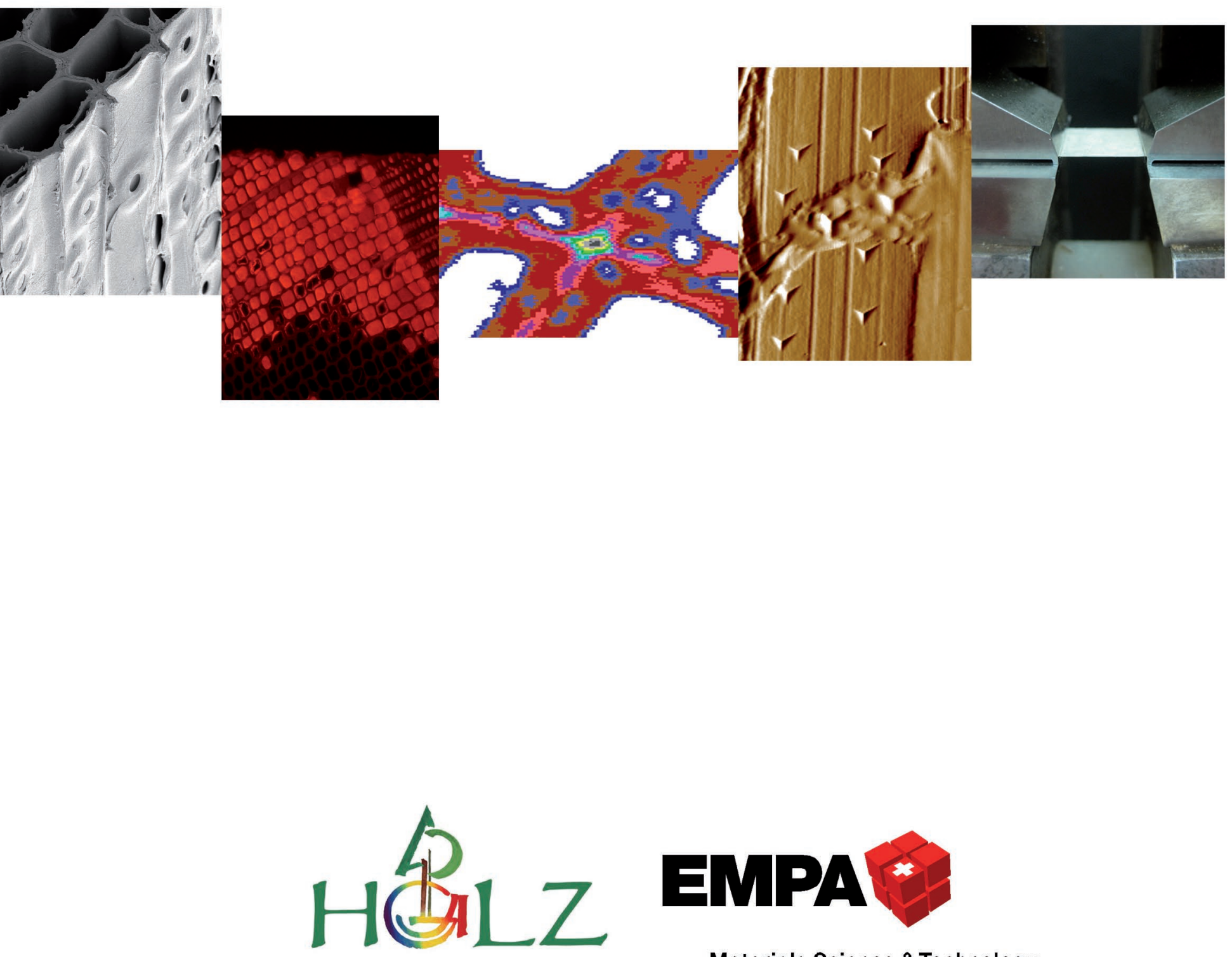

Materials Science \& Technology

Wood Biology and Wood Products Georg-August-University Göttingen Büsgenweg 4 Wood Laboratory Empa - Swiss Federal Laboratories for Materials Science and Technology Überlandstrasse 129 D-37077 Göttingen $\quad \mathrm{CH}-8600$ Dübendorf 